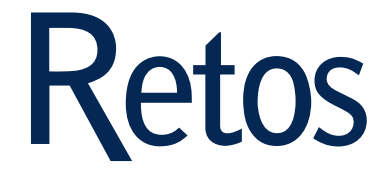

Revista de Ciencias de la Administración y Economía
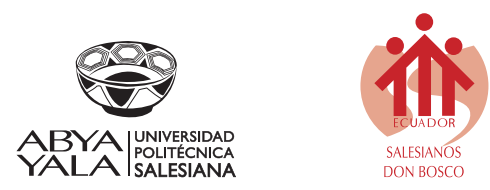

Universidad Politécnica Salesiana del Ecuador 



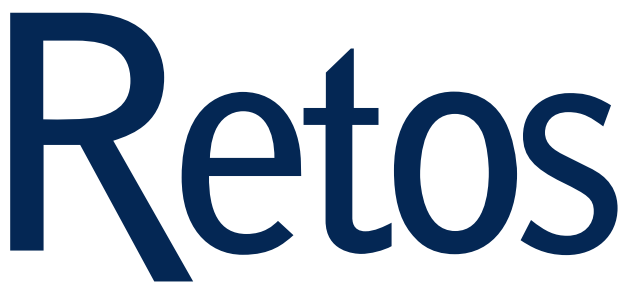

Revista de Ciencias de la Administración y Economía Año VII, Número 14, octubre 2017-marzo 2018 ISSN impreso: 1390-6291 / ISSN electrónico: 1390-8618

La Administración de RETOS se realiza a través de los siguientes parámetros:

La revista utiliza el sistema anti plagio académico Crossref Similarity Check

URKUND

Los artículos cuentan con código de identificación

(Digital Object Identifier)

El proceso editorial se gestiona a través del OJS

Open Journal System

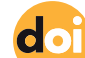

Es una publicación de acceso abierto

(Open Access) con licencia Creative Commons

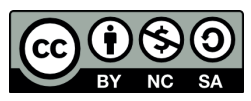

Las políticas copyright y de uso post print, se encuentran publicadas en el Repositorio de Políticas de Autoarchivo SHERPA/ROMEO.

Los artículos de la presente edición pueden consultarse en: http://revistas. ups.edu.ec/index.php/retos 
Retos está indexada en las siguientes Bases de Datos y sistemas de información científica:

\section{BASE DE DATOS SELECTIVAS}

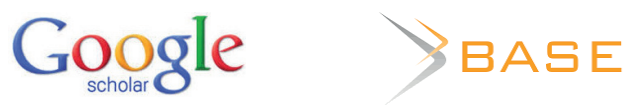

C.I.R.C.

EC3metrics

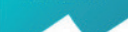

PLATAFORMAS DE EVALUACIÓN DE REVISTAS

MIAR

DIRECTORIOS SELECTIVOS
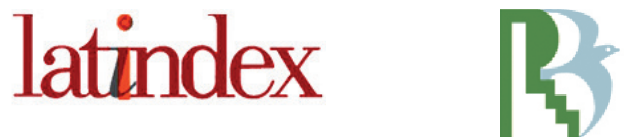

Journal Seeker
Research Bible

HEMEROTECAS SELECTIVAS

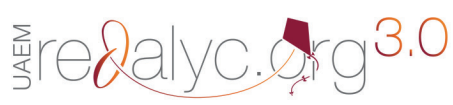

REDIB

Red Iberoamerican

BUSCADORES DE LITERATURA CIENTÍFICA OPEN ACCESS

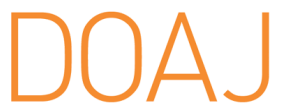

DS EXALEAD

POLÍTICAS DE COPYRIGHT DE LAS EDITORIALES Y AUTOARCHIVO

○’ SHERPA/Romeo

OTRAS BASES DE DATOS BIBLIOGRÁFICAS

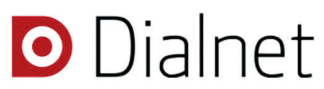

Portal de Difusión de la Produc-

ción Científica

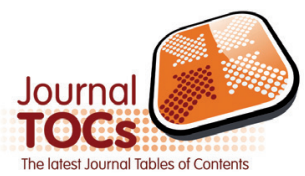




\section{CATÁLOGO DE BIBLIOTECAS INTERNACIONALES UNIVERSITARIAS}
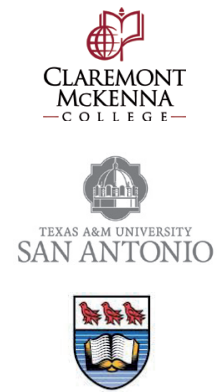

University of Victoria

University

of Regina

ॠ DEPAULUNIVERSITY

Virginia

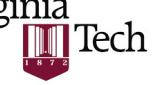

FRANLIN_MARSHALL
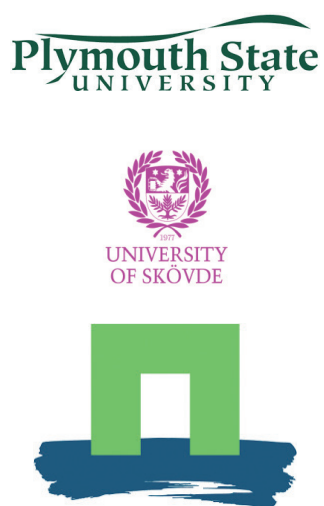

Wageningen University

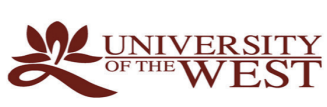

SIMPSON

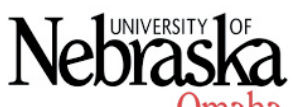

Omaha
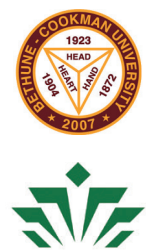

UNC CHARLOTTE

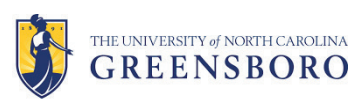

$\frac{\text { MUHLENBERG }}{\text { COLLEGE }}$

$6 \frac{\text { Un IVERS ITY OF }}{\text { LIVERPOOL }}$

Hanzehogeschool

Groningen

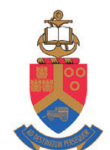

UNIVERSITEIT VAN PRETORIA

UN IVERSITY OF PRETORIA YUNIBESITHI YA PRETORIA

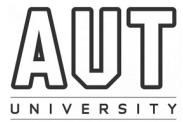

Southwestern University

\author{
DEPAUL \\ UNIVERSITY \\ COLLEGE OF LAW
}

(⿻)
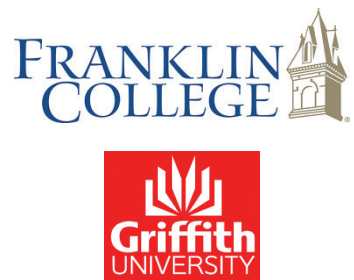

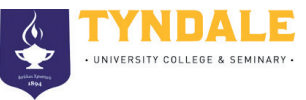
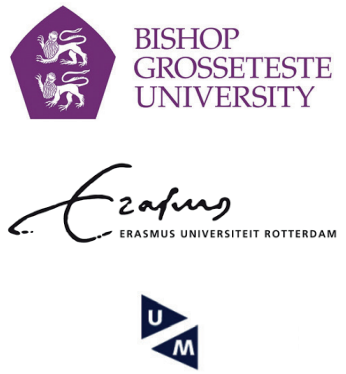

Maastricht University

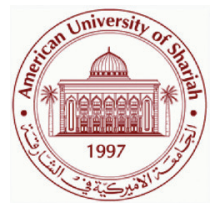


Rector

Javier Herrán Gómez, sdb

Vicerrector General Académico

Luis Tobar Pesántez

Vicerrector Docente

Fernando Pesántez Avilés

Vicerrector de Investigación

Juan Pablo Salgado Guerrero

Vicerrectores de sede

César Vásquez Vásquez (Cuenca)

José Juncosa Blasco (Quito)

Andrés Bayolo Garay (Guayaquil)

«Retos» es una publicación científica bilingüe de la Universidad Politécnica Salesiana de Ecuador, editada desde enero de 2011 de forma ininterrumpida, con periodicidad fija semestral ( 1 de abril y 1 de octubre), especializada en Desarrollo y sus líneas transdisciplinares como Administración Pública, Economía Social, Marketing, Turismo, Emprendimiento, Gerencia, Ciencias Administrativas y Económicas, entre otras. Es una Revista Científica arbitrada, que utiliza el sistema de evaluación externa por expertos (peer-review), bajo metodología de pares ciegos (doble-blind review), conforme a las normas de publicación de la American Psychological Association (APA). El cumplimiento de este sistema permite garantizar a los autores un proceso de revisión objetivo, imparcial y transparente, lo que facilita a la publicación su inclusión en bases de datos, repositorios e indexaciones internacionales de referencia. La Revista se edita en doble versión: impresa (ISSN: 1390-62911) y electrónica (e-ISSN: 1390-8618), en español e inglés. Todos los artículos están disponibles en la Web de la revista (http:// retos.ups.edu.ec).

Domicilio de la publicación: Universidad Politécnica Salesiana del Ecuador, casilla postal 2074, Cuenca-Ecuador. Teléfono (+5937) 2050000. Fax: (+5937) 4088958. Correo electrónico: revistaretos@ups.edu.ec

(c) RETOS. Revista de Ciencias de la Administración y Economía. Impreso en Ecuador

Los conceptos expresados en los artículos competen a sus autores. Se permite la reproducción de textos citando la fuente. Los artículos de la presente edición pueden consultarse en la página web de la Universidad. 


\section{Consejo de Editores}

\section{EDITOR JEFE}

Dr. Luis M. Romero-Rodríguez

Universidad Internacional de La Rioja, España

\section{EDITORES ADJUNTOS}

- MSc. Andrés Bayolo Garay, UPS, Ecuador

- MSc. Fabricio Freire Morán, UPS, Ecuador

- MSc. Javier Carrera Jiménez, UPS, Ecuador

\section{EDITORES TEMÁTICOS}

- Dra. Iria Puyosa, Universidad Central de Venezuela.

- Dr. Armando Chaguaceda, Universidad de Guanajuato, México.

\section{Consejo Cientifico}

- Dr. Michele Bagella, Universidad Tor Vergata de Roma, Italia

- Dra. Sofía Vásquez Herrera, UPAEP, México

- Dra. María Cristina Vallejo, Flacso, Ecuador

- Dr. Javier Rojas Villanueva, UNMSM, Perú

- Dr. Alfonso Moro, Radio France International

- Dr. Andrés Rosas Wulfers, Pontificia Universidad Javeriana, Colombia

- Dra. Judith Cavazos Arroyo, UPAEP, México

- Dr. Ángel Cervera Paz, Universidad de Cádiz, España

- Dr. Ebor Fairlie Frisancho, UNMSM, Perú

- Dr. Eduardo Dittmar, Universidad Autónoma de Chile

- Dra. Rosa de las Nieves Galaz, UPAEP, México

- Dr. Geovanny Herrera Enríquez, ESPE, Ecuador

- Dr. Pedro Tito Huamaní, UNMSM, Perú

- Dr. Guillermo Gutiérrez Montoya, Universidad Don Bosco, El Salvador

- Dr. Mario Humberto Hernández, UNAM, México

- Dra. Pilar Marín, Universidad de Huelva, España

- Dr. Augusto Hidalgo Sánchez, UNMSM, Perú

- Dr. Mario Lagunes Pérez, UPAEP, México

- Dra. Jenny Vargas Portillo, Universidad Autónoma de Chile

- Dr. José Albuja Salazar, ESPE, Ecuador

- Dr. José Lázaro Quintero, Universidad Nebrija, España

- Dr. Luis Cruz Soto, UNAM, México

- Dr. Pablo Mauricio Pachas, UNMSM, Perú

- Dr. Rodrigo Muñoz Grisales, Universidad EAFIT, Colombia

- Dr. Víctor Manuel Castillo, Universidad de Guadalajara, México

- Dra. Tania Chicaiza Villalba, Universidad Politécnica Salesiana, Ecuador

- Dra. Rebeca Martínez Sánchez, Unam, México

- Dr. Rodrigo Mendieta Muñoz, Universidad de Cuenca, Ecuador

- Dr. Vlashkiv Mosquera Aldana, UPAEP, México
- Dr. Edgar Izquierdo Orellana, Espol, Ecuador

- Dr. Alberto Arroyo Picard, UAM, México

- MSc. Carlos Izquierdo Maldonado, UPS, Ecuador

- MSc. Fernando Barrera Salgado, UPS, Ecuador

- MSc. Juanita Salinas Vásquez, UPS, Ecuador

- MSc. Marcelo Yánez Pérez, Universidad Católica Silva Henríquez, Chile

- Msc. Vanessa León León, Espol, Ecuador

- MSc. Oscar William Caicedo Alarcón, Universidad EAFIT, Colombia

- MSc. Pedro Montero Tamayo, UPS, Ecuador.

- MSc. Raúl Álvarez Guale, Universidad Politécnica Salesiana, Ecuador

\section{Consejo Editorial Institucional UPS}

\section{CONSEJO DE PUBLICACIONES}

- Dr. Javier Herrán Gómez, sdb.

- Dr. Juan Bottasso Boeti, sdb.

- MSc. Juan Pablo Salgado Guerrero.

- Dr. Luis Álvarez-Rodas.

- MSc. Fabricio Freire-Morán

- MSc. José Juncosa Blanco

- MSc. Jaime Padilla Verdugo

- Dra. Floralba Aguilar Gordón

- MSc. Sheila Serrano Vicenti

- MSc. John Calle Sigüencia

- MSc. René Unda Lara

- MSc. Armando Gijalva Brito

- MSc. Andrea De Santis

- MSc. Mónica Ruiz Vásquez

\section{EDITOR GENERAL UPS}

Dr. Luis Álvarez-Rodas

\section{CONSEJO TÉCNICO}

MSc. Tania Barrezueta Cabrera

Dr. Ángel Torres-Toukoumidis

\section{SERVICIO DE PUBLICACIONES}

Hernán Hermosa (Coordinación General)

Marco Gutiérrez (Soporte OJS)

Paulina Torres (Edición)

Martha Vinueza (Maquetación)

Raysa Andrade (Maquetación)

\section{TRADUCTOR}

Joaquín Crespo

\section{EDITORIAL}

Editorial Abya Yala (Quito-Ecuador)

Avenida 12 de octubre N422 y Wilson, Bloque A,

UPS Quito, Ecuador. Casilla 17-12-719

Teléfonos: (593-2) 3962800 ext. 2638

Correo electrónico: editorial@abyayala.org 


\section{UNIVERSIDAD POLITÉCNICA SALESIANA DEL ECUADOR}

Javier Herrán Gómez, sdb

Rector

(C) Universidad Politécnica Salesiana

Turuhuayco 3-69 y Calle Vieja

Casilla postal 2074

Cuenca, Ecuador.

Teléfono: (+593 7) 2050000

Fax: (+593 7) 4088958

E-mail: srector@ups.edu.ec

$$
\text { CANJE }
$$

Se acepta canje con otras publicaciones periódicas

Dirigirse a:

Secretaría Técnica de Comunicación y Cultura

Universidad Politécnica Salesiana

Av. Turuhuayco 3-69 y Calle Vieja

Casilla postal 2074

Cuenca, Ecuador.

PBX: (+593 7) 2050000 - Ext. 1182

Fax: (+593 7) 4088958

Correo electrónico: rpublicas@ups.edu.ec

www.ups.edu.ec

Cuenca - Ecuador 


\section{Índice}

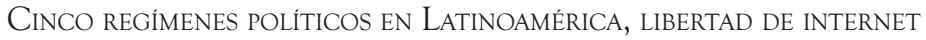

Y MECANISMOS DE CONTROL . . . . . . . . . . . . . . . . . 11

Five political regimes in Latin America, Internet freedom

and mechanisms of control . . . . . . . . . . . . . . . . . . 11

Dra. Iria Puyosa

Dr. Armando Chaguaceda

La Reforma de Telecomunicaciones en México 2014.

UNA APROXIMACIÓN ANALÍTICA . . . . . . . . . . . . . . . . . . 39

The Telecommunications Reform in Mexico 2014. An analytical approach . 39

Dr. Carlos Manuel Rodríguez Arechavaleta

Vigilia y Vigilancia: AnÁlisis de contenido del Registro Nacional

de Acceso a Internet en Brasil. . . . . . . . . . . . . . . . . . 63

Watch and surveillance: A content analysis of the National Registry

of Internet Access in Brazil . . . . . . . . . . . . . . . . . . . . . . . . 63

Fernando Nobre Cavalcante

Nivel de USO de Las Redes SOCIALES EN El PROCESO DE COMUNICACIÓN

EN LAS MIPES DE CUENCA . . . . . . . . . . . . . . . . . 81

Level of use of social networks in the communication process

in the micro and small sized enterprises of Cuenca . . . . . . . . . . . . 81

Efrén Aucay Piedra

Priscilla Herrera Torres

LA INVERSIÓN EN PUblicidAd Y SU EFECTO EN LAS MEDIANAS EMPRESAS

DE GuAYAQUil . . . . . . . . . . . . . . . . . . . . . . . . . . . . 99

The Investment in advertising and its effect on the Medium

Enterprises of Guayaquil . . . . . . . . . . . . . . . . . . . . . . . . . 99

Catalina Falquez Arce

Blanca Silva Guerrero

Vanessa Rojas Herrera 
UNA APROXIMACIÓN TEÓRICA PARA MEJORAR LOS RESULTADOS

DE INNOVACIÓN EN LAS EMPRESAS DESDE LA PERSPECTIVA Del "Happiness Management . . . . . . . . . . . . . . . . . . . . 113

A theoretical review to improve outcomes of innovation in enterprises from the perspective of "Happiness Management" . . . . . . . . . . . . . 113 Dr. Rafael Ravina Ripoll

Dr. Francisco Villena Manzanares

Dr. Guillermo Antonio Gutiérrez Montoya

ANÁLISIS DE FACTIBILIDAD EN LA PRODUCCIÓN DE CALZADO ORTOPÉDICO PARA niÑos EN LA PROVINCIA DE TungURAHUA. . . . . . . . . . . . 131 Feasibility analysis in the production of orthopedic footwear for children in the Province of Tungurahua . . . . . . . . . . . . . . . 131 Arturo Montenegro

Ruth Zamora Sánchez

Valeria Arias-Villavicencio

¿LO VOLVERÍA A HACER? REVISITANDO LA IMPLEMENTACIÓN DEL PARADIGMA DEL EMPRENDIMIENTO EN UNA UNIVERSIDAD DE MÉXICO . . . . . . . . . . . 147 Would I do it again? Revisiting the implementation of the entrepreneurship paradigm in a University in Mexico . . . . . . . . . . 147 Oscar Montiel Claudia Ivette Rodríguez Lucio

Microempresas Panificadoras en el AzUay (Ecuador) Y SU PRODUCTIVIDAD . . . . . . . . . . . . . . . . . . . . . . . . . . 167

Bakery small business in Azuay (Ecuador) and their productivity. . . . . . . 167 Carlos Armando Romero Galarza

Gustavo Geovvani Flores Sánchez

Jorge Arturo Campoverde Campoverde

Katherine Tatiana Coronel Pangole

MEJORES PRÁCTICAS EMPRESARIALES DE RESPONSABILIDAD SOCIAL

EN LA INCLUSIÓN DE PERSONAS CON DISCAPACIDAD. ESTUDIO

DE CASO En EMPRESAS de AMbATo, EcuAdor. . . . . . . . . . . . . . . . . . . . . . 189

Corporate Social Responsibility in the inclusion of people

with Disability. Case Study Ambato Companies, Ecuador . . . . . . . . . . . . 189

Fanny Paulina Pico Barrionuevo

Silvia Susana Torres

Normas EdTTORIALES BÁsICAS . . . . . . . . . . . . . . . . . . . . . . 201

BASIC WRITING RULES . . . . . . . . . . . . . . . . . . . . . 207 


\title{
Cinco regímenes políticos en Latinoamérica, libertad de internet y mecanismos de control
}

\section{Five political regimes in Latin America, Internet freedom and mechanisms of control}

\author{
Dra. Iria Puyosa es profesora/investigadora de la Universidad Central de Venezuela (Venezuela) (iria.puyosa@
} gmail.com) (http://orcid.org/0000-0002-8725-6871)

Dr. Armando Chaguaceda es profesor investigador en la División de Ciencias Sociales y Humanidades de la Universidad de Guanajuato (México) (xarchano@gmail.com) (http://orcid.org/0000-0002-2497-178X)

\begin{abstract}
Resumen
Desde 2010 se ha observado una tendencia al establecimiento de políticas de control y securitización de internet (Freedom House, 2016). En la literatura sobre el tema se indica que los mecanismos de control de internet varían según el tipo de regímenes políticos. El objetivo de este trabajo es observar si las políticas de control de internet en Latinoamérica varían según el tipo de régimen político imperante. Para el estudio se seleccionaron cinco países latinoamericanos que son categorizados como ejemplos de distintos regímenes políticos: Chile, México, Ecuador, Venezuela y Cuba. Para cada uno de los casos, se reportan los indicadores relativos a la libertad de expresión en internet vigentes de acuerdo con los datos proporcionados por "Varieties of Democracy". Como complemento se usan las categorizaciones de "Freedom on the Net». Los resultados indican que efectivamente existe correlación entre régimen político (medido por índice de poliarquía) y libertad de internet. Mientras más autocrático es el régimen más se observan controles de internet de primera generación, con censura de contenidos y violaciones a los derechos de los usuarios. Mientras que en los regímenes híbridos se observan más comúnmente controles de segunda generación, que involucran obstáculos al acceso, sin que se llegue al bloqueo de contenidos y a los apagones de la red.
\end{abstract}

\begin{abstract}
Since 2010, there has been a trend towards establishing internet control and securitization policies (Freedom House, 2016). The literature on the subject indicates that the mechanisms of internet control vary according to the type of political regimes. The objective of this work is to verify if the policies of control of Internet in Latin America vary according to the type of prevailing political regime. For the study were selected five Latin American countries that are categorized as examples of different political regimes: Chile, Mexico, Ecuador, Venezuela and Cuba. For each case, the indicators related to freedom of expression on the internet are reported in accordance with the data provided by "Varieties of Democracy». "Freedom on the Net» categorizations are used as a complement. The results indicate that there is a correlation between political regime (measured by polyarchy index) and internet freedom. Indeed the more autocratic the regime is, the more first-generation internet controls are observed, with censorship of contents and violations of users' rights. While in hybrid regimes second-generation controls are more commonly observed, which involve obstacles to access, without reaching content blocking and network outages.
\end{abstract}

\section{Palabras clave | keywords}

Regímenes políticos, internet, políticas de control, democracia, autoritarismo, censura, derechos de los usuarios de internet.

Political regimes, internet, control policies, democracy, authoritarianism, censorship, rights of internet users. 
A escala internacional existe diversidad de formas de organizar, en los marcos de una sociedad y Estado nacionales, el acceso, ejercicio, ratificación y/o salida del poder político. Los regímenes políticos abarcan un continuum que tiene en un extremo la mayor autonomía y protagonismo ciudadano y en el otro el poder concentrado y no responsivo de caudillos, partidos y/o camarillas. Así, las democracias de calidad, las poliarquías de bajo desempeño, las democracias delegativas, los regímenes híbridos (autoritarismos competitivos), los autoritarismos cerrados y los regímenes totalitarios conforman el espectro de los regímenes políticos.

Las democracias contemporáneas son regímenes que abarcan, como elementos básicos, las características -elecciones justas, libres y competidas; pluralismo político; derechos ciudadanos a la organización, información, expresión y movilización; mecanismos de rendición de cuentas y control de los funcionarios públicos- que Robert Dahl (1989) ha identificado como constituyentes de las poliarquías -democracias realmente existentes-; pero que pueden expandirse hasta alcanzar a la constitución de democracias de calidad, con ciudadanías dotadas de amplios derechos (civiles, políticos, sociales) y un aparato estatal de alta capacidad, en donde se protege y habilita el ejercicio de la ciudadanía (Tilly, 2010). Así, la democracia contemporánea reúne tanto las conquistas y demandas orientadas a la mayor equidad y participación en los asuntos públicos, como a la mejor calidad de la representación y deliberación políticas.

Los regímenes híbridos (Levitsky \& Way, 2010) son aquellos donde se mantienen elementos formales de la democracia -elecciones con un mínimo de competencia, una oposición legal, derechos a manifestación, medios de información independientes- pero dentro de un orden que otorga al oficialismo -a menudo en la forma de partido dominante y un líder carismático- el control mayor de recursos institucionales, materiales, comunicacionales, que le permiten inclinar la cancha a su favor en detrimento de la oposición.

Las autocracias adoptan históricamente diversos ropajes, siendo los tipos más reconocidos por la ciencia política: la dictadura militar, el régimen de partido único, el sultanismo y modalidades híbridas de éstas. Asimismo, a raíz de la experiencia del siglo XX, las autocracias se subdividen entre una mayoría de regímenes autoritarios -con pluralismo limitado, carácter conservador y mentalidades oficiales- y algunos 
totalitarismos -monistas, revolucionarios e ideológicos-, en ambos casos opuestos a las repúblicas liberales de masas (Pérez-Liñán, 2017) comúnmente llamadas democracias.

\section{Control político de internet}

A medida que ha ido aumentando la penetración de internet y se ha hecho evidente la creciente importancia de sus usos políticos, regímenes de todo tipo (democráticos, híbridos y autocráticos) han establecido políticas de creciente control y securitización de internet, tal como reflejan los informes de «Freedom on the Net» (Freedom House, 2016). Las prácticas de control más evidentes son los apagones de internet, el filtrado de contenidos por palabras clave y el bloqueo de URLs por DNS. A partir de 2009 empiezan a generalizarse controles de segunda generación como: restricción temporal de la conectividad en regiones en donde se producen protestas, bloqueo just-on-time de aplicaciones móviles, requerimientos informales de remoción de contenidos a los ISPs y a los administradores de sitios web, ralentización de las conexiones en momentos de alta conflictividad política y establecimiento de altos costos de los servicios para limitar el acceso masivo a internet (Deibert \& Rohozinski, 2010; Pearce \& Kendzior, 2012; Crete-Nishihata, Deibert $\&$ Senft, 2013; Puyosa, 2015).

En la literatura sobre control de internet, también se reportan evidencias de que los países con regímenes autoritarios tienden a limitar el desarrollo de la infraestructura de acceso a internet y a incrementar los controles sobre los proveedores de servicios (Drezner, 2009). Asimismo, se encuentra evidencia de prácticas de control y securitización que no requieren mecanismos técnicos sino que se basan en mecanismos policiales, judiciales o administrativos como: impuestos al uso de internet, requerimientos administrativos a los proveedores de acceso, reportes policiales rutinarios de la actividad ciudadana en internet y prisión por expresión política en la web (Drezner, 2010; Kerr, 2014; Puyosa, 2015). Finalmente, se observan prácticas de monitoreo masivo (en ocasiones visibilizado por el propio gobierno), uso de información publicada en-línea para hostigar o acusar legalmente a activistas políticos, uso de botnets y otras formas de propaganda automatizada, así como ciberataques perpetrados contra activistas opositores o «patriotic hacking» (Deibert 
\& Rohozinski, 2010; Drezner 2010; Kerr, 2014; Puyosa, 2015; Puyosa, 2017b).

Tomando en consideración el modelo del «dilema del dictador digital» (Kerr, 2014) se hipotetiza que los mecanismos tradicionales de filtrado de palabras clave y bloqueo de sitios web solo se hacen prominentes bajo regímenes autoritarios. Los mecanismos de control de primera generación, filtrado de palabras clave y bloqueo de contenidos, son considerados muy costosos en términos de reputación internacional y legitimidad interna, por lo tanto son evitados por los regímenes más democráticos. Los regímenes híbridos sólo utilizan mecanismos de control de primera generación en momentos de alta conflictividad política, especialmente si se producen protestas masivas que pudieran amenazar su estabilidad y que son amplificadas por el uso de social media.

El modelo también hipotetiza que el uso de mecanismos de control de segunda generación es más probable bajo regímenes híbridos y autoritarismos competitivos. El aumento de la penetración de internet y sus usos políticos actúa como un disparador del establecimiento de políticas de control de segunda generación (Kerr, 2014; Puyosa, 2015). Los regímenes híbridos restringen el acceso a contenidos y aplicaciones que puedan contribuir a ampliar la protesta en-línea o a movilizar a los ciudadanos para la acción colectiva fuera de línea. Asimismo, en estos regímenes se despliegan ejércitos de botnets para inundar las plataformas de redes sociales con comentarios pro-gubernamentales, influir en discusiones en línea, reportar o atacar a quienes hacen comentarios antigubernamentales o simplemente publicar contenidos de desinformación (Puyosa, 2015; Puyosa, 2017c, 2017b; Marwick \& Lewis, 2017; Puddington, 2017).

\section{Análisis de los casos}

Dado que el objetivo del estudio es explorar si las políticas de control de internet en Latinoamérica varían según el tipo de régimen político imperante en cada país, se siguió una metodología de muestra casos típicos. Así se seleccionaron cinco países latinoamericanos que son categorizados como ejemplos de distintos tipos en el continuum de los regímenes políticos: Chile (una democracia de alta calidad), México (una democracia de baja calidad), Ecuador (una democracia delegativa), Venezuela (una autocracia, en tránsito desde el autoritarismo competiti- 
vo al autoritarismo hegemónico) y Cuba (un post-totalitarismo reciente). Para cada uno de los casos, se reporta el tipo de políticas y prácticas de control de internet vigentes de acuerdo con los datos proporcionados por la base de datos del proyecto Varieties of Democracy ${ }^{1}$ y por el informe anual de Freedom on the $\mathrm{Net}^{2}$.

En esta sección del estudio, se presenta en primer lugar una breve descripción del régimen político que impera en cada uno de los países seleccionados. Conjuntamente con la categorización cualitativa, reportamos el Índice aditivo de poliarquía de V-Dem. En segundo lugar se presentan los datos del proyecto V-Dem sobre los indicadores: i) Censura gubernamental de internet; ii) censura gubernamental de medios; iii) hostigamiento a los periodistas; iv) libertad de expresión académica y cultural y; v) represión de las organizaciones de la sociedad civil, en el período 2006-2016. En tercer lugar se presenta la categorización y puntaje obtenido por el país en el informe Freedom on the Net (2016), así como un sumario las políticas o prácticas vigentes de mayor importancia e impacto ${ }^{3}$.

\section{Descripción de las variables}

Para verificar cuantitativamente el régimen político se usa el Índice aditivo de poliarquía de V-Dem. Este índice responde a la pregunta ¿Hasta qué punto se alcanza el principio electoral de la democracia? Los criterios son que el principio electoral de la democracia busca lograr la capacidad de respuesta y la rendición de cuentas entre los líderes y los ciudadanos a través del mecanismo de elecciones. Se supone que esto se alcanza cuando el derecho al sufragio es extendido; las organizaciones políticas y las organizaciones de la sociedad civil pueden funcionar libremente; las elecciones son limpias y no manipuladas por fraude o

1 El proyecto V-Dem es co-organizado por el Departamento de Ciencias Políticas de la Universidad de Gothenburg (Suecia) y el Kellogg Institute en la Universidad de Notre Dame (USA). El proyecto es una colaboración entre más de 50 especialistas en todo el mundo y 2800 expertos de País. Genera una base de datos actualizada anualmente con mediciones de variables e indicadores relativos a siete principios de democracia: electoral, liberal, participativo, deliberativo, igualitario, mayoritario y consensual.

2 Freedom on the Net es un reporte anual sobre el estado de internet realizado por Freedom House y una red de investigadores locales en 65 países.

3 Chile no es incluido en los informes de Freedom on the Net. 
irregularidades sistemáticas; y se selecciona al jefe del ejecutivo del país (directa o indirectamente) a través de elecciones. La escala es de intervalo.

Para examinar libertad y control de internet, el estudio toma los datos correspondientes a las siguientes preguntas del proyecto V-Dem (Coppedge et al., 2017):

Pregunta 13.2: ¿El gobierno intenta, directa o indirectamente, censurar a la prensa o a los medios de radiodifusión?

Las formas indirectas de censura podrían incluir la concesión de frecuencias de emisión por motivos políticos, la retirada de apoyo financiero, la influencia sobre las instalaciones de impresión y las redes de distribución, la asignación selectiva de publicidad, los requisitos de registro onerosos, los aranceles prohibitivos y el soborno. No incluye la censura de temas no políticos como la pornografía infantil, las declaraciones ofensivas a una religión en particular o el discurso difamatorio, a menos que este tipo de censura se use como pretexto para censurar el discurso político.

Respuestas:

0: Los intentos de censura son directos y rutinarios.

1: Los intentos de censura son indirectos pero sin embargo rutinarios.

2: Los intentos de censura son directos pero limitados a cuestiones especialmente delicadas.

3: Los intentos de censura son indirectos y se limitan a cuestiones especialmente delicadas.

4: El gobierno rara vez intenta censurar a los principales medios de comunicación en cualquier forma, y cuando se descubren tales intentos excepcionales, los funcionarios responsables son generalmente castigados.

Escala: Ordinal, convertida a intervalo por el modelo de medición.

Pregunta 13.3: ¿El gobierno intenta censurar información (texto, audio o imágenes) en internet?

Los intentos de censura incluyen el filtrado de Internet (bloqueo del acceso a ciertos sitios web o navegadores), ataques de denegación de servicio y cortes parciales o totales de Internet. No nos preocupa la censura de temas tales como pornografía infantil, información altamente clasificada como secretos militares o de inteligencia, declaraciones ofensivas a una religión en particular o discurso difamatorio, a menos que este tipo de censura se use como pretexto para censurar información u opiniones políticas. Tampoco nos preocupa el alcance del acceso a Internet, a menos que no haya absolutamente ningún acceso (en cuyo caso la codificación debería ser 0).

Respuestas: 
1: El gobierno bloquea con éxito el acceso a Internet excepto a los sitios que son pro-gobierno o carente de contenido político.

2: El gobierno intenta bloquear el acceso a Internet excepto a sitios que son progubernamentales o carentes de contenido político, pero muchos usuarios son capaces de eludir dichos controles.

3: El gobierno permite el acceso a Internet, incluyendo a algunos sitios que son críticos del gobierno, pero bloquea sitios seleccionados que tratan temas especialmente delicados políticamente.

4: El gobierno permite el acceso a Internet sin restricciones, con las excepciones mencionadas anteriormente.

Escala: Ordinal, convertida a intervalo por el modelo de medición.

Pregunta 13.8: ¿Son acosados los periodistas -es decir, amenazados con difamación, detenidos, encarcelados, golpeados o asesinados-por actores gubernamentales o no-gubernamentales poderosos mientras participan en actividades periodísticas legítimas?

Respuestas:

0: Ningún periodista se atreve a participar en actividades periodísticas que pudieran molestar a los actores poderosos porque seguramente sufrirían acoso o algo peor.

1: Algunos periodistas ocasionalmente publican contenidos que molestan a actores poderosos, pero casi siempre son acosados o algo peor y, finalmente, se ven obligados a detener dichas publicaciones.

2: Algunos periodistas que publican contenidos que molestan a actores poderosos se ven obligados a detener sus publicaciones, pero otros logran continuar practicando el periodismo libremente durante largos períodos de tiempo.

3: Es raro que cualquier periodista sea acosado por publican contenidos que molesten a actores poderosos, y si esto sucediera, los responsables del acoso serían identificados y castigados.

4: Los periodistas nunca son hostigados por actores gubernamentales o no-gubernamentales poderosos mientras participan en actividades periodísticas legítimas.

Escala: Ordinal, convertida a intervalo por el modelo de medición.

Pregunta 10.2: ¿Hay libertad académica y libertad de expresión cultural relacionada con problemas políticos?

Respuestas:

0: No son respetadas por las autoridades públicas. La censura y la intimidación son frecuentes. Las actividades académicas y las expresiones culturales están severamente restringidas o controladas por el gobierno. 
1: Deficientemente respetadas por las autoridades públicas. La libertad académica y la libertad de expresión cultural se practican de vez en cuando, pero la crítica directa al gobierno se enfrenta generalmente a la represión.

2: Algo respetadas por las autoridades públicas. Libertad académica y libertad de expresión cultural se practican rutinariamente, pero la crítica fuerte al gobierno se resuelve en ocasiones con la represión.

3: Generalmente respetadas por las autoridades públicas. Hay pocas limitaciones a la libertad académica y la libertad de expresión cultural, y las sanciones resultantes tienden a ser infrecuentes y suaves.

4: Totalmente respetadas por las autoridades públicas. No hay restricciones sobre la libertad académica o la expresión cultural.

Escala: Ordinal, convertida a intervalo por el modelo de medición.

Aunque esta pregunta no se relaciona directamente con internet, la incluimos porque hemos observado que entre las modalidades comunes de limitación a la expresión de académicos e intelectuales en la región se encuentran el ciberacoso, hacking a sus cuentas de correo electrónico y social media, y los procesos policiales o judiciales por opiniones expresadas en la web.

Pregunta 12.3: ¿El gobierno intenta reprimir a las organizaciones de la sociedad civil (OSC)?

Respuestas:

0: Severamente. El gobierno persigue de forma violenta y activa a todos los miembros reales e incluso algunos imaginarios de las OSC. No sólo tratan de disuadir la actividad de esos grupos, sino de liquidarlos efectivamente.

1: Sustancialmente. Además de los tipos de acoso expuestos en las respuestas 2 y 3 a continuación, el gobierno también detiene, procesa y aprisiona a líderes y participantes en OSC que han actuado legalmente. Otras sanciones incluyen la interrupción de las reuniones públicas y las sanciones violentas a los activistas (golpizas, amenazas a las familias, destrucción de bienes valiosos).

2: Moderadamente. Además de las sanciones materiales descritas en la respuesta 3 a continuación, el gobierno también se ocupa de acoso legal menor (detenciones, encarcelamiento a corto plazo) para disuadir a las OSC de actuar o expresarse. El gobierno también puede restringir el alcance de sus acciones a través de medidas que restringen la asociación de organizaciones de la sociedad civil entre sí o con partidos políticos, impiden que las organizaciones de la sociedad civil tomen ciertas medidas o bloquea los contactos internacionales. 
3: Débilmente. El gobierno usa sanciones materiales (multas, despidos, negación de servicios sociales) para disuadir a las OSC de actuar o expresarse. También pueden utilizar procedimientos de registro o incorporación onerosos para retrasar la formación de nuevas organizaciones de la sociedad civil y desviarlas del compromiso. El gobierno también puede organizar GONGOs para expulsar a organizaciones independientes. 4: No. Las organizaciones de la sociedad civil son libres de organizarse, asociarse, hacer huelga, expresarse y criticar al gobierno sin temor a las sanciones o acoso del gobierno.

Escala: Ordinal, convertida a intervalo por el modelo de medición.

Aunque esta pregunta no se relaciona directamente con internet, la incluimos porque hemos observado que entre las modalidades comunes de represión a las organizaciones de la sociedad civil en la región se encuentran el ciberacoso a sus activistas, hacking a sus cuentas de correo electrónico y social media, y bloqueo a sus páginas web.

La metodología de «Freedom on the Net» incluye 21 macro-preguntas y cerca de 100 ítems, en tres categorías: 1) Obstáculos al acceso: barreras de infraestructura y barreras económicas al acceso, control legal y de propiedad de los proveedores de servicios de Internet e independencia de los organismos reguladores; 2) Límites del contenido: regulaciones legales sobre el contenido, filtrado técnico y bloqueo de sitios web, autocensura, vitalidad y diversidad de los medios de comunicación en línea y el uso de herramientas digitales para la movilización cívica; y 3) Violaciones de los derechos de los usuarios: vigilancia gubernamental, privacidad, repercusiones en la expresión y las actividades en línea, encarcelamiento, acoso extralegal o ciberataques. Basado en la puntuación en el conjunto de los ítems, Freedom House asigna las siguientes calificaciones de libertad de internet: Puntuaciones 0-30 = Libre; Puntuaciones 31-60 $=$ Parcialmente Libre; Puntuaciones 61-100 = No libre. En este estudio, usamos la categorización y el puntaje asignado a cada país en el informe 2016 de Freedom on the Net.

\section{Chile}

El caso chileno representa un modelo de transición democrática y de reforma económica exitoso tanto en su dinámica como en sus resultados ${ }^{4}$. Una democracia en progresiva consolidación desde hace un cuarto

4 Agradecemos los aportes de Carlos Durán Migliardi para el abordaje del caso chileno. 
de siglo, articulada alrededor de dos bloques político-partidarios (desde la centro-izquierda nucleada en la oposición a la dictadura versus las derechas herederas del proyecto neoliberal) con niveles apreciables de gobernabilidad y con tasas de crecimiento inéditas para la región. Estos son algunos de los antecedentes que se señalan para caracterizar a este país como un caso particular dentro de la inestabilidad política y estancamiento económico que ha caracterizado la deriva de las naciones latinoamericanas. Chile, así, aparece como una democracia consolidada, capaz de alcanzar una gobernabilidad duradera en un contexto sociopolítico altamente volátil y complejo como es el contexto de las transiciones democráticas. Sin embargo, esta consolidación supuso una progresiva tecnocratización del discurso político y sus lógicas de acción, desafiadas por movilizaciones sociales recientes en pro de la gratuidad y el derecho a la educación, mejoras en diversos servicios públicos y cambios en la constitución heredada de la dictadura (Garretón, 2012; Hunneus, 2014; Durán, 2016). El Índice aditivo de poliarquía de V-Dem obtenido por Chile es 0.95 .

Chile tiene una población de 18 millones de habitantes y una penetración de internet de $77 \%$ de la población (Internet World Stats, 2017). De acuerdo con los datos proporcionados por V-Dem, Chile obtiene en 2016 un puntaje de 5.56 en censura de internet, lo que implica que el gobierno chileno permite el acceso a Internet sin restricciones. El país austral se ha mantenido en el más alto nivel de respeto a la libertad de expresión en internet en todo el período 2006-2016. En cambio, obtiene en 2016 un puntaje de 2.42 en censura de medios, lo que implica que existen intentos de censura directos pero limitados a cuestiones especialmente delicadas. En este intervalo 2015-2016, Chile retrocedió con respecto a los años 2013 y 2014, cuando los datos de V-Dem reportaban que el gobierno rara vez intentaba censurar a los principales medios de comunicación en cualquier forma, y cuando se descubrían tales intentos excepcionales, los funcionarios responsables eran castigados. Con respecto al acoso a periodistas, Chile obtiene en 2016 un puntaje de 3.34, lo que implica que es raro que un periodista sea acosado por ofender a actores poderosos y, si esto llega a suceder, los responsables del acoso son identificados y castigados; el país sureño se ha mantenido en este intervalo durante todo el período de estudio. 
Finalmente, en 2016, Chile obtiene un puntaje de 4.64 en represión a las OSC, lo que implica que las organizaciones de la sociedad civil son libres de organizarse, asociarse, hacer huelga, expresarse y criticar al gobierno sin temor a sanciones o acoso gubernamental; el país se ha mantenido en este intervalo durante todo el período de estudio. En los años 2015 y 2016, V-Dem no midió libertad académica y libertad de expresión en Chile; en 2013 y 2014, este país se había ubicado en el máximo intervalo, es decir que los datos reportaban que no ocurrían casos de restricciones sobre la libertad académica o la expresión cultural (ver gráfico 1).

Gráfico 1. Indicadores V-Dem Chile (2016)

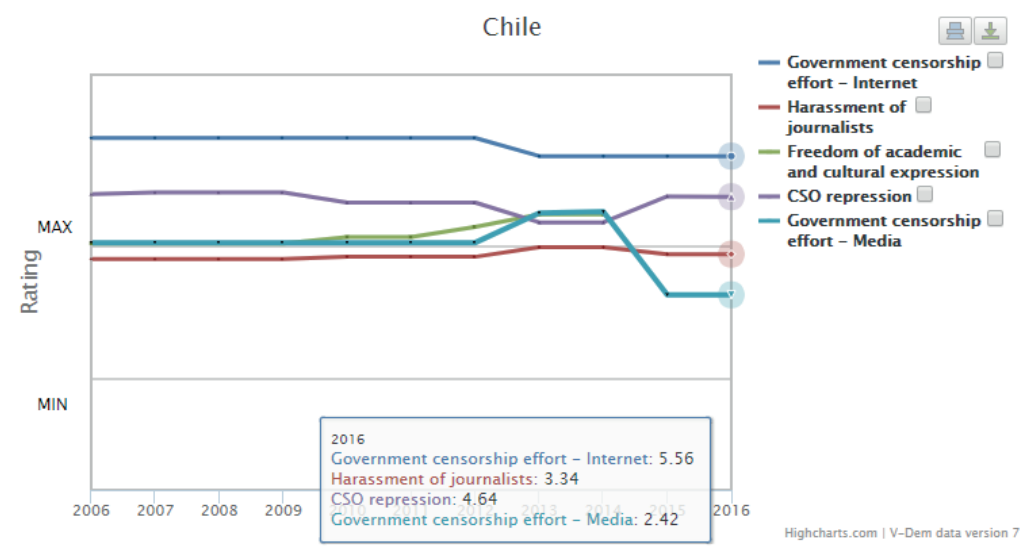

Fuente: $V$-Dem data version 7

\section{México}

En México, el régimen político emanado de la alternancia a partir del 2000 puede ser catalogado formalmente como una poliarquía, aunque con déficits en dimensiones centrales tales como el ámbito electoral y la calidad de la vida partidaria. Frecuentemente, sus actores dominantes (en particular los partidos) operan con modos oligárquicos, limitando la participación activa de sus militantes, capturando la agenda política nacional -restringiendo las demandas y participación ciudadanas- e indiferenciado sus programas políticos. Asistimos pues, a nivel federal, a un pluralismo limitado y una democracia de baja calidad. En el ámbito 
estatal, vemos regímenes políticos subnacionales que oscilan entre la democracia delegativa -con gobernadores poderosos que imponen la pauta de la vida política regional- y expresiones puntuales de autoritarismo electoral, con su cuota de represión y uso de la violencia. En una parte de los gobiernos regionales y locales, la alternancia política y los modos civiles de ejercer el poder se resienten, hay control de la prensa y de los empleados públicos (Marti, Ortega, Somuano \& Wright, 2014; Loza \& Méndez, 2016; Somuano \& Nieto, 2016). El Índice aditivo de poliarquía de V-Dem obtenido por México es 0.85 .

México tiene una población de 127 millones de habitantes y una penetración de internet de $57 \%$ de la población (Freedom House, 2016). En los datos proporcionados por V-Dem, México obtiene en 2016 un puntaje de 4.28 en censura de internet, lo que implica que el gobierno permite el acceso sin restricciones. Asimismo, el país del norte se ha mantenido en el más alto nivel de respeto a la libertad de acceso a la red en todo el período 2006-2016. En cambio, obtiene en 2016 un puntaje de 2.44 en censura de medios, lo que implica que existen intentos de censura directos pero limitados a cuestiones especialmente delicadas. México se ha ubicado en este intervalo desde 2011, avanzando con respecto a los primeros años del siglo cuando los datos de V-Dem reportaban que los intentos de censura eran rutinarios, aunque indirectos. Con respecto al acoso a periodistas, México obtiene en 2016 un puntaje de 1.65 , lo que implica que los periodistas son severamente acosados y en ocasiones sufren ataques mayores -que pueden llegar al asesinato, siendo el país con más asesinatos de periodistas en la región- hasta que son obligados a dejar de publicar sobre asuntos que puedan molestar a los poderosos. México se ha mantenido en este intervalo durante todo el período de estudio.

En relación con la libertad académica y la libertad de expresión, México obtiene un puntaje de 2,85, lo que implica que los académicos e intelectuales ejercen rutinariamente sus derechos y libertades, pero la crítica fuerte al gobierno puede conllevar formas de represión en algunas ocasiones; el país norteño se ha mantenido en este intervalo desde 2013, anteriormente encontrándose en un intervalo superior y los datos indican que había pocas limitaciones a la libertad académica y la libertad de expresión cultural, con sanciones gubernamentales infrecuentes. Finalmente, en 2016, México obtiene un puntaje de 3.56 en represión 
a las OSC, lo que implica que el gobierno mexicano usa sanciones administrativas para disuadir a las OSC de actuar o expresarse y que pueden existir GONGOs que ocupan espacios de las organizaciones independientes; el país se ha mantenido en este intervalo durante todo el período de estudio (ver gráfico 2).

Gráfico 2. Indicadores V-Dem México (2016)

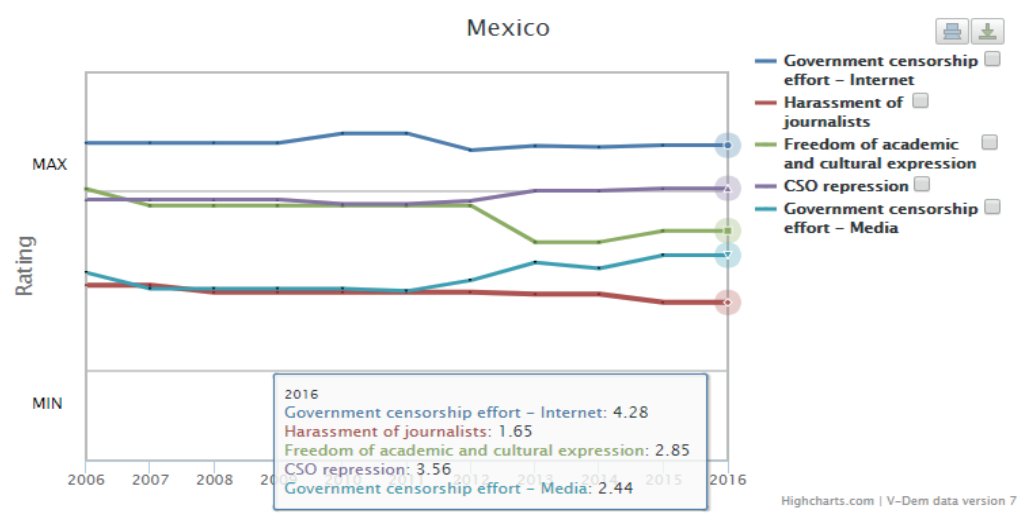

Fuente: $V$-Dem data version 7

El informe de «Freedom on the Net 2016» reporta que México es un país en donde internet es parcialmente libre y la prensa no es libre. México recibe un puntaje de 38 puntos sobre 100 y registra sus peores indicadores en la dimensión de Violaciones a los Derechos de los Usuarios (ver tabla 1). El principal indicador negativo es que al menos tres periodistas que cubrían en-línea historias sensibles fueron asesinados entre 2015 y 2016. Asimismo, se reportan usuarios de internet arrestados por sus publicaciones o expresiones en-línea.

A pesar de la presión de la sociedad civil, en 2016, la Suprema Corte de Justicia de México confirmó nuevos requisitos de retención de datos y disposiciones de geolocalización en tiempo real aprobadas en 2014, aunque sentenció que es necesario que las autoridades obtengan una orden judicial para acceder a los metadatos de los usuarios. Esto amplía las capacidades de vigilancia del Estado mexicano y vulnera derechos de privacidad y anonimato de los usuarios. Con respecto a ataques técnicos, al menos tres sitios de noticias sufrieron ciberataques en junio 2016, durante 
las elecciones estatales en Puebla, con lo que se interrumpió el acceso de los votantes a la información en un momento crítico.

Tabla 1. México Freedom on the Net (2016)

\begin{tabular}{|l|c|c|c|c|}
\hline \multicolumn{1}{|c|}{ Status } & $\begin{array}{c}\text { Puntaje } \\
\text { Total }\end{array}$ & $\begin{array}{c}\text { Obstáculos } \\
\text { al Acceso }\end{array}$ & $\begin{array}{c}\text { Límites en } \\
\text { Contenidos }\end{array}$ & $\begin{array}{c}\text { Violaciones } \\
\text { a los Derechos } \\
\text { de los Usuarios }\end{array}$ \\
\hline Partly Free & 38 & 8 & 10 & 20 \\
\hline
\end{tabular}

\section{Ecuador}

Ecuador es una democracia delegativa, lastrada históricamente por una débil institucionalidad estatal y por la inestabilidad política ${ }^{5}$ Sin embargo, en la última década se obtuvieron logros importantes en derechos e institucionalidad a partir de la Constitución vigente, que se encuentra entre las más innovadoras de América Latina. En la última década, con la fuerza que toma Alianza País como partido de gobierno y la mayoría legislativa que consigue, surgen serias dudas sobre la independencia de poderes. Pese a existir elecciones libres, abiertas y competitivas, el diseño del sistema electoral -distribución de circunscripciones, el tipo de lista y las fórmulas de asignación de escaños- favorece al partido mayoritario. Asimismo, la relación ejecutivo-legislativo favorece al primero bajo un esquema hiper-presidencialista, con todas las atribuciones que la Constitución le otorga al presidente -como la de gobernar por decreto y la capacidad de veto-; mientras que el legislativo no tiene la capacidad de destituir ministros de Estado, lo que se aúna a un sistema de partidos históricamente débil y a una sociedad civil beligerante pero asediada por el oficialismo. Además, dado el carácter mayoritario del partido de gobierno, con frecuencia la elección de autoridades para los restantes poderes y funciones del Estado responde al mismo círculo político dominante (Mantilla \& Mejía, 2012; Ortiz, 2013; Ulloa, 2017). El Índice aditivo de poliarquía de V-Dem obtenido por Ecuador es 0.82.

Ecuador tiene una población de 16 millones de habitantes y una penetración de internet de 49\% de la población (Freedom House, 2016). En los datos proporcionados por V-Dem, Ecuador obtiene en 2016 un puntaje de 3.77 en censura de internet, lo que implica que el

5 Agradecemos los aportes de Coralia Barahona para el abordaje del caso ecuatoriano. 
gobierno permite el acceso a Internet, incluyendo a algunos sitios que son críticos del gobierno, pero bloquea sitios seleccionados que tratan temas especialmente delicados políticamente. El país se ha mantenido en este intervalo en los años 2015 y 2016, luego de que en los años 2013 y 2014 se le había ubicado en el intervalo superior. Con respecto a censura de medios, Ecuador obtiene en 2016 un puntaje de 1.89 lo que implica que los intentos de censura son rutinarios, aunque indirectos. El país andino se ha ubicado en este intervalo desde 2009, cayendo con respecto a los primeros años del siglo cuando los datos de V-Dem reportaban que los intentos de censura eran directos pero limitados a cuestiones especialmente delicadas. Con respecto al acoso a periodistas, Ecuador obtiene en 2016 un puntaje de 2.32, lo que implica que algunos profesionales de la información que publican contenidos que molestan a actores poderosos son obligados a detener sus publicaciones, pero otros logran continuar practicando el periodismo libremente en el largo plazo. Ecuador se ha mantenido en este intervalo desde 2013, mientras que anteriormente, durante el período 2009-2012, los datos de V-Dem indican que los periodistas en este país eran severamente acosados y en ocasiones sufrían ataques mayores hasta que eran obligados a interrumpir las publicaciones sobre asuntos que podían molestar a los poderosos.

Con respecto a la libertad académica y a la libertad de expresión, Ecuador obtiene un puntaje de 2.70, lo que implica que los académicos e intelectuales ejercen rutinariamente sus derechos y libertades, pero la crítica fuerte al gobierno puede conllevar formas de represión en algunas ocasiones. El país andino se ha mantenido en este intervalo desde 2009, anteriormente se encontraba en un intervalo superior y los datos indican que había pocas limitaciones a la libertad académica y la libertad de expresión cultural, con sanciones gubernamentales infrecuentes. Finalmente en 2016, Ecuador obtiene un puntaje de 1.56 en represión a las OSC, lo que implica que el gobierno ecuatoriano detiene, procesa y aprisiona a líderes y activistas en OSC que han actuado legalmente; el país se ha mantenido en este intervalo desde 2013 (ver gráfico 3).

El informe de Freedom on the Net 2016 reporta que Ecuador es un país en donde internet es parcialmente libre, mientras que la prensa no es libre. Ecuador recibe un puntaje de 41 puntos sobre 100 y registra sus peores indicadores en la dimensión de Violaciones a los Derechos de los Usuarios (ver tabla 2). El informe recoge evidencias de que el 
gobierno de Ecuador realiza actividades de vigilancia en-línea que afectan a una amplia gama de individuos (políticos, periodistas y activistas). Demandas por difamación y frecuentes ataques verbales son usados para disuadir a los usuarios de internet de expresar en-línea comentarios críticos al gobierno. En este sentido, por ejemplo, dos dirigentes políticos opositores fueron sentenciados a 15 y 30 días de cárcel respectivamente por sus comentarios en social media. Varios medios digitales sufrieron ciberataques después de publicar informaciones sobre los vínculos entre la agencia de inteligencia de Ecuador y la empresa de vigilancia Hacking Team; otros medios digitales fueron atacados luego de cubrir protestas antigubernamentales en junio de 2015. Notablemente, el uso de notas de infracción de derechos de autor se ha convertido en un recurso usado comúnmente para forzar a retirar de los medios digitales y de las plataformas sociales contenido crítico al gobierno.

\section{Gráfico 3. Indicadores V-Dem Ecuador 2016}

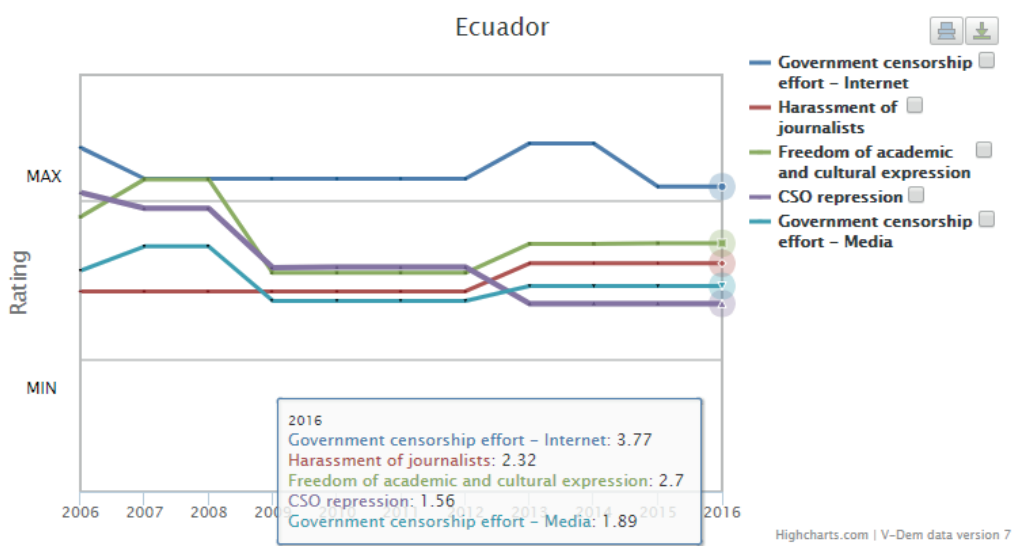

Tabla 2. Ecuador Freedom on the Net 2016

\begin{tabular}{|l|c|c|c|c|}
\hline Status & $\begin{array}{c}\text { Puntaje } \\
\text { Total }\end{array}$ & $\begin{array}{c}\text { Obstáculos al } \\
\text { Acceso }\end{array}$ & $\begin{array}{c}\text { Límites en } \\
\text { Contenidos }\end{array}$ & $\begin{array}{c}\text { Violaciones } \\
\text { a los Derechos } \\
\text { de los Usuarios }\end{array}$ \\
\hline Partly Free & 41 & 8 & 12 & 21 \\
\hline
\end{tabular}




\section{Venezuela}

En el caso venezolano, el ascenso y posterior consolidación del chavismo estuvo aparejado con un cambio paulatino del régimen político que tendió a la personalización y la autocratización, con un clientilizado aparato estatal sostenido por la abundante renta petrolera. Desde su temprana fase de democracia delegativa (1999-2005), el chavismo tuvo un carácter marcadamente presidencialista; el presidente Chávez obtuvo leyes habilitantes en varias ocasiones para decidir sobre diversas áreas de política pública con amplísimas competencias. El segundo tramo en el mandato de Chávez (2006-2013) se corresponde con el autoritarismo competitivo. En esta etapa se expresan variables coincidentes con dicho modelo, como el abuso en el uso de los recursos del Estado para financiar las campañas electorales, el avance hacia un modelo de partido hegemónico, el control a los medios y la sociedad civil, la criminalización de activistas y dirigentes opositores. Por último, a partir de 2014, bajo la presidencia de Nicolás Maduro, el autoritarismo se ha vuelto más afín a la variante cerrada, poniendo a la oposición al filo de la ilegalización y acudiendo a la represión masiva de las protestas ciudadanas.

Con la implantación de la llamada Asamblea Nacional Constituyente se dan pasos a una ulterior autocratización del régimen, que comienza a asumir rasgos prototípicamente totalitarios, en algunos aspectos similar al régimen cubano (Corrales \& Hidalgo, 2013; Gómez \& Arenas, 2013; Chaguaceda \& Puerta, 2015). El Índice aditivo de poliarquía de V-Dem obtenido por Venezuela es 0.61 .

Venezuela tiene una población de 31 millones de habitantes y una penetración de internet de $62 \%$ de la población (Freedom House, 2016). En los datos proporcionados por V-Dem, Venezuela obtiene en 2016 un puntaje de 3.22 en censura de internet, lo que implica que el gobierno permite el acceso a Internet, incluyendo algunos sitios que son críticos del gobierno, pero bloquea sitios seleccionados que tratan temas especialmente delicados políticamente. El país se ha mantenido en este intervalo desde 2013, luego de que en los años previos se le había ubicado en el intervalo superior. Con respecto a censura de medios, Venezuela obtiene en 2016 un puntaje de 0.50, lo que implica que la censura es directa y rutinaria. El país caribeño se ha ubicado en este intervalo desde 2013 y previamente se ubicó en el intervalo inmediatamente superior en el cual la censura era rutinaria pero indirecta. Con respecto al acoso 
a periodistas, Venezuela obtiene en 2016 un puntaje de 1.38, lo que implica que los periodistas son severamente acosados y, en ocasiones, sufren ataques mayores hasta que son obligados a dejar de publicar sobre los asuntos que puedan molestar a los poderosos; el país se ha mantenido en este intervalo durante toda la década de estudio.

Con respecto a libertad académica y libertad de expresión, Venezuela obtiene un puntaje de 1.92, lo que implica que los académicos e intelectuales intentan ejercer sus derechos y libertades, pero la crítica al gobierno lleva generalmente a enfrentar la represión. El país se ha mantenido en este intervalo desde 2015, mientras que anteriormente se encontraba en un intervalo superior y los datos indican que hasta 2014 más académicos e intelectuales lograban expresarse libremente sin exponerse a sanciones gubernamentales. Finalmente, en 2016, Venezuela obtiene un puntaje de 1.80 en represión a las OSC, lo que implica que el gobierno venezolano detiene, procesa y aprisiona a líderes y activistas en OSC que han actuado legalmente. Los datos de V-Dem indican que detenciones y encarcelamientos de activistas que actúan dentro del marco de la ley han sido comunes en Venezuela durante toda la década de estudio (ver gráfico 4).

Gráfico 4. Indicadores V-Dem Venezuela 2016

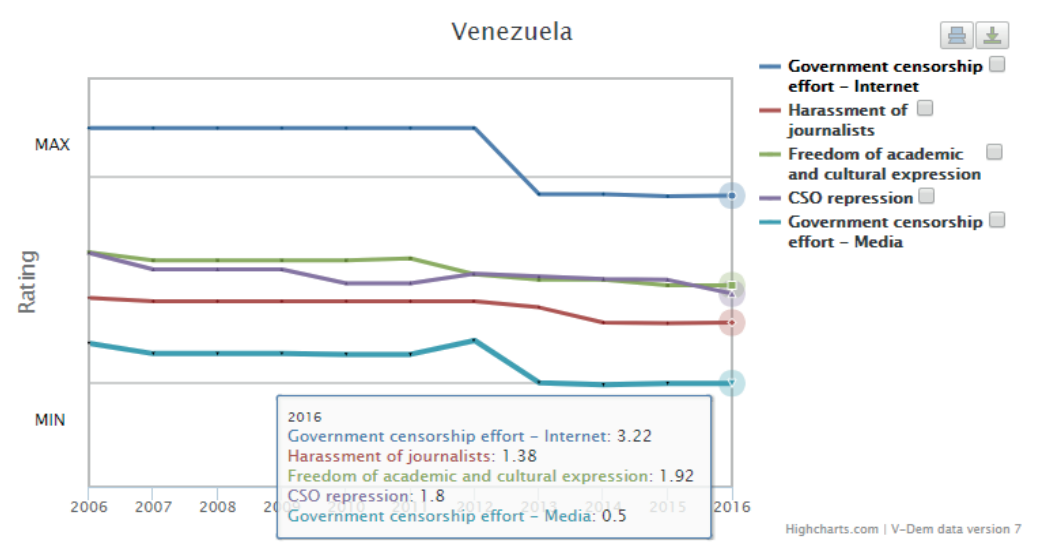

Fuente: $\mathrm{V}$-Dem data version 7

El informe de Freedom on the Net 2016 reporta que Venezuela es un país en donde internet es parcialmente libre, mientras que la 
prensa no lo es. Venezuela recibe un puntaje de 60 puntos sobre 100 y registra indicadores negativos en las tres dimensiones Violaciones a los Derechos de los Usuarios, Obstáculos al Acceso y Limitaciones de Contenidos (ver tabla 3). El informe recoge evidencias de que las fuerzas de seguridad venezolanas arrestan rutinaria y arbitrariamente a periodistas digitales, confiscan teléfonos celulares y obligan a los usuarios a borrar imágenes de protestas o de colas para comprar comida.

Tabla 3. Venezuela Freedom on the Net 2016

\begin{tabular}{|l|c|c|c|c|}
\hline Status & $\begin{array}{c}\text { Puntaje } \\
\text { Total }\end{array}$ & $\begin{array}{c}\text { Obstáculos } \\
\text { al Acceso }\end{array}$ & $\begin{array}{c}\text { Límites en } \\
\text { Contenidos }\end{array}$ & $\begin{array}{c}\text { Violaciones } \\
\text { a los Derechos } \\
\text { de los Usuarios }\end{array}$ \\
\hline Partly Free & 60 & 18 & 17 & 25 \\
\hline
\end{tabular}

En septiembre de 2015, el político de la oposición Leopoldo López fue sentenciado a casi 14 años de prisión después de que los fiscales alegaron que incitó a la violencia; como principal evidencia en el juicio en su contra, los fiscales presentaron cientos de tweets y un video de YouTube en el cual el líder decía la frase "tenemos que salir a conquistar la democracia" y la testigo clave de la acusación fue una lingüista que analizó el discurso de @leopoldolopez para concluir se usó esa cuenta en Twitter para convocar subliminalmente manifestaciones en contra del gobierno.

Por su parte, la intercepción de los correos electrónicos de periodistas y activistas opositores continúa siendo una táctica muy utilizada por el gobierno de Venezuela, que ha venido estableciendo mecanismos de vigilancia masiva y automatizada en internet desde 2010. Desde junio de 2014, la Comisión Nacional de Telecomunicaciones (CONATEL) estableció como práctica rutinaria el bloqueo de páginas web que publican tasas de cambio del mercado paralelo de divisas; estos y otros sitios web continuaron siendo bloqueados en 2015 y 2016.

La velocidad media de banda ancha no supera los $2 \mathrm{Mbps}$, menos del 5\% de las conexiones son más rápidas que 4 Mbps. Según cifras oficiales, la penetración de Internet se mantuvo por encima del 60 por ciento, aunque el número total de suscriptores ha disminuido y hay una brecha significativa entre las zonas rurales y urbanas. Los controles de divisas afectan negativamente a la industria de las telecomunicaciones, 
mientras que el racionamiento de electricidad impide a los usuarios el acceso a la conexión a internet.

\section{Cuba}

Cuba es una autocracia, en tanto se trata de un régimen donde el poder está concentrado y/o personalizado, se ejerce de forma vertical y con diversos grados de arbitrariedad y los habitantes de la nación mantienen con el Estado una relación de subordinación que les impide ejercer derechos ciudadanos. Perteneciendo a la familia milenaria y extensa de las autocracias, la de Cuba no es una dictadura tradicional o un autoritarismo militar. Tampoco es un post-totalitarismo maduro. Su régimen se encuentra aún en una fase temprana -y dura, susceptible de recaídas- de la evolución post-totalitaria (Farber, 2011; Rojas, 2015; Chaguaceda \& Geoffray, 2015): un post-totalitarismo inicial, en el que varios núcleos totalitarios (partido único, control político y policíaco, ideología de Estado) siguen siendo centrales en la constitución, reproducción y funcionamiento cotidianos del orden político, pero donde se pasa de un liderazgo carismático a otro colegiado y burocrático (Pasquino, 2014; Linz, 2000; Linz y Stephan, 1997). El Índice aditivo de poliarquía de V-Dem obtenido por Cuba es 0.38 .

Cuba tiene una población de 11 millones de habitantes y una penetración de internet de 5\% de la población (Freedom House, 2016). En los datos proporcionados por V-Dem, Cuba obtiene en 2016 un puntaje de 1.32 en censura de internet, lo que implica que se censura rutinaria y sistemáticamente el uso de internet, aunque generalmente sea con mecanismos indirectos. La isla se ha mantenido en este intervalo desde 2013, cuando comienza a abrirse el acceso a internet para los ciudadanos cubanos. Con respecto a censura de medios, Cuba obtiene en 2016 un puntaje de $-\mathbf{0 . 4 8}$, lo que implica que la censura a los medios es total y sistemática y así lo ha sido durante todo el período de estudio. Con respecto al acoso a periodistas, Cuba obtiene en 2016 un puntaje de 1.27 , lo que implica que los periodistas son severamente acosados y en ocasiones sufren ataques mayores para forzarlos a no publicar sobre los asuntos que puedan molestar a los poderosos; penosamente, esto constituye una ligera mejora en la isla caribeña en donde hasta 2015 los periodistas ni siquiera se atrevían a intentar reportar sobre asuntos que pudieran molestar a los poderosos. 
En relación a la libertad académica y libertad de expresión, Cuba obtiene un puntaje de 0.18 , dado que las actividades académicas y las expresiones culturales están severamente restringidas o controladas por el gobierno y así ha sido durante todo el período de estudio. Finalmente, en 2016, Cuba obtiene un puntaje de 0.98 en represión a las OSC, lo que implica que el gobierno comunista persigue de forma violenta y activa a todos los miembros reales e incluso algunos supuestos de las OSC y no solo trata de disuadir la actividad de esos grupos, sino de liquidarlos efectivamente. Paradójicamente, los indicadores de persecución de la sociedad civil cubana han empeorado desde 2014 (ver gráfico 5).

\section{Gráfico 5. Indicadores V-Dem Cuba 2016}

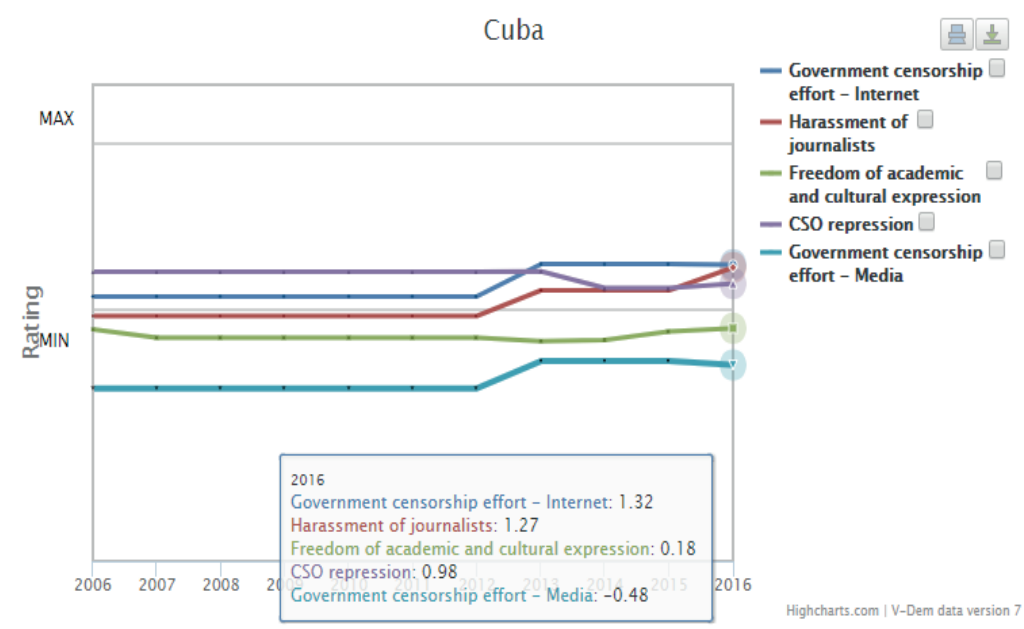

Fuente: $V$-Dem data version 7

El informe de Freedom on the Net 2016 reporta que Cuba es un país en donde internet no es libre y tampoco es libre la prensa. Cuba recibe un puntaje de 79 puntos sobre 100 y registra indicadores negativos en las tres dimensiones: Violaciones a los Derechos de los Usuarios, Obstáculos al Acceso y Limitaciones de Contenidos (ver tabla 4). 
Tabla 4. Cuba Freedom on the Net 2016

\begin{tabular}{|l|c|c|c|c|}
\hline \multicolumn{1}{|c|}{ Status } & $\begin{array}{c}\text { Puntaje } \\
\text { Total }\end{array}$ & $\begin{array}{c}\text { Obstáculos al } \\
\text { Acceso }\end{array}$ & $\begin{array}{c}\text { Límites en } \\
\text { Contenidos }\end{array}$ & $\begin{array}{c}\text { Violaciones a los } \\
\text { Derechos de los } \\
\text { Usuarios }\end{array}$ \\
\hline No Free & 79 & 21 & 26 & 32 \\
\hline
\end{tabular}

Desde que Estados Unidos y Cuba restablecieron oficialmente relaciones diplomáticas, nuevas regulaciones han disminuido las restricciones a las compañías de telecomunicaciones estadounidenses para que comiencen a ofrecer servicios en la isla. El gobierno cubano lanzó sus primeros Wi-Fi hotspots públicos en junio y julio de 2015. Si bien estos hotspots se han convertido en una forma popular de acceder a Internet, las conexiones limitadas y costosas siguen constituyendo una importante barrera. Los bloggers y periodistas independientes continúan enfrentándose a la censura, la intimidación y los arrestos. Durante este período se reportaron varias remociones de contenido en la plataforma de blogs patrocinada por el gobierno: Reflejos. A pesar de la severa censura del contenido considerado como «contrarrevolucionario», los cubanos han lanzado una serie de sitios web independientes, que ofrecen información alternativa sobre la realidad cubana.

\section{Discusión de resultados}

En este trabajo intentamos demostrar que el control de internet varía en asociación con los regímenes políticos vigentes. Los datos de V-Dem nos permiten hacer un comparativo del puntaje de libertad de internet obtenido por cada uno de los países y correlacionarlo con su índice de poliarquía (ver gráfico 6). El orden obtenido por los cinco países en la variable «Libertad de Internet» y en el «Índice de Poliarquía» coincide. El análisis de correlación Pearson arroja como resultado que el valor de $\mathrm{R}$ es 0,9692 , siendo el valor $p=0,017788$. El resultado es significativo en $\mathrm{p}<0,05$. Ésta es una fuerte correlación positiva, lo que significa que mientras más alto es el «Índice de Poliarquía» más alto es el puntaje en la variable de «Libertad de Internet». Esto aporta evidencia estadística para apoyar la hipótesis de que a mayor calidad de la democracia, mayor libertad de internet y a mayor autocracia, mayor censura de internet. 


\section{Gráfico 6. Libertad de Internet / Índice de Poliarquía por países}

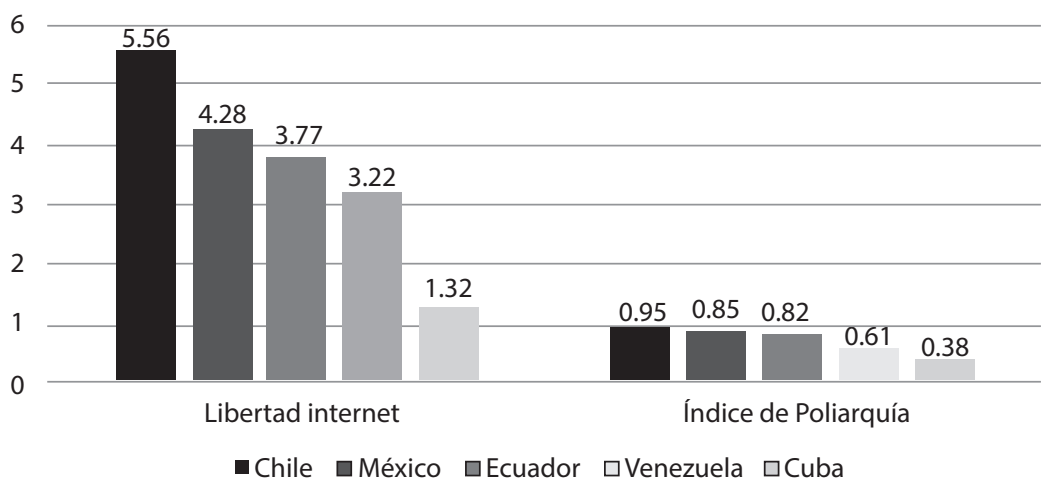

En resumen, este estudio exploratorio presenta evidencias que permiten asociar régimen político e índice de poliarquía con libertad de internet. Chile, una democracia de alta calidad obtiene un elevado Índice de Poliarquía (0.95) y un elevado puntaje en la variable Libertad de Internet (5.56), con ausencia de controles a la circulación de información en-línea. México, una democracia de baja calidad obtiene un Índice de Poliarquía elevado (0.85) y un puntaje en la variable Libertad de Internet (4.28) moderadamente elevado, con controles selectivos de segunda generación a la circulación de información en-línea. Ecuador, una democracia delegativa, obtiene un Índice de Poliarquía elevado $(0.82)$ y un puntaje mediano en la variable Libertad de Internet (3.77), con controles selectivos de segunda generación a la circulación de información en-línea. Venezuela, un autoritarismo hegemónico de reciente instauración obtiene un Índice de Poliarquía mediano (0.61) y un puntaje mediano en la variable Libertad de Internet (3.22), con controles selectivos de primera y de segunda generación a la circulación de información en-línea. Cuba, un post-totalitarismo temprano obtiene un Índice de Poliarquía bajo (0.38) y un puntaje bajo en la variable Libertad de Internet (1.32), con controles sistemáticos de primera generación a la circulación de información en-línea.

Mientras que los regímenes autocráticos, como Cuba, impiden el uso generalizado de internet por temor a que se quiebre el monopolio estatal de la información (Puddington, 2017), los regímenes híbridos y 
las democracias de baja calidad, como Ecuador y México, toleran que se alcance una moderada tasa de penetración de Internet, por ser esencial para participar en la economía global y porque les ayuda a sostener su legitimidad internacional. Bajo los autoritarismos competitivos y otras formas neo-autoritarias, en la medida en que los medios digitales van consolidándose como una alternativa real a las fuentes de noticias tradicionales y las plataformas de social media se constituyeron en herramientas cruciales para la movilización política de los ciudadanos, se comienza a interferir en el acceso y uso de internet inicialmente con mecanismos de control de segunda generación y posteriormente con controles de primera generación (Deibert \& Rohozinski, 2010; Crete-Nishihata, Deibert \& Senft, 2013; Puyosa, 2015; Puddington, 2017; Puyosa, 2017c), tal como fue ocurriendo en el caso de Venezuela, a partir de 2009 y con más intensidad a partir de 2014. Finalmente, bajo regímenes democráticos se avanza en políticas de protección de los derechos de los usuarios, de ampliación de las condiciones de acceso y se discute la neutralidad de la red, como ocurre en Chile.

\section{Conclusiones}

Desde fines de la primera década del siglo XXI, coincidiendo con la expansión global del Internet y en relación con su impacto político, las acciones y políticas dirigidas al control de internet se han extendido a escala internacional. De forma más puntual y (generalmente) regulada dentro de normas jurídicas, regímenes democráticos han avanzado en monitorear el flujo de información y comunicaciones en-línea para prevenir fenómenos como el terrorismo o el extremismo en sus diversas manifestaciones. Bajo las coordenadas de regímenes híbridos o abiertamente autocráticos, los gobernantes han ampliado no sólo su vigilancia, censura y sanción sobre internet, procurando monitorear y acotar el disenso respecto a sus políticas, sino también han comenzado a utilizar la red como vehículo para promover agendas oficiales.

Consideramos, por el análisis de la evidencia revisada -tanto la información general de los casos como sus desempeños desglosados en los estudios e indicadores de Varieties of Democracy y Freedom on the Net-, que existe una relación entre el tipo de las políticas de control de internet aplicadas y la naturaleza (más cerrada o abierta, más autocrática o democrática) del tipo de régimen político imperante en cada país. 
En ese sentido, mientras más autocrático es el régimen más se observan controles de internet de primera generación, que censuran contenidos y bloquean el acceso a internet. En los regímenes híbridos, por su parte, se privilegian los controles de segunda generación, que involucran obstáculos al acceso sin bloquear totalmente el servicio y en ocasiones se criminaliza a usuarios y proveedores.

A partir de los resultados de este estudio exploratorio se puede proponer la realización de un estudio que abarque todos los países de Latinoamérica y que analice estadísticamente la correlación entre el índice de poliarquía y las variables de libertad de expresión, así como las relaciones entre la categorización cualitativa del régimen político con la adopción de medidas de control de la información de primera o de segunda generación.

\section{Referencias}

Chaguaceda, A. \& Geoffray, M. L. (2015). Cuba: dimensiones y transformaciones político-institucionales de un modelo en transición. En Bobes, V. C (Ed.), Cuba, ¿ajuste o transición? Impacto de la reforma en el contexto del restablecimiento de las relaciones con los Estados Unidos, pp. 47-86. México DF: FLACSO.

Chaguaceda, A. \& Puerta, M. I. (2015). Quo vadis Venezuela: de la democracia delegativa al autoritarismo del siglo XXI. Revista Mexicana de Análisis y Administración Pública, 4(1), 175-202.

Coppedge, M., Gerring, J., Lindberg, S., Skaaning, S-E., Teorell, J., Altman, D., Andersson, F., Bernhard, M., Fish, M.S., Glynn, A., Hicken, A., Knutsen, C., Marquardt, K., McMann, K., Mechkova, V., Paxton, P., Pemstein, D., Saxer, L., Seim, B., Sigman, R. \& Staton, J. (2017). V-Dem Codebook E Dataset v7.1 Varieties of Democracy. (V-Dem) Project., University of Gothenburg, and Helen Kellogg Institute for International Studies, University of Notre Dame. Disponible en https://www.v-dem.net/en/data/data-version-7-1/

Corrales, J. \& Hidalgo, M. (2013). El régimen híbrido de Hugo Chávez en transición (2009-2013). Revista Desafíos, 25(1), 45-84.

Crete-Nishihata, M., Deibert, R., \& Senft, A. (2013). Not by technical means alone: the multidisciplinary challenge of studying information controls. Internet Computing. IEEE, 17(3), 34-41.

Dahl, R. (1989). La poliarquía. Madrid: Tecnos.

Durán, C. (2016). Chile vuelve al vecindario: De la complacencia al malestar. En Caldera, A. \& Chaguaceda, A. (coords.), Democracia en América Latina. Entre el ideal utópico y las realidades politicas, pp. 187-209. México DF: Editorial Fontamara/Universidad de Guanajuato.

Deibert, R., \& Rohozinski, R. (2010). Liberation vs. control: The future of cyberspace. Journal of Democracy, 21(4), 43-57. 
Drezner, D. W. (2010). Weighing the scales: The Internet's effect on state-society relations. The Brown Journal of World Affairs, 16(2), 31-44.

Farber, S (2011) Cuba Since the Revolution of 1959: A Critical Assessment. Chicago: Haymarket Books.

Freedom House (2016). Freedom on the Net. Silencing the Messenger: Communication Apps Under Pressure. Disponible en https://freedomhouse.org/report/freedom-net/freedom-net-2016

Garretón, M. A. (2012). Neoliberalismo corregido y progresismo limitado. Los gobiernos de la concertación en Chile, 1990-2010. Santiago: Clacso-ARCIS

Gómez, L. \& Arenas, N. (2013). El populismo chavista: autoritarismo electoral para amigos y enemigos. Cuadernos del Cendes, 30(82), 17-34.

Hunneus, C. (2014). La democracia semi-soberana. Chile después de Pinochet. Santiago: Taurus.

Internet World Stats (2017). Usage and population statistics. Disponible en http://www. internetworldstats.com/south.htm

Kerr, J. (2014). The Digital Dictator's Dilemma: Internet Regulation and Political Control in Non-Democratic States. Palo Alto: The Center for International Security and Cooperation - Stanford University.

Levitsky, S. \& Way, L. (2010). Competitive authoritarianism: Hybrid regimes after the Cold War. New York: Cambridge University Press.

Linz, J. (2000). Totalitarian and authoritarian regimes. Boulder: Lynne Rienne.

Linz, J. \& Stephan, A. (1997). Problems of Democratic transition and consolidation: Southern Europe, South America and Post-communist Europe, Baltimore: The Johns Hopkins University Press.

Loza, N. \& Méndez, I. (2016). Poderes y democracias. La política subnacional en México. México DF: FLACSO México/Instituto Electoral del Distrito Federal.

Mantilla, S. \& Mejía, S. (2012). Rafael Correa. Balance de la Revolución Ciudadana. Quito: Editorial Planeta del Ecuador.

Marti, S., Ortega, Y., Somuano, M. F., \& Wright, C. (2014). Democracy in Mexico. Attitudes and perceptions of citizens at national and local level. London: Institute of Latin American Studies.

Marwick, A., \& Lewis, R. (2017). Media manipulation and disinformation online. New York: Data \& Society Research Institute.

Ortiz, A. (2013). La sociedad civil ecuatoriana en el laberinto de la Revolución Ciudadana. Quito: FLACSO Ecuador.

Pasquino, G. (2014). Nuevo curso de ciencia política. México DF: Fondo de Cultura Económica.

Pearce, K. E., \& Kendzior, S. (2012). Networked authoritarianism and social media in Azerbaijan. Journal of Communication, 62(2), 283-298.

Pérez-Liñán, A. (2017). ¿Podrá la democracia sobrevivir al siglo XXI? Buenos Aires: Nueva Sociedad. 
Puddington, A. (2017). Breaking Down Democracy: Goals, Strategies, and Methods of Modern Authoritarians. Freedom House.

Puyosa, I. (2015). Control político de internet en el contexto de un régimen híbrido Venezuela 2007-2015. Revista Teknokultura, 12(3), 501-526.

Puyosa, I. (2017a). Cómo llegar al sumak kawsay en una campaña permanente. En Ponce, M., \& O. Rincón. Medios de lucha. La comunicación de los presidentes en América Latina. Madrid: Ediciones B / Penguin Random House Grupo Editorial.

Puyosa, I. (2017b). Bots políticos en Twitter en la campaña presidencial \#Ecuador 2017. Revista Contratexto, 27. Lima: Universidad de Lima.

Puyosa, I. (En imprenta, 2017c). Control político de la información en los autoritarismos del s. XXI. En Kozak, Gisela (ed.), El laberinto de la sinrazón. Madrid: Alfa Editorial.

Rojas, R. (2015). Historia mínima de la Revolución cubana. México DF: El Colegio de México.

Somuano, M. F. \& Nieto, F. (2016). Ciudadanía en México ¿Ciudadanía activa? México DF: INE/ Colmex.

Tilly, C. (2010). Democracia. Madrid: Akal.

Ulloa, C. (2017). El populismo en escena ¿Por qué emerge en unos países y en otros no? Quito: FLACSO Ecuador. 



\title{
La Reforma de Telecomunicaciones en México 2014. Una aproximación analítica ${ }^{1}$
}

\section{The Telecommunications Reform in Mexico 2014. An analytical approach}

Dr. Carlos Manuel Rodríguez Arechavaleta es profesor/investigador del Departamento de Comunicación, Universidad Iberoamericana (México) (carlos.rodriguez@ibero.mx) (http://orcid.org/0000-0002-1 188-2403)

\section{Resumen}

La presente investigación aborda la Reforma de Telecomunicaciones en México, aprobada y publicada en 2014. Partiendo de ubicar en el escenario latinoamericano las reformas en dos bloques diferenciados a partir de un reordenamiento de la integración económica y política regional en el 2014, se propone un marco teórico que permita una aproximación sistemática a las diversas variables que intervienen en la configuración de las coaliciones de política comercial ganadoras orientadas a la liberalización comercial o proteccionista. El caso mexicano se puede explicar vinculando las políticas económicas con las instituciones del Estado, la sociedad y el sistema internacional en una interacción dinámica, de constante reconfiguración a partir de tres variables analíticas: i) el contexto internacional; ii) la capacidad de influencia (leverage), las preferencias y las estrategias de los empresarios y; iii) las vulnerabilidades del Estado, intereses e iniciativas. Esta derivación lógica-inferencial propone un juego de hipótesis explicativas para la reforma de Telecomunciaciones en México y llama la atención sobre la importancia de su enfoque integrativo para la literatura reciente de calidad democrática en América Latina.

\begin{abstract}
The work I present addresses the Telecommunications Reform in Mexico, approved and published in 2014. From locate in the Latin American scenario reforms in two distinct blocks from a reordering of economic integration and regional policy in 2014 , it is proposed a theoretical framework to systematically to the various variables involved in shaping coalitions winning commercial policy aimed at trade liberalization or protectionist approach. The Mexican case can be explained by linking economic policies with state institutions, society and the international system as a dynamic interaction, constant reconfiguration from three analytical variables: i) the international context, ii) the ability to influence (leverage), preferences and strategies of employers, iii) State vulnerabilities, interests and initiatives. This logic-inferential derivation proposes a set of explanatory hypotheses for reform Telecomunciaciones in Mexico, and draws attention to the importance of integrative to the recent literature of democratic quality in Latin America approach.
\end{abstract}

\section{Palabras clave | keywords}

Reforma de Telecomunicaciones, coaliciones distributivas, coaliciones legislativas, contexto internacional, sector empresarial, estado.

Telecommunications reform, distributional coalitions, legislative coalitions, international context, business sector, state.

1 El trabajo constituye un resumen de un proyecto de investigación en curso, presentado por el autor a la Dirección de Investigación de la Universidad Iberoamericana para su evaluación por una comisión externa de dictaminadores, optando por financiamiento institucional. Avances discretos fueron presentados recientemente en un congreso de ALICE. Es importante enfatizar que no presenta resultados concluyentes; su exposición pretende perfeccionar el marco teórico-interpretativo en construcción, así como precisar la lógica inferencial del argumento. En palabras de Verba, Kim \& Keohane (2000), "mejorar teorías y evidencias" es su único fin en estos momentos. 


\section{El contexto latinoamericano}

En julio del año 2012, el ex-partido hegemónico mexicano Revolucionario Institucional (PRI) gana la Presidencia. Lección aprendida, su «joven» candidato enfatiza en su campaña la necesidad de «mover» -reformar- la dinámica político-económica del país, y así garantizar una renovación en la imagen internacional de México. Revertir seis años de violento enfrentamiento al narcotráfico, rasgo típico de la presidencia anterior; romper el inmovilismo legislativo y desplazar antiguas estructuras corporativas que inhiben el desarrollo y el liderazgo internacional del país. En suma, una nueva estrategia de modernización nacional será el centro de su campaña y gestión de gobierno.

Entre el paquete de reformas propuesto se incluye una añeja deuda: reformar las Telecomunicaciones en un escenario histórico de alta concentración mediática y de Tecnologías de Información, con el duopolio Televisa y TV Azteca $-85 \%$ de la audiencia de televisión abierta y por cable- por un lado y por el otro TELMEX, propiedad del magnate Carlos Slim, controlando la telefonía fija, celular y las conexiones internacionales. Ante estos entes corporativos con un sofisticado lobby legislativo y estrechos vínculos con actores políticos, negociar una reforma implica consensuar el interés comercial corporativo con la nueva dinámica emanada del «Pacto por México» y la 'mayoría' legislativa del partido de gobierno (PRI).

Pero surge el quid de la cuestión: ¿El nuevo escenario político garantizará una reforma que modifique los fundamentos de un mercado con actores mediáticos y tecnológicos monopólicos, de competencia limitada y oferta de altos costos? ¿Podrá modificarse el diseño predominante de televisión comercial (duopolio privado)? ¿Aumentará el número de canales de televisión privada y pública? ¿Se fortalecerá el modelo de televisión pública -no estatal- con autonomía del gobierno? ¿Qué sucederá con los medios comunitarios? Por otro lado ¿Serán reformadas las funciones de la Comisión Federal de Telecomunicaciones (COFETEL) -órgano regulador-? ¿Qué grado de participación tendrá la sociedad civil en esta reforma?

A partir de estas interrogantes la presente investigación propone: a) reconstruir los antecedentes; b) analizar el contexto institucional; c) esbozar las estrategias de los actores políticos (A1), mediáticos y tecnológicos (A2) y la sociedad civil (A3). En fin, el recorrido analítico 
anterior nos permitirá interpretar -contextualizando- la propuesta de reforma entregada por el Presidente al Legislativo, su discusión, y, finalmente, los alcances, elementos contradictorios y reacciones públicas a la Ley aprobada, así como su singularidad dentro del contexto reformista latinoamericano. Como corolario también se pretende d) evaluar a la luz de la literatura teórica la calidad de la democracia en los aportes de la reforma de Telecomunicaciones en México.

Es importante ubicar la precitada reforma en el contexto latinoamericano actual, caracterizado por un intenso debate sobre la relación Estado-medios de comunicación-sociedad civil, específicamente en los países donde los gobiernos de orientación neo-populista de izquierda han tomado acciones para enfrentar la intensa doble tensión con los grandes conglomerados mediáticos: a) los grandes actores mediáticos han asumido la función de oposición política al gobierno ${ }^{2}$ y b) la concentrada estructura de propiedad de los actores mediáticos (Mastrini y Becerra, 2009) limita la expresión y circulación de la diversidad de discursos alternativos. En palabras de Santander, "a pesar de los triunfos electorales, los discursos mediáticos hegemónicos siguen siendo los de la oposición” (2014, p. 17). Por su parte Kitzberger reconoce que además de desafiar a la prensa colocándola, en clave populista, en el lugar del «antipueblo» o del «establishment», los gobiernos de la región han apelado a formas de comunicación directa que disputan al periodismo su pretension de mediador exclusivo entre el Estado y la sociedad civil (2009, p. 168).

Intentando sintetizar el escenario reformista Estado-medios y telecomunicaciones en América Latina, podríamos ubicar las refor-

2 Una interesante explicación podría ser que las derrotas electorales de los antiguos partidos tradicionales y el triunfo de los gobiernos progresistas tornaron muy inestable el sistema político tradicional, provocando dinámicas centrífugas, una reconfiguración del mapa, el repliegue de las antiguas organizaciones partidarias y la consolidación de nuevas, es decir, el nacimiento de «un nuevo bloque de poder en Sudamérica». En dicho contexto, el sistema de medios en Sudamérica ha proveído refugio y retaguardia a los actores de la derecha, pues los cambios políticos de la última década, si bien permitieron desplazar a las oligarquías del Poder Ejecutivo, apenas han cambiado las relaciones medios-Estado construidas en las décadas de 1980 y 1990 (Santander, 2014). En esta misma dirección, Sader asume que los principales medios sudamericanos comienzan a ejercer en la última década "la dirección política e ideológica de la derecha latinoamericana", y se convierten en el lugar desde el cual actúan "los intelectuales orgánicos de la oligarquía” (2009, cit. en Santander, 2014, p. 22). 
mas en dos bloques diferenciados a partir de un reordenamiento de la integración económica y política regional: el primer bloque incluyó a los gobiernos progresistas (reformas moderadas) y gobiernos radicales (reformas radicales) que se integraron en organizaciones como el Mercosur, el ALBA y CELAC con una orientación de izquierda alternativa al capitalismo neoliberal del Consenso de Washington. El bloque lo integraron países como Brasil, Argentina, Uruguay (Reformistas Moderados) y Venezuela, Ecuador y Bolivia (Reformistas Radicales). Tanto unos como otros se caracterizaron por una confrontación política de variable intensidad entre el Estado y el sistema de medios, con su respectiva polarización ideológica (Kitzberger, 2010).

El segundo bloque se caracteriza por gobiernos de orientación neo-liberal condicionados por la integración en la Alianza del Pacífico y los Tratados de Libre Comercio con el América del Norte (TLCAN), incluyendo a México, Perú, Colombia y Chile, donde las reformas están orientadas a perfeccionar los marcos regulatorios ${ }^{3}$ y sus objetivos fueron: (i) fomentar mercados abiertos a la competencia para promover una prestación eficaz de los servicios (calidad adecuada, servicios modernos y precios eficientes); (ii) prevenir abusos del poder de mercado (fijación de precios excesivos y conductas anticompetitivas) por las empresas dominantes, donde no existan o fracasen los mercados competitivos; (iii) crear entornos favorables a la inversión para ampliar las redes de telecomunicaciones; (iv) promover la confianza en los mercados mediante procedimientos transparentes de reglamentación y concesión de licencias; (v) impulsar una mayor conectividad mediante acuerdos de interconexión eficaces; (vi) optimizar la utilización de recursos escasos, como el espectro radioeléctrico, la numeración y los derechos de paso. Es importante reconocer que la eficacia del órgano regulatorio y su impacto sobre calidad del servicio dependen del respe-

3 La regulación se aplica generalmente a mercados cuya estructura hace poco probable que la competencia opere eficazmente. En el pasado, en esos mercados, con altos costos fijos y tendencia al monopolio natural, la función del regulador era acercar, en lo posible, el desempeño de la industria a los resultados que ella tendría si opera en condiciones de competencia. En la medida que los avances tecnológicos han permitido la entrada exitosa de más de una empresa en los mercados de telecomunicaciones, la función del regulador ha cambiado. Actualmente, su objetivo es generar un entorno y condiciones que promuevan la competencia efectiva, de manera que, cada vez, sea menos necesario el uso de la regulación (Razo y Rojas Mejía, 2007). 
to a sus dos características centrales: la independencia ${ }^{4}$ y la capacidad técnica. $^{5}$

Finalmente, en un mercado altamente concentrado (Mastrini y Becerra, 2009; Huerta-Wong y Gómez, 2013), con un órgano regulador (COFETEL) poco eficaz (Mariscal y Rivera; 2005), actores mediáticos y tecnológicos con propiedad cruzada, lo que les garantiza amplio dominio del mercado y elevado «expertise» en el lobby político (Telebancada), y a su vez, actores políticos con estrechos vínculos con los corporativos mediáticos, además de una limitada capacidad organizativa y movilizativa de la sociedad civil interesada, constituyen el complejo entorno para la discusión y aprobación de la reforma en Telecomunicaciones en México. Vale la pena preguntar entonces si dicha reforma traerá modificaciones importantes a la dinámica de las telecomunicaciones en el país, aumentará la competitividad del sector, aumentando las opciones informativas y disminuirán los costos de los servicios, y si tendrá más canales y opciones de expresión y deliberación la sociedad civil mexicana.

4 Aunque existen diferentes modelos de organización del regulador, la estructura institucional más aceptada tiene como componente fundamental su independencia. Un regulador independiente está en mejores condiciones de aplicar la normativa de manera objetiva e imparcial. Esa independencia aumenta la probabilidad de que el regulador proteja a la competencia y no a los competidores, lo que tiene efectos positivos para el desarrollo del sector. Adicionalmente, la confianza de los agentes económicos en la imparcialidad de las decisiones reglamentarias aumenta con el grado de independencia de los reguladores. Esta confianza puede estimular la inversión de los operadores incumbentes y de nuevos competidores. Las decisiones del regulador a menudo tienden a generar controversia entre los posibles afectados y, por lo tanto, intentos de ejercer presión sobre el mismo. La independencia ayuda al regulador a actuar con neutralidad y autonomía con respecto a presiones políticas o de los operadores -riesgo de captura- (Razo y Rojas-Mejía, 2007; Mariscal y Rivera, 2005; Rozas-Balbontín, 2002 ).

5 La capacidad técnica es esencial para identificar el tipo e intensidad de la regulación que debe tener un sector, ya que se debe evaluar permanentemente la evolución de los mercados, los avances tecnológicos y las modificaciones en las estructuras y estrategias de los operadores. La determinación del grado de regulación necesaria en el sector es una tarea fundamental del regulador. Una regulación excesiva puede ser contraproducente y frenar el desarrollo. Por el contrario, una liberalización apresurada (desregulación) puede generar prácticas anticompetitivas, sobre todo si hay operadores con posición dominante o poder significativo de mercado. (Razo y Rojas-Mejía, 2007; Mariscal y Rivera, 2005; Rozas-Balbontín, 2002). 


\section{Gráfico 1. Bloques de Gobiernos Reformistas en Telecomunicaciones en América Latina 2014}

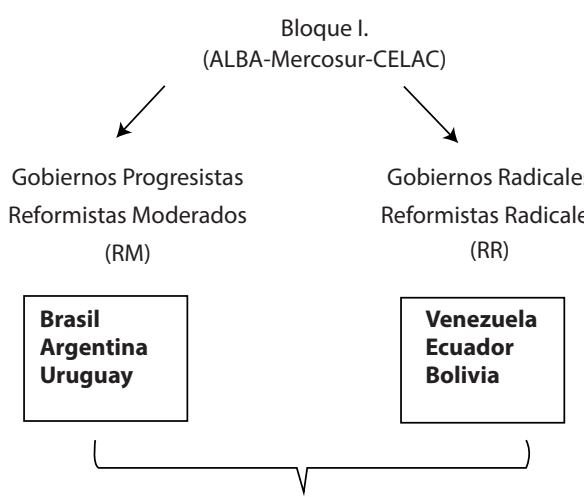

Confrontación Sistema Político-Sistema de Medios
Bloque II.

(TLCAN-Alianza Pacífico)

Gobiernos Neo-Liberales Reformistas Neo-Lib.

(RNL)

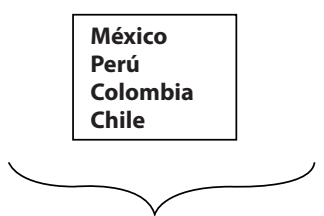

Regulación técnica orientada mercado

Fuente: Elaboración propia.

\section{Marco teórico}

Existe una prolífica literatura sobre las reformas estructurales y su costo político en América Latina (Schneider \& Wolfson, 2005; Haggard \& Kaufman, 1995; Smith, Acuña \& Gamarra (eds), 1994). Por otro lado, la rápida y radical apertura económica desarrollada en México a partir de la segunda mitad de la década de los ochenta y su implementación en los noventa ha sido objeto de interesantes estudios (Palma-Rangel, 2007; Thacker, 2000; Heredia, 2002).

El proyecto actual intenta explicar la reciente reforma de Telecomunicaciones en México desde una perspectiva teórica que nos permita integrar las diversas variables interactuantes y los factores contextuales que inciden en la aprobación de la Ley referenciada ut supra. Al respecto la teoría desarrollada por S. Thacker en Big Business, the State, and free trade. Constructing Coalitions in Mexico (2000), resulta útil y sugerente interpretativamente, además de un excelente antídoto para las explicaciones de corto alcance -frecuentemente ideologizadas- que predominan en la discusión pública mexicana.

El autor en referencia (op. cit), partiendo de interrogantes sobre el por qué la variación en los patrones de liberalización comercial en paí- 
ses en desarrollo, a pesar del similar contexto internacional de los años ochenta, enfatiza que los factores externos pueden proveer ciertas oportunidades y recursos políticos que serán movilizados, bajo ciertas condiciones, para rediseñar la arena política doméstica en la cual tendrán lugar las reformas de políticas públicas. Así, el enfoque integra variables del contexto internacional con un énfasis en las dinámicas específicas de cada país al interior de sus instituciones políticas (Estado, sistema de partidos, vínculos ejecutivo-legislativo, autonomía de los niveles de gobierno, reglas formales e informales para la configuración y rotación de las élites políticas, etc.) y las formas de vincularse con los sectores sociales activos políticamente. Derivado de esta dinámica en cada caso surgirán las «coaliciones de política comercial» (trade policy coalitions), es decir, las competidas alianzas que vinculan a los líderes del sector público y privado con similares intereses para promover $\mathrm{u}$ oponerse a ciertas políticas comerciales (Thacker, 2000, pp. 20-ss). ${ }^{6}$

Bajo la premisa de que las coaliciones políticas «vencedoras» definen cuál política será implementada y exitosamente sostenida, vinculando las políticas económicas con las instituciones del Estado, la sociedad y el sistema internacional en una interacción dinámica y de constante reconfiguración, el autor propone un marco analítico donde la variable interviniente -tanto causa como efecto- serán las «coaliciones» (ver Gráfico 2). Así, sus tres variables analíticas propuestas son: i) el contexto internacional, ii) la capacidad de influencia (leverage), las

6 Thacker evalúa el enfoque predominante en los estudios de la apertura económica mexicana centrados en la distancia institucional de potenciales oponentes al libre comercio (sindicatos), otrora aliados corporativos del presidencialismo priista, de la decisión de la apertura comercial, lo que disminuye los costos de la apertura y su viabilidad, así como las características propias del presidencialismo corporativo del PRI. Sin embargo, considera que no son variables que expliquen exhaustivamente la reforma de apertura mexicana, por lo que focaliza su atención en el proceso de incorporación de empresarios potencialmente ganadores en un contexto de libre comercio (internacional) al interior del aparato de diseño e implementación de políticas públicas (2000, pp. 17-20). Estudios posteriores reconocen como su «gran mérito» el análisis empírico de las preferencias de los empresarios e identificar la gama de factores que gravitan en la actitud a adoptar frente a las reformas de mercado. Un conjunto de esos factores gira en torno de los elementos contextuales que influyen en los cálculos de intereses; otro conjunto considera las características de las grandes empresas o de las plantas individuales que afectan las decisiones empresariales (Schneider \& Wolfson; 2005, p. 353). 
preferencias y las estrategias de los empresarios y, iii) las vulnerabilidades del Estado, intereses, y las iniciativas.

\subsection{Contexto Internacional}

Actores internacionales como el Banco Mundial, el FMI y gobiernos que aporten créditos internacionales imponen fuertes «constreñimientos» sobre las opciones políticas, desde el uso condicional de sus practicas de créditos, la aplicación de sus expertises técnicos y la imposición de sanciones económicas. Tales presiones pueden alterar los cálculos de los beneficios relativos de diferentes políticas. Otro factor contextual importante son las crisis económicas que suelen preceder a las reformas y su impacto sobre las percepciones y expectativas de los agentes económicos (Schneider \& Wolfson, 2005)7. El relativo peso de los constreñimientos internacionales y las oportunidades dependen de la ubicación de un país en el sistema internacional y la habilidad de sus actores políticos para capturar y canalizar las fuerzas internacionales. Otro factor importante serán las oportunidades internacionales presentadas. La crisis de 1982 convierte a México en uno de los dos grandes países en vías de desarrollo más endeudados; sin embargo, su cercanía geográfica y vínculos políticos con los EEUU le permite el acceso a un programa de reestructuración o reducción de deuda y amplios créditos de organismos crediticios internacionales (FMI, Banco Mundial y el propio gobierno de los EEUU). Por su parte, la geografía mexicana y su larga frontera con los Estados Unidos le permitió el acceso a grandes mercados externos (como el del propio país del norte), constituyendo un incentivo para plataformas de desarrollo basadas en la exportación, radicalmente diferente al modelo de desarrollo a partir de la sustitución de importaciones de la década de los setenta.

7 Los autores reconocen que la crisis económica hace que los empresarios estén más abiertos a la innovación en materia de políticas públicas, porque perciben que el status quo es insostenible. Para otros autores citados, la crisis reduce las rentas públicas obtenidas bajo el antiguo régimen, así como los incentivos para defender el status quo, y en general debilita a los grupos de interés. Otros sostienen que las malas épocas económicas hacen que tanto los votantes como los políticos estén más dispuestos a correr riesgos y, por tanto, a aceptar reformas radicales que prometen ser muy redituables, a pesar de que también puedan provocar grandes pérdidas (Kingstone y Weyland, citados en Schneider \& Wolfson, 2005, p. 353). 


\subsection{Sector Empresarial}

a. La capacidad de influencia estructural (leverage), entendida como la habilidad de un actor para ejercer presión sobre otro, deriva del control del sector privado sobre los recursos de inversión. Por tanto, los diseñadores de políticas públicas deben prestar gran atención a los intereses de quienes controlan los recursos de capital móvil cuando los niveles de movilidad de capital internacional encaran al país. Estos inversores pueden convertirse en atractivos socios de coalición ${ }^{8}$.

b. Los intereses/preferencias se refieren al relativo atractivo de diferentes segmentos del sector privado como socios de coalición y los intereses de política comercial arraigados en diferentes grupos del sector privado. Para Thacker (2000) generalmente, los titulares de los mayores recursos móviles son capaces de ajustarse mejor a la liberalización del comercio. El tamaño de la empresa generalmente hace la liberalización más fácil pues el costo del ajuste frecuentemente es menor sobre las grandes firmas que sobre las pequeñas. Las diferencias entre el tipo de recurso de capital también afecta los intereses respecto a la política comercial, pues los titulares de recursos líquidos estarán mejor situados para responder a las señales del nuevo mercado que resulte de la apertura comercial, así como reasignar sus recursos de capital del sector perdedor al ganador en las nuevas condiciones. Por tanto, los empresarios titulares de grandes capitales móviles pueden disfrutar de ventajas competitivas bajo el libre comercio y serán más favorables a convertirse en miembros de coaliciones favorables a la apertura comercial. Inversamente, las empresas pequeñas de capital fijo serán menos capaces de ajustarse a las nuevas señales del mercado, siendo más favorables a simpatizar con coaliciones proteccionistas.

c. La intensidad de las preferencias hacia la política comercial (sector, tamaño, movilidad de recursos) determina los incentivos a participar en coaliciones de política comercial. La dirección de estos intereses (hacia el proteccionismo o libre comercio) define en cuál

8 Según el autor, los Estados frecuentemente desarrollan concesiones políticas específicas orientadas a aumentar el ajuste de expectativas sobre riesgo de retorno del capital sobre otros países y atraer internacionalmente recursos móviles de inversión (Thacker, 2000, p. 29). 
coalición de política comercial procurará participar. Schneider \& Wolfson enfatizan que si se suma el fluido y el cambiante contexto, así como las múltiples facetas de la organización empresarial, se vuelve más complicado discernir cuáles podrían ser las preferencias de los empresarios respecto a las reformas de mercado (2005, p. 355).

Resumiendo lo anterior, cuando el empresario posee alta puntuación en la capacidad de influencia estructural (structural leverage) e interés hacia el libre comercio, será más favorable incluirse en una coalición orientada al libre comercio. Por el contrario, si posee una significativa capacidad de influencia estructural pero su interés se orienta al proteccionismo, estará más orientado a incorporarse en una coalición proteccionista.

\section{Gráfico 2. Coaliciones Políticas y Libre Comercio}

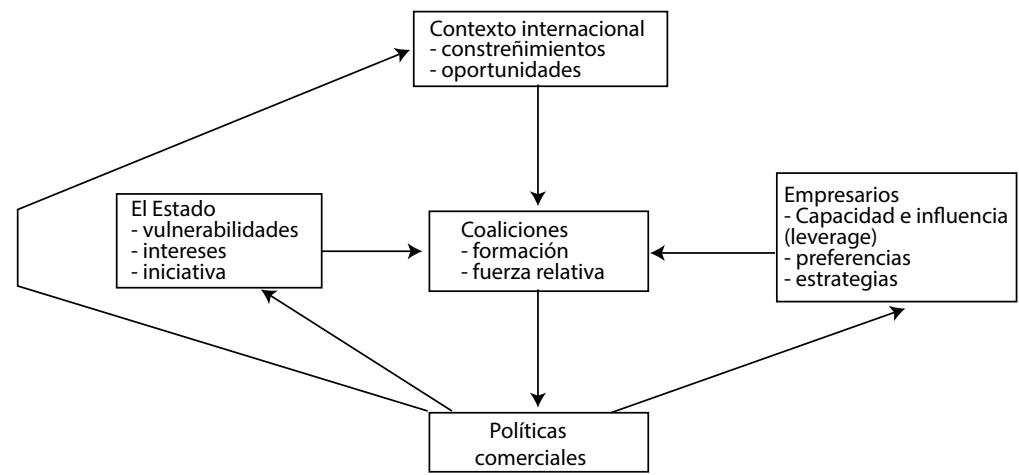

Fuente: Thacker (2000, p. 34).

Actores con poca capacidad de influencia estructural pero claro interés hacia la política comercial podrían ser miembros de la respectiva coalición, pero no serán particularmente influyentes. Las combinaciones presentadas ayudan a explicar tanto las cambiantes identidades como la relativa fuerza de las coaliciones competitivas sobre las políticas de comercio desde la perspectiva de los empresarios (Thacker, 2000, pp. 34-ss).

d. Las estrategias. La participación de diferentes facciones del sector privado en las coaliciones de política comercial depende de una serie de factores. Grandes segmentos del sector privado cuya capacidad de influencia estructural tiende a ser mayor, frecuentemente presen- 
tan menores problemas de acción colectiva al participar directamente en coaliciones de políticas comercial. En contraste, las pequeñas firmas cuya capacidad de influencia estructural tiende a ser menor -capital fijo- normalmente son más dispersas y menos propensa a participar en coaliciones.

Variables organizacionales e institucionales también influyen, pues las pequeñas firmas generalmente presentan mayores problemas de logística o altos costos de transacción en participar directamente; mientras que las grandes firmas frecuentemente tienen recursos y tiempo necesario para las relaciones con el gobierno y participar en las coaliciones. Las pequeñas firmas tienden a tener una representación indirecta en los canales institucionales -cámaras de comercio y asociaciones-, por lo que sectores y firmas con más efectiva representación institucional pueden contrarestar esos efectos, sin llegar a lograr la participación activa de las grandes firmas.

\subsection{El Estado (policy makers) y su vulnerabilidad}

Se refiere a las presiones sociales que enfrenta el Estado para mentener su autoridad. La vulnerabilidad estructural está vinculada con la dependencia del Estado de la inversion del sector privado para lograr crecimiento económico y el empleo (capacidad de influencia estructural de los empresarios). Además, el Estado puede ser vulnerable a la presión electoral y la dinámica de la competencia partidista. Una completa explicación de las vulnerabilidades del Estado combina variables estructurales y no estructurales que condicionan los procesos políticos en los cuales las coaliciones son construidas. En el caso de México, la vulnerabilidad estructural del Estado mexicano es una importante razón para la incorporación formal de los empresarios en los procesos de estabilización y reforma a fines de los años ochente y principios de los noventa. La vulnerabilidad del Estado a las presiones estructurales dependerá entonces de qué tanto este pueda enfrentar sin el apoyo de los empresarios -o con des-inversión- los retos económicos. Cuando el Estado tiene acceso a recursos alternativos de capital y los puede usar para fomentar el empleo y el crecimiento económico, puede prestar menos atención a los intereses del capital privado. Por ejemplo, el boom petrolero y el crecimiento de la economía mexicana en los setenta hizo menos vulnerable al Estado 
a los capitales privados; el colapso de los precios del petróleo a mediados de los ochenta tuvo el efecto opuesto.

Los retos electorales a la autoridad política pueden inspirar un desplazamiento en la coalición de políticas económicas y generar incentivos para que quienes diseñan e implementan las políticas públicas las cambien en función de reflejar la fuerza y la identidad de las nuevas bases de apoyo. En México, las crecientes presiones electorales resultado de las victorias electorales del PAN en los ochenta y la creación del Frente Democrático Nacional (FDN) de izquierda y su resultado electoral en 1988, obligó al gobierno del PRI a formar una alianza no oficial con el liderazgo del PAN, reconociendo sus victorias electorales a cambio de apoyo para la implementación de su agenda reformista de apertura económica.

Las características de las instituciones del Estado y sus intereses, así como sus líderes (policy makers) orientan la participación del Estado en las coaliciones de política comercial. Factores como el balance de poder entre las agencias del Estado, la identidad e intereses de los principales implementadores de políticas públicas, el grado de independencia del Ejecutivo respecto al poder Legislativo y Judicial, así como la efectividad del control organizacional del Estado sobre los grupos sociales. Otro elemento importante es el control corporativo de los grupos sociales, lo cual puede facilitar a quienes implementan las políticas públicas aislar a politicos partidarios de políticas públicas 'perdedoras' y organizar e incluir a los apoyos de políticas 'ganadoras'. En México el fuerte presidencialismo y la dominancia del Ejecutivo sobre otros poderes permitió al Estado aislar a los potenciales opositores de las políticas de apertura económica en otros sectores del gobierno. Además, el control del PRI del movimiento sindical y la participación de la Cámara de Comercio Mexicana en la firma de los acuerdos sumó a la coalición de apertura económica en los noventa.

En este sentido, se considera útil para el análisis de la reforma de Telecomunicaciones en México la tipología de coaliciones en la política de reforma económica propuesta por Schneider \& Wolfson (2005, pp. 360-ss):

Según los precitados autores (op. cit), la literatura sobre las reformas económicas se ha centrado en las coaliciones distributivas y de políticas públicas, prestando poca atención a las «legislativas» y «electorales». Una «coalición legislativa» (o legislativa-ejecutiva) consiste en 
dos o más partidos representados en la legislatura que votan en forma consistente en favor del presidente y el poder ejecutivo. Características del sistema de partidos como la polarización y la fragmentación constituyen obstáculos para la reforma, de ahí las ventajas de contar con gobiernos mayoritarios. Sin embargo, estudios recientes apuntan a que un número mayor de partidos efectivos puede favorecer, en la práctica, a la creación de coaliciones y así permitir una mayor gestión pública?.

Tabla 1. Tipos de coaliciones en la política de reforma económica

\begin{tabular}{|c|c|c|c|c|}
\hline & Electorales & Legislativas & Distributivas & $\begin{array}{l}\text { En defensa } \\
\text { de las políticas } \\
\text { públicas }\end{array}$ \\
\hline $\begin{array}{l}\text { Tipos } \\
\text { de miembros }\end{array}$ & $\begin{array}{l}\text { Grupos de } \\
\text { votantes }\end{array}$ & Partidos políticos & $\begin{array}{l}\text { Empresas } \\
\text { y grupos de inte- } \\
\text { reses organizados }\end{array}$ & $\begin{array}{l}\text { Individuos de los } \\
\text { sectores públicos } \\
\text { y privados }\end{array}$ \\
\hline $\begin{array}{l}\text { Actividades } \\
\text { primarias }\end{array}$ & $\begin{array}{l}\text { Campañas } \\
\text { políticas }\end{array}$ & $\begin{array}{l}\text { Legislar e implemen- } \\
\text { tar políticas públicas }\end{array}$ & Lobbying & $\begin{array}{l}\text { Creación } \\
\text { de redes y análisis } \\
\text { de propuestas }\end{array}$ \\
\hline $\begin{array}{l}\text { Base del } \\
\text { intercambio }\end{array}$ & Votos & $\begin{array}{l}\text { Votos en la legis- } \\
\text { latura }\end{array}$ & $\begin{array}{l}\text { Recursos } \\
\text { económicos }\end{array}$ & $\begin{array}{l}\text { Vínculos personales } \\
\text { e ideología }\end{array}$ \\
\hline $\begin{array}{l}\text { Interacción entre } \\
\text { los miembros }\end{array}$ & Escasa & $\begin{array}{l}\text { Intensa, formal y } \\
\text { permanente }\end{array}$ & $\begin{array}{l}\text { Variable, } \\
\text { a menudo informal }\end{array}$ & $\begin{array}{l}\text { Intensa, informal } \\
\text { y permanente }\end{array}$ \\
\hline
\end{tabular}

Fuente: (Schneider \& Wolson; 2005).

Las «coaliciones a favor de políticas públicas» consisten en conjuntos más o menos fluidos de individuos que participan de la gestión del gobierno en áreas específicas, siendo una cantidad pequeña que se decide individualmente y varía según las políticas, períodos y países. Casi todas las variantes de estas coaliciones comienzan con funcionarios ubicados en altos cargos económicos (ministro de Hacienda, presidente del Banco Central) y por lo general incluyen a varios representantes de grupos sociales organizados, empresarios, consultores y académicos

9 Cuando compite un cierto número (de cuatro a ocho, digamos) de partidos relativamente estables y ninguno de ellos puede albergar con realismo la ambición de ser mayoría, el único camino hacia los cargos del poder ejecutivo son las coaliciones (Brasil y Chile década de los noventa). En otros casos, (la evolución hacia un sistema con tres partidos efectivos -México- u otro de más partidos pero en el que uno de ellos es dominante (Argentina), ciertos dirigentes políticos pueden tener la esperanza de alcanzar la mayoría en las próximas elecciones, y con esa expectativa pueden optar por permanecer fuera de las coaliciones y en consecuencia dejar que los gobiernos minoritarios simplemente se mantengan a flote (Schneider \& Wolfson; 2005, pp. 364-ss). 
independientes, así como representantes de las instituciones financieras internacionales.

Las «coaliciones electorales» se presentan bajo dos variantes: construidas y espontáneas. En el primer tipo, los partidos y coaliciones legislativas tratan a veces de conformar coaliciones electorales apoyando conjuntamente a determinados candidatos e instando a sus votantes tradicionales a que los apoyen. En el segundo tipo, coaliciones informales de votantes confluyen más espontáneamente en el curso de una campaña electoral a medida que los grupos se van aproximando a ciertos partidos o candidatos. En comparación con otras coaliciones, las electorales son heterogéneas, se movilizan durante un periodo breve y en ellas el contacto entre los grupos que las componen es escaso, y sus principales protagonistas son los «empresarios de políticas»: candidatos, dirigentes partidarios, contribuyentes a la campaña y empresas ligadas a los medios de comunicación.

$\mathrm{Al}$ respecto, resulta sugerente revisar el enfoque propuesto por Sosa Hernández a partir del enfoque de la «teoría distribucional del cambio gradual» que reconoce el cambio constante de las instuticiones a partir de una combinación de tres elementos: la ambigüedad de las reglas, el papel de la agencia y el poder (2016, pp. 94). La agencia o actor estarán orientados a la distribución y el poder como efecto de la institución, y si el cambio lo impulsa el poder, se permite que se produzca ambigüedad en la regla (su interpretación y ejecución). Los actores serán «agentes del cambio» con preferencias definidas y estrategias preferidas consistentes en contextos institucionales específicos, por lo que los tipos de agentes frente al cambio pueden tener posiciones variables para promoverlo o resistirlo: a) «los rebeldes», que buscan eliminar las reglas y no las respetan; b) «los simbiontes» (o simbióticos), que cuando ocurre el cambio su modelo a seguir es inercial, siguen las reglas en tanto obtienen beneficios; c) «los subversivos», que siguen las reglas en tanto encuentran el momento oportuno para cambiarlas y; d) «los oportunistas», que siguen las reglas sin tener en claro si desean cambiarlas.

\section{La Reforma de Telecomunicaciones en México}

La Reforma de Telecomunicaciones es parte de un paquete priorizado de cinco reformas fundamentales impulsadas por la Presidencia de la República como ejes del crecimiento económico y la gobernabilidad 
democrática en el marco de un acuerdo de cooperación legislativa entre los diversos partidos políticos. En un contexto de alta concentración de propiedad mediática, con una historia de estrechos vínculos entre el Estado y los actores mediáticos y tecnológicos, y los negativos antecedentes de reformas previas en el sector, la iniciativa presidencial de reforma necesitaba condiciones organizativas e institucionales propicias para su aprobación. López Leyva (2015, p. 81) señala la conjunción de ciertos factores facilitadores para la concreción de las reformas en el primer tercio del gobierno de Enrique Peña Nieto:

a. Un contexto previo favorable en términos de distensión y entendimiento, en el que a la agenda reformista del Presidente se le agregaron demandas generadas en campaña por grupos sociales (p. e. el Movimiento «yosoy132»).

b. La generación de un espacio de negociación alterno al Congreso de la Unión que permitió darle salida eficaz a la agenda del Ejecutivo en consonancia con las agendas específicas de los partidos politicos participantes, con un cuidadoso timing.

c. Un cambio en las estrategias de relación política de los dos partidos de oposición, en las que tuvo relevancia la pérdida de peso de sus dos figuras más fuertes (Felipe Calderón y Andrés Manuel López Obrador, respectivamente).

En efecto, el contexto político caracterizado por la ausencia de fuertes cuestionamientos a la elección previa y a la legitimidad del Presidente electo favoreció la negociación paralela como estrategia conciliadora de las agendas de los principales actores políticos (el Ejecutivo y los principales partidos de oposición). Así en su versión oficial el «Pacto por México» se convierte en "el acuerdo político más relevante que se ha realizado en décadas en México". Su alcance fue comparado, incluso, con los célebres Pactos de la Moncloa, pues "es un acuerdo para realizar grandes acciones y reformas específicas que proyecten a México hacia un futuro más próspero"10. Los actores firmantes estaban:

(...) conscientes que es indispensable un Pacto Nacional, formado con los puntos coincidentes de las diversas visiones políticas de un México, que comprometa al gobierno y a las principales fuerzas políticas dis-

10 Extraído de www.pactopormexico.org 
puestas a impulsar un conjunto de iniciativas y reformas, para realizar acciones efectivas para que nuestro país mejore (ibid).

Como acertadamente reconoce López-Leyva (2015, p. 77), su más grande virtud fue ser un canal eficaz de negociación, se convertió en su antípoda objeto de muchas críticas: pareciera anular la diferencia al privilegiar la unanimidad en la deliberación legislativa.

La estrategia de alianzas que constituyó el «Pacto por México» permitió aprobar en apenas dos años un paquete de reformas estructurales importantes. La iniciativa de reforma en material de telecomunicaciones presentada por el Presidente, luego de un breve periodo de discusión en el Congreso, fue aprobada en ambas Cámaras con amplios respaldo de los legisladores: en la Cámara de Diputados tuvo el voto a favor del $92 \%$ de los legisladores, mientras que en la de Senadores obtuvo el 96\% (LópezLeyva, 2015; Sosa-Hernández, 2016; Sánchez-García, 2014).

Respecto a los actores mediáticos ${ }^{11}$, Sosa-Hernández (2016) detalla como su "reducido activismo" para defender sus posiciones revela algún cálculo acerca de los costos y beneficios esperados de la reforma sin representar un tema de conflicto con el Congreso ${ }^{12}$, actuando como agentes oportunistas que no combatieron la reforma, "la dejaron correr", y se adaptan a su impacto, sin que ello implique su pleno acuerdo ${ }^{13}$. Dicho cambio de estrate-

11 Sosa-Hernández los conceptualiza como grupos de poder mediático (GPM): 1. Grupo selecto de dueños de los medios que tienen el dominio de una concesión de un bien público, en específico, de las bandas de frecuencia que conforman el espectro radioeléctrico. 2. Siendo este el centro de sus actividades empresariales, tiende a la concentración del mercado (monopolio) o bien, a compartir cerradamente un espacio del mismo (duopolio). 3. Hace uso de mecanismos de acción tanto proactivos como reactivos; estos últimos cuando la coyuntura lo amerita y require defender intereses que en el corto plazo infieren que serán atacados. 4. Se desarrollan mejor en la opacidad, porque bajo el manto de la invisibilidad pueden ejercer sin cortapizas su capacidad de influencia y presión con resultados más efectivos (2016, p. 96).

12 Para Sosa-Hernández la actitud de los grupos de poder mediatico (GPM) fue de cautelosa combinación de estrategias de discusion pública con el uso de mecanismos de interlocución de carácter institucionalizado como el cabildeo y la participación en las consultas abiertas. El activismo más claro provino del Consejo Coordinador Empresarial bajo consideraciones que tenian que ver con la (in) certidumbre jurídica y el derecho a la propiedad (2016, p. 113).

13 Respecto a los grupos de poder mediático, la autora los define finalmente como agentes ambiguos hacia el cambio, pues es la valoración de las condiciones la que les permite inclinarse por una u otra opción (2016, p. 115). 
gia se explica por el perfil del presidente entrante, y más enfáticamente, con la propia estrategia presidencial diseñada para procesar las transformaciones que emprendería: la reforma fue propuesta y articulada en alianza entre el Ejecutivo y los partidos de oposición (2016, p. 114).

Los espacios deliberativos donde la sociedad civil interesada pudiera contrarrestar la iniciativa de los actores políticos y mediáticos fueron limitados. La Cámara de Representantes dio prioridad en su consulta a los empresarios mediáticos. Sin embargo, los Senadores del PRD recibieron en 10 días a representantes de diversos sectores políticos, especialistas y académicos, específicamente de la Universidad Nacional Autónoma de México (UNAM). Posteriormente, las cuatro comisiones involucradas en la dictaminación de la iniciativa acordaron recibir a expertos, funcionarios y concesionarios en foros públicos. Entre los participantes estarían el presidente de la CIRT, el presidente del CCE, el director de TV UNAM, los consejeros de la COFETEL, la totalidad de comisionados de la COFECO, investigadores, académicos, e incluso, integrantes del Movimiento \#YoSoy132.

Uno de los grupos más activos de la sociedad civil fue la Asociación Mexicana del Derecho a la Información (AMEDI), la cual había entregado -según su propia versión- una propuesta regulatoria en octubre del 2013 a legisladores de diversos partidos, consiguiendo que 18 senadores la suscribieran ${ }^{14}$. En un foro organizado en el Senado en los primeros días de abril de 2014, la asociación reconoce haber expresado -en voz de su presidente Agustín Ramírez Ramírez- sus argumentos en contra de los aspectos negativos de la iniciativa presidencial, pues ésta "pervertía la finalidad de la reforma constitucional, pues estaba muy alejada del propósito que le dio origen," es decir, satisfacer los derechos fundamentales de libertad de expresión, derecho a la información y derecho de acceso a las Tecnologías de la Información y la Comunicación, así como las condiciones para una efectiva competencia en los servicios de radiodifusión y telecomunicaciones ${ }^{15}$.

14 Cfr. "Reforma a telecomunicaciones y radiodifusión en México: la perspectiva de la Asociación Mexicana del Derecho a la Información”, TLA, Revista de Ciencias Sociales, Facultad de Derecho y Ciencias Sociales, BUAP: Nueva Época, Año 9, No. 39, octubre 2015-marzo 2016, pp. 188-212.

15 La AMEDI consideraba que era una regulación asimétrica en el trato que otorgaba a los mercados regulados; mientras que por una parte es por fortuna muy puntual en las medidas que pueden imponerse a la telefonía, es muy limitada en el tratamiento 
Para AMEDI, la iniciativa pretendía un regulador débil, supeditado a los intereses del ejecutivo federal, al permitir a la Secretaria de Gobernación conservar la vigilancia de los servicios de radio y televisión e instancias del gobierno federal como la Secretaria de Comunicaciones y Transportes y la Comisión Federal de Mejora Regulatoria de la Secretaria de Economía interfirieran en los proyectos regulatorios del Instituto Federal de Telecomunicaciones. Por otro lado, la iniciativa desfiguraba el principio de neutralidad de la red, condición básica para garantizar el acceso universal a las Tecnologías de la Información y la Comunicación, e ignoraba los derechos de las audiencias, la importancia de los medios públicos y de uso social, "omisión grosera" que limitaba la expresión de las diversidades ideológicas, étnicas y culturales. Incluso, excluía a las Instituciones de Educación Superior de los medios de uso público "asfixiándolos con requisitos discrecionales", además de prohibiciones para contar con fuentes de financiamiento.

Sin embargo, el intento más visible de contrarreforma desde la sociedad civil parece haber sido el "Frente por la Comunicación Democrática”, conformado el 11 de abril de 2014 por políticos de varios partidos, académicos, expertos, artistas e intelectuales con una postura crítica ante la iniciativa presidencial, la cual se reflejó en un documento público estampado con sus firmas ${ }^{16}$, e incluso la amenaza de recurrir a la Surprema Corte de Justicia de la Nación para resolver la inconstitucionalidad de la iniciativa presidencial. Sin embargo, el intento de contrarreforma cívica no pudo detener el desenlace: la aprobación por amplia mayoría legislativa de la iniciativa presidencial "sin mayores cambios."

que en apariencia se impone a la televisión." "Reforma a las telecomunicaciones y radiodifusión en México:....” Ibidem, p. 208.

16 El "Frente por la Comunicación Democrática" suscrito por personajes públicos como Cuauhtémoc Cárdenas, Javier Corral Jurado, Sergio Aguayo, Elisa Alanís, Alma Rosa Alva de la Selva, Virgilio Caballero, Manuel Camacho Solís, Purificación Carpinteyro, Tatiana Clouthier, Gael García Bernal, Daniel Gimenez Cacho, etc. El crítico documento público firmado por los integrantes del FCD se puede consultar en http://www.amedi.org.mx/prensa/comunicados/867-lacontrarreforma-en-comunicaciones-de-pena-nieto 


\section{Un modelo hipotético-deductivo para explicar la Reforma}

La Ley Federal de Telecomunicaciones y Radiodifusión, publicada en el Diario Oficial de la Federación el día 14 de Julio del 2014, permite un ejercicio argumentativo interesante al integrar variables del contexto político con factores institucionales, de organización social y de liderazgo.

V1. El «Pacto por México» como estrategia de negociación política previa produjo incentivos para la construcción de una amplia coalición legislativa de apoyo a la iniciativa presidencial.

V2. El vínculo entre el Presidente y los principales actores políticos (A1) con monopólicos actores mediáticos y tecnológicos (Televisa/ TELMEX) (A2) favorece la conjunción de intereses, expectativas y estrategias orientadas a la apertura comercial y el libre comercio.

V3. La relevancia en el escenario internacional de los flujos de capital móvil de estas empresas (Televisa, TV Azteca y TELMEX), que constituyen conglomerados con recursos, capitales, tecnología e influencias internacionales. Han sido empresarios exitosos en el escenario internacional, incluso con acciones y propiedades importantes en los Estados Unidos, Europa y América Latina.

V4. Alta capacidad de influencia estructural de estos actores mediáticos y tecnológicos sobre la economía nacional, lo cual ejerce una presión sobre las expectativas de crecimiento y estabilidad económica del gobierno.

V3 + V4. Convierte a los empresarios de medios (Televisa, TV Azteca y TELMEX) en atractivos socios de «Coaliciones de Política Comercial» orientada al mercado y el libre comercio (ganadores).

V5. La respuesta fragmentada y focalizada en un sector específico de la sociedad civil a las reformas en el sector y sus nulos antecedentes organizativos.

V6. Elelevadoexpertise técnicodela materiade Telecomunicaciones eleva el costo congnitivo de sus temas, y limita su potencial deliberativo para amplios sectores sociales.

V5 + V6. Limitada, fragmentada y escasa influencia de la contrareforma propuesta por sectores de la sociedad civil mexicana a la iniciativa de la Ley.

Derivado de lo anterior se puede inferir que:

V1 + V2 (A1): El «Pacto por México» generó un escenario de negociación cooperativa y permitió integrar coaliciones legislativas 
«ganadoras», mayoritarias en apoyo a la iniciativa del Ejecutivo, incluyendo los actores políticos de oposición.

$\mathrm{V} 3$ + V4 (A2): El contexto internacional favorable al flujo de capital y la inversión en el sector de las telecomunicaciones marcados por la convergencia digital tecnológica y la integración de México en tratados internacionales de orientación neoliberal (Tratado de Libre Comercio con América del Norte, Alianza del Pacífico), más la alta capacidad de influencia estructural de los actores mediáticos/tecnológicos (A2), facilitó la identificación de los intereses y expectativas de este sector empresarial con los policy makers (diseñadores de políticas comerciales), convirtiéndolos en atractivos 'socios' de «coaliciones de políticas comerciales» orientadas al mercado y el libre comercio.

V5 + V6 (A3): La limitada influencia de la sociedad civil en la negociación y aprobación de la Ley de Telecomunicaciones en México.

Como se puede apreciar, se puede abordar de forma integral y sistemática las diversas variables contextuales, organizativas, institucionales y de liderazgo que permiten explicar cómo la iniciativa presidencial de reformar las telecomunicaciones logra ser aprobada, quiénes fueron sus principales apoyos u oponentes, qué factor o dinámica institucional generó los incentivos para la cooperación y la construcción de la mayoría legislativa necesaria para su aprobación, cuáles papeles jugaron los actores mediáticos/tecnológicos en el proceso de discusión y negociación, y cuáles fueron las principales reacciones críticas de la sociedad civil.

\section{Consideraciones Finales}

El trabajo intenta llamar la atención sobre la especificidad del proceso de negociación política que permitió la aprobación de la Ley de Telecomunicaciones y Radiodifusión en México en el 2014. Su especificidad revela la complejidad de dicho proceso, al centrarse en aspectos diversos que vinculan el contexto político, la dinámica institucional, el potencial organizativo de la sociedad y la interacción de intereses, expectativas y estrategias de los diversos actores implicados.

Toda iniciativa política convertida en propuesta legislativa produce un escenario de negociación entre los diversos actores políticos, desplegando sus recursos e influencias. Sin embargo, el resultado político generalmente activa diversas dinámicas condicionadas en primera instancia por las reglas e instituciones, pero tambien por la capacidad de 
influir en el resultado que presentan otros actores implicados. En el caso abordado, la capacidad de influencia estructural del sector empresarial en la dinámica económica lo convierte en un potencial actor político. La convergencia de intereses y expectativas al interior de las élites, condicionadas por las situaciones internacionales y la correlación de fuerzas en la dinámica competitiva de los actores políticos, ejercen una influencia determinante en el diseño de políticas públicas. La capacidad de presión, determinada por la historia organizativa y el activismo político de ciertos sectores de la sociedad civil, aporta poder explicativo; es decir, la capacidad de ciertos sectores sociales para construir deliberativamente una demanda y convertirla en un tema de deliberación y negociación política.

Además de lo anterior, la presente investigación pretende llamar la atención sobre la relación entre el derecho a la información y la calidad de la democracia en construcción. Como reconocen Levine y Molina, si la igualdad política formal (cada persona un voto) es un requisito mínimo de la democracia, la igualdad política sustantiva, uno de cuyos componentes principales es la distribución de recursos cognitivos entre la población, es un indicador de la calidad de la democracia dada su vinculación directa con uno de sus elementos cruciales: la medida en que el electorado puede tomar decisiones políticas informadas (2007, p. 24). Formas diversas de elaboración y expresión de contenidos pueden impactar en la capacidad informativa de las audiencias/electores, y al diferenciarse las agendas, el efecto «agenda setting» de los medios con mayor infraestructura tecnológica -o contextos monopólicos-, pero enfáticamente comerciales o con vínculos estratégicos coyunturales con los politicos, será menor sobre el ciudadano/elector.

Finalmente, las democracias actuales implican multiplicidad de procesos interactivos, selectivos, informativos, electivos, deliberativos; donde cada vez la participación cívica debe tener un costo menor, e inversamente, un mayor impacto sobre el control del ejercicio del poder; es decir, una mayor incidencia en las decisiones de las políticas públicas, la rendición de cuenta de las élites, el estado de derecho, los consensos que fundamenten la legitimidad de ciertas leyes, las nuevas formas de participación ciudadana, etc. Así, la conexión del estudio con la literatura de calidad democrática en América Latina resulta explícita y aportativa. 


\section{Referencias}

Acuña, C. H., Smith, W., \& Wolfson, L. (1996). La economía política del ajuste estructural: la lógica de apoyo y oposición a las reformas neoliberals. Desarrollo Económico, 36(141), 355-389. doi: https://doi.org/10.2307/3467397

Barreda, M. (2011). La calidad de la democracia. Un análisis comparado de América Latina. Política y Gobierno, 18(2), 265-295.

Culebro M.J., González, C. (2013). Regulación y evolución de organismos reguladores en telecomunicaciones: el caso de México y Francia. Gestión y Políticas Públicas, $12(1), 45-83$.

Ellner, S. (2012). The Distinguishing Features of Latin America's New Left in Power. Latin American Perspective, 39(1), 96-114. doi: https://doi.org/10. 1177/0094582X11425333

Haggard, S. \& Kauffman, R. (1995). The political economy of democratic transitions, Princeton University Press.

Hallin, D. (2000). Media, political power and democratization in Mexico. En J. Curran \& Myung-Jin Park (Eds.), De-Westernizing Media Studies. London: Routledge.

Heredia, B. (2002). Estructura política y reforma económica: el caso de México. En Lecturas sobre el cambio político en México. México: CIDE-FCE.

Holzner, C. (2007). Voz y Voto: participación política y calidad de la democracia en México. América Latina Hoy, 45, 69-87.

Huerta-Wong, J. E., \& Gómez, R. (2013). Concentración y diversidad de los medios de comunicación y las telecomunicaciones en México. Comunicación y Sociedad, $19,113-152$.

Katz, C. (2012). The Singularities of Latin America. Socialist Register, 48. UK: TheMerlinPress.

Kitzberbger, P. (2009). Las relaciones gobierno-prensa y el giro político en América Latina. POSTData, 14, 157-181.

Kitzberger, P. (2010). The Media Activism of Latin America's Leftist Goverments: Does Ideology Matter? GIGA Research Unit: Institute of Latin America Studies, 151.

Levine, D. H., \& Molina, J. E. (2007). La calidad de la democracia en América Latina. Revista América Latina Hoy, 45, 69-87.

López-Leyva, M.A. (2015). El episodio reformista en México (2012-2014): explorando las razones del cambio en la segunda alternancia. Estudios Políticos, 35, 61-85.

Mastrini, G., \& Becerra, M. (2009). Los dueños de la palabra. Buenos Aires: Prometeo.

Mariscal, J., \& Rivera, E. (2005). Organización industrial y competencia en las telecomunicaciones en América Latina: estrategias empresariales. Santiago de Chile: CEPAL.

Montes-de-Oca, L.B. (2014). ¿Innovaciones democráticas? Análisis del Consejo Consultivo de telecomunicaciones en México. Revista Mexicana de Sociología, 76(2), 287-320.

Piedras, E. (sf). Regulación y Desempeño del Sector de Telecomunicaciones: el impacto en el Bienestar, la productividad y la competitividad en México. México DF: CIDE.

Porto, M., \& Hallin, D. (2009). Media and Democratization in Latin America. International Journal of Press/Politics, 14(3), 291-295. doi: https://doi. org/10.1177/1940161209336231 
Thacker, S. (2000). Big Business, the state, and free trade. Constructing Coalitions in Mexico, Cambridge University Press.

Tovar-Landa, R. (2015). La Reforma en Telecomunicaciones y Radiodifusión: un enfoque crítico. El Cotidiano, 190, 41-47.

Razo, C., \& Rojas-Mejía, F. (2007). Del Monopolio de Estado a la convergencia tecnológica: evolución y retos de la regulación de telecomunicaciones en América Latina. Santiago de Chile: CEPAL-ONU.

Rangel, M. P. (2007). Reforma microeconómica y arreglos institucionales: la política de competencia económica en México. Revista Mexicana de Sociología, 69(1), 39-68.

Rodríguez-Arechavaleta, C. M. (2012). Lógica mediática y calidad de la democracia. Apuntes de un modelo normative. En La buena Democracia. Claves de su calidad (pp. 203-215). Universidad de Granada.

Rodríguez-Arechavaleta, C. M. (2011). Apuntes sobre el Derecho a la Información en México en los años 70'. Entre el Nuevo Orden Informativo Internacional y la crisis de legitimidad interna. Derecom, 6, 1-17.

Rozas-Balbontín, P. (2002). Competencia y conflictos regulatorios en la industria de las telecomunicaciones de América Latina. Santiago de Chile: ILPES, CEPAL.

Sánchez-García, K. (2014). La Reforma en Telecomunicaciones y las negociaciones en el Congreso. México Interdisciplinario, 4(7), 69-83.

Santander, P. (2014). Nuevas leyes de medios en Sudamérica: enfrentando políticamente la concentración mediática. Convergencia, 21(66), 13-38.

Schneider, B. R., \& Wolfson, L. (2005). La organización de los intereses económicos y las coaliciones políticas en el proceso de las reformas de mercado en América Latina. Desarrollo Económico, 45, 179.

Solís-Leere, B. (2013). Derechos por construir: los derechos de los ciudadanos en la reforma constitucional de 2013 en telecomunicaciones, radiodifusión y competencia. El Cotidiano, 181, 17-23.

Sosa-Hernández, G. G. (2016). Los grupos de poder mediático ante el cambio institucional: la reforma en telecomunicaciones (2013-2015). Estudios Políticos, 9(39), 91-119.

Valdés-de-Vega, M.E. (2016). Reforma a telecomunicaciones y radiodifusión en México: la perspectiva de la Asociación Mexicana del Derecho a la Información. Tla Melaua, 9(39), 188-212.

Wohlers, M. (2008), Convergencia tecnológica y agenda regulatoria de lastelecomunicaciones en América Latina. Santiago de Chile: CEPAL-ONU. 



\title{
Vigilia y vigilancia: Análisis de contenido del Registro Nacional de Acceso a Internet en Brasil
}

\section{Watch and surveillance: A content analysis of the National Registry of Internet Access in Brazil}

Fernando Nobre Cavalcante es doctorando en Estudios de los Medios en la Universidade Federal do Rio Grande do Norte y docente de la UNI7 (Brasil) (fernandocavalcante@gmail.com) (http://orcid.org/0000-00032803-52911

\begin{abstract}
Resumen
La legalización e institucionalización de la vigilancia de las informaciones digitales de los ciudadanos brasileños han sido promovidas por intereses de grupos políticos protestantes que argumentan ideas de fe y moralidad en proyectos de leyes que potencian nuevas formas de control de Internet. Desde 2015, diferentes proyectos de ley amenazan el derecho a la privacidad y a la libertad de expresión en las comunicaciones digitales, garantizados por la Ley No 12.965, del 23 de abril de 2014 (Marco Civil de Internet). La presente investigación analiza los puntos críticos de los proyectos de normativas de control de Internet promovidos por políticos evangélicos y justificados en argumentos morales de protección de niños y adolescentes. El presente artículo establece un diálogo teórico con los postulados de Manuel Castells en un intento por desmitificar los argumentos a favor del control y utiliza una investigación cualitativa por medio de un levantamiento y análisis de contenido de los proyectos de leyes que aún se tramitan en el Congreso Nacional brasileño. Se evidencia que los actuales proyectos de ley establecen amenazas fecundas en los principios orientadores, garantías, derechos y deberes para el uso de Internet en Brasil, camuflados en narrativas moralistas y de argumentos disonantes e interesados de la Ley $\mathrm{N}^{\circ}$ 12.965, llevando al entendimiento que hay eminentes posibilidades de ampliación del control y vigilancia de las informaciones que consumen y producen los internautas brasileños.
\end{abstract}

\begin{abstract}
The legalization and institutionalization of the surveillance of the digital information of the Brazilian citizens has been promoted by interests of Protestant political groups that argue ideas of faith and morality in draft laws that promote new forms of Internet control. Since 2015, different bills have threatened the right to privacy and freedom of expression in digital communications, guaranteed by Act No. 12.965, of April 23, 2014 (Civil Internet Framework). The present research analyzes the critical points of the projects of law of control of Internet promoted by evangelical politicians and justified in moral arguments of protection of children and adolescents. The present article establishes a theoretical dialogue with the postulates of Manuel Castells in an attempt to demystify the arguments in favor of the control and uses a qualitative investigation by means of a survey and analysis of content of the bills of laws that still are processed in the National Brazilian Congress. It is evident that the current draft legislation establishes fruitful threats to the guiding principles, guarantees, rights and duties for the use of the Internet in Brazil, camouflaged in moralistic narratives and dissonant and interested arguments of Law No. 12,965, leading to the understanding that there are eminent possibilities of expanding the control and monitoring of the information consumed and produced by Brazilian Internet users.
\end{abstract}

\section{Palabras clave | keywords}

Marco Civil Internet; Registro Nacional de Acceso a Internet; control de Internet en Brasil; análisis documental. Civil Internet Framework; National Registry of Internet Access; Internet control in Brazil; documentary analysis. 


\section{Introducción}

Poco más de un año antes de la solicitud de aceptación del proceso de destitución de la presidenta Dilma Rousseff, la Ley nº 12.965, del 23 de abril de 2014 -también conocida como «Marco Civil de Internet»-, fue sancionada. En ésta, temas como la neutralidad de Internet, el registro de datos de conexión y navegación, entre puntos que establecen derechos inalienables como la libertad de expresión, la privacidad, la intimidad de los usuarios y la inviolabilidad de las comunicaciones, están garantizadas, aunque estos principios se encuentran actualmente amenazados.

El proyecto de Ley 2390/2015, de la autoría del diputado federal Pastor Franklin y el 5096/2016, propuesto por el diputado federal Célio Silveira, amenazan la confidencialidad de datos de los internautas brasileños y esperan ser expuestos ante la Comisión de Ciencia y Tecnología, Comunicación e Informática (CCTCI) del Congreso brasileño por el diputado Misionero José Olimpio. Los proyectos de leyes referenciados ut supra ponen en cuestión el «Marco Civil de Internet» que es, hasta el momento, la única expresión legislativa que regula los derechos y deberes de ciudadanos en ambientes virtuales en Brasil.

Estos proyectos de normativa se tratan de iniciativas legislativas de la bancada evangélica de líderes políticos y religiosos en el Congreso Nacional, cuyos argumentos parten de la preservación de los derechos de niños y adolescentes; aunque esta justificación sucumbe a los reales intereses de mayor control de datos y de la navegabilidad del ciudadano brasileño por la propuesta de institucionalización de un «Registro Nacional de Acceso a Internet».

El presente artículo inicia discutiendo la dicotomía moralista y pragmática del control de la información en el paradigma de la sociedad de la información, mediante un análisis de los postulados de Manuel Castells, para posteriormente analizar, utilizando la técnica cualitativa de análisis de contenido de base interpretativa, la ley «Marco Civil de Internet», frente a las nuevas propuestas legislativas anteriormente referenciadas. Para el análisis de contenido se hace el levantamiento de datos con el mayor número de palabras proferidas en la Ley vigente, en los proyectos ut supra citados y el análisis de los principales puntos que el Comité Gestor de Internet explica contrarios al proyecto. Así la presente investigación intentará dilucidar si las propuestas legislativas 
significarían un mayor control de la vida digital de los ciudadanos brasileños por parte de las instituciones gubernamentales.

\section{Sociedad en red: Promesa y control}

En muchos países hemos visto evolucionar nuevas formas de control de la información en Internet afectando directamente la libertad de los ciudadanos que están sujetos a represión por parte de sus gobiernos (Murdoch \& Roberts, 2013). Los cambios políticos también evolucionan las formas de mantener el control de acceso a la información para los ciudadanos (Kerr, 2014). En la sociedad de la información, promesa y control parecen mezclarse con la misma potencia de la aglutinación de la producción y el consumo de las mercancías digitales. La promesa de libertad y democratización de la información se superpone a las reales políticas de control y acceso amplio de las informaciones por parte de imperios privados y Estados. Para Manuel Castells (2005) la tecnología es el nuevo modo de producción en nuestra actual sociedad, donde las informaciones pasan a ser incorporadas en el seno de una economía globalizada. Es significativo que el autor (op. cit) se centra en la productividad informacional como los motores apalancadores del crecimiento económico, ya que estos todavía organizan las sociedades alrededor de sus centenarias lógicas de apropiación de los procesos de trabajo y de acumulación de riquezas. Estos son los aspectos inmutables de las dinámicas en los que coexiste la dualidad capitalista de encanto y control, de riqueza y miseria. Conceptos dudosos contenidos en toda la trilogía de Castells: La Era de la información: Economía, sociedad y cultura. Puyosa (2015) también coincide en que están apareciendo nuevas formas de control del Estado en la sociedad de la información al investigar empíricamente el concepto que denomina «dilema del dictador» en el caso venezolano.

En la red encontramos la entrega de la «acción carismática» (Pierucci, 2003) por parte de los emprendedores que se arriesgan en el afán de tener su propio negocio en el ecosistema digital, la entrega del intelecto y talento de programadores, diseñadores, responsables de comunicación y marketing, administradores y todo el cuerpo colectivo de colaboradores y creadores de contenidos. Por el otro lado en las interacciones se encuentra el alma encantada de consumidores que confían y proporcionan su información a cambio de servicios digitales, convirtiéndose en usuarios de mercancías informativas que aún no han des- 
pertado al sesgo mediático detrás de una gratuidad en la prestación de servicios -aplicaciones, sitios web, ofertas, entre otras- que hasta ahora nunca habían sido necesarios para un bienestar social, pero que así se convierten por la masificación cíclica e interminable de la cultura consumista de comprar y descartar (Gorz, 2005). En ese juego de la sociedad en red también aparecen los gobernantes que, en busca de expandir sus nichos electorales, intentan utilizar la red para sus intereses personales por medio de políticas públicas, discursos reconfortantes o promesas en las campañas electorales.

Cleland \& Brodsky (2012) recuerdan en su obra que el periódico USA Today reveló que en 2004, 98\% de las donaciones a campañas federales efectuadas por funcionarios de Google fueron para los políticos del partido demócrata: "Eric Schmift apoyó a Barack Obama, participó activamente en su campaña y fue miembro del Consejo Consultivo del Presidente para Ciencia y Tecnología y de su Consejo de Transición sobre la Economía" (op. cit, p. 201). El sitio estadounidense de noticias Sputnick News, en abril de 2015, reveló que el fundador de WikiLeaks, Julian Assange, previó que Google podría desempeñar un papel crucial en la campaña presidencial de Hillary Clinton en 2016 pues, según el reportaje, el director de «Google Ideas», Jared Cohen, fue asesor de Clinton. En Brasil, distante al escenario de las aseveraciones de Assange, vemos actitudes semejantes por parte de los miembros líderes religiosos que asumen funciones políticas, como por ejemplo del grupo parlamentario de evangélicos del Congreso Nacional que desde 2015 proponen proyectos de Ley que endosan la relación de control del Estado para el ejercicio de derechos ciudadanos.

"La red no es garante de libertad, pero vuelve más difícil la opresión. La censura permite identificar y castigar al mensajero, pero no puede detener el mensaje", afirma Manuel Castells al periódico brasileño Zero Hora ${ }^{1}$. Castells (2005), al mencionar el eslogan de la campaña presidencial de Bill Clinton en 1992, constata que la globalización fue en ese gobierno la principal estrategia de la política económica estadounidense, mientras surgía una mayor desregulación y liberalización -doméstica e internacional- postulando así:

1 Entrevista ofrecida el 09/06/13. Disponible en: https://goo.gl/DbRsqK (25/06/17). 
A resposta é clara para o principal globalizador, o governo dos EUA: uma economia mais aberta e integrada é vantajosa para para as empresas estadunidenses. Isso se dá em razão da vantagem tecnológica, e da flexibilidade administrativa superior, de que gozam os EUA em comparação com o resto do mundo. Junto com a presença de longa data das multinacionais estadunidenses no mundo inteiro, e com a presença hegemônica dos EUA nas instituições internacionais de comércio e finanças, a globalização é primordial para aumentar a prosperidade econômica dos EUA, embora decerto não para todas as empresas, e não para todo o povo dos Estados Unidos. Esse interesse econômico estadunidense é algo de que Clinton e sua equipe econômica, especialmente Rubin, Summers e Tyson entendiam bem. Trabalharam com afinco para divulgar o evangelho liberal no mundo, aplicando a força econômica e política dos EUA quando necessárioº (Castells, 2005, p. 184).

En otras palabras, para Castells (op. cit), en ausencia de conflictos o choques externos -revoluciones políticas, guerras, desastres naturalesla transformación del capitalismo está dirigida por intentos para sostener el crecimiento económico, simplemente porque el propio sistema tiene una lógica expansionista. Las presiones competitivas internas de las economías nacionales recompensan a aquellas cuya productividad es más elevada. En consecuencia, Castells mantiene la idea de que si nosotros entendemos cómo cambia la sociedad contemporánea, tenemos que empezar analizando las estrategias implementadas por los agentes económicos apuntando al crecimiento de la eficiencia de éstas, cobrando en este contexto mayor sentido la famosa frase del sociólogo Daniel Bell "hacer mucho con poco" (citado por Stalder, 2006, p. 43).

2 "La respuesta es clara para el principal globalizador, el gobierno de EEUU: una economía más abierta e integrada es ventajosa para las empresas estadounidenses. Esto se da en razón de la ventaja tecnológica y de la flexibilidad administrativa superior de la que goza Estados Unidos en comparación con el resto del mundo. Junto con la presencia de larga data de las multinacionales estadounidenses en todo el mundo y con la presencia hegemónica de EEUU en las instituciones internacionales de comercio y finanzas, la globalización es primordial para aumentar la prosperidad económica de Estados Unidos, aunque ciertamente no para todas las empresas y no para todo el pueblo de los Estados Unidos. Este interés económico es algo que Clinton y su equipo económico, especialmente Rubin, Summers y Tyson entendían bien. Trabajaron con ahínco para divulgar el evangelio liberal en el mundo, aplicando la fuerza económica y política de EEUU cuando era necesario" (Traducción libre al español por el autor). 
Stalder (2006) comprende que la referencia a Bell no es baladí. En realidad, el trabajo de Bell desempeñó un papel importante para la crítica de Castells, en su teoría de «post-industrialismo», que dominó por mucho tiempo el análisis de los cambios económicos contemporáneos y favoreció su teoría. Entre los académicos que analizaron las transformaciones de la economía en el último cuarto del siglo XX, Daniel Bell sostuvo una posición prominente por un tiempo considerable. Desde la publicación de The Coming of Postindustrial Society, en 1973, la teoría de Bell ha ejercido una influencia profunda en el discurso sobre la economía en la era de la información. Su argumento básico fue ampliamente popularizado por futuristas como Alvin Toffler, particularmente en La Tercera Ola. Ambos autores detectaron un cambio histórico en los procesos de creación de mercancías para la provisión de servicios como actividad esencial de las economías avanzadas.

Esta transformación, según los autores citados en referencia, es más o menos igual en importancia a la Revolución Industrial, la cual desplazó el grueso de la actividad económica en extraer recursos de la naturaleza a través de la agricultura y la minería para la producción de mercancías en los mercados masivos. Stalder (2006, p. 43) nos recuerda que Bell declaró que "las sociedades industriales son mercancías que producen sociedades. La vida es un juego contra la naturaleza fabricada [...] Una sociedad postindustrial se basa en servicios. En consecuencia, ese es un juego entre personas".

Continuando con el análisis de Stalder (op. cit), Castells usó la teoría de post-industrialismo desde mediados de la década de los setenta como un realce para discutir con los argumentos contrarios. A pesar de su disgusto por el futurismo -tan característico de su análisis postindustrial- la perspectiva de Castells se superpone con los temas más importantes de Bell. En primer lugar, ambos sitúan primariamente cambios cruciales en el nivel de relaciones técnicas de producción (modos de desarrollo) y solo secundariamente al nivel de sus relaciones sociales (modos de producción). Esto les permite hablar al mismo tiempo sobre un profundo cambio en la forma en que se crean los principios económicos y sobre la continuidad de la forma en que los principios son apropiados. Esta distinción ha sido durante mucho tiempo una tesis central para el análisis de Castells, en especial en la trilogía de la «Era de la Información», más específicamente en el primer volumen La Sociedad 
en Red, donde el autor defiende una nueva forma de capitalismo que emergió en el último cuarto del siglo XX.

El propio argumento de Castells puede ser entendido como un intento de superar lo que él ve como fallas fundamentales en el enfoque, mientras las mantiene como un importante punto de referencia. La crítica de Castells al post-industrialismo culmina en su análisis sobre la reestructuración de una época: la crisis económica de la década de los setenta; y se desdobla en cuatro principales conceptos de la sociedad en red: i) la internacionalización de la economía; ii) el crecimiento de los mercados financieros globales; iii) las empresas de red; iv) y la individualización del trabajo.

La masificación de los nuevos servicios tecnológicos a través de la venta de espacios publicitarios en los enmarañados flujos de información revela las mismas viejas bases estructurales de acumulación y control. En el centro de este paradigma vemos el incontestable intento de mayor control de la información con intereses privados. Tal y como afirman Cleland y Brodsky (2012, p. 123), "el componente microeconómico es más importante. En él es en el que el tráfico o el comportamiento de los consumidores son analizados, permitiendo a Google prever dicho comportamiento, atraer a más usuarios y vender más anuncios".

La gratuidad en los servicios de las firmas que producen información y conocimiento a través de la innovación son ejemplos que se contextualizan en la (in)explicable ambivalencia. De hecho, en sus negocios se denota facilitar, agilizar y organizar nuestras vidas en las más variadas texturas generales de nuestras experiencias sociales, tal y como explica Silverstone (2005); y así lo hacen al considerar las necesidades creadas en la cíclica cultura de consumo (Bauman, 2008) donde el querer inmediato suplanta el deseo y la necesidad.

Parece que hoy, más que nunca, el escenario predicho por Toffler (2007) en La Tercera Ola, donde los consumidores se acercan más a la apropiación del modo de producción teniendo un estatus de productores-consumidores (prosumers) es más real cuando observamos el control de los insumos inmateriales, el control de la información. ¿Estaríamos ante una contradictoria economía del conocimiento en la constancia de la vigilancia? Para Gorz (2010, p. 12) "El valor del conocimiento en la economía capitalista es indefinible [...] Su precio no tiene un fundamento objetivo y es continuamente fluctuante", siguiendo esto la misma lógica del sistema capitalista: Control y promesa. 


\section{3. «Marco Civil de Internet» versus «Registro Nacional de Acceso a Internet»}

La Ley 12.965 sancionada el 23 de abril de 2014 por la presidenta Dilma Rousseff estableció derechos y deberes referentes al acceso a la información en Brasil. Se trata de una norma enmarcada en la Constitución brasileña que contribuye a mantener una Internet «libre y segura», aunque no ha estado exenta de ser un punto de continuos choques y debates acalorados en la esfera política de Brasil. Conocida como «Marco Civil de Internet», la ley apareció conjuntamente con otros 36 proyectos de similares propuestas temáticas e incluyó temas polémicos como la neutralidad y los derechos ciudadanos de acceso a la red. Este artículo destaca cuatro puntos recolectados en una de las colecciones de la serie Legislación, de la Edições Câmara publicado en 2014.

El primer punto de la propuesta de «Marco Civil de Internet» se refiere a la neutralidad relativa de las redes, que permite el control de tráfico por los operadores privados, buscando mantener mayor transparencia con el usuario, expresado en el capítulo tercero, artículo noveno:

II - agir com proporcionalidade, transparência e isonomia; [...] III informar previamente de modo transparente, claro e suficientemente descritivo aos seus usuários sobre as práticas de gerenciamento e mitigação de tráfego adotadas, inclusive as relacionadas à segurança da rede $^{3}$ (Marco Civil da Internet, 2014, p. 32).

Sobre el acopio de la información del usuario, el Marco garantiza en el plazo de hasta un año el almacenamiento de datos de conexión referente a la navegación (dirección IP utilizada, hora de conexión, entre otros) por parte de los proveedores de Internet. El objetivo, que al fondo pasaba a identificar al usuario, también lo protegería de eventuales delitos cibernéticos. Asimismo se justificaba en la protección a la intimidad personal del ciudadano, sancionando eventuales incumplimientos por parte de los proveedores:

Art. 10. A guarda e a disponibilização dos registros de conexão e de acesso a aplicações de internet de que trata esta Lei, bem como de dados pessoais

3 II - actuar con proporcionalidad, transparencia e isonomía; (...) III - informar previamente de manera transparente, clara y suficientemente descriptiva a sus usuarios sobre las prácticas de gestión y mitigación de tráfico adoptadas, incluidas las relacionadas con la seguridad de la red (traducción libre por el autor). 
e do conteúdo de comunicações privadas, devem atender à preservação da intimidade, da vida privada, da honra e da imagem das partes direta ou indiretamente envolvidas. [...] Art. 11. Em qualquer operação de coleta, armazenamento, guarda e tratamento de registros, de dados pessoais ou de comunicações por provedores de conexão e de aplicações de internet em que pelo menos um desses atos ocorra em território nacional, deverão ser obrigatoriamente respeitados a legislação brasileira e os direitos à privacidade, à proteção dos dados pessoais e ao sigilo das comunicações privadas e dos registros ${ }^{4}$ (Marco Civil da Internet, 2014, p. 33-34).

El tercer punto se refiere al registro de historial de navegación del usuario. De acuerdo con la propuesta original, los proveedores de Internet eran vetados de almacenar cualquier dato referente al historial de navegación del usuario -excepto cuando el poder judicial ordenara lo contrario-, siendo proporcionado a proveedores de contenido, como por ejemplo empresas de redes sociales, portales de noticias y entretenimiento o motores de búsqueda, que tenían algún servicio de hospedaje de la información:

Art. 14. Na provisão de conexão, onerosa ou gratuita, é vedado guardar os registros de acesso a aplicações de internet. [...] Art. 15. O provedor de aplicações de internet constituído na forma de pessoa jurídica e que exerça essa atividade de forma organizada, profissionalmente e com fins econômicos deverá manter os respectivos registros de acesso a aplicações de internet, sob sigilo, em ambiente controlado e de segurança, pelo prazo de 6 (seis) meses, nos termos do regulamento. [..] $§ 2^{\circ} \mathrm{A}$ autoridade policial ou administrativa ou o Ministério Público poderão requerer cautelarmente a qualquer provedor de aplicações de internet que os registros de acesso a aplicações de internet sejam guardados [... $]^{5}$ (Marco Civil da Internet, 2014, p. 36).

4 Art. 10. La custodia y la disponibilidad de los registros de conexión y de acceso a las aplicaciones de Internet de que trata esta Ley, así como de datos personales y del contenido de comunicaciones privadas, deben atender a la preservación de la intimidad, la vida privada, El honor y la imagen de las partes directa o indirectamente implicadas. [...] Art. 11. En cualquier operación de recolección, almacenamiento, custodia y tratamiento de registros, de datos personales o de comunicaciones por proveedores de conexión y de aplicaciones de Internet en que al menos uno de esos actos ocurra en territorio nacional, Se deben respetar obligatoriamente la legislación brasileña y los derechos a la privacidad, a la protección de los datos personales y al secreto de las comunicaciones privadas y de los registros (traducción libre por el autor).

5 Art. 14. En la provisión de conexión, onerosa o gratuita, es vedado guardar los registros de acceso a aplicaciones de internet. [...] Art. 15. El proveedor de aplicaciones de Internet constituido en forma de persona jurídica y que ejerza esa actividad de forma 
El cuarto punto polémico incluido en el Marco normaliza la responsabilidad de contenido en la red, expresados en la práctica de la "notificación y retirada del aire". Esta tipificación se refiere a materiales infractores protegidos por derechos de autor, difamatorios o calumniosos:

Art. 18. O provedor de conexão à internet não será responsabilizado civilmente por danos decorrentes de conteúdo gerado por terceiros. [...] Art. 19. Com o intuito de assegurar a liberdade de expressão e impedir a censura, o provedor de aplicações de internet somente poderá ser responsabilizado civilmente por danos decorrentes de conteúdo gerado por terceiros se, após ordem judicial específica, não tomar as providências para, no âmbito e nos limites técnicos do seu serviço e dentro do prazo assinalado, tornar indisponível o conteúdo apontado como infringente, ressalvadas as disposições legais em contrário. [...] Art. 20. Sempre que tiver informações de contato do usuário diretamente responsável pelo conteúdo a que se refere o art. 19, caberá ao provedor de aplicações de internet comunicar-lhe os motivos e informações relativos à indisponibilização de conteúdo, com informações que permitam o contraditório e a ampla defesa em juízo, salvo expressa previsão legal ou expressa determinação judicial fundamentada em contrário ${ }^{6}$ (Marco Civil da Internet, 2014, p. 37).

organizada, profesionalmente y con fines económicos deberá mantener los respectivos registros de acceso a aplicaciones de internet, bajo secreto, En un ambiente controlado y de seguridad, por el plazo de 6 (seis) meses, de conformidad con el Reglamento. [...] § 2o La autoridad policial o administrativa o el Ministerio Público podrán requerir cautelarmente a cualquier proveedor de aplicaciones de Internet que los registros de acceso a aplicaciones de Internet sean guardados [...] (traducción libre por el autor).

6 Art. 18. El proveedor de conexión a Internet no será responsabilizado civilmente por daños derivados del contenido generado por terceros. [...] Art. 19. Con el fin de asegurar la libertad de expresión e impedir la censura, el proveedor de aplicaciones de Internet sólo podrá ser responsabilizado civilmente por daños derivados del contenido generado por terceros si, después de una orden judicial específica, no Tomar las providencias para, en el marco y dentro de los límites técnicos de su servicio y dentro del plazo señalado, hacer no disponible el contenido señalado como infringente, salvo las disposiciones legales en contrario. [...] Art. 20. Siempre que tenga información de contacto del usuario directamente responsable del contenido a que se refiere el art. 19, corresponderá al proveedor de aplicaciones de internet comunicarle los motivos e informaciones relativos a la indisponibilidad del contenido, con informaciones que permitan el contradictorio y la amplia defensa en juicio, salvo expresa previsión legal o expresa determinación judicial fundamentada en contrario (traducción libre por el autor). 
En resumen, las políticas de neutralidad pasaron a legislar y proteger el tráfico de Internet permitiendo que el usuario sea informado de las políticas y condiciones del contrato. Con la vigente Ley de «Marco Civil de Internet» el usuario tendrá que dar autorización expresa para la recolección de sus hábitos de navegación y aunque se opte en no proporcionar la información, podrá ser impedido de utilizar los servicios si no acepta los términos establecidos por el sitio. Uno de los puntos de conflicto en relación al control de la información por empresas privadas y el gobierno se refiere a la obligatoriedad de almacenamiento de registros de conexión y navegación definido por un período determinado en la legislación, pero al mismo tiempo no presentando obligación de continuos almacenamientos en algunos casos explicitados por la Ley. Además, otro punto importante al derecho del usuario se refiere a que los derechos constitucionales se validan también para la realidad digital.

Sin embargo, dos años más tarde de la sanción del «Marco Civil de Internet», el Comité Gestor da Internet no Brasil (en lo sucesivo CGI.br) divulgó el 18 de octubre de 2016 una nota pública contraria a las propuestas legislativas que pretendían crear un «Registro Nacional de Acceso a Internet» (Cadastro Nacional de Acesso à Internet). Una de las atribuciones del CGI.br es la proposición de normas y procedimientos relativos a la regulación de las actividades en Internet. El órgano se mostró radicalmente contrario al proyecto de Ley liderado por el Frente Evangélico Parlamentario del Congreso Nacional, compuesto enteramente por diputados evangélicos, defensores de un mayor control del acceso a la información y vigilancia de la ciudadanía brasileña:

O COMITÊ GESTOR DA INTERNET NO BRASIL - CGI.br, após tomar conhecimento, no último dia 05 de outubro de 2016, da leitura do parecer de aprovação e do substitutivo apresentado aos Projetos de Lei $n^{\circ}$ s $2390 / 2015,3597 / 2015,5016 / 2016$ e 5096/2016, bem como do pedido de vista conjunto de parte dos parlamentares integrantes da Comissão de Ciência e Tecnologia, Comunicação e Informática/CCTCI, [...]VEM A PÚBLICO. Expressar grande preocupação com a proposta de criação do denominado "Cadastro Nacional de Acesso à Internet", o qual possui barreiras técnicas para a sua implantação, bem como negligencia o controle parental e soluções que contemplem todos os aspectos envolvidos para garantir uma Internet livre, aberta, democrática e que seja um ambiente seguro para as crianças e adolescentes.2. Argumentar que a pretensão de acautelar riscos inerentes à navegação na Internet 
- que podem e devem ser mitigados com a educação dos usuários e de seus responsáveis - não deve justificar a criação de controles inconsistentes e passíveis de serem burlados, e que atentariam contra princípios fundamentais consagrados pelo Marco Civil da Internet, criando nova gama de riscos aos cidadãos que se pretende proteger $^{7}$ (CGI.BR, 2016) . $^{8}$.

Los proyectos de Ley números 2390/2015, 3597/2015, 5016/2016 y 5096/2016, agrupados en la eventual Ley que alude al «Catastro Nacional de Acceso a Internet» y que aún se encuentran en trámite en el Congreso $\mathrm{Nacional}^{9}$, han sido fuertemente criticados por proponer modificaciones que amenazan los principales principios y derechos postulados en el «Marco Civil de Internet», explicado con anterioridad.

\section{Materiales y método}

Para la presente investigación se realizó un levantamiento de los principales proyectos de Ley que actualmente se encuentran en trámite en el Congreso Nacional brasileño y que denotan nuevas formas de control de Internet, para posteriormente realizar un análisis de contenido de base interpretativa asignado de forma cuantitativa a las llaves lexicales más frecuentes en estos documentos verbales (transcripciones) y documentos legislativos. Para ello se analizó el contenido de las principales expresiones verbales y no verbales de las leyes ya discutidas, comparando

7 EL COMITÉ GESTOR DE INTERNET EN BRASIL - CGI.br, tras tomar conocimiento, el último día 05 de octubre de 2016, de la lectura del dictamen de aprobación y del sustitutivo presentado a los Proyectos de Ley no 2390/2015, 3597/2015, 5016 / 2016 y 5096/2016, así como de la solicitud de vista conjunto de parte de los parlamentarios integrantes de la Comisión de Ciencia y Tecnología, Comunicación e Informática / CCTCI, [...] HACEN PÚBLICO. Expresar gran preocupación con la propuesta de creación del denominado "Catastro Nacional de Acceso a Internet", el cual tiene barreras técnicas para su implantación, así como descuida el control parental y soluciones que contemplan todos los aspectos involucrados para garantizar una Internet libre, abierta Democrática y que sea un ambiente seguro para los niños y adolescentes.2. Argumentar que la pretensión de salvaguardar riesgos inherentes a la navegación en Internet -que pueden y deben ser mitigados con la educación de los usuarios y de sus responsables- no debe justificar la creación de controles inconsistentes y pasibles de ser burlados, y que atentarian contra principios fundamentales consagrados Por Marco Civil de Internet, creando una nueva gama de riesgos para los ciudadanos que se pretende proteger (traducción libre por el autor).

8 Disponible en: https://goo.gl/rUYhwk (26/04/17).

9 Hasta la fecha de elaboración de este artículo el 01/08/17. 
el discurso presentado en estas unidades documentales con la visión de repudio de los documentos de posicionamiento oficial de la asociación que representa a la sociedad civil (CGI.br) contraria al proyecto de «Catastro Nacional de Acceso a Internet».

Las políticas públicas que promulgan el control de Internet, más que en los propios textos legislativos, evidencian poder por palabras escritas, verbalizadas y mediatizadas. En cuanto a la preponderante presencia de textos en los fenómenos sociales contemporáneos, sobre todo en las comunicaciones políticas gubernamentales, Boréus \& Bergström (2017) indican que los estudios de los medios y de la comunicación deben sobrellevar el análisis textual como metodología de investigación de los campos de las Ciencias Sociales y en especial, de la Comunicación. Con la finalidad de organizar los diferentes sesgos analíticos para debatir sobre el «poder», se analizarán los discursos escritos, verbalizados o publicados, tomando en consideración tanto los pronunciamientos políticos como las críticas mediáticas.

El análisis de contenido se utiliza además para la codificación en un prisma cuantitativo o cualitativo, con el fin de sistematizar, definir, categorizar o describir el significado de los textos. Al mismo tiempo, los objetos de investigación, aproximándose a los sesgos cuantitativos y cualitativos, incluyen en estos análisis la producción de contenido de los medios de comunicación tradicionales y digitales (Boréus \& Bergström, 2017).

$\mathrm{Al}$ escoger el análisis de contenido, el investigador puede hacer comparaciones basadas en cuantificaciones de diferentes elementos en textos, lo que puede ser necesario si el objetivo es revisar los cambios en el transcurso del tiempo de determinado contenido. La principal característica de este tipo de análisis es el entendimiento que al dimensionar la frecuencia de determinadas palabras se podrán percibir características exteriores al texto. El análisis de contenido puede concentrarse en los aspectos ideales e interpersonales de los textos, manteniéndose como método deductivo en la búsqueda de elementos hipotéticos y teóricos. Las principales críticas a este tipo de método se refieren a que no todo se puede generalizar en frecuencia, porque existe un mayor carácter analítico a lo que es más explícito que implícito, en especial en la técnica de la búsqueda de códigos, y en relación a cuestiones de validación y de interpretación del investigador al sobreponerse a la realidad de los contenidos, tal como explican O'Connell (1999), McMillan (2009), Krippendorff (2013), Schreier (2014) y Boréus \& Bergström (2017). 
Para esta investigación se utilizó la plataforma ATLAS.ti para hacer el levantamiento de la frecuencia de palabras claves (lexicones) más presentes en los textos escritos y/o verbales de los principales puntos entre los dos proyectos de Ley referenciados (PL 2390/2015 y 2390/2015), incluyendo una comparación con el «Marco Civil de Internet». Además, fueron cuantificadas las palabras clave presentes con mayor frecuencia en el «Marco Civil de Internet» (ver tabla 1) y la posición del Comité Gestor de Internet do Brasil (ver tabla 2).

\section{Resultados}

\section{Tabla 1. Análisis comparativo de frecuencia de palabras clave contenidas en el "Marco Civil de Internet" y en los proyectos de Ley 12.965/2014 y 2390/2015}

\begin{tabular}{|c|c|c|c|c|c|}
\hline Texto analizado & Autoria & \multicolumn{4}{|c|}{$\begin{array}{l}\text { Palabras con mayor frecuencia } \\
\text { textual (escrito y /o verbal) }\end{array}$} \\
\hline $\begin{array}{l}\text { (1) } \\
\text { Ley n. 12.965/2014 } \\
\text { MARCO CIVIL } \\
\text { DE } \\
\text { INTERNET }\end{array}$ & $\begin{array}{l}\text { Sancionada } \\
\text { por la presi- } \\
\text { denta Dilma } \\
\text { Rousseff }\end{array}$ & $\begin{array}{l}\text { "INTERNET" } \\
\text { Qtd: } 70\end{array}$ & $\begin{array}{l}\text { "APLI- } \\
\text { CAÇÕES" } \\
\text { Qtd: } 35 \\
\\
\text { Palabra clave } \\
\text { no comisera- } \\
\text { da: "art" (43) }\end{array}$ & $\begin{array}{l}\text { "REGISTROS" } \\
\text { Qtd: } 35\end{array}$ & $\begin{array}{l}\text { "LEl" } \\
\text { Qtd: } 26 \\
\text { "ACESSO"; "DADOS"; } \\
\text { "CONEXÃO" } \\
\text { Qtd: } 23 \\
\text { "CONTEÚDO" (Qtd: } \\
\text { 20); "FORMA" } \\
\text { (Qtd: 19) }\end{array}$ \\
\hline $\begin{array}{l}\text { (2) } \\
\text { Proyecto de ley } \\
2390 / 2015\end{array}$ & $\begin{array}{l}\text { Pastor Franklin } \\
\text { (Partido Polí- } \\
\text { tico: PTdoB/ } \\
\text { MG) }\end{array}$ & $\begin{array}{l}\text { "INTER- } \\
\text { NET" } \\
\text { Qtd: } 27\end{array}$ & $\begin{array}{l}\text { "ACESSO" } \\
\text { Qtd: } 24\end{array}$ & $\begin{array}{l}\text { "CADASTRO" } \\
\text { Qtd: } 20\end{array}$ & $\begin{array}{l}\text { "PÚBLICO"; } \\
\text { "ADOLESCENTE"; } \\
\text { "CRIANÇA" } \\
\text { Qtd: } 11\end{array}$ \\
\hline $\begin{array}{l}\text { (3) } \\
\text { Proyecto de ley } \\
5016 / 2016\end{array}$ & $\begin{array}{l}\text { Célio Silveira } \\
\text { - (Partido } \\
\text { Político: PSDB/ } \\
\text { GO) }\end{array}$ & $\begin{array}{l}\text { "ACESSO" } \\
\text { Qtd: } 15\end{array}$ & $\begin{array}{l}\text { "INTERNET" } \\
\text { Qtd: } 12\end{array}$ & $\begin{array}{l}\text { "LEl" } \\
\text { Qtd: } 11\end{array}$ & $\begin{array}{l}\text { "APLICATIVOS"; } \\
\text { "ADOLESCENTE" } \\
\text { Qtd: } 9\end{array}$ \\
\hline $\begin{array}{l}\text { (4) Discurso } \\
\text { pronunciado en la } \\
\text { Sala das Sessões, en } \\
27 \text { de abril de } 2016 \\
\text { por Deputado Célio } \\
\text { Silveira }\end{array}$ & $\begin{array}{l}\text { Célio Silveira } \\
\text { - (Partido Po- } \\
\text { lítico: PSDB/ } \\
\text { GO) }\end{array}$ & $\begin{array}{l}\text { "VÍDEOS"; } \\
\text { "INTER- } \\
\text { NET" } \\
\text { Qtd: } 10\end{array}$ & $\begin{array}{l}\text { “LEl” } \\
\text { Qtd: } 07\end{array}$ & $\begin{array}{l}\text { "CLASSI- } \\
\text { FICAÇÃO"; } \\
\text { "VIOLÊNCIA" } \\
\text { Qtd: } 06\end{array}$ & $\begin{array}{l}\text { "INDICATIVA"; } \\
\text { "SíTIOS"; "CENAS"; } \\
\text { "SEXO"; } \\
\text { "ANOS" } \\
\text { Qtd: } 5\end{array}$ \\
\hline $\begin{array}{l}\text { (5) } \\
\text { Discurso pronun- } \\
\text { ciado en la Sessões, } \\
14 \text { de abril de } 2016 \\
\text { por Deputado Célio } \\
\text { Silveira }\end{array}$ & $\begin{array}{l}\text { Célio Silveira } \\
\text { - (Partido } \\
\text { Político: PSDB/ } \\
\text { GO) }\end{array}$ & $\begin{array}{l}\text { "ACESSO" } \\
\text { Qtd: } 15\end{array}$ & $\begin{array}{l}\text { "INTERNET"; } \\
\text { "LEI" } \\
\text { Qtd: } 12\end{array}$ & $\begin{array}{l}\text { "APLICATI- } \\
\text { VOS" } \\
\text { Qtd: } 9\end{array}$ & $\begin{array}{l}\text { "SITES" } \\
\text { "ADOLESCENTES"; } \\
\text { "CRIANÇAS" } \\
\text { Qtd: } 8\end{array}$ \\
\hline
\end{tabular}




\section{Tabla 2. Posición del Comité Gestor de Internet do Brasil contraria a los proyectos de Ley "Registro Nacional de Acceso a Internet»}

a. que la protección en línea de niños y adolescentes a través de la creación de un "Catastro Nacional de Acceso a Internet", el cual, en teoría, restringiría el acceso al contenido "inadecuado" clasificado de forma unilateral por los propios "proveedores de información, marginaliza el papel de los padres en ejercer control sobre qué tipo de contenido sus hijos o hijas deberían consumir, haciéndolos coadyuvantes en la conducción de esa parte crucial del proceso educativo;

b. que existen diversos programas de computadoras para el ejercicio de control parental en cuanto al contenido visitado por niños y adolescentes, lo que está garantizado como una opción de libre elección en cualquier terminal de acceso a Internet y que debe ser objeto de políticas públicas en los términos del artículo 29. de la Ley 12.965/2014 (Marco Civil de Internet). Tales tecnologías empoderan a los padres con la habilidad de controlar las informaciones consumidas por sus hijos e hijas, lo que está más de acuerdo con su papel de protagonistas de esa porción importante del proceso educativo y que forma parte de la libre planificación familiar asegurada por la Constitución Federal (Artículo 226, §7º);

c. que hay la necesidad de esfuerzos coordinados entre el Poder Público, la sociedad civil, la comunidad científica y tecnológica y los proveedores de conexión y aplicación para establecer de forma estructurada los parámetros para el tratamiento de la circulación de material inadecuado por Internet;

d. que la obligatoriedad de sistemas de control embarcados en los equipos vincularía a la industria de bienes de informática con la obligación de agregarles la suscitada nueva funcionalidad, lo que inevitablemente será repasado al consumidor final, generando, en último análisis, efectos colaterales para la universalización de la conectividad en el país, así como para la viabilidad de la actividad de las pequeñas y medianas empresas;

e. que en una red local (residencial o corporativa) puede haber decenas de usuarios, dado que la mayoría de las veces se comparte el mismo número IP público. Por lo tanto, el proveedor de conexión tendría que autentificar cada uno de los miles de accesos de los miles de puntos de su red, lo que no guarda relación con dicho intercambio de protocolo IP y, en particular, con la interfaz de los hardwares de los actuales aparatos routers de conexión a Internet. En este último caso, que incluye las redes inalámbricas, la autenticación se haría sólo en el acceso principal y sólo una vez, lo que imposibilita el control de cada usuario;

f. por último, que cualquier sistema de registro podría ser fácil de burlar. En primer lugar, porque podría haber una autenticación falsa, como la creación o la utilización de registros que no por sus verdaderos titulares. Segundo, porque hay varias herramientas de enmascaramiento de la conexión, lo que la haría no rastreable por los proveedores y, en última instancia, por el "Catastro Nacional de Acceso a Internet";

Fuente: CGI.BR (2016). 
Tabla 3. Análisis comparativo de frecuencia
de palabras clave contenidas en la tabla 2

\begin{tabular}{|c|c|c|c|c|c|}
\hline $\begin{array}{c}\text { Texto } \\
\text { analizado }\end{array}$ & Autoria & \multicolumn{4}{|c|}{ Palabras con mayor frecuencia textual (escrito) } \\
\hline $\begin{array}{l}\text { (6) } \\
\text { Nota oficial } \\
\text { da CGI.BR } \\
\text { (2016) }\end{array}$ & $\begin{array}{l}\text { Comité } \\
\text { Gestor da } \\
\text { Internet no } \\
\text { Brasil (CGl. } \\
\text { br) }\end{array}$ & $\begin{array}{l}\text { "INTERNET" } \\
\text { Qtd: } 6\end{array}$ & $\begin{array}{l}\text { "ACESSO" } \\
\text { Qtd: } 5\end{array}$ & $\begin{array}{l}\text { "CONTROLE”; } \\
\text { "CONEXÃO" } \\
\text { Qtd: } 4\end{array}$ & $\begin{array}{l}\text { "CONTEÚDO" } \\
\text { "PROVEDORES" } \\
\text { Qtd: } 3\end{array}$ \\
\hline
\end{tabular}

Además del objeto central de la investigación de las palabras "Internet" y "acceso", en la tabla 1 se muestran los diferentes argumentos utilizados en los textos escritos y hablados señalados en los textos (2), (3) y (4), como «adolescentes» y «niños«. Esto pone en meridiana evidencia los valores morales que contextualizan la posición de la bancada evangélica que discuten -y justifican- temas relativos a la familia en muchos de sus discursos para un asunto de eminente naturaleza técnica y que involucra cuestiones de control de la información del ciudadano. El objetivo, de acuerdo con los diputados evangélicos, es "prohibir el acceso de niños y adolescentes a sitios electrónicos con contenido inadecuado". Para ello, la propuesta establece la creación de un registro nacional de personas y sitios, con datos personales que deberán ser verificados para cada acceso. La solución señalada por el «Registro Nacional de Acceso a Internet» impondría la creación de una base de datos en la que quedarían registradas "entre otras informaciones, el nombre completo, dirección completa, número del documento oficial de identidad y número de registro en el Catastro de Personas Físicas (CPF) del Ministerio de Hacienda", además de una lista de sitios con contenido inapropiado para niños y adolescentes. También se da cuenta el carácter disonante entre los puntos de los textos (1) y el otro en la tabla 1, posibilitando que la impresión de que el nuevo proyecto se expanda más allá de la atención formalizada en Ley vigente «Marco Civil de Internet».

Por su parte, la tabla 2 muestra la posición del CGI.br en la nota oficial divulgando los puntos contrarios al nuevo proyecto de Ley, que va más allá de los argumentos que se extraen de la tabla 1, sobre todo en la mayor cantidad de palabras claves en los textos escritos y hablados. Estos hechos se suman y se observan con meridiana claridad en la 
cuantificación expresada en la tabla 3 como "controle", donde la raíz "control" expresa denotativamente que los argumentos de la Ley en cuestión pueden tener un interés subyacente.

\section{Conclusión}

La Comisión de Ciencia y Tecnología, Comunicación e Informática (CCTCI) de la Cámara de Diputados tiene en la agenda de votaciones el informe del proyecto de Ley (PL) № 2.390/2015, que consolidado al PL 5016/201, proponen la creación de un «Registro Nacional de Acceso de Internet» defendido por la bancada evangélica y por líderes religiosos políticos en el Congreso brasileño, quienes argumentan que la preocupación por la protección de niños y adolescentes viene ganando apoyo de parte de la población en Brasil.

Este artículo analizó cuantitativamente, por medio de un análisis de contenido de base interpretativa, la mayor incidencia (frecuencia) de palabras claves proferidas por discursos verbales y escritos sobre estos proyectos de Ley que amenazan puntos importantes del «Marco Civil de Internet». En comparación con los textos analizados del proyecto de Ley, se puede contrastar con los puntos críticos que el Comité Gestor de Internet do Brasil posicionó en 2016 en nota oficial. Se percibió que palabras como "adolescente", "niño" y "acceso" pueden confundirse con "control" de manera connotativa o incluso denotativa. Como futuras líneas de investigación, la presente investigación ha identificado que merece ser ampliado para un análisis cualitativo más aproximado en eventos futuros y concluye que el actual proyecto que tramita en el Poder Legislativo brasileño puede intensificar el uso de informaciones de los ciudadanos, datos de navegabilidad e histórico de las actividades mapeadas a través del registro, provocando una amenaza directa a los derechos de los usuarios.

\section{Referencias}

Boréus, K. \& Bergström, G. (2017). Content Analysis. En Bergström, Göran \& Boréus, Kristina (Eds.), Analyzing text and discourse: Eight approaches for the Social Sciences. London: Sage Publications.

Castells, M. (2005). A Sociedade em Rede ( $8^{\underline{a}}$ ed). São Bernardo do Campo: Paz e Terra. (2008). O Poder da identidade (6 $6^{\mathbf{a}}$ ed). São Paulo: Paz e Terra.

Cleland, S. \& Brodsky, I. (2012). Busque e destrua: por que você não pode confiar no Google Inc. São Paulo: Matrix. 
Dovring, K. (2009). Quantitative Semantics in 18th Century Sweden. En K. Krippendorff \& M.A. Bock (Eds.), The Content Analysis Reader. London: Sage.

Gorz, A. (2005). O imaterial: conhecimento, valor e capital. São Paulo: Annablume.

Kerr, O. S. (2014). The Fourth Amendment and the Global Internet. GWU Law School Public Law Research Paper No. 2014-30; GWU Legal Studies Research Paper No. 2014-30. Disponible en SSRN: https://ssrn.com/abstract $=2428042$

Marco Civil da Internet (2014). Câmara dos Deputados, Brasil. Brasilia: Edições Câmara. McMillan, S.J. (2009). The Challegen of applying Content Analysis to the WorldWide Web. En K. Krippendorff \& M.A. Bock (Eds.), The Content Analysis Reader. London: Sage.

Murdoch, S. J. \& Roberts, H. (2013). Internet Censorship and Control. IEEE Internet Computing, 17(3), 6-9. http://dx.doi.org/10.1109/mic.2013.51

O'Connell, M. (1999). Is Irish public opinion towards crime distorted by media bias? European Journal of Communication, 14(2), 191-212.

Pierucci, A. (2003). O desencantamento do mundo: todos os passos do conceito em Max Weber. São Paulo: Editora 34.

Puyosa, I. (2015). Control politico de internet en el contexto de un régimen híbrido. Venezuela 2007-2015. Teknokultura, 12(3), 501-526. http://dx.doi. org/10.5209/rev_tk.2015.v12.n3.50392.

Schreier, M. (2014). Qualitative Content Analysis? En U. Flick (Eds.), The Sage Handbook of Qualitative Data Analysis. London: Sage.

Silverstone, R. (2005). Por que estudar a mídia? (2ª ed). São Paulo: Edições Loyola. 
Retos, $n^{\circ} \mid 4$, vol.VIII, 2017

\title{
Nivel de uso de las redes sociales en el proceso de comunicación en las MIPES de Cuenca
}

\section{Level of use of social networks in the communication process in the micro and small sized enterprises of Cuenca}

Efrén Aucay Piedra es ingeniero commercial por la Universidad Politécnica Salesiana (Ecuador) (iaucay@est.ups.edu.ec) (http://orcid.org/0000-0003-3617-5235)

Priscilla Herrera Torres es profesora/investigadora de la Universidad Politécnica Salesiana (Ecuador) (dherrerat@ups.edu.ec) (http://orcid.org/0000-0002-0693-2621)

\begin{abstract}
Resumen
La investigación se desarrolló en Cuenca, tercera ciudad más importante del Ecuador, cuyo objetivo principal se enfocó en analizar el nivel de uso, así como la administración de redes sociales y aplicaciones móviles en los procesos de comunicación y mercadotecnia en las Micro y Pequeñas Empresas (MIPES). Debido a que la globalización del internet ha hecho que las empresas deban adaptarse a entornos cada vez más complejos y competitivos, creando estrategias de valor para llegar a satisfacer a un nuevo estilo de demandantes, que influenciados por publicaciones en diferentes medios virtuales, están cada vez más informados, lo que repercute en una sociedad más exigente de confort. La investigación es de tipo cuantitativa, la muestra se tomó de las Micro y Pequeñas empresas de la ciudad. Para la recolección de información se implementó una encuesta, instrumento que fue aplicado a los establecimientos seleccionados. Los constructos de medición se validaron mediante el uso del alfa de Cronbach. Los resultados obtenidos demuestran un bajo nivel de adopción de redes sociales en la microempresa y un nivel medio en la pequeña empresa. Adicionalmente, se observa que en los establecimientos que utilizan las redes sociales y las aplicaciones móviles para actividades de comunicación y mercadotecnia, éstas no se explotan en su totalidad por múltiples factores como: desconocimiento en el uso y administración, no lo consideran necesario, falta de confianza y credibilidad entre otros aspectos.
\end{abstract}

\begin{abstract}
The research was carried out in Cuenca, the third most important city of Ecuador. Its main objective is to analyze the level of use, the administration of social networks and mobile applications, in the communication and marketing processes in Micro and Small sized enterprises (MIPES). Due to the globalization of the Internet, it has meant that companies have to adapt to increasingly complex and competitive environments, creating value strategies to meet a new style of demanders, influenced by publications in different virtual media. Consumers are increasingly informed, and it has repercussions in a more demanding society of comfort. It is a quantitative research, and the sample was taken from the Micro and Small enterprises of the city. For the collection of information, a survey was implemented. Then, an instrument was applied to selected establishments. The measurement constructs were validated using the Cronbach's alpha. The results show a low level of adoption of social networks in the microenterprise and a medium level in the small company. Additionally, it has been observed that establishments that use social networks and mobile applications for communication and marketing activities, it is not fully exploited, due to many factors such as: the lack of knowledge about the use and administration of social networks, it is deemed necessary, and the lack of trust and credibility among others.
\end{abstract}

\section{Palabras clave | keywords}

Redes sociales, aplicaciones móviles, comunicación, marketing, microempresas y pequeña empresas. Social networks, mobile apps, communication, marketing, micro and small sized enterprises. 


\section{Introducción}

Las empresas del siglo XXI siguen transformándose por la globalización del internet y el crecimiento vertiginoso de las redes sociales y aplicaciones móviles, hecho que ha ocasionado cambios en los ámbitos interno y externo de las empresas, las mismas que deben adaptarse a entornos que cada día son más complejos y competitivos, donde los administradores deben poseer habilidad y experticia para crear estrategias de valor y para llegar a satisfacer a un nuevo estilo de demandantes, que influenciados por las publicaciones presentadas a través de los diferentes medios virtuales, están cada vez más informados; lo que repercute en una sociedad más exigente de confort. Las redes sociales y aplicaciones móviles han llegado para quedarse y constituirse en un aliado clave para la gestión empresarial en los campos de comunicación y mercadotecnia. Por tal razón amerita investigar el papel que desempeñan las redes sociales y aplicaciones móviles, empleadas en actividades de comunicación y mercadotecnia en las MIPES de la ciudad de Cuenca, en ámbitos de cobertura, nivel de uso, administración y aspectos de percepción.

\subsection{Las Micro y Pequeñas Empresas (MIPES)}

Las Micro y Pequeñas Empresas (MIPES) son establecimientos que tienen ciertas características en común a nivel mundial, pero existen algunas particularidades a nivel de cada territorio. Como se citó en Tobar (2015, p.81) "La Unión Europea clasifica como microempresa a toda unidad económica con menos de diez trabajadores, así como aquellas que tienen un nivel de ventas anuales menor a dos millones de euros". En Chile, de acuerdo a Dini y Stumpo se clasifican como "microempresas aquellas unidades productivas que ocupan entre 1 y 4 personas, y pequeñas empresas a las que ocupan entre 5 y 49 personas" (2002, p.10).

En Ecuador, según el directorio de empresas y establecimientos (INEC, 2014), se clasifica a las MIPES por el personal laboral empleado y nivel de ingresos anuales, denominando como microempresas aquellos establecimientos que tienen de 1 a 9 empleados y ventas anuales menores o igual a $\$ 100000$. En cuanto a las pequeñas empresas, por tener de $10 \mathrm{a}$ 49 empleados e ingresos por ventas anuales de \$100001 a un 1000000 . Por otra parte, la naturaleza y razón de ser de las MIPES es de carácter sencilla y autónoma, acorde con Anzola es por "la necesidad de las personas de ser independientes en el aspecto laboral y económico" (2010a, p.14). 
En este sentido las MIPES desde sus inicios han sido creadas y administradas en su mayoría por sus propietarios, personas innovadoras y creativas que aportan al crecimiento económico y al desarrollo de los pueblos, llegando a constituirse en los negocios más representativos en América Latina. Según Anzola (op. cit) "la pequeña empresa junto con la micro empresa representan el 95\% de los negocios en América Latina" (2010b, p.17). Sin embargo, la globalización del internet se ha convertido en un desafío para algunos establecimientos. Según Liberona y Ruiz (2013, p.152) "se está desarrollando una red cada vez más compleja de relaciones de conocimiento dentro y fuera de las fronteras organizacionales". No obstante, internet y la telefonía móvil, según Muñiz y O’Guinn como se citó en Casaló, Flavián \& Guinalíu (2012, p.43) "ha permitido la constante evolución de las redes sociales gracias a la posibilidad que ofrecen dichos canales para unir individuos que se encuentran geográficamente dispersos pero que tienen un interés común".

El internet y la telefonía móvil han permitido el surgimiento y proliferación de las redes sociales y aplicaciones móviles, los mismos que están al alcance de los individuos y las empresas; medios que sirven para la gestión de las relaciones con todos los involucrados en algún tema de interés en común, que acorde a Mitchell como se citó en Lozares (s/f, p.108) "pueden definirse como un conjunto bien delimitado de actores -individuos, grupos, organizaciones, comunidades, sociedades globales, etc.- vinculados unos a otros a través de una relación o un conjunto de relaciones sociales". En este mismo sentido, las redes sociales nos permiten estar a seis pasos de interactuar con las personas a nivel global, siguiendo a González (2014, p. 279) quien indica que "todos estamos conectados con cualquier otra persona del planeta a través de una cadena de conocidos, que no tiene más de cinco intermediarios".

En el ámbito comunicativo en las empresas las redes sociales y aplicaciones móviles, según Richard y Chandra como se citó en Bigné, Küster y Hernández (2013, pp. 9-10) han:

(...) provocado profundos cambios en la forma en que las empresas se contactan con sus clientes posibilitando, por una parte, una comunicación selectiva y una posición más activa del receptor dando al consumidor un mayor poder sobre el proceso de comunicación en comparación con los medios tradicionales y, por otra parte, facilitando el modo en que los consumidores y usuarios se relacionan entre sí. 
En este sentido las redes sociales y las aplicaciones móviles en las empresas están "intentando tratar de ser otro contacto con los que frecuentemente mantienen una relación, permitiendo así esta comunicación bidireccional" (Romero, Alarcón y Gómez, 2011, p. 201). Ante estos aspectos, los servicios de las redes sociales y aplicaciones móviles en la esfera de la comunicación, de acuerdo a Barker, Barker, Bormann y Niher "simplifican el proceso de intercambio de información" (2015, p.178). Los mismos que son necesarios para una comunicación efectiva, que acorde a Garrido la empresa en estos tiempos "requiere una gestión de comunicación eficiente, rentable y sin detalles dejados al azar" (2004, p. 22). En este mismo orden de ideas Lam, Hair y McDaniel explican que "las empresas están interesadas en la comunicación en línea porque goza de enorme popularidad" (2014, p. 308). No obstante

las PYMES tienen muchos problemas para administrar los escasos recursos de comunicación que tienen para sus empresas, ya sea porque gastan en campañas que no son las adecuadas o porque van dirigidas no siempre al público apropiado desperdiciando tiempo y dinero (Hoyos y Lasso, 2017, p. 67).

En el campo de la mercadotecnia, las redes sociales se presentan como un pilar fundamental para brindar información de campañas publicitarias y promocionales. Según Barker (2015) en su misma publicación manifiesta que las redes sociales pueden ser una alternativa para localizar clientes potenciales y hacer llegar alguna promoción. Estos medios facilitan el marketing social, acorde a Laudon y Guercio "El marketing social implica el uso de las redes sociales y comunidades en línea para construir marcas y aumentar los ingresos por ventas" (2014, p.175).

En este mismo contexto, aparece el término marketing móvil, que consiste en:

(...) el uso de los smartphones, también llamados teléfonos inteligentes, que no solo han cambiado nuestra vida, más en contacto con la tecnología, sino también la forma en que consumimos contenidos y accedemos a la información. De este modo ha surgido una nueva forma de entender el marketing, basada en el uso de los teléfonos móviles para transmitir mensajes, servicios e ideas promocionales... a pesar de ser una disciplina joven se diferencia del marketing tradicional en disponer una mayor variedad de medios o herramientas para llegar a los usuarios (Estrade et al., 2013, p. 37). 
Sin embargo existen dificultades para medir las actividades de mercadotecnia dirigidas a través de las redes sociales digitales (RSD), según Clemons como se citó en Uribe, Rialp y Llonch (2013, p. 208) "hay un consenso entre los profesionales del marketing en que existe un problema complejo a la hora de medir y monetizar las actividades de marketing en las RSD".

Las redes sociales y las aplicaciones móviles se están constituyendo con rapidez en una herramienta para compartir ideas, entre todos los stakeholders en el ámbito corporativo; además "es una importante ventaja competitiva no solo en términos de nuevos mercados, sino en términos de Know-How" (González, 2014, p. 52). Así, el uso y administración de las redes sociales y aplicaciones móviles en las empresas comienza por el alto nivel de acogida de estos por la sociedad en general, creciendo a un ritmo constante desde el año 2005 (Barker, 2015), sin ningún indicio de disminución.

En este escenario las redes sociales para la empresa según la conectividad, acorde a Ureña y Valenzuela "representan potenciales repositorios de información” (2011, pp. 131, 132). Ante estas circunstancias, los negocios están expuestos a este nuevo sistema de comunicación, pues según Valls (2016, p. 24), la empresa "requiere de estrategias comunicativas nuevas que aprecien estos cambios sociales, se adapten al nuevo entorno y le den más importancia a la comunicación”, aunque es preciso hacer hincapié en los diferentes tipos de redes sociales que tienen mayor impacto en las empresas y la sociedad, las mismas que se ilustran en la tabla 1, incluyendo el criterio de algunos autores al respecto.

Tabla 1. Tipos de redes sociales

\begin{tabular}{|l|l|l|}
\hline Red social & \multicolumn{1}{|c}{ Tipo de red social } & \multicolumn{1}{c|}{ Al respecto los autores expresan: } \\
\hline Facebook & $\begin{array}{l}\text { Red social generalista; Puesto } \\
\text { que albergan a todo tipo de } \\
\text { personas y admite todo tipo de } \\
\text { contenido (Martos, 2010, p.73) }\end{array}$ & $\begin{array}{l}\text { "Las páginas profesionales de } \\
\text { Facebook páginas de fans o fan page } \\
\text { permite a las empresas y profesionales } \\
\text { tener una presencia en Facebook que } \\
\text { es visible, no solo por los usuarios de } \\
\text { Facebook, sino por cualquier usuario } \\
\text { de internet" (Carballar, 2012, p. 93) }\end{array}$ \\
\hline YouTube & $\begin{array}{l}\text { Es una red social de contenidos, } \\
\text { donde el principal factor es el } \\
\text { material que en esa red se com- } \\
\text { parte (Junta de castilla y León, } \\
\text { 2012, p.8) }\end{array}$ & $\begin{array}{l}\text { "Utilizar YouTube en las estrategia } \\
\text { de redes sociales de su empresa, } \\
\text { le permite diferenciarse de sus } \\
\text { competencia" (Mejía, 2013a, p.142) }\end{array}$ \\
\hline
\end{tabular}




\begin{tabular}{|c|c|c|}
\hline Red social & Tipo de red social & Al respecto los autores expresan: \\
\hline Twitter & $\begin{array}{l}\text { Es una red social con un servicio } \\
\text { de microblogging gratuito que } \\
\text { permite a los usuarios enviar y } \\
\text { compartir entradas cortas, de- } \\
\text { nominadas "tweets", no mayores } \\
\text { de } 140 \text { caracteres. (Medina y } \\
\text { Montjoy, } 2015, \text { p. 8) }\end{array}$ & $\begin{array}{l}\text { "Esta red social se ha convertido en } \\
\text { un medio social de interés para que } \\
\text { las empresas puedan comunicar } \\
\text { determinadas ofertas, resolver las } \\
\text { dudas..." (Gómez \& Suárez, 2012a, } \\
\text { p.195) }\end{array}$ \\
\hline Linkedln & $\begin{array}{l}\text { Es una red social profesional } \\
\text { (Hütt, 2012, p.123) }\end{array}$ & $\begin{array}{l}\text { Linkedln, "se ha convertido en un } \\
\text { soporte especialmente atractivo } \\
\text { para la inclusión de anuncios y } \\
\text { mensajes publicitarios que se } \\
\text { pueden dirigir a un público objetivo } \\
\text { muy bien definido" (Gómez \& } \\
\text { Suárez, 2012b, p. 200) }\end{array}$ \\
\hline Instagram & $\begin{array}{l}\text { Es una red social basada en } \\
\text { compartir elementos multime- } \\
\text { dia (Estrade, Soro \& Hernán- } \\
\text { dez, 2013, p.131) }\end{array}$ & $\begin{array}{l}\text { En Instagram, “Las imágenes para } \\
\text { compartir se pueden modificar a } \\
\text { través de una serie de filtros que se } \\
\text { han ido sofisticando a lo largo de } \\
\text { las sucesivas versiones del progra- } \\
\text { ma" (Mejía, 2013d, p.152) }\end{array}$ \\
\hline
\end{tabular}

En este contexto es preciso destacar que Facebook en el Ecuador "cuenta con una audiencia de 8900000 de usuarios, de los cuales 1400000 son administradores de páginas Facebook, muchas de las cuales pertenecen a marcas, emprendimientos" (Formación gerencial, 2015). Por otro lado en relación a las aplicaciones móviles, Barker et al. (2015b, p. 263) manifiestan que "la mayoría de las personas tienen dispositivos móviles a la mano, de modo que están conectadas a las redes sociales las 24 horas al día los siete días a la semana". En palabras de Estrade et al. (2013, p. 129):

(...) las redes sociales y los dispositivos móviles de última generación han establecido una interesante relación de simbiosis. Unos (las redes sociales) han ofrecido un medio que permite a las personas comunicarse de una forma más efectiva, hasta el punto de que compartir información con otra persona mediante tu móvil se puede convertir en una experiencia placentera. Los otros los dispositivos móviles son el aquí y ahora la posibilidad de poder interactuar con tu comunidad virtual.

Asimismo se hace referencia a los servicios ofrecidos tanto de datos como de voz en el mismo dispositivo. De acuerdo a Laudon (2012, p. 264): 
la mensajería instantánea es un tipo de servicio de chat que permite a los participantes crear sus propios canales privados. El sistema de mensajería instantánea alerta al usuario cada vez que alguien en su lista privada está en línea, de modo que pueda iniciar una sesión de chat con otros individuos. Algunos de los sistemas de mensajería instantánea para los consumidores son Yahoo!, Messenger, Google Talk, Windows live Messenger.

Las aplicaciones móviles nativas para los dispositivos "deben ser descargadas de una tienda de aplicaciones (App Store de Apple, Google Play de Android, Windows Mobile Marketplace para Windows Phone, etc." (Estrade et al., 2013, p. 92). En este contexto y haciendo hincapié en los dispositivos móviles en Ecuador, según Espinoza como se citó en Rosero \& Montalvo (2015), uno de los mercados que crece dinámicamente son los de los smartphones, que hasta octubre de 2014 superaron los 18 millones en ventas, donde 3 de cada 5 son teléfonos inteligentes. De acuerdo con estos planteamientos, las redes sociales y aplicaciones móviles son cada vez más amplias y versátiles, las mismas que están al alcance de todo tipo de empresa, independientemente del sector económico e industria a la que pertenezca.

En tal virtud en la empresa el "conocimiento existente tiene que aplicarse y el nuevo debe generarse para satisfacer las necesidades de los clientes internos y externos" (Jiménez, 2011, p.175). Las redes sociales y aplicaciones móviles, son un aliado clave, a la vez que una ventana hacia la eficiencia. Si los esfuerzos de administración son dirigidos a la audiencia indicada y el momento oportuno, se puede lograr ubicar las MIPES en una mejor posición competitiva en el mercado. De acuerdo con Moyano, Bruque \& Eisenberg (2007, p.162) "las organizaciones deberían considerar a las redes sociales como otro activo empresarial más, o como una dimensión de capital humano que merece atención".

Por último, es necesario hacer referencia a la cifra de MIPES en Ecuador. De acuerdo al directorio de empresas y establecimientos (INEC, 2014) el país registra 843644 empresas, de las cuales el 97\% de los establecimientos están dentro de las categorías MIPES. En concordancia con esta información, en las cuatro provincias más pobladas del Ecuador es donde se concentra el $57 \%$ de empresas, a saber: en la provincia de Pichincha se asientan el 23\% de establecimientos, en Guayas el 19\%, en Manabí el 8,3\% y en la provincia del Azuay el 5,8\%. 
En la ciudad de Cuenca, capital de la provincia del Azuay y tercera ciudad más importante del país -objeto del presente análisis-, es donde se enfoca la investigación, de acuerdo a la información proporcionada por el Ministerio de Industrias y Productividad (MIPRO). El 96\% de establecimientos están categorizados como MIPES.

En base a esta información se demuestra que son negocios altamente representativos de la ciudad ut supra reseñada. No obstante, según Elizalde y Morocho (2014, p. 45) "las PYMES cuencanas no dan el suficiente valor e importancia a las redes sociales, por desconocimiento de uso de las mismas o por desconfianza de efectividad".

De acuerdo con estos planteamientos, se formulan las variables de estudio, partiendo por examinar la situación actual de las empresas en relación a: i) nivel de uso; ii) gestión; iii) conocimiento para administrar las redes sociales y aplicaciones móviles enfocadas en la comunicación y marketing. Asimismo, la presente investigación busca determinar el nivel de presencia de las redes sociales en las estrategias de comunicación, promoción y publicidad.

\section{Metodología}

Esta investigación tiene un enfoque cuantitativo. La población comprendida para el estudio fueron las MIPES de la ciudad de Cuenca (Ecuador). Para el efecto se implementó una encuesta con 28 preguntas, la misma que fue dirigida a los encargados del manejo de las TIC, o las personas responsables de la comunicación de marketing de las MIPES.

Este instrumento sirvió para obtener la información de 133 Microempresas y 42 Pequeñas empresas. La investigación abarca a todas las áreas de economía de las MIPES, a través de una estratificación a conveniencia.

Para determinar el tamaño de la muestra se calculó con un nivel de confianza del $95 \%$ para las dos categorías de empresa y un margen de error de $+/-5 \%$ para la Microempresa y $+/-6 \%$ para la Pequeña empresa. Fue utilizado para el procesamiento de datos el programa estadístico IBM SPSS® (Statistical Package for the Social Sciences). El análisis de los resultados tiene una base descriptiva; mientras que los constructos de medición están validados mediante el uso del Alfa de Cronbach resultante de 0,730. Siguiendo a Peterson como se citó en Uribe, Rialp \& Llonch (2013, p. 215) "un valor menor que 0.7 demuestra una baja 
consistencia interna de la escala" por lo que los resultados obtenidos son satisfactorios.

Para determinar el nivel de uso se realizó mediante un escala ordinal y de intervalos que según Romero, Rébori y Camino en la escala "ordinal, se agrega la noción de orden (las categorías poseen un orden que conlleva a la posibilidad de ordenar los datos) y en el intervalar, se agrega la posibilidad de cuantificar distancias entre diferentes categorías o valores de la variable" (2010, p.19). En concordancia con este planteamiento, se determinaron cinco niveles de uso; se asignó un nivel de 0 a 20 como muy bajo, de 21 a 40 nivel bajo, de 41 a 60 como nivel medio, de 61 a 80 nivel alto y de 81 a 100 como un nivel muy alto.

\section{Resultados}

Los resultados de la investigación, una vez realizado el respectivo proceso para la obtención de información, se presentan en dos partes. La primera, correspondiente a las microempresas y la segunda, una comparación entre microempresas y pequeñas empresas. A continuación en el gráfico 1 se presentan los resultados del nivel de uso de las redes sociales y aplicaciones móviles en la microempresa en comparación con la pequeña empresa.

\section{Gráfico 1. Nivel de uso de las redes sociales y aplicaciones móviles}

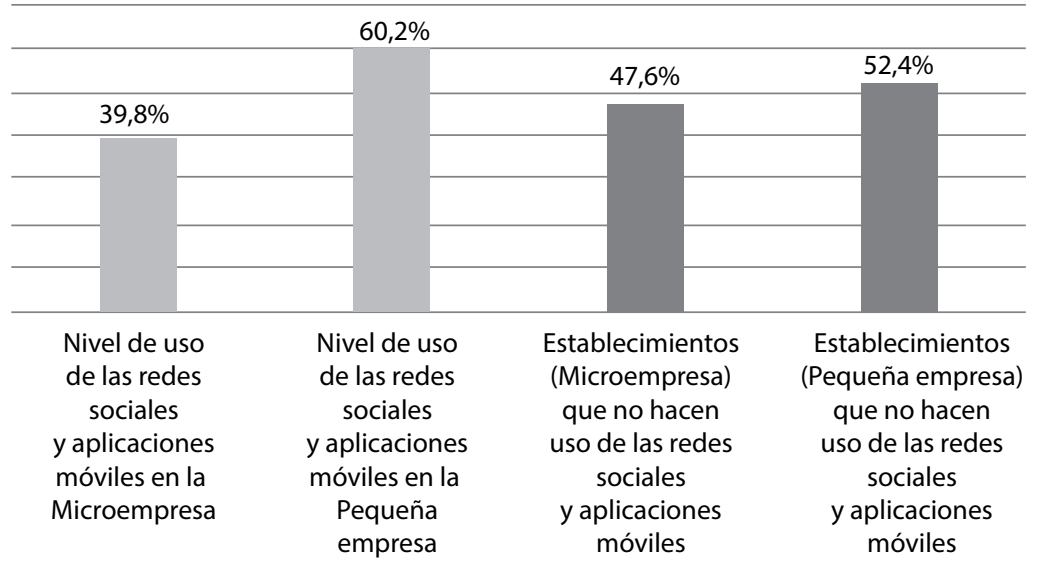




\subsection{Estudio de la microempresa}

Ámbito de cobertura

En las Microempresas, el $83 \%$ de estos establecimientos tienen acceso internet, de los cuales un $70 \%$ señala que la calidad del servicio de internet está entre buena y muy buena. La conexión a la red tiene mayor acogida a través computadoras portátiles y smartphones. En la Microempresa, solo el 39,8\% tiene una cuenta corporativa en redes sociales, en el siguiente gráfico (2) se observan las diferentes redes sociales utilizadas, liderando Facebook con una amplia mayoría de 58\%.

Gráfico 2. Redes sociales y aplicaciones móviles

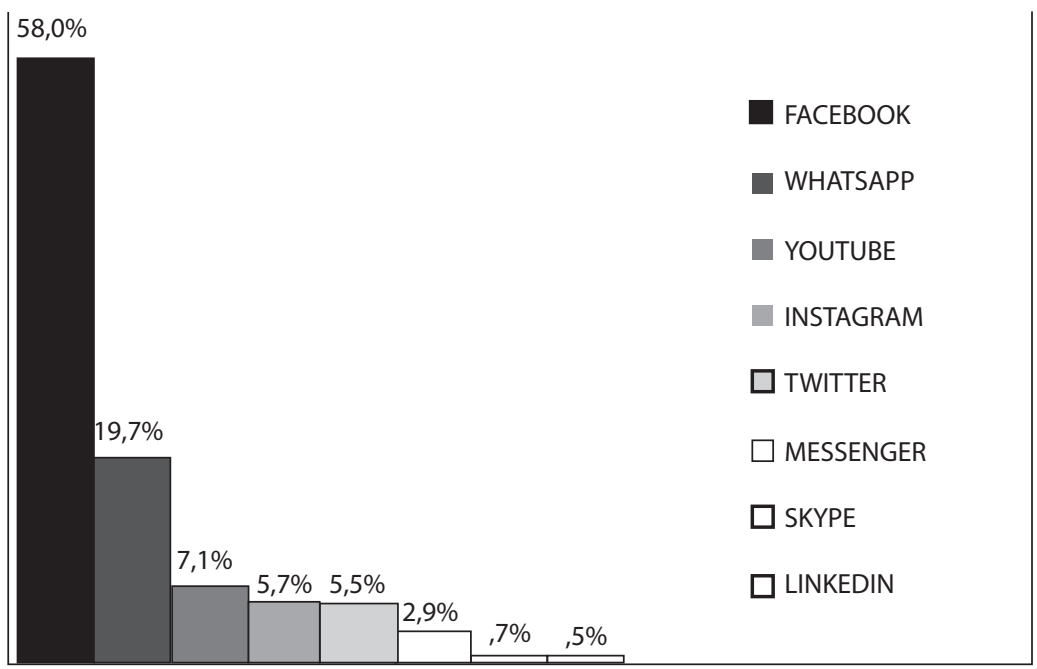

El 60,2\% de establecimientos no hacen uso de las redes sociales. Tras evaluar las razones aducidas, se han tipificado los siguientes aspectos, los mismos que se ilustran en el gráfico 3, demostrando que las principales razones son por: a) Falta de conocimiento en el uso y administración, b) No lo considera necesario, c) Falta de confianza y credibilidad. 
Gráfico 3. Microempresas y las redes sociales

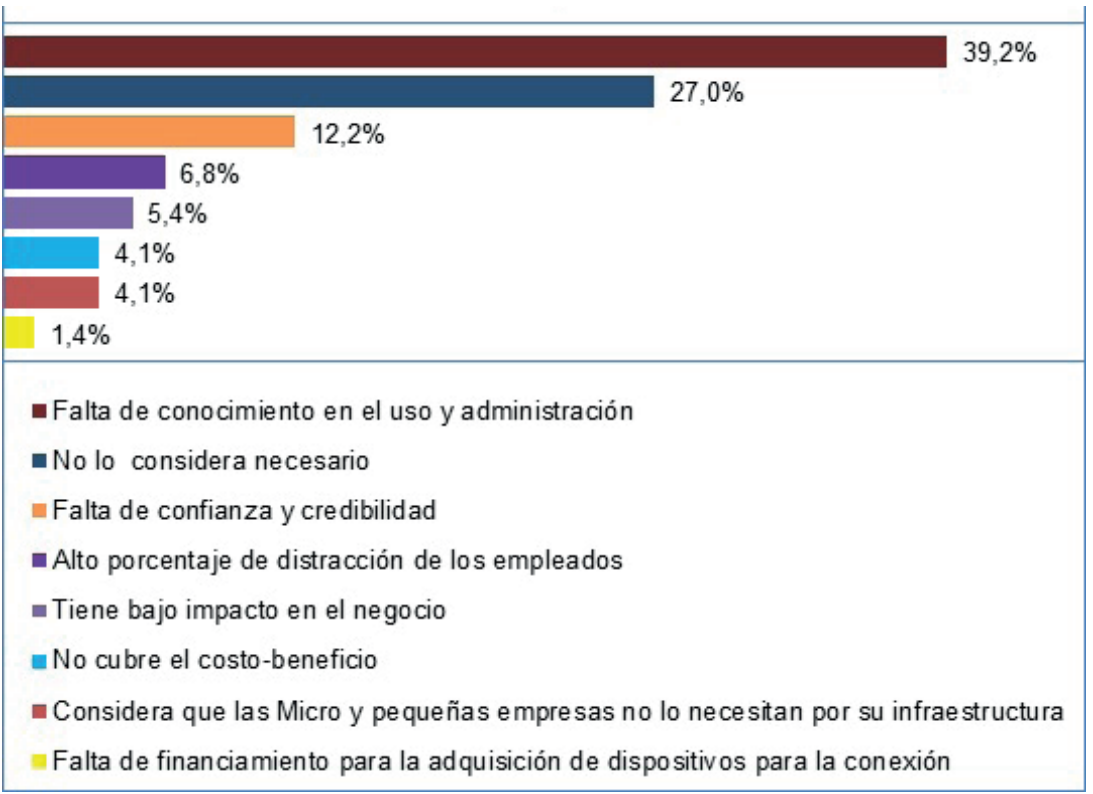

Ámbito de uso y administración

Los resultados proporcionados en este ámbito son de los establecimientos que hacen uso de las redes sociales a través de una o más cuentas corporativas. En concordancia con esto, se demuestra que el 97\% de estos establecimientos utilizan las redes sociales de forma diaria para actividades de comunicación. El 37\% publica y promociona de forma mensual en estos medios, mientras que los demás establecimientos lo hacen en diferentes fechas y ocasiones del año.

Para la gestión de estas actividades, el 38\% de estos establecimientos están conectados a estas redes más de tres horas al día, un 30\% está entre 1 y 3 horas al día y los demás lo consideran menos de una hora al día. En este sentido los usuarios manifestaron mayoritariamente tener un nivel de confianza y credibilidad entre medio y alto en las redes sociales para actividades de comunicación y marketing; los mismos que son utilizados para la consecución de los diferentes fines organizacionales. Ante esto en la tabla 2 se ilustra la relación entre el uso y los objetivos que buscan las organizaciones a través de las redes sociales. 
Tabla 2. Redes sociales y aplicaciones móviles

\begin{tabular}{|c|c|c|c|c|c|}
\hline \multicolumn{6}{|c|}{$\begin{array}{l}\text { Nivel de distribución de las redes sociales } \\
\text { y aplicaciones móviles acorde a los objetivos empresariales }\end{array}$} \\
\hline \multicolumn{3}{|c|}{ Brindar información } & \multicolumn{3}{|c|}{ Mejorar la imagen de la empresa } \\
\hline & Facebook & $74 \%$ & & Facebook & $64 \%$ \\
\hline & Twitter & $11 \%$ & & Twitter & $20 \%$ \\
\hline (0) & Instagram & $9 \%$ & & Instagram & $16 \%$ \\
\hline & WhatsApp & $4 \%$ & \multicolumn{3}{|c|}{ Promociones y acciones publicitarias } \\
\hline & Messenger & $4 \%$ & & Facebook & $90 \%$ \\
\hline \multicolumn{3}{|c|}{ Comunicación con todos los stakeholders } & & Instagram & $10 \%$ \\
\hline & WhatsApp & $81 \%$ & \multicolumn{3}{|c|}{ Para seguimiento post-venta } \\
\hline & Facebook & $11 \%$ & & Facebook & $55 \%$ \\
\hline & Messenger & $6 \%$ & & WhatsApp & $39 \%$ \\
\hline$\alpha$ & Skype & $2 \%$ & & Messenger & $6 \%$ \\
\hline
\end{tabular}

Ante lo expuesto en la tabla 2, se recalca que existen otros objetivos de uso como: i) observar a la competencia; ii) formación; iii) captar talentos; iv) recoger opiniones y sugerencias; sin embargo para estos objetivos, se hace uso en menor medida las redes sociales y aplicaciones móviles. En este mismo apartado es preciso reiterar que el $83 \%$ de los establecimientos manifiesta como indispensable el uso del chat para envio de archivos, tanto de datos como de voz, actividad que se realiza con todos los stakeholders, destacándose la interacción con el cliente (CRM). Con el interés de conocer la efectividad de la comunicación y el marketing a través de las redes sociales, se realizó una comparación con los medios convencionales, en donde el 79\% de los establecimien- 
tos que hacen uso de las redes sociales y aplicaciones móviles manifestaron que las acciones de comunicación son más efectivas en estos medios, mientras que para acciones de mercadotecnia, el $73 \%$ de encuestados afirman que son efectivos las redes sociales para esta actividad; la diferencia proporcional a cada acción respectivamente indicaron que son efectivos los medios convencionales para estas acciones (comunicación y mercadotecnia).

Por otro lado, en el ámbito administrativo, el 49\% de los directivos o dueños realizan un análisis previo a la implementación de las redes sociales, con el objetivo de identificar los riesgos y beneficios proporcionados por estos medios para los establecimientos, de los cuales el $45 \%$ asegura contar con un community manager, persona que se encarga de administrar el material dirigido a la red. Para este efecto solo el 21\% tiene un plan de capacitación continua para el talento humano de esta área.

En este escenario el $40 \%$ de establecimientos realiza un seguimiento del impacto como estadísticas, conteo de likes, administración de comentarios de las actividades realizadas en la red, el 36\% utiliza Fanpage para acciones de marketing y el $40 \%$ mide el retorno de la inversión de las acciones publicitarias realizadas en las redes sociales.

En aspectos de prevención, tan solo el 11\% tiene un manual o plan para evitar fuga de información a través de estos medios, por lo tanto hay una debilidad bastante evidente en temas de prevención. Por otra parte en aspectos de percepción el $93 \%$ piensa que puede llegar directamente al consumidor final con sus productos/servicios y el $32 \%$ piensa que puede aparecer en las tiendas online con la ayuda de las redes sociales.

En este apartado las Microempresas revelan las ventajas obtenidas por el uso y administración de las redes sociales y aplicaciones móviles en la gestión empresarial en el campo comunicación y de mercadotecnia, las mismas que se observan en el gráfico 4 , resaltando la rapidez en comunicación y difusión de información en $22 \%$.

En este mismo aspecto, la información obtenida a través de estos medios se asegura útil para la toma decisiones, las mismas que contribuyen a mejorar aspectos que carecen de una gestión efectiva o situaciones que desde el punto de vista del cliente no llegan a satisfacer las expectativas esperadas. 


\section{Gráfico 4. Uso y administración de redes sociales y aplicaciones móviles}

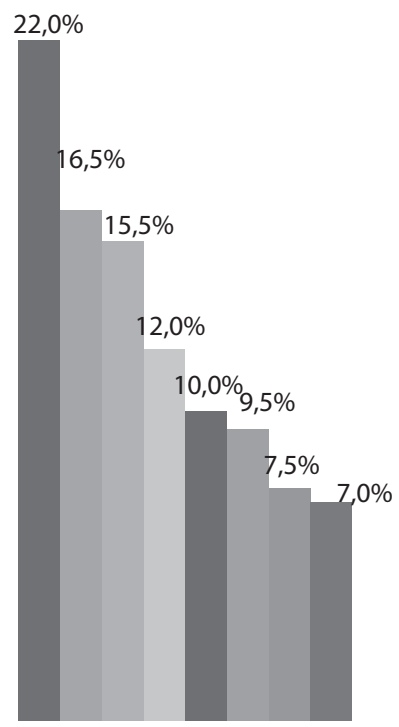

Mayor rapidez en comunicación y difusión de información

Costos bajos de comunicación

Costos bajos en promoción y publicidad

Mayor eficiencia en el servicio

Ser una empresa más competitiva

Aumentar las ventas

Mayor productividad de los colaboradores

Fidelizar al cliente

Por su parte, el 51\% asegura que las redes ayudan a mejorar el servicio, el $31 \%$ opina que mejora la imagen corporativa y el resto (18\%) mejora el producto. Asimismo los encuestados consideran que como se obtienen ventajas por el uso y administración de las redes sociales y aplicaciones móviles, también existen desventajas: El 55\% de los dueños de establecimientos que hacen uso de estos medios manifiestan que es la distracción de los colaboradores, un 26\% piensan que le inspira desconfianza al cliente, mientras que el restante manifiesta que no confían en estos medios.

\subsection{Microempresas vs Pequeña Empresa}

La Pequeña Empresa tiene similitudes muy cercanas con la Microempresa en el uso de las redes sociales y aplicaciones móviles en los campos de comunicación y mercadotecnia, destacando que el tamaño de los establecimientos no influye en mayor proporción en estas áreas de investigación; salvo en algunos aspectos específicos difieren, pero en ninguno de los ámbitos es mayor al 10\%. A conti- 
nuación se puntualizan estas diferencias existentes en los ámbitos de cobertura, uso y administración:

- En el ámbito de cobertura, el 9,9\% más de establecimientos de la pequeña empresa tiene acceso a internet en relación con la microempresa. La acogida por las redes sociales, es mayor en 7,8\% en correspondencia con la microempresa. No obstante existe un nivel bajo en la microempresa y medio en la pequeña empresa en adopción de redes sociales.

- En el ámbito de uso, se ve una disminución en la pequeña empresa de 7,5\% en la utilización diaria de las redes sociales y aplicaciones móviles para actividades de comunicación. Sin embargo, la administración es mayor en la pequeña empresa. Una de las razones es que existe más talento humano contratado para esta área. En relación con la Microempresa difieren en 10 puntos porcentuales, lo que repercute en un ligero aumento en la administración de estos medios, reflejando una mejor gestión de herramientas y páginas como Fanpages. Además se observa un ligero incremento en el manejo de análisis estadísticos, monitoreo y administración de comentarios por acciones de comunicación y mercadotecnia realizados en las redes sociales.

\section{Conclusiones}

La Microempresa y la Pequeña Empresa (MIPES) de Cuenca, si bien es cierto son negocios representativos en la ciudad, alrededor del $90 \%$ de estos establecimientos tienen acceso a internet y dispositivos tecnológicos para sus operaciones. No obstante, según los resultados obtenidos, el nivel de adopción de las redes sociales de acuerdo a la escala establecida es bajo para la microempresa y medio para la pequeña empresa. Las principales razones por las cuales los establecimientos no utilizan estos medios es por: a) Falta desconocimiento en el uso y administración, b) No lo consideran necesario, y c) Falta de confianza y credibilidad entre otros aspectos considerados en menor proporción.

Los establecimientos que hacen uso de las redes sociales y aplicaciones móviles han conseguido, en términos generales, que la relación entre el uso y objetivos propuestos como: comunicación, publicidad, promoción, mejora de la imagen de la empresa, entre otros fines; se logren alcanzar por las organizaciones, resaltando beneficios encontra- 
dos como: Mayor rapidez en la comunicación y difusión de información, mayor eficiencia en el servicio, costos más bajos en comunicación, promoción y publicidad. En cuanto a las acciones publicitarias, el 73\% de estos establecimientos indica que son efectivas las redes sociales para estos fines. Además, en este aspecto, se demuestra que el 90\% de estas actividades se realizan en Facebook, red social líder en audiencia a escala local, nacional e internacional. Sin embargo, se puede concluir en esta investigación que las redes sociales no son explotadas a toda su potencialidad por los establecimientos que hacen uso de estos medios, debido a que únicamente el $40 \%$ de estos establecimientos realiza un seguimiento de impacto como estadísticas, administración y monitoreo de comentarios, entre otras actividades de auditoría y análisis de las redes sociales. Como futuras líneas de investigación se recomienda plantear un nuevo estudio de la comunicación del marketing interno, tema que aportaría para hacer un análisis comparativo entre los dos aspectos.

\section{Referencias}

Alcazar, J. (01 de febreo de 2016). Estadísticas Facebook Ecuador. Obtenido de Formacón Gerencial: (https://goo.gl/gszxXN)

Anzola, S. (2010). Administración de pequeñas empresas. México: McGraw-Hill/Interamerivada.

Barker, M., Barker, D., Nicholas, B., \& Niher., K. (2015). Marketing para medios sociales. Mexico: Cengage learning.

Bigné, E., Küster, I., \& Hernández, A. (2013). Las redes sociales virtuales y las marcas: Influencia del intercambiode experiencias eC2C sobre la actitud de los usuarios hacia la marca[The social networks sites and the brands. Influence of eC2C exchange experience on brand users' Attitudes. Revista Española de investigación En Marketing ESIC, 17(2). 7-27. doi:https://doi.org/10.1016/S11381442(14)60022-X.

Carballar, J. (2012). Social Media marketing personal y profesional. México: Alfaomega.

Casaló, L., Flavián, C., \& Guinalíu, M. (2012). Redes sociales virtuales desarrolladas por organizaciones empresariales: antecedentes de la intención de participación del consumidor[Firm-hosted online social networks: Antecedents of consumer intention to participate]. Cuadernos de Economía y Dirección de la Empresa, 15(1). 42-51. (http://bibliotecavirtual.ups.edu.ec:2353/10.1016/j. cede.2011.06.003).

Elizalde, M., \& Morocho, M. (2014). Análisis para la elaboración de una guia para el manejo estrátegico de Facebook y Twitter para la pequeña empresa cuencana. (tesis de pregrado).Universidad del Azuay, Cuenca, Ecuador.

Estrade, J., Soro, D., \& Hernández, Á. (2013). Marketing Digital. Madrid: Ediciones Anaya. 
Garrido, F. (2004). Comunicación Estrategica. España: Ediciones Gestión 2000.

Gómez, Á., \& Suárez, C. (2012). Sistemas de información. Madrid: RA-MA Editorial. González, Ó. (2014). Comercio Electrónico 2.0. Madrid: Ediciones Anaya.

Hoyos, A., \& Lasso, M. (2017). Pymes como modelo económico en la creación de estrategias de comunicación [SMEs as an economic model in the creation of communication strategies]. Retos, 7(13), 59-74. doi:http://dx.doi.org/10.17163/ret. n13.2017.04.

Hütt Herrera, H. (2012). Las redes sociales: una nueva herramienta de difusión. Reflexiones, 91(2),121-128. (https://goo.gl/Ofx03c).

INEC. (2014). Directorio de empresas y establecimientos. Obtenido de (https://goo.gl/ $\mathrm{n} 4 \mathrm{H} 1 \mathrm{IC})$

Jiménez, M. (2011). La gestion Informatica de la empresa. Madrid: RA-MA Editorial.

Lamb, C., Hair, J., \& McDaniel, C. (2014). MKTG Marketing. méxico: Cengage Learning.

Laudon, J., \& Laudon, K. y. (2012). Sistemas de Información Gerencial. México: Pearson Educación.

Laudon, K. C., \& Traver, C. G. (2014). E-comerce 2013. Mexico: Pearson Educación.

León, J. d. (2012). Guía de usos y estilos en las redes sociales. Obtenido de (https://goo. $\mathrm{gl} / \mathrm{utP} 6 \mathrm{Ld})$

Liberona, D., \& Ruiz, M. (21 de 09 de 2013). Sience Direct. Obtenido de (http://bibliotecavirtual.ups.edu.ec:2229/science/article/pii/S0123592313000041)

Lozares, C. (1996). La teoría de redes sociales. Universitat Autónoma de Barcelona. Departamento de Sociología, (48), 103-126.(file://C:/Users/usuario/Downloads/ 25386-58835-1-PB\%20(2).pdf).

Martos, A. (2010). Redes Sociales. Madrid: Ediciones Anaya.

Medina, A., \& Montjoy, R. (2015). El marketing directo en las redes sociales y su influencia en el campo empresarial. (Tesis de pregrado). Universidad Técnica de Machala, Machala, Ecuador.

Mejía, J. (2013). La Guía del Community Manager. Madrid: Ediciones Anaya.

Moyano, J., Bruque, S., \& Eisenberg, J. (2007). La influencia de las redes socialesen la adaptación de los trabajadores en el cambio tecnólogico. Cuademos de Economía y Dirección de la Empresa, (31), 147-170. (http://bibliotecavirtual.ups.edu. ec:2211/ehost/pdfviewer/pdfviewer?sid=b8955c12-5861-4575-91a9-8e3c5c$44858 \mathrm{f} \% 40$ sessionmgr4010\&vid=4\&hid=4106).

Romero, C., Alrcón, M., \& Gómez, M. (2011). Adopción de redes sociales virtuales: ampliación del modelo de aceptación tecnológica integrando confianza y riesgo percibido[Adoption of social networking sites: extending the technology acceptance model integrating trust and perceived risk]. Cuadernos de Economía y Dirección de la Empresa, 14(3). 194-205. (http://bibliotecavirtual.ups.edu. ec:2353/10.1016/j.cede.2010.12.003).

Romero, M., Rébori, A., \& Camino, M. (2010). Un índice para "medir" el nivel de innovación tecnologica en las empresas. RAI (Revista de Administração e Inovação), 7(1).3-20. (https://goo.gl/0CDoim).

Rosero, C., \& Montalvo, H. (2015). La disonancia cognitiva como factor motivador en las decisiones del consumidor: caso Smartphone [The cognitive dissonance 
as a motivating factor in consumer decisions: smartphones case. Retos, 5(10), 177-192. doi: http://dx.doi.org/10.17163/ret.n10.

Stumpo, M. D. (2002). Análisis de la política de fomento a las pequeñas y medianas empresas en Chile. Santiago de Chile: Impreso en Naciones Unidas, Santiago De Chile.

Tobar, L. (2015). Análisis competitivo de las pequeñas y medianas empresas en Cuenca Ecuador [Competitive analysis of small and medium enterprises in Cuenca, Ecuador]. Revista Internacional Administración Ë Finanzas, 8(3), 79-92. (https:// goo.gl/MPS80p).

Ureña, G., \& Valenzuela, J. (2011). Contactos de redes sociales en línea como repositorios de información. RUSC, 8(1). 128-141. (https://search.proquest.com/ docview/1018856266? accountid=32861).

Uribe, F., Rialp, J., \& Llonch, J. (2013). El uso de las redes sociales digitales como herramienta de marketing en el desempeño empresarial. Universitat Autònoma de Barcelona, 205-231. (http://bibliotecavirtual.ups.edu.ec:2211/ehost/pdfviewer/ pdfviewer?vid=4\&sid=0faeb380-aceb-4fb9-86c7-03f2c09af16d\%40sessionmgr4009\& hid=4101).

Valls, M. (2016). Redes sociales herramienta de gestión empresarial. Buenos Aires: Ugerman editor. 


\title{
La inversión en publicidad y su efecto en las Medianas Empresas de Guayaquil
}

\section{The Investment in advertising and its effect on the Medium Enterprises of Guayaquil}

\begin{abstract}
Catalina Falquez Arce es profesora/investigadora de la carrera de ingeniería en marketing y negociación comercial de la Universidad de Guayaquil (Ecuador) (catalina.falqueza@ug.edu.ec) (http://orcid.org/0000-00030954-3290)
\end{abstract}

Blanca Silva Guerrero es profesora/investigadora de la carrera de ingeniería en marketing y negociación comercial de la Universidad de Guayaquil (Ecuador) (blanca.silvag@ug.edu.ec) (http://orcid.org/orcid.org/00000003-4140-4856)

Vanessa Rojas Herrera es funcionaria de auditoría tributaria en el Servicio de Rentas Internas (Ecuador) (vcrojas@sri.gob.ec) (http://orcid.org/0000-0002-0654-1110)

\begin{abstract}
Resumen
El análisis de las alternativas para mejorar las ventas en las medianas empresas puede presentar el dilema sobre qué tan efectivo será invertir en publicidad. Si bien es cierto que referentes de la aplicación de estrategias de mercadotecnia confirman los efectos de información, persuasión y recordación que obtiene la publicidad, los actuales contextos económicos y sociales exigen mejores argumentos de apoyo. Por lo tanto, y a pesar de que pueden presentarse un sinnúmero de variables relacionadas a otros componentes del marketing, de gestión administrativa, o financiera; el presente estudio procuró determinar el efecto de la publicidad con relación a las ventas de las medianas empresas de Guayaquil en el año 2015, aplicando el modelo de regresión lineal. Como principales resultados se logra determinar que la elasticidad de la variable dependiente «In Ventas» respecto de la variable independiente «In Gastos» de Publicidad es de 3.21, concluyendo que las ventas son influenciadas por los cambios en los gastos de publicidad, corroborando las afirmaciones establecidas desde los diferentes referentes teóricos sobre la importancia de una campaña publicitaria efectiva y la necesidad de empezar a medirla como inversión y no como un gasto.
\end{abstract}

\begin{abstract}
The Analysis of alternatives to improve sales in medium-sized companies may present the dilemma about how effective it will be to invest in Advertising; Although referents of the application of marketing strategies confirm the effects of information, persuasion and recall obtained by advertising, the current economic and social contexts demand better arguments of support. Therefore, and despite the fact that there may be a number of variables related to other marketing, administrative, or financial components; the study sought to determine the effect of advertising in relation to sales of midsize companies in Guayaquil in 2015, using the linear regression model, achieving determining the elasticity of the In dependent variable sales over the independent variable In Advertising Expenses is 3.21, concluding that sales are influenced by changes in advertising expenses, corroborating the affirmations established in the different theoretical references, the importance of an effective advertising campaign and the need to start measuring it as an investment And not as an expense.
\end{abstract}

\section{Palabras clave | keywords}

Mercadotecnia, empresas, ventas, gastos, publicidad, inversión. Marketing, business, sales, advertising, expenses, investment. 


\section{Introducción}

Uno de los retos de los empresarios es alcanzar resultados sostenibles en el tiempo que le permitan mantener el principio del «negocio en marcha». Algunos estudios al respecto afirman que para que esto suceda la empresa debe estar orientada al mercado logrando ventaja competitiva, enfatizando en la generación continua de valor para el comprador y tratando de asegurar su supervivencia a mediano y largo plazo (Álvarez, Santos y Vázquez, 2001; Kohli y Jaworski, 1990; Narver y Slater, 1990). Muchas veces se encuentran Pequeñas y Medianas Empresas (PYMES) que por desconocimiento o falta de presupuesto aún están atrapadas en los enfoques pasivos, es decir enfocadas en producir o comercializar productos y que al tratar de venderlos no tienen clientes fieles, pues los productos o servicios no satisfacen sus expectativas. Los inversionistas de estas compañías tienen que realizar un cambio de enfoque, involucrando un marketing activo en sus estrategias. Analizando algunos postulados sobre el marketing se puede llegar a la conclusión de que es evidente que las organizaciones deben prestar atención a los mecanismos necesarios para captar valor desde y para sus clientes, refrendándose el Marketing como un intercambio de valor entre individuos y organizaciones para poder alcanzar lo que necesitan y así satisfacer las necesidades (Armstrong \& Kotler, 2013). Es interesante observar cómo en las nuevas orientaciones ya se empieza a destacar en las empresas la importancia de crear y mantener las relaciones con los clientes, pues no solo se debe delimitar a la aplicación de un «plan de marketing», sino que se deben saber gestionar las relaciones de intercambio con sus clientes luego de haberse aplicado las estrategias de Marketing Mix.

Afirma Rojas (2016) que además en las nuevas corrientes se da importancia al auge de la tecnología y cómo la empresa debe afrontar la nueva forma de captar clientes y sobrevivir a la economía colaborativa y digital. Por su parte Kotler et al. (2002, pp. 48-51) incluye los últimos conceptos de Marketing definidos por la AMA (2004) como un conjunto de procesos que identifican, crean y distribuyen valor para desarrollar relaciones satisfactorias y de largo plazo que coadyuven a alcanzar beneficios empresariales.

Por lo tanto, no solamente los empresarios, sino los especialistas en marketing, deben reconocer la importancia de la toma de decisiones financieras, creando un contexto de seguridad que apoyará la aplicación de estrategias de marketing de éxito. (Dominguez Doncel \& Muñoz Vera, 2010). 
Monferrer (2013) afirma que es significativo que la comunicación actúe sobre los clientes actuales y potenciales; de allí la importancia de la publicidad como mecanismo para dar a conocer estos productos a los consumidores que están demandando. Según Rojas (2016) citando a Talaya et al. (2008), la publicidad se define como un proceso de comunicación que es realizado por el emisor (vendedor) hacia un grupo de receptores (consumidores reales o potenciales), con el objetivo de dar a conocer los beneficios de valor de sus productos o servicios, persuadiéndolos para su compra.

Para Kotler (2001) una de las más complejas decisiones dentro del marketing es la fijación del presupuesto de promoción y publicidad debido a que deben ser efectivos al momento de asignar presupuesto a la promoción de ventas, publicidad, relaciones públicas, mercadeo directo y fuerza de ventas, en la medida que lo necesita. Existen algunas formas que las empresas utilizan para asignar recursos a este rubro, siendo una de las más utilizadas la fijación de metas en base al porcentaje de venta. Sin embargo, para el autor (op. cit), el método más beneficioso es el de «objetivo y tarea», ya que necesita que se fijen primero los objetivos de la publicidad y luego se definan los costos de cada actividad que se va a requerir.

Es importante también tomar en consideración la estrategia que se va a proponer para lograr alcanzar los objetivos definidos en los presupuestos de publicidad. En este sentido Kotler (2001) detalla cuatro factores que deberían tomarse en consideración al momento de hacer el presupuesto de publicidad: i) el ciclo de vida del producto; ii) la participación en el mercado; iii) la competencia y; iv) la posibilidad de sustitución del producto.

De acuerdo con Rojas (2016), los presupuestos de promoción y publicidad pueden resultar onerosos para las compañías, en especial para las Pequeñas y Medianas (PYMES). Debido a esto, en el momento de la toma de decisiones respecto a la inversión en recursos que generen ingresos, es precisamente la publicidad uno de los rubros que origina ciertas dudas. Por esta razón es común que se dé como práctica relevar los gastos destinados a comunicación y marketing a aspectos como talento humano o producción, ya que no está claramente determinada la influencia o no de la publicidad en los resultados de la empresa.

En el presente trabajo de investigación no se proyectó evaluar cómo las medianas empresas establecieron los presupuestos de promo- 
ción y publicidad, o si los métodos utilizados fueron los idóneos, sino que tiene por objeto analizar cómo los gastos de promoción y publicidad reflejados en sus estados de resultados causaron un efecto en el incremento de sus ventas. Sin embargo, considerando que todo empresario busca maximizar las utilidades de la empresa, es importante conocer si sus recursos están siendo invertidos eficientemente. Por lo tanto, se intenta valorar cuál es el efecto de la inversión de la publicidad en los resultados de las ventas, tomándose como marco muestral las medianas empresas de Guayaquil (Guayas, Ecuador) durante el año 2015.

\section{Metodología}

Según Hernández-Sampieri (2006), la recopilación de información es la forma de recolección de datos sobre variables propias de lo que se analiza. La presente investigación utiliza un enfoque cuantitativo, debido a que, como lo mencionan los autores referidos anteriormente, se necesita recoger datos para poder probar con un análisis estadístico, en este caso puntual, el efecto que tiene la inversión de publicidad en las ventas de las medianas empresas de Guayaquil. Se utilizó el método deductivo, en razón de que se inicia examinando estudios, teorías, análisis y escritos realizados a nivel mundial sobre el impacto de la inversión en publicidad en los rendimientos de las empresas. El tipo de investigación es causal, mientras que el diseño es cuantitativo.

\subsection{Población y Muestra}

El sujeto de estudio son las medianas empresas de Guayaquil. Para llegar a la muestra se siguieron varios criterios de descarte, analizando la base de empresas publicada por la Superintendencia de Compañías del Ecuador. Se parte de la definición de Pequeñas y Medianas empresas tipificadas en el Código Orgánico de la Producción, Comercio e Inversiones. Según el reporte de la Superintendencia de Compañías, se establece que las empresas están clasificadas por su tamaño en Micro, Pequeñas, Medianas y Grandes. Con la finalidad de conseguir una base de datos selecta, se utilizó información del Servicio de Rentas Internas. Según los datos correspondientes a esta base, el universo queda establecido en 46.893 empresas activas y gestionables, registradas en el Registro Único de Contribuyentes de la Zonal 8 (constituida por los cantones de Guayaquil, Samborondón y Durán). Partiendo de este grupo de datos, con la finalidad de constituir 
la muestra de las medianas empresas de la ciudad de Guayaquil, se llevó a cabo el descarte de 6.545 empresas que se hallaban supervisadas por otros organismos diferentes a la Superintendencia de Compañías.

Una vez ejecutado el primer descarte, quedaron 40348 empresas controladas por la Superintendencia de Compañías; de ellas se descartaron 3280 que pertenecían a los cantones de Samborondón y Daule, habiendo, por diferenciación, 37068 empresas de la ciudad de Guayaquil. Posteriormente fueron ordenados los datos por ramas o sectores de la economía basados en el código CIIU1․ En base a este juicio, se exceptúan de la base de datos 6283 empresas que incumben a 12 sectores de actividades de escasa representación comercial y que pueden distorsionar los resultados del análisis, por lo tanto, de esta tercera criba, quedaron configuradas 30785 empresas.

A continuación, y bajo el criterio de empresas que presentaron su declaración de Impuesto a la Renta del año 2015, se seleccionaron 20 438 , pues se entiende que son empresas con actividad comercial actual. De ese grupo se marginaron las empresas cuyos ingresos totales expresados en la declaración de Impuesto a la Renta fluctuaron entre USD 1 000 001,00 hasta USD 5000 000,00, que corresponde a la clasificación de medianas empresas según el Código Orgánico ut supra reseñado. Como consecuencia de esta cuarta criba se obtuvieron 2174 medianas empresas de la ciudad de Guayaquil, las cuales corresponden a la muestra efectiva para el presente estudio y que se presentan por rubro, ventas e inversión publicitaria en la tabla 1.

\subsection{Hipótesis}

Esta investigación intenta como hipótesis de partida determinar si al asignar capital para publicidad se incrementarían las ventas de las empresas en análisis. Una segunda hipótesis plantea comprobar si las ventas se aumentan además por la influencia de la cuota de mercado.

\subsection{Variables}

El estudio realiza el análisis de tres variables: i) monto de ventas (variable dependiente); ii) total de gasto de promoción y publicidad (variable

1 Clasificación sistemática de todas las actividades económicas cuya finalidad es la de establecer su codificación armonizada a nivel mundial. 
independiente) y; iii) cuota de mercado (variable independiente). Esta última se consideró debido a que las ventas determinan la participación de mercado. Esta información corresponde a datos de rubros contables expresados en USD, cuya información fue adquirida de fuentes secundarias como la base de datos de la Superintendencia de Compañías y del Servicio de Rentas Internas, según se observa en las declaraciones reportadas por las empresas como resultados del ejercicio económico 2015. Cabe indicar que para el estudio no se consideran otras variables que también pueden incidir en los resultados de la empresa, como descuentos en ventas y otras promociones y estrategias de venta personal o de distribución, debido a que el tema central del análisis es la publicidad y su importancia como herramienta de comunicación, persuasión y memorización del mensaje de venta.

Tabla 1. Extracto de $n$ de Medianas Empresas de Guayaquil por Sector

\begin{tabular}{|l|l|l|l|}
\hline \multicolumn{1}{|c|}{ SECTOR } & NORDEN & $\begin{array}{r}\text { TOTAL } \\
\text { DE VENTAS }\end{array}$ & $\begin{array}{c}\text { TOTAL DE } \\
\text { GASTO DE } \\
\text { PUBLICIDAD }\end{array}$ \\
\hline $\begin{array}{l}\text { Actividades de alojamiento y de servi- } \\
\text { cio de comidas. }\end{array}$ & 49 & 98518570,35 & 837028,60 \\
\hline $\begin{array}{l}\text { Actividades de atención de la salud } \\
\text { humana y de asistencia social. }\end{array}$ & 59 & 128739490,20 & 389772,18 \\
\hline Actividades inmobiliarias. & 73 & 128236236,21 & 1137099,18 \\
\hline $\begin{array}{l}\text { Actividades profesionales, científicas } \\
\text { y técnicas. }\end{array}$ & 159 & 321740118,79 & $6.108297,47$ \\
\hline $\begin{array}{l}\text { Agricultura, ganadería, silvicultura y } \\
\text { pesca. }\end{array}$ & 261 & 526949003,31 & 250256,33 \\
\hline $\begin{array}{l}\text { Comercio al por mayor y al por menor; } \\
\text { reparación de vehículos automotores } \\
\text { y motocicletas. }\end{array}$ & 976 & 2160955593,12 & 11661466,14 \\
\hline Construcción. & 162 & 321893390,89 & 292472,80 \\
\hline Industrias manufactureras. & 258 & 572782166,62 & 3410424,45 \\
\hline Otras actividades de servicios. & 32 & 54780740,13 & 281633,86 \\
\hline Transporte y almacenamiento. & 145 & 294650992,24 & 484525,29 \\
\hline Total USD (US\$) & 2174 & 4609246301,86 & 24852976,30 \\
\hline
\end{tabular}

Fuente: Servicio de Rentas Internas

Nota: *Tomado de Rojas (2016) 


\subsection{Análisis estadístico}

Según Gujarati \& Porter (2010), existen modelos que pueden ser lineales en los parámetros. Sin embargo en las variables no lineales requieren una transformación de las variables para obtener una mejor interpretación de los resultados del modelo de regresión. Así, el presente estudio utiliza el modelo Log-lineal, y como herramienta fue utilizado XLSTAT, con el cual se aplicó este modelo de regresión lineal.

Para aplicar las fórmulas de regresión lineal, en el caso de la variable dependiente, se tomaron datos de los ingresos publicados por el servicio de rentas internas que se relacionan con sus movimientos habituales como son las ventas, monto que asciende a USD 4609246301,86 en el total ventas declaradas (ver tabla 1 y 2). En el caso de la variable independiente «gastos de publicidad», se eligieron los montos declarados en los servicios tributarios bajo el concepto «costos y gastos de promoción y publicidad», cantidades que se incorporaron en relación del presente análisis: USD 24852 976,30 (ver tabla 1).

Para Gujarati \& Porter (2010), emplear exclusivamente dos variables, la dependiente y la explicativa, no es tan real en la práctica. La situación es que sobre la variable «ventas» pueden existir muchas variables que la pueden afectar; por lo tanto, en la presente investigación se incluye otra variable independiente como es la «cuota de mercado». Para determinar el valor correspondiente a esta variable se utilizó la información de la variable «ventas», explicada en párrafos anteriores; estableciéndose así el valor total de ventas operacionales de cada sector económico. Posteriormente se obtuvo el porcentaje de las ventas de cada mediana empresa de Guayaquil, lográndose determinar de esta manera la cuota de mercado correspondiente a su sector, como se observa en la tabla 2.

Tabla 2. Declaración de Impuesto a la Renta Año 2015 2175 Medianas Empresas de Guayaquil

\begin{tabular}{|l|l|l|}
\hline \multicolumn{1}{|c|}{ CAS. } & \multicolumn{1}{|c|}{ DESCRIPCIÓN } & \multicolumn{1}{c|}{ VALOR USD } \\
\hline 6999 & Total, de ingresos declarados & $4.687 .592 .567,54$ \\
\hline Casilleros escogidos correspondiente a ingresos operacionales: \\
\hline 6001 & $\begin{array}{l}\text { Ventas netas locales gravadas con tarifa 12\% } \\
\text { de IVA }\end{array}$ & $2.380 .221 .449,47$ \\
\hline 6005 & $\begin{array}{l}\text { Prestaciones locales de servicios gravadas } \\
\text { con tarifa 12\% de IVA }\end{array}$ & $655.389 .176,26$ \\
\hline
\end{tabular}




\begin{tabular}{|c|c|c|}
\hline CAS. & DESCRIPCIÓN & VALOR USD \\
\hline 6002 & $\begin{array}{l}\text { Valor exento ventas netas locales gravadas } \\
\text { con tarifa } 12 \% \text { de IVA }\end{array}$ & $49.193,47$ \\
\hline 6003 & $\begin{array}{l}\text { Ventas netas locales gravadas con tarifa cero } \\
\text { o exentas de IVA }\end{array}$ & $976.711 .407,17$ \\
\hline 6007 & $\begin{array}{l}\text { Prestaciones locales de servicios gravadas } \\
\text { con tarifa cero o exentas de IVA }\end{array}$ & $247.224 .527,20$ \\
\hline 6008 & $\begin{array}{l}\text { Valor exento prestaciones locales de servicios } \\
\text { gravadas con tarifa cero o exentas de IVA }\end{array}$ & $1.166 .750,33$ \\
\hline 6004 & $\begin{array}{l}\text { Valor exento ventas netas locales gravadas } \\
\text { con tarifa cero o exentas de IVA }\end{array}$ & $2.968 .933,48$ \\
\hline 6009 & Exportaciones netas de bienes & $161.366 .315,62$ \\
\hline 6011 & Exportaciones netas de servicios & $47.046 .720,67$ \\
\hline 6012 & Valor exento exportaciones netas de servicios & $1.344 .995,19$ \\
\hline 6010 & Valor exento exportaciones netas de bienes & $11.833,68$ \\
\hline 6013 & $\begin{array}{l}\text { Ingresos por prestación de servicios de cons- } \\
\text { trucción }\end{array}$ & $103.532 .370,96$ \\
\hline 6091 & Otros ingresos del exterior & $2.204 .075,67$ \\
\hline 6015 & $\begin{array}{l}\text { Ingresos obtenidos bajo la modalidad de } \\
\text { comisiones o similares }\end{array}$ & $13.890 .740,35$ \\
\hline 6092 & Valor exento otros ingresos del exterior & $1.289 .397,29$ \\
\hline 6017 & $\begin{array}{l}\text { Ingresos obtenidos por arrendamientos } \\
\text { operativos }\end{array}$ & $14.828 .415,05$ \\
\hline \multicolumn{2}{|c|}{ Total de ventas base para el análisis } & 4.609.246.301,86 \\
\hline
\end{tabular}

Fuente: Servicio de Rentas Internas

\subsection{Modelo Log-lineal}

En razón de que los datos de las variables «ventas», «gasto de publicidad» y «cuota de mercado», están muy disgregados; se transformaron las variables a «ln», lo cual va a expresar mejor el modelo. Una vez explicadas las variables que se utilizan en el modelo de regresión lineal múltiple, se procura señalar las relaciones de dichas variables y el efecto de la inversión en publicidad sobre el horizonte de las ventas de las medianas empresas de Guayaquil, en términos porcentuales.

\section{Resultados}

Al integrarse los datos referidos ut supra en la herramienta estadística XLSTAT, se encuentra que la variable explicativa es el gasto de promoción 
y publicidad expresado en «ln», y la variable respuesta es el «ln Ingresos por ventas»; es decir que la variable de «promoción y publicidad» puede manifestar el nivel de ventas de las medianas empresas de Guayaquil. Los datos presentan una relación lineal directamente proporcional.

\subsection{Estadísticos descriptivos}

Con un intervalo de confianza del 95\% y un nivel de tolerancia del 0.0001, a continuación se presentan los estadísticos descriptivos de las variables estudiadas:

Tabla 3. Estadísticos descriptivos de las variables analizadas

\begin{tabular}{|l|l|l|l|l|l|l|l|}
\hline \multicolumn{1}{|c|}{ Variable } & $\begin{array}{c}\text { Observa- } \\
\text { ciones }\end{array}$ & $\begin{array}{c}\text { Obs. con } \\
\text { datos } \\
\text { perdidos }\end{array}$ & $\begin{array}{c}\text { Obs. sin } \\
\text { datos } \\
\text { perdidos }\end{array}$ & Mínimo & Máximo & Media & $\begin{array}{c}\text { Desv. } \\
\text { típica }\end{array}$ \\
\hline In Ventas & 1093 & 0 & 1093 & 13,545 & 15,419 & 14,527 & 0,46 \\
\hline $\begin{array}{l}\text { In Gastos } \\
\text { de Publicidad }\end{array}$ & 1093 & 0 & 1093 & 1,902 & 14,66 & 8,111 & 2,143 \\
\hline $\begin{array}{l}\text { In cuota } \\
\text { de mercado }\end{array}$ & 1093 & 0 & 1093 & $-7,806$ & $-2,686$ & $-5,997$ & 1,131 \\
\hline
\end{tabular}

Los estadísticos descriptivos de la variable «ln ventas» revelan una desviación típica de 0.46, con una media de 14,527 en un rango entre 12,545 y 15,419 , mientras en el caso de la variable «ln gasto de publicidad» se presenta una desviación típica de 2,143. Además se pretende determinar si el coeficiente $\mathrm{R}^{2}$ se ajusta al perfil de regresión lineal a los datos. Así, en el modelo se establece el grado de relación de las variables, no una relación de causalidad.

Gujarati \& Porter (2010) mencionan que existen muchos investigadores tratando de ajustar sus modelos a un coeficiente cercano a 1 para demostrar la efectividad de los mismos. Sin embargo, los precitados autores mencionan que el investigador debe centrarse más en los resultados estadísticos de las variables explicativas con respecto a la variable dependiente. De esta forma concluyen que el hecho de que el resultado del coeficiente de determinación esté alejado del 1, no significa que el modelo sea malo. En la tabla 4 se presentan los resultados de regresión de la variable «In ventas» con bondad del ajuste, emergiendo que el coeficiente de determinación $\mathrm{R}^{2}$ es de $12 \%$. 
Tabla 4. Regresión Lineal de las Variables

\begin{tabular}{|l|l|}
\hline \multicolumn{2}{|c|}{$\begin{array}{c}\text { Regresión de la variable In VENTAS } \\
\text { Estadísticos de bondad del ajuste (In vtas) }\end{array}$} \\
\hline Observaciones & 1093 \\
\hline Suma de los pesos & 1093 \\
\hline GL & 1090 \\
\hline$R^{2}$ & 0,124 \\
\hline$R^{2}$ ajustado & 0,122 \\
\hline
\end{tabular}

\subsection{Análisis de Varianza}

Se logra determinar la variabilidad de «In ventas» por medio de la información obtenida del análisis de varianza de las dos variables independientes (tabla 5).

Tabla 5. Análisis de Varianza y de suma de cuadrados

\begin{tabular}{|c|c|c|c|c|c|}
\hline \multicolumn{6}{|c|}{ Análisis de varianza (In ventas) } \\
\hline Fuente & $\mathrm{L}$ & $\begin{array}{c}\text { Suma de } \\
\text { cuadrados }\end{array}$ & $\begin{array}{c}\text { Cuadrados } \\
\text { medios }\end{array}$ & & $r>F$ \\
\hline Modelo & & 8,609 & 4,305 & 7,024 & 0,0001 \\
\hline Error & 090 & 02,429 &, 186 & & \\
\hline Total corregido & 092 & 31,039 & & & \\
\hline \multicolumn{6}{|c|}{ Calculado contra el modelo $Y=$ Media(Y) } \\
\hline \multicolumn{6}{|c|}{ Análisis Suma de Cuadrados Tipo I (In vtas) } \\
\hline Fuente & $\mathrm{L}$ & $\begin{array}{c}\text { Suma de } \\
\text { cuadrados }\end{array}$ & $\begin{array}{c}\text { Cuadrados } \\
\text { medios }\end{array}$ & & $r>F$ \\
\hline In Gasto de publicidad & & ,888 & ,888 & 1,706 & 0,0001 \\
\hline In Cuota de mercado & & 2,721 & 2,721 & 22,343 & 0,0001 \\
\hline \multicolumn{6}{|c|}{ Análisis Suma de Cuadrados Tipo III (In vtas) } \\
\hline Fuente & $\mathrm{L}$ & $\begin{array}{c}\text { Suma de } \\
\text { cuadrados }\end{array}$ & $\begin{array}{c}\text { Cuadrados } \\
\text { medios }\end{array}$ & & $r>F$ \\
\hline In Gasto de publicidad & &, 17 &, 17 & 7,841 & 0,0001 \\
\hline In Cuota de mercado & & 2,721 & 2,721 & 22,343 & 0,0001 \\
\hline
\end{tabular}

Debido a que el valor $\mathrm{p}$ (valor de probabilidad) es mayor que el estadístico $\mathrm{F}$ en el modelo y por ende en las dos variables independientes, se puede interpretar que la información dada por las variables independientes «ln gastos de publicidad» e «ln cuota de mercado» explica 
significativamente la variabilidad de «ln ventas», así como la influencia de la variable «cuota de mercado».

\subsection{Análisis de la regresión}

Finalmente se determina la elasticidad de la variable dependiente «In ventas» respecto de la variable independiente «In gastos de publicidad».

Tabla 6. Análisis de la Regresión

\begin{tabular}{|l|l|l|l|l|l|l|}
\hline \multicolumn{7}{|c|}{ Parámetros del modelo (Ln vtas) } \\
\hline Fuente & Valor & $\begin{array}{l}\text { Error } \\
\text { estándar }\end{array}$ & $T$ & Pr>|t| & $\begin{array}{l}\text { Límite } \\
\text { inferior } \\
(95 \%)\end{array}$ & $\begin{array}{l}\text { Límite } \\
\text { superior } \\
(95 \%)\end{array}$ \\
\hline Intercepción & 15,032 & 0,087 & 172,269 & $<0,0001$ & 14,861 & 15,203 \\
\hline $\begin{array}{l}\text { In Gasto de } \\
\text { publicidad }\end{array}$ & 0,032 & 0,006 & 5,276 & $<0,0001$ & 0,02 & 0,044 \\
\hline $\begin{array}{l}\text { In Cuota de } \\
\text { Mercado }\end{array}$ & 0,128 & 0,012 & 11,061 & $<0,0001$ & 0,105 & 0,15 \\
\hline
\end{tabular}

Ecuación del modelo Regresión Lineal (In Ventas):

Como resultado de la aplicación, la elasticidad de la variable dependiente «ln ventas» respecto de la variable independiente «ln gastos de publicidad» es de 3.21, lo que indica que si las otras variables permanecen constates, al aumentarle $1 \%$ en «ln gasto de publicidad», le corresponde un aumento de $3.21 \%$ en «ln ventas», por lo que se evidencia con meridiana claridad que en el caso de análisis las ventas son impactadas directamente por los cambios en los gastos de publicidad.

\section{Discusión}

Los resultados de la presente investigación demuestran la importancia que se está dando a la variable de inversión en promoción y publicidad, con respecto a la variación en ventas en un grupo de Medianas Empresas de la ciudad de Guayaquil. Es significativo aclarar que la inversión en promoción y publicidad reflejada como un gasto en el estado de resultados de una compañía no es la única variable que afecta a la variación en ventas, como ya se mencionó en referencia. 
Sin embargo el estudio es coherente con las manifestaciones de otros autores que demuestran que las ventas y los beneficios están directamente relacionados con la publicidad y que son variables importantes para poder evaluar si realmente se está siendo efectivo en la inversión de publicidad, siendo el beneficio el producto del margen unitario por las unidades vendidas. No obstante, para todas las empresas no emerge el mismo resultado debido a que puede variar por diferentes motivos como costos diferentes, precios, entre otros (Tellis \& Redondo, 2002).

Kotler (2001) afirma la importancia de la mercadotecnia y sus estrategias -entre las que se encuentra la publicidad-, ya que a medida que la empresa empieza a darle más fuerza, su potencial de ventas se va acercando a su mercado potencial, estableciendo una relación directa entre el nivel de ventas y el nivel de mercadotecnia, lo cual se evidencia en el análisis realizado.

Cabe mencionar otros estudios con resultados similares al presente, considerando el estudio efectuado por Sellamen-Garzón \& ArceMeza, (2010) sobre las decisiones publicitarias y su influencia en las ventas de los productos en tiendas de Bogotá, quienes concluyen que aplicando el método de regresión lineal se evidencia una relación directa entre las cantidades demandadas y la inversión en publicidad.

Tellis \& Redondo (2002) por su parte señalan que existen algunas investigaciones sobre la relación publicidad-ventas, las cuales han aportado buenos resultados sobre los efectos de la publicidad, así como ciertos estudios de campo que han alcanzado obtener como resultado que si se aumenta la presión publicitaria en el $1 \%$, se va a obtener un incremento del $0.01 \%$ en las ventas.

\section{Conclusión}

Según el modelo de regresión lineal múltiple aplicado en el presente trabajo de investigación con los datos de las medianas empresas de la ciudad de Guayaquil, se concluye que las variables: a) ventas, b) gasto de publicidad y c) cuota de mercado, están directamente relacionadas, siendo la variable «ventas» dependiente de las variables explicativas «gasto de publicidad»y «cuota de mercado».

Asimismo se demostró que a medida que se incrementa el gasto de publicidad crece el nivel de ventas, resultados que corroboran las conclusiones establecidas en los diferentes referentes teóricos mencio- 
nados en el presente trabajo de investigación. Debido a que muchos de los autores citados ut supra estudian al Marketing desde una perspectiva teórica, destacan la importancia de la aplicación de estrategias de mercadotecnia con el objetivo de satisfacer al consumidor, crear relaciones de intercambio de valor y por ende alcanzar las metas de las empresas, maximizando las utilidades de los accionistas o inversores.

Se debe mencionar que en los resultados de la investigación se pudo evidenciar que las medianas empresas de la ciudad de Guayaquil no están destinando los suficientes recursos al rubro de marketing, lo que se observa en los valores señalados como gasto de publicidad en las declaraciones de impuesto a la renta, en los que esta partida presupuestaria declarada representa -en promedio- un $0.54 \%$ con respecto a los ingresos operacionales; aspecto que requiere un análisis en posteriores investigaciones.

La presente investigación no analiza la causa de los niveles de gasto en publicidad de cada sector económico de las medianas empresas, por ello es recomendable realizar a futuro un estudio a medianas empresas de sectores explícitos de las diferentes regiones del país, con el fin de analizar su variación de inversión en publicidad y si ésta tiene efecto en las ventas, incluso pudiéndose diseñar un patrón más completo con otras variables independientes. Además, con las actuales reformas tributarias en el Ecuador sobre los procesos de deducción del gasto de publicidad, otro estudio a futuro podría ser el análisis del impacto de dicha deducción en los procesos de toma de decisiones de las medianas y grandes empresas en esta materia.

\section{Referencias}

AMA (2013). Definición de Marketing. Recuperado el 16 de Jullio de 2016, de https:// www.ama.org

Armstrong, G., \& Kotler, P. (2013). Fundamentos del Marketing. México: Pearson Educación de México.

Clow, K. E., \& Baack, D. (2010). Publicidad, Promoción y Comunicación Integral en Marketing ( $4^{\underline{a}}$ Ed). México: Pearson Educación.

Dominguez-Doncel, A., \& Muñoz-Vera, G. (2010). Métricas del Marketing (2 ${ }^{\underline{a}}$ Ed). Madrid: Esic Editorial.

Garza-Castaño, R. (2000). Creación de PYMES: Objetivo emprendedor. Ingenierías, 54-58.

Gujarati, D. N., \& Porter, D. (2010). Econometría (5ํㅗ Ed). México: McGraw-Hill/ Interamericana Editores.

Hernández-Sampieri, Fernández \& Baptista (2006). Metodología de la Investigación (4⿻ Ed). México: Pearson Education. 
Kelmansky, D. M. (2009). Estadística para Todos. Buenos Aires: Ministerio de Educación-Instituto Nacional de Educación Tecnológica.

Kotler, P. (2001). Dirección de Mercadotecnia, Análisis, Planeación, Implementación y Control ( $8^{\underline{a}}$. Ed). Lima: Pearson Educación.

Monferrer, D. (2013). Fundamentos de Marketing. Castellón de la Plana: Unión de Editoriales Universitarias Españolas.

Rojas, V. (2016). Efecto financiero de la inversión de Publicidad en los resultados de las Medianas empresas de Guayaquil.

Sellamen-Garzón, A., \& Arce-Meza, A. (2010). Las decisiones publicitarias dependen de las ventas en los Productos. Criterio Libre, 8(12), 143-161.

Talaya, A. E., García-De-Madariaga-Miranda, J., Narros-González, M. J., Olarte.Pascual, C., Reinares-Lara, E. M., \& Saco-Vázquez, M. (2008). Principios de Marketing $\left(3^{\underline{a}} \mathrm{Ed}\right)$. Madrid: Esic Editorial.

Tellis, G. J., \& Redondo, I. (2002). Estrategias de Promoción y Publicidad. Madrid: Pearson Education. 


\title{
Una aproximación teórica para mejorar los resultados de innovación en las empresas desde la perspectiva del "Happiness Management"
}

\section{A theoretical review to improve outcomes of innovation in enterprises from the perspective of "Happiness Management"}

Dr. Rafael Ravina Ripoll es Profesor de Organización de Empresa de la Universidad de Cádiz (España) (rafael. ravina@uca.es) (http://orcid.org/0000-0001-7007-3123)

Dr. Francisco Villena Manzanares es Profesor en el Departamento de Ingeniería del Diseño de la Universidad de Sevilla (España) (fvillena@us.es) (http://orcid.org/ 0000-000 1-8753-5590)

Dr. Guillermo Antonio Gutiérrez Montoya es Decano de Ciencias Económicas de la Universidad Don Bosco (El Salvador) (guillermo@udb.edu.sv) (http://orcid.org/0000-0003-1305-6030)

\section{Resumen}

En el presente artículo, se plantea una reflexión sobre cómo aumenta la productividad de la empresa cuando se fomenta el bienestar corporativo. Se presenta un modelo teórico que va en varias fases en las cuales se esbozan las etapas que deben interactuar para dar soluciones a problemas en las organizaciones en el presente siglo. Las actuales tendencias de la administración ya empiezan a considerar los principios o filosofía del «Happiness Management» como futuras tendencias que pueden aplicarse a cualquier organización independientemente del sector donde operen. Por eso se hace necesario implantar culturas dispuestas a conseguir resultados competitivos y sostenibles en la empresa, renovando con ello en primer lugar el bienestar corporativo y en consecuencia su productividad laboral, y en segundo lugar mejorando el rendimiento organizativo generando competitividad. Por último, la cultura de innovación basada en incrementar el bienestar corporativo mejora la imagen de la compañía proyectándose positiva hacia todos sus stakeholders.

\begin{abstract}
This paper is a theoretical reviews of research in the field of organizational behavior. The purpose of the study is to reflect on how business productivity increases when corporate welfare is promoted. The model theoretical created titled "Generator model of the Culture of Innovation applying Happiness Management» has been divided into several phases, with an outline of the steps which must interact to provide solutions to problems in organizations in the current century. Current trends of management are beginning to consider the principles or philosophy of "Happiness Management" as future trends that can be applied to any organization, regardless of the sector where they operate. That is the reason why nowadays, it is necessary to implement cultures willing to get competitive and sustainable results in the company, thereby renewing in the first place corporate welfare and, consequently, its labor productivity, and secondly improving organizational performance generating competitiveness. Finally, the culture of innovation based on increasing corporate welfare improves the image of the company, being it projected in a positive way towards all its stakeholders.
\end{abstract}

\section{Palabras clave | keywords}

Happiness management; culture of innovation; labor productivity; creativity; corporate welfare; competitiveness.

Happiness management; cultura de innovación; productividad laboral; creatividad; bienestar corporativo; competitividad. 


\section{Introducción al bienestar corporativo}

Actualmente, vivimos en una economía globalizada e interconectada, donde la mano de obra con alta formación académica se establece como el verdadero motor de la innovación y transferencia de conocimiento científico, siempre y cuando haya un tejido industrial en las tecnologías de la información y la comunicación (TIC) así como un sistema educativo que lo impulse dentro de las aulas: pensamiento reflexivo, creatividad, talento, felicidad, emprendimiento, etc. Ambos factores contribuyen al impulso de la actividad productiva de las universidades en la generación de contratos de investigación colaborativa, consultoría de ingresos, licencias, patentes, y las empresas spin-off y start-up.

En la era de los Grandes Datos, el capital humano con educación superior en ingeniería e informática es uno de los principales activos propiedad de multinacionales de base tecnológica al establecer estrategias innovadoras en bienes, servicios y procesos. Estas entidades destinan recursos fuertes monetarios a la $I+D$ interna y desarrollan una política de recursos humanos que fomente el compromiso colectivo y la satisfacción laboral. Entre otras cosas, esta última requiere un entorno interno que aliente la discusión aristotélica, la autoestima, el trabajo en equipo, las relaciones sociales y el bienestar subjetivo de los trabajadores. (Zelenski, Murphy \& Jenkins, 2008). Hoy en día, nadie discute que gran parte del éxito económico de las empresas de spin-off y start-up proviene principalmente de poseer un personal de empleados creativos, innovadores y felices (Binder \& Broekel, 2012). Teniendo en cuenta esto, pretendemos exponer que la felicidad laboral ayuda a mejorar el clima organizacional mejorando el rendimiento productivo de su capital humano y, por tanto, la competitividad de la empresa. Por otro lado, la alta dirección de las empresas es la que debe actuar y comprometerse directamente en fomentar un estilo de trabajo que promueva el bienestar subjetivo en todos los niveles de la organización, utilizando incentivos, por ejemplo. Esto requiere, entre otras cosas, de la creación de un ambiente de trabajo adecuado para fomentar la flexibilidad, mejorar la mentalidad compartida, el talento, la innovación, el aprendizaje participativo, la participación, la eficiencia, el dinamismo, la adaptabilidad, etc.

Seligman (2003) dice que el desarrollo profesional tiene una gran influencia en el bienestar subjetivo de los individuos. De esta afir- 
mación, un gran número de investigadores, especialmente psicólogos y economistas, se están interesando en el estudio de la cultura corporativa de empresas que se centran en proporcionar felicidad a sus empleados (Luthans y Youssef, 2007). De esta manera, podemos saber si la felicidad laboral es un factor clave para acelerar procesos creativos e innovadores desarrollados dentro de las organizaciones, especialmente en aquellas con base digital y tecnológica. Como curiosidad, Google fue una de las primeras multinacionales en el mundo en llevar a cabo algunos cursos de concienciación y mentalidad positiva para mejorar la inteligencia emocional de su capital humano y promover el bienestar colectivo. La implementación de estos seminarios se realizó al mismo tiempo que la publicación del artículo titulado "La Organización Virtuosa: El Valor de la Felicidad en el Lugar de Trabajo". El atractivo de este trabajo académico es que sus autores descubren que "para hacer feliz a la gente en su vida, es una condición necesaria para que sean felices en su trabajo" (Gavin \& Mason, 2004). Años más tarde, grandes empresas estadounidenses -después del camino iniciado hace tiempo por Google-comenzaron a preocuparse por el bienestar subjetivo de sus empleados como uno de los activos intangibles más importantes que las empresas tienen disponibles para incrementar no sólo la imagen corporativa de la empresa, sino también para lograr una mayor productividad laboral (Wright et al., 2002). Según esta tesis, podemos decir que la felicidad laboral debe convertirse en una de las principales funciones de la dirección y también en un talento humano (Wolf, 2013). Entre 2005 y 2010, la literatura se centró principalmente en examinar las variables socioeconómicas, culturales, demográficas y psicológicas que afectan a la felicidad o al bienestar subjetivo de las personas (Mochón y Ahn, 2007; Ferrer i Carbonell, 2012). Explicar el bienestar corporativo de los trabajadores desde el punto de vista de la satisfacción laboral es nuevo porque afecta el desempeño organizacional de las empresas de manera muy significativa (Beauregard, 2010). Varias razones pueden justificar la falta de un estudio descriptivo sobre la satisfacción en el trabajo variable en el trabajo académico citado en el párrafo anterior. Uno de ellos puede ser causado por la existencia de numerosos estudios académicos que han minimizado la importancia de la felicidad en las empresas durante la primera década del siglo, cuyo objetivo básico es generar riqueza haciendo de las habilidades y destrezas requeridas un talento humano. Fisher (2010) señala 
que no hay suficientes explicaciones sobre la felicidad laboral y sugiere que la felicidad en las empresas con fines lucrativos o comerciales crecen significativamente.

- Un ambiente de trabajo diseñado para permitir el empoderamiento, la creatividad, el compromiso afectivo, la interacción entre las personas, el aprendizaje colaborativo, la comunicación positiva, y así sucesivamente.

- Una cultura organizacional basada en los principios de justicia, respeto, trabajo en equipo, tolerancia y solidaridad.

- Un liderazgo participativo y transformacional dirigido a facilitar el desarrollo del bienestar organizacional y la innovación tecnológica.

En la actualidad, la felicidad organizacional de las empresas es un tema que muy rara vez se aborda en la literatura económica (Salas Vallina, 2013), a pesar del conocimiento científico que afirma que una persona que es feliz en el desempeño de su trabajo suele ser más creativa y productiva, eficaz, innovadora, receptiva, optimista, altruista (por ejemplo, Vazquez, 2016, Dolan y Metcalfe, 2012; Rego et al., 2011; Hosie, \& Sevastos, 2009). Por lo tanto, no es sorprendente que las ventajas competitivas de las empresas deriven principalmente del bienestar subjetivo y psicológico de sus clientes internos (Swaroop, 2016; Straume \& Vitters $\varnothing, 2015)$.

Achor (2010) afirma que la felicidad conduce al éxito y que las buenas relaciones interpersonales en el lugar de trabajo aumentan significativamente el bienestar organizacional. Esto lleva a grandes empresas como 'Opinno' una consultora de innovación, a implementar un modelo de gestión de recursos humanos con la misión de hacer felices a sus empleados mediante la creación de la figura del jefe de felicidad o gerente feliz. (Gillet-Goinard, Molet \& Monteiller, 2016). Por lo tanto, una de las principales funciones de los profesionales a que se refiere el párrafo anterior será la de cultivar el bienestar colectivo. Por lo tanto, una de las principales funciones de los profesionales referidos anteriormente será la de cultivar el bienestar colectivo. Esto implica que las empresas tengan una estructura organizativa plana, dinámica y flexible para que puedan promover la asertividad, el trabajo en equipo, la comunicación interna entre la dirección y los empleados, la retención de talentos, la cooperación... etc. Sin embargo, para aquellos que piensan que la felicidad laboral no ayuda a alcanzar los objetivos establecidos por la alta dirección, debemos decir que muchos estudios académicos sobre 
la economía de la felicidad han demostrado el vínculo positivo entre el precio de las acciones y el entorno organizacional. (e.g. Erdogan et al., 2012). Sin embargo, es una paradoja que, a pesar de la dramática proliferación de literatura sobre la ciencia de la felicidad, actualmente sabemos poco sobre el papel importante que puede desempeñar en la aplicación de un modelo de gestión de la felicidad en la gestión de los recursos humanos en empresas tecnológicas (por ejemplo Cera, 2012). Para obtener más información sobre este tema, pasamos ahora a la productividad laboral como el elemento generador de la innovación, la creatividad y la competitividad.

La felicidad es una emoción innata en la naturaleza del ser humano y tiene un tácito en la empresa, ya que los miembros de cualquier organización son responsables de cumplir con los objetivos establecidos por la administración, y tener componentes productivos recae en el desempeño de la empresa tanto en lo tangible e intangible.

A medida que las personas se adaptan a las nuevas tecnologías de la información y la comunicación, se requiere cada vez más conocimiento tecnológico y esta situación ha generado empresas con nuevos métodos y nuevas formas de interacción debido a cambios recientes e importantes en la economía y en mercados cada vez más saturados.

Las organizaciones que proponen nuevos métodos para entender cómo mantener felices a sus empleados sin aumentar los costos generan una atmósfera creativa que mejora el desempeño organizacional (esto es un hecho real en grandes corporaciones tecnológicas como Google, Telefónica, etc.). Este tipo de enfoques están lejos de otros tipos de empresas, como las PYMEs, que van a necesitar gradualmente nuevos modelos para desarrollar su competitividad. El objetivo de esta investigación es revisar la literatura para generar un enfoque teórico para mejorar los resultados de la innovación en las empresas desde la perspectiva de la "Gestión de la Felicidad".

\section{La productividad laboral como recurso competitivo para las empresas}

La productividad laboral en las empresas puede orientarse hacia un buen ambiente de trabajo mediante la adopción de determinadas acciones para gestionar el tiempo y los recursos o mejorar las capacidades de la empresa, tanto a nivel tecnológico como procesal. Una buena 
productividad empresarial puede desarrollar una gestión empresarial favorable para lograr la sostenibilidad y la viabilidad futura de la empresa. Debemos diferenciar los términos productividad y competitividad, aunque se relacionen y dependan mutuamente. La productividad es un indicador que ayuda a medir el uso eficiente de los recursos en la producción de bienes y servicios, mientras que la competitividad se define como la capacidad que tiene la empresa para obtener una mayor rentabilidad que otros competidores, con un número limitado de recursos y factores de trabajo. Aunque se trata de la productividad de los recursos humanos o de la productividad del trabajo, también podemos hablar de otros tipos de productividad (por ejemplo, productividad del proceso, productividad de marketing, productividad de la innovación, productividad del conocimiento). Obviamente, los factores que mejoran la productividad laboral afectan directamente el desempeño de las empresas. Algunos de estos factores pueden ser identificados como determinantes de la productividad (como el ausentismo, la rotación de personal, el uso y operación de maquinaria y otros factores del entorno interno y externo de la empresa). Por lo tanto, la cultura organizacional instituida en la organización es una influencia crucial en la productividad laboral, ya que una cultura organizacional flexible y motivadora está relacionada con la mejora del rendimiento del negocio.

Como puede verse, el factor humano siempre está presente en el hecho productivo, ya que requiere la participación de individuos y una relación laboral social permanente para lograr los resultados esperados. En este sentido, muchos autores han sugerido la relación y la influencia positiva del factor humano en la productividad y el desempeño organizacional (Kemppilä \& Lönnqvist, 2003; Saari \& Judge, 2004).

Otros estudios consideran que la formación afecta directamente a la productividad, ya que el ser humano es eficiente y eficaz. Esto es concluyente para el éxito de las organizaciones, ya que la capacitación de los recursos humanos se convierte en una ventaja competitiva sostenible, lo que da como resultado el mejor retorno de su inversión (Lagarde $\&$ Urquidy, 2007; Luthans \& Youssef, 2004). En la literatura, la productividad de los recursos humanos se considera un indicador de la efectividad organizacional como la capacidad del capital humano que incorpora la experiencia, las habilidades y los conocimientos adquiridos para encontrar la mejor manera de hacer la empresa más eficiente y productiva 
(Quijano, 2006). Autores como Visintin et al. (2008) afirman que la mejora de la competitividad de las empresas también se logra mediante mejoras en la productividad laboral.

\section{Productividad laboral en empresas e innovación}

Es indiscutible que la innovación mejora la competitividad de las empresas para hacer frente a un entorno cada vez más competitivo y más globalizado. Este fenómeno afecta a todas las empresas, independientemente de su tamaño o sector. Para lograr una mayor productividad a través de la innovación, el modelo se ha desplazado de los modelos de gestión económica y empresarial basados en el trabajo y el capital (segunda mitad de los noventa) para establecer como factores críticos: el conocimiento, la formación y el capital intelectual, marcando la economía basada en la gestión del conocimiento. Esto significa que ha cambiado de modelos basados en modelos tangibles a modelos basados en recursos de valor agregado o intangibles. En la actualidad, "Gestión de la felicidad" marca una nueva tendencia en los modelos de gestión en la que para lograr resultados innovadores es necesario tener en cuenta el bienestar del empleado. Sin embargo, se plantean las siguientes preguntas: ipuede un empleado con excelente formación ser más eficiente y productivo si trabaja de manera motivada y con una perspectiva de crecimiento o con un plan de incentivos de la empresa donde trabaja? ¿En qué medida la inversión en la cultura de la innovación mejora la rentabilidad de la empresa?

La orientación innovadora de una empresa se mide en parte por el número de patentes, los contratos con el centro de investigación, el gasto en $\mathrm{I}+\mathrm{D}$, el personal dedicado a $\mathrm{I}+\mathrm{D}$ como el más significativo. La relación entre la I + D y la productividad, ha sido analizada en la literatura (por ejemplo, Graschsels \& Jaumandreu, 2013).

La evidencia empírica de una relación positiva entre la productividad empresarial y el desempeño de I + D se encuentra en ellos. Para Hall (2011), las empresas que invierten en I + D pueden aumentar su producción de eficiencia y mejorar los productos que ofrecen, aumentando su demanda y reduciendo sus costos de producción, lo cual mejora el crecimiento del negocio. No olvide que en la literatura académica, la calidad y la productividad en las empresas se relacionan positivamente. Una mejora de la calidad puede conducir a una mejora de la produc- 
tividad y esto puede lograrse mediante una reducción de los costes o aumentando el número de unidades producidas. Crépon, Duguet \& Mairesse (1998) estudia la relación entre productividad, innovación e inversión en I + D y estima que la productividad de las empresas se basa en sus actividades innovadoras. Como podemos ver, la productividad está estrechamente ligada a la innovación y, por lo tanto, esta última es una clave para el crecimiento empresarial y competitivo. El papel de la innovación es concluyente para asumir cambios tecnológicos, la aparición de nuevos sectores de conocimiento altamente intensivos y la aparición de nuevos mercados y oportunidades.

\section{La cultura de la innovación, la creatividad y el bienestar corporativo}

La innovación y la creatividad en el lugar de trabajo se han convertido en determinantes cada vez más importantes del rendimiento organizacional, el éxito y la supervivencia a largo plazo. Las organizaciones buscan aprovechar las ideas y sugerencias de sus empleados para lograr ventajas competitivas (Anderson, De Dreu \& Nijstad, 2004; Zhou \& Shalley, 2003). Amabile et al. (2005) muestran que los flujos positivos causan mayores niveles de creatividad en las personas. Lo anterior muestra que la felicidad nos lleva a la creatividad y no al revés. En la actualidad, no es de extrañar que los gerentes de los departamentos de recursos humanos de grandes corporaciones, como el caso de la multinacional Toyota, se dedican a mejorar continuamente sus procesos productivos de I $+\mathrm{D}$, creando una atmósfera positiva dentro de la organización que fomenta de manera exponencial la innovación, inteligencia emocional, creatividad y bienestar corporativo (Takeuchi, Osono \& Shimiza, 2008). Cameron y Quinn (1999) afirman que una organización con una cultura emprendedora se sustenta en el compromiso con la experimentación y la innovación. Actualmente, una de las cuestiones más importantes es el hecho de que la innovación misma es tan importante como crear un ambiente favorable para generar innovación y promover una verdadera cultura de innovación dentro de las empresas. Por esta última razón, el Gráfico 1 muestra un modelo teórico que incrementa el bienestar corporativo de la fuerza de trabajo mediante la aplicación de la "Gestión de la Felicidad" y es capaz de generar una "cultura de innova- 
ción” para mejorar la competitividad, optimizar y ampliar las actividades innovadoras de la empresa.

Gráfico 1. Modelo generador de Cultura de Innovación aplicando la gestión de la felicidad

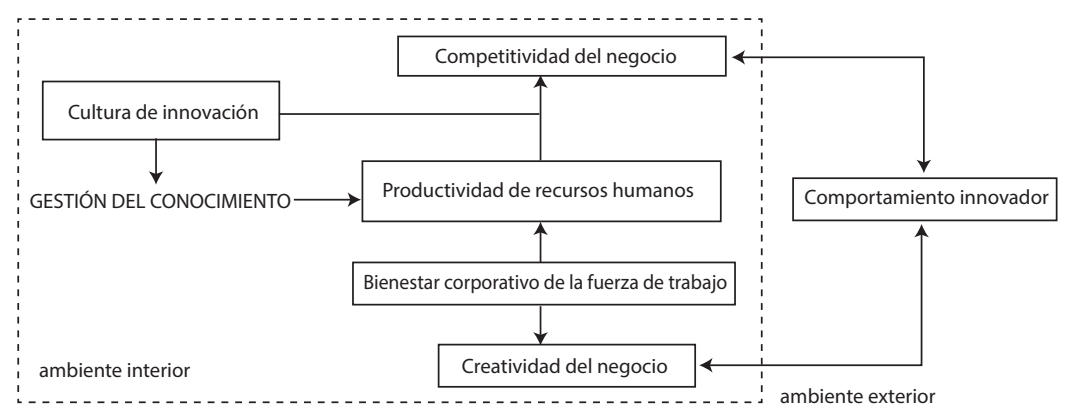

En el modelo anterior, observamos principalmente que el bienestar corporativo de la fuerza de trabajo debe ser fomentado dentro del entorno interno de la empresa donde queremos implementar una cultura de innovación, como un vínculo entre la creatividad empresarial y la competitividad empresarial. Al mismo tiempo, para que el bienestar corporativo sea efectivo, la empresa debe gestionar sus conocimientos de la manera más adecuada. En este punto, es importante el papel de las capacidades y los recursos que cada empresa tiene disponible para su operación, teniendo en cuenta que la administración es responsable de promover la cultura y los valores. Como se muestra en el Gráfico 1, una mejora productiva de los recursos humanos, además de impulsar la competitividad, se convierte en bienestar corporativo fomentando una mayor creatividad colectiva. En el modelo anterior, si ponemos la competitividad, la productividad de los recursos humanos y el desempeño de la innovación juntos, son las variables que generan mayor impacto en la rentabilidad de una organización. Por lo tanto, se presenta un modelo que se adapta a las nuevas tendencias de negocio donde el intangible trae más valor a las empresas para generar beneficios. La literatura también da un lugar preferido al estilo de gestión como crucial para poder manejar el conocimiento, ya que el estilo de gestión apoya los comportamientos y metas de la organización. Por lo tanto, el estilo de liderazgo es clave para una adecuada gestión del conocimiento, siendo estilos 
colaborativos o participativos que favorecen dicho proceso. Cuando se habla de gestión del conocimiento es imprescindible hablar de la cultura corporativa fomentada por la organización, ya que determina el conjunto de valores o creencias que definen el comportamiento estratégico de la organización para su progreso. La gestión del conocimiento implica y abarca muchas variables empresariales (cultura, estilo de gestión, recursos humanos, tecnologías de la información y comunicación, etc.), por lo que se puede explicar mejor desde una perspectiva estratégica y se convierte en esencial cuando existe una preocupación por el bienestar corporativo según la perspectiva de la "Gestión de la Felicidad".

La felicidad corporativa es un concepto complejo y estratégico en la gestión de recursos humanos y organizaciones. Por ejemplo, Baker, Greenberg y Hemingway (2006) contrastan que la felicidad es un comportamiento organizacional y el resultado de una visión estratégica. La definición de organización feliz es definida por los mismos autores como la que cada individuo, en todos los niveles jerárquicos, tiene fortalezas, trabaja en equipo hacia un objetivo común, obtiene satisfacción al desarrollar nuevos productos o servicios y, a través de estos nuevos productos o servicios, a menudo proporciona una diferencia positiva en la vida de los demás.

Por lo tanto, podemos ver cómo el concepto de felicidad organizacional abarca un campo más amplio que el de la satisfacción laboral. Para otros autores, la felicidad empresarial o organizacional es una función del compromiso afectivo a la organización, el sentido de bienestar en el desempeño de sus funciones durante el trabajo y la satisfacción en el trabajo (Hosie, Sevastos \& Cooper, 2007).

La relación entre el desempeño empresarial y la felicidad de los empleados ha sido tratada y discutida por la literatura académica como un aspecto importante a ser determinado, aunque los diferentes estudios varían dependiendo de los diferentes países donde se han realizado, así como los tipos de negocios y sectores. Entre otros investigadores, destacamos Hosie, Sevastos y Cooper (2007) como investigadores que han tratado de determinar la relación entre la felicidad de los empleados y la mejora del desempeño empresarial. Los autores concluyen que existe una correlación positiva entre el desempeño de la organización y los empleados más felices, de acuerdo con el estudio de Fisher (2010).

Como podemos ver, las empresas que se preocupan por la "gestión de la felicidad de los empleados" en la adminitración y la acción 
de los recursos humanos no sólo mejoran el bienestar de los empleados, sino que también generan una herramienta para la propia empresa: un impacto positivo en la productividad de la empresa.

Según diferentes perspectivas y estudios, vemos que una relación entre productividad y felicidad es directa y, sin duda, el cambio empresarial ha sido el responsable de que esas organizaciones no sólo se centren en la producción y la estandarización, sino también en considerar a sus empleados de una manera diferente, ya que son la clave del éxito ya que no hay mejor factor intangible que el humano.

Otros autores demuestran que la felicidad predice resultados e indicadores importantes, como un aumento de la productividad y del rendimiento laboral, un mayor autocontrol, una excelente relación interpersonal y una mejor salud física y mental. (Lyubomirsky, King \& Diener, 2005, Peterson, Luthans, Avolio, Walumbwa \& Zhang, 2011; Pryce-Jones, 2010).

\section{La innovación está en el estilo de gestión del modelo de negocio}

En la actualidad, existe un amplio consenso dentro de la gestión empresarial para señalar la innovación (ya sea en bienes, servicios, procesos o sistemas de gestión) como uno de los elementos clave para mejorar la actividad productiva, aumentar la facturación o lograr ventajas competitivas sostenibles en el mercado (Robbins \& O'Gorman, 2016, Löfsten, 2014, Kmieciak, Michna \& Meczynska, 2012, Sorescu et al., 2011, Varis \& Littunen, 2010) Se ha llevado a cabo un gran número de investigaciones para demostrar la relación entre la innovación y el rendimiento de la empresa, (véase, en este sentido, por ejemplo, De Lema, GálvezAlbarracín \& Maldonado-Guzmán, 2016, Mir, Casadesús \& Petnj 2016; $\&$ Kuo, 2016, Cho \& Pucik, 2005). Sin embargo, los enfoques adoptados en estos estudios no han tenido en cuenta las variables que están en nuestra revisión teórica si tomamos en cuenta tales como la promoción de la satisfacción laboral y la promoción de la creatividad empresarial como motor de la innovación. En este sentido, algunos estudios incluyen la cultura del esfuerzo y la promoción de la motivación de los empleados para mejorar la innovación, por ejemplo Kang et al. (2016), confirman que las empresas deben adoptar modelos de gestión empresarial enfocados a aumentar la pasión de los empleados, fomentando un 
clima participativo dentro de la organización, ambos factores aumentan significativamente el comportamiento innovador de la compañía y sus resultados. Finalmente, se hace un llamamiento a los directivos de las empresas para que reflexionen sobre su estilo de gestión y de la revisión teórica realizada, se les anima a promover un estilo de liderazgo basado en la Gestión de la Felicidad por las ventajas que se logran de manera intangible para el organización.

\section{Conclusiones y discusión}

Nuestro modelo teórico contribuye a la literatura de Gestión de la Felicidad en diferentes aspectos: Desde las capacidades dinámicas, proponemos que las empresas son capaces de mejorar sus resultados innovadores y competir en el mercado no sólo por su capacidad para explotar sus recursos y sus capacidades existentes, pero también gracias a su capacidad para iniciar, renovar y desarrollar el bienestar corporativo (Teece, Pisano \& Shuen, 1997), haciendo hincapié en que la gestión del conocimiento es crucial.

Se propone un modelo sencillo y claro que ayude a los administradores a explotar mejor sus capacidades de mejora organizativa. En cuanto a las implicaciones para la gestión, podemos demostrar que el modelo propuesto podría mejorar la gestión actual de las empresas, ya que el bienestar corporativo optimiza la productividad laboral y la creatividad al permitir a estas empresas lograr la mejora de sus resultados innovadores. Anderson, Potočnik y Zhou (2014) proponen la siguiente definición integradora sobre creatividad e innovación en el trabajo:

La creatividad y la innovación en el trabajo son el proceso, los resultados y los productos de los intentos de desarrollar e introducir maneras nuevas y mejoradas de hacer las cosas. La etapa de creatividad de este proceso se refiere a la generación de ideas, y la innovación se refiere a la etapa posterior de implementar ideas hacia mejores procedimientos, prácticas o productos. La creatividad y la innovación pueden ocurrir a nivel del individuo, del equipo de trabajo, de la organización o en más de uno de estos niveles combinados, pero siempre resultarán en beneficios identificables en uno o más de estos niveles de análisis.

Esta definición es excelente, pero no toma en cuenta la gestión de la felicidad como responsable de generar bienestar corporativo. Proponemos una reflexión a los directivos para que puedan promover 
un entorno de apoyo y colaboración para su capital humano y sus grupos de interés. Esto repercutirá en la gestión de los conocimientos, lo que facilitará las empresas inmersas en un proceso continuo de cambio y adaptación, siempre y cuando adopten una estructura organizativa flexible y dinámica.

Desde la perspectiva de la Gestión de la Felicidad, ofrecemos una forma de desarrollar capacidades de cambio y ayudar a las empresas con un modelo teórico que represente el bienestar corporativo, como un proceso o como un ciclo espiral donde los valores culturales promovidos son responsables de generar competitividad y creatividad. Ambos aspectos son esenciales para mejorar los resultados de innovación.

Como limitación de nuestro trabajo, basta con observar que el modelo de negocio presentado se centra en las variables de negocio, que consideramos críticas debido a su especial relación con la innovación. Por lo tanto, una o más variables adicionales deberían haber sido incluidas para estudiar sus efectos. Por ejemplo, la capacidad de mejorar la competitividad llevada a cabo por la alta gerencia, o incluso analizar cómo factores como la empresa que colabora con centros tecnológicos, o mantener alianzas estratégicas con otras empresas afecta el modelo teórico propuesto. En investigaciones futuras, se debe hacer una prueba empírica del modelo para verificar su validez y su impacto en la gestión de las organizaciones y sus resultados.

Las conclusiones finales después de la revisión de la literatura apoyan lo que algunos autores confirman principalmente que un trabajador está más motivado, tiene menos ausentismo, es más creativo, tiene mejores relaciones con sus colegas y con los clientes u otras partes interesadas, es más productivo, etc. arriba indica que las empresas que manejan la felicidad en su organización en la búsqueda del bienestar subjetivo del trabajador obtienen mayores beneficios y logran que algunos clientes satisfechos mejoren su productividad (Harter et al., 2010).

\section{Referencias}

Amabile, T. M., Barsade S.G, Mueller, J.S. \& Staw B.M.(2005). Affect and Creativity at Work. Administrative Science Quarterly, (50), 367-403. https://doi. org/10.2189/asqu.2005.50.3.367

Anderson, N., De Dreu, C. K. W., \& Nijstad, B. A. (2004). The routinization of innovation research: A constructively critical review of the state-of-the-science. Journal of Organizational Behavior, (25), 147-173. https://doi.org/10.1002/job.236 
Andersron, N. Potočnik, K, and Zhou J. (2014) Innovation and Creativity in Organizations. A State-of-the-Science Review, Prospective Commentary, and Guiding Framework. Journal of Management, (40), 1297-1333. https://doi. org/10.1177/0149206314527128

Baker, D., Greenberg, C., \& Hemingway, C. (2006). What Happy Companies Know. New Jersey: Pearson.

Beauregard, A. (2010). Introduction: The Import of Intrapersonal and Interpersonal Dynamics in Work Performance. British Journal of Management, (21), 225-261. https://doi.org/10.1111/j.1467-8551.2010.00704

Binder, M., \& T. Broekel. (2012). Happiness no matter the cost? An examination on how efficiently individuals reach their happiness levels. Journal of Happiness Studies, (13), 621-645. https://doi.org/10.1007/s10902-011-9283-5

Cameron, K., \& Quinn R. (1999). Diagnosing and changing organizational culture: Based on the competing values framework. Addison-Wesley.

Cera Cera, R. (2012). "New mission for competitive business: Happiness Management. Human capital". Journal for the integration and development of human resources (265), 90-94.

Cho, H., \& Pucik, V. (2005). Relationship between innovativeness, quality, growth, profitability, and market value. Strategic Management Journal, 26(6), 555-575. https://doi.org/10.1002/smj.461

Crépon, B., Duguet, E., \& Mairesse, J. (1998). Research and Development, Innovation and Productivity: An Econometric Analysis at the Firm Level. Economics of Innovation and New Technology, (7), 115-158. https://doi.org/10.3386/w6696

De Lema, D. G. P., Gálvez-Albarracín, E. J., \& Maldonado-Guzmán, G. (2016). Efecto de la innovación en el crecimiento y el desempeño de las Mipymes de la Alianza del Pacífico. Un estudio empírico. Estudios Gerenciales, (32), 326-335. https://doi.org/10.1016/j.estger.2016.07.003

Dolan, P., \& Metcalfe, R. (2012). The relationship between innovation and subjective wellbeing. Research Policy, (41), 1489-1498. https://oi.org/10.1016/j.respol.2012.04.001

Doraszelski, U., \& Jaumandreu, J. (2013). R\&D and Productivity: Estimating endogenous productivity. Review of Economic Studies, (8)0, 1338-1283. https://doi. org/10.1093/restud/rdt011

Erdogan, B., Bauer, T. N., Truxillo, D. M., \& Mansfield, L. R. (2012). Whistle while you work: A review of the life satisfaction literature. Journal of Management, (38), 1038-1083. https://doi.org/10.1177/0149206311429379

Ferrer-i-Carbonell, A. (2012).Happiness economics. Series, (4), 35-60. https://doi. org/10.1007/s13209-012-0086-7

Fisher, C. (2010). Happiness at work. International Journal of Management Review, 12(4), 384-412. https://doi.org/10.1111/j.1468-2370.2009.00270

Gavin, J.H., \& Mason, R.O. (2004). The virtuous organization: the value of happiness in the workplace. Organizational Dynamics Journal, (33), 379-392. https://doi. org/10.1016/j.orgdyn.2004.09.005 
Gillet-Goinard, F., Molet, H., \& Monteiller, G. (2016). Happy management: Osez manager par l'enthousiasme. París: Dunod Editions

Griliches, Z. (1970). R\&D and the productivity slowdown. American Economic Review, (2), 343-348. https://doi.org/ 10.3386/w0434

Hall, B. (2011). Innovation and productivity. UNIT-MERIT Working Paper Series 2011-028. https://doi.org/10.3386/w17178

Harter, J. K., Schmidt, F. L., Asplund, J. W., Killham, E. A., \& Agrawal, S. (2010). Causal impact of employee work perceptions on the bottom line of organizations. Perspectives on Psychological Science, (5), 378-389. https://doi. org/10.1177/1745691610374589

Hosie, P. Sevastos, P. \& Cooper, C. (2007). The Happy Productive Worker Thesis and Australian Managers. Journal of Human Values, (13), 151-176. https:// doi.org/10.1177/097168580701300207

Hosie, P., \& Sevastos, P. (2009). Does the happy-productive worker thesis apply to managers?. International Journal of Workplace Health Management, 2, 131-160. https://doi.org/10.1108/17538350910970219

Kang, J. H., Matusik, J. G., Kim, T. Y., \& Phillips, J. M. (2016). Interactive effects of multiple organizational climates on employee innovative behavior in entrepreneurial firms: A cross-level investigation. Journal of Business Venturing, (31), 628-642. https://doi.org/10.1016/j.jbusvent.2016.08.002

Kemppilä, S., \& Lönnqvist, A. (2003). Subjective productivity measurement. The Journal of American Academy of Business, (2), 531-537. (http:// goo.gl/RjazVi) (16-05-2017)

Kmieciak, R., Michna, A., \& Meczynska, A. (2012). Innovativeness, empowerment and IT capability: evidence from SMEs, Industrial Management \& Data Systems, (112), 707-728. https://doi.org/10.1108/02635571211232280

Lagarda, A.M., \& Urquidy, M.R. (2007). Human capital and productivity in microenterprises. Economic Research, (66), 81-115. (http:// goo.gl/Sc68Qt) (13-062017)

Lii, P., \& Kuo, F. I. (2016). Innovation-oriented supply chain integration for combined competitiveness and firm performance. International. Journal of Production Economics, (174),142-155. https://doi.org/10.1016/j.ijpe.2016.01.018

Löfsten, H. (2014). Product innovation processes and the trade-off between product innovation performance and business performance. European Journal of Innovation Management, (17), 61-84. https://doi.org/10.1108/ejim-04-2013-0034

Luthans, F., \& Youssef, C. (2007). Emerging positive organizational behavior. Journal of Management, (33), 321-349. https://doi.org/10.1177/0149206307300814

Luthans, F., \& Youssef, C.M. (2004). Human, Social, and Now Positive Psychological Capital Management: Investing in People for Competitive Advantage. Organizational Dynamics, (33), 143-160. https://doi.org/10.1016/j.orgdyn.2004.01.003

Lyubomirsky, S., King, L. \&Diener, E. (2005). The benefits of frequent positive affect: does happiness lead to success?. Psychological Bulletin, (131), 803-855. https:// doi.org/10.1037/0033-2909.131.6.803 
Máñez, J.A., Rochina-Barrachina, M.E., \& Sanchis-Llopis, J.A. (2006). The decision to invest in R\&D: a panel data analysis for Spanish manufacturing. International Journal of Applied Economics, (3), 80-94. (http:// goo.gl/jiZ1oZ) (16-052017)

Mir, M., Casadesús, M., \& Petnji, L. H. (2016). The impact of standardized innovation management systems on innovation capability and business performance: An empirical study. Journal of Engineering and Technology Management, (41), 26-44. https://doi.org/10.1016/j.jengtecman.2016.06.002

Peterson, S.J., Luthans, F., Avolio B.J., Walumbwa F.O., \& Zhang Z. (2011). Psychological Capital and Employee Performance: A Latent Growth Modeling Approach. Personnel Psychology, (64), 427-450. https://doi.org/10.1111 /j.1744-6570.2011.01215

Pryce-Jones, J. (2010). Happiness at work: Maximizing your psychological capital for success. UK: Wiley-Blackwell. https://doi.org/10.1002/9780470666845

Quijano, S. (2006). Human Resources Management and Consulting in Organizations. Barcelona: Icaria.

Rego, A., Ribeiro, N., Pina, M., \& Correia Jesuino, J. (2011). How happiness mediates the organizational virtuousness and affective commitment relationship. Journal of Business Research, (64), 524-532. https://doi.org/10.1016/j.jbusres.2010.04.009

Robbins, P., \& O'Gorman, C. (2016). Innovation processes: do they help or hinder new product development outcomes in Irish SMEs?, The Irish Journal of Management, (35), 104-107. https://doi.org/10.1515/ijm-2016-0006

Saari, L.M., \& Judge, T.A. (2004). Employee attitudes and job satisfaction. Human Resource Management, (43), 395-407. https://doi.org/10.1002/hrm.20032

Salas Vallina, A. (2013). Leadership transformational capacity organizational learning and happiness in work. Doctoral Thesis. University of Valencia. (http:// goo.gl/ AegDy6) (16-05-2017)

Seligman, M.E.P. (2003). True happiness. Barcelona: Ediciones B.

Shawn, A. (2010). The happiness advantage. The Seven Principles of Positive Psychology That Fuel Success and Performance at Work. Nueva York: Broadway Books.

Sorescu, A., Frambach, R. T., Singh, J., Rangaswamy, A., \& Bridges, C. (2011). Innovations in retail business models. Journal of Retailing, (87), 3-16. https://doi. org/10.1016/j.jretai.2011.04.005

Straume, L. V., \& Vitterso, J. (2015). Well-Being at Work: Some Differences Between Life Satisfaction and Personal Growth as Predictors of Subjective Health and Sick-Leave. Journal of Happiness Studies, (16), 149-168. https://doi. org/10.1007/s10902-014-9502-y

Swaroop, P. (2016). Effects of happiness as a Brand Building Strategy. International Journal of Management and Economics, (2), 547-552. (http:// goo.gl/pvu7BI) (16-05-2017)

Takeuchi H., Osono, E., \& Shimiza, N. (2008). The contradictions that drive Toyota's success. Harvard Bussiness Review, 86 (6), 116-124. https://doi.org/10.1108/ sd.2009.05625aad.009 
Teece, D. J., Pisano, G., \& Shuen, A. (1997). Dynamic Capabilities and Strategic Management. Strategic Management Journal, 18(7), 509-533. https://doi. org/10.1002/(sici)1097-0266(199708)18:7<509::aid-smj882>3.0.co;2-z

Tomas Jodar, D. (2015). The happiest company in the world. Barcelona: Empresa Activa. Ulrich, D., \& Ulrich, W. (2010). The why of work. U.S: McGraw Hill.

Varis, M., \& Littunen, H. (2010). Types of innovation, sources of information and performance in entrepreneurial SMEs. European. Journal of Innovation Management, (13), 128-154. https://doi.org/10.1108/14601061011040221

Vázquez, S. (2012). Happiness at Work and in Life. A Coruña: Actualia Editorial.

Vázquez, S. (2016). A people management model oriented happiness at work. Doctoral Thesis. University of Compostela. (http:// goo.gl/Ml3qkS) (16-05-2017)

Visintin, S., Di Meglio, G., Rubalcaba, L., \& Cuadrado, J.R. (2008). Competitiveness and international trade in services in Spain. Spanish papers Economy, 65-78.

Wolf, R. (2013). Corporate Social Responsibility as a tool to increase happiness among workers in an organization. Indian Journal of Management, (6), 45-49. https:// doi.org/10.17010/pijom/2013/v6i3/59986

Wright, T., Cropanzano, R., Denney, P., \& Moline, G. (2002). When a happy worker is a productive worker: a preliminary examination of three models. Canadian Journal of Behavioural Science, 34, 146-150. https://doi.org/10.1037/h0087165

Zelenski, J. M., Murphy, S. A., \& Jenkins, D. A. (2008). The happy-productive worker thesis revisited. Journal of Happiness Studies, (9), 521-537. https://doi. org/10.1007/s10902-008-9087-4

Zhou, J., \& Shalley, C. (2003). Research on employee creativity: A critical review and directions for future research. In J. J. Martocchio \& G. R. Ferris (Eds.), Research in personnel and human resources management, (22),165-217. https:// doi.org/10.1016/s0742-7301(03)22004-1 



\title{
Análisis de factibilidad en la producción de calzado ortopédico para niños en la provincia de Tungurahua
}

\section{Feasibility analysis in the production of orthopedic footwear for children in the Province of Tungurahua}

\author{
Arturo Montenegro es Profesor de la Universidad Técnica de Ambato (Ecuador) (af.montenegro@uta.edu.ec) \\ (http://orcid.org/0000-0003-0630-2272)
}

Ruth Zamora Sánchez es Profesora de la Universidad Técnica de Ambato (Ecuador) (ra.zamora@uta.edu.ec) (http://orcid.org/0000-0003-4982-8741)

Valeria Arias-Villavicencio es Profesora de la Pontificia Universidad Católica de Ecuador (valeariass1129@ gmail.com) (http://orcid.org/0000-0002-1213-6621)

\begin{abstract}
Resumen
El presente trabajo analiza, la factibilidad en la producción de calzado ortopédico en Tungurahua para niños en edades comprendidas entre los 0 y 4 años, en los cuales se pueden evidenciar patologías de los pies, que, con el debido tratamiento y el calzado adecuado, se puede solucionar gracias al uso de la tecnología, con lo cual propone cubrir un mercado actualmente desatendido como es el calzado ortopédico para edad temprana. La investigación es de tipo descriptiva, cuantitativa, no experimental con muestreo probabilístico, basada en el análisis de datos obtenidos durante un horizonte de tiempo de 1 año, teniendo como técnicas de recopilación de información fichas de observación directa y entrevistas a expertos calzadistas; y la realización de una encuesta a quienes utilizan los productos motivo de la investigación. La interpretación fue mediante discusiones participativas. En lo referente a resultados, el mercado de la producción de calzado existe muy poca competencia y dedicación por parte los productores a elaborar calzado ortopédico ya que como se indica es necesario realizar inversiones adicionales con la finalidad de obtener un producto de calidad. Como principales hallazgos de la investigación, se comprobó que gran parte de los encuestados desconocen la existencia de patologías, tales como: pie plano, pie pronador y pie supinador. De igual manera, se verifica la necesidad de contar con un especialista en el tratamiento de problemas de los pies en el proceso de fabricación de calzado ortopédico, el cual vaya verificando el uso de los materiales adecuados para corregir cada problema.
\end{abstract}

\begin{abstract}
The present study analyzes the feasibility of the production of orthopedic footwear in the province of Tungurahua for children between 0 and 4 years of age, in which pathologies of the feet can be evidenced, which, with proper treatment and footwear suitable, can be solved thanks to the use of the technology with which it proposes to cover a currently neglected market such as orthopedic footwear for early age. The research is of a descriptive, quantitative, non-experimental type with probabilistic sampling, based on the analysis of data obtained during a time horizon of 1 year, having as techniques of information collection direct observation chips and interviews with experts; And a survey using the products that were the subject of research and interpretation was through participatory discussions. In terms of results, the market for shoe production there is very little competition and dedication on the part of producers to develop orthopedic footwear since as indicated it is necessary to make additional investments in order to obtain a quality product. As the main findings of the investigation, it was verified that a great part of the respondents do not know the existence of pathologies, such as: flat foot, pronated foot and supinated foot. Likewise, there is a need to have a specialist in the treatment of foot problems in the manufacturing process of orthopedic footwear, which will verify the use of suitable materials to correct each problem.
\end{abstract}

\section{Palabras clave | keywords}

Patología, calzado infantil, calzado ortopédico, comercialización, calzado, Tungurahua. Pathology, children's footwear, orthopedic footwear, marketing, footwear, Tungurahua. 


\section{Introducción}

El entorno de negocios de Tungurahua ofrece las características propias de la cercanía territorial para la conformación de clústeres ${ }^{1}$ estratégicos, los cuales inciden en la competitividad esencialmente mediante el crecimiento de la productividad empresarial y el progreso tecnológico, la misma que contribuye a crear y mejorar productos que satisfacen las necesidades sociales. De igual manera, la colaboración entre los profesionales del mismo clúster ${ }^{2}$ permite la profesionalización de los empresarios dentro de su actividad económica.

La apertura de los mercados hacia un contexto más amplio de comercio ha contribuido a un crecimiento de entornos más competitivos, en donde las empresas deben desarrollar sus actividades. Este proceso de internacionalización ha afectado principalmente a los sectores productivos más tradicionales debido a la incapacidad que presentaban para enfrentarse a los grandes competidores globales, como: acceso a tecnología, falta de capacitación, limitado conocimiento de creación, ilustración y diseño de calzado, etc.

Tungurahua se ha diferenciado de otras zonas productivas del país debido a su conglomeración empresarial, más precisamente, en ella se concentran alrededor de un $5 \%$ de las empresas ecuatorianas, mayoritariamente microempresas, con un $92,25 \%$ de participación en la provincia (INEC, 2014).

La economía provincial depende principalmente de los siguientes clústeres: cuero y calzado, comercio y reparación de vehículos, textil, madera y muebles, y artesanías. No obstante, las empresas ya no sólo consideran la relación de costos como un atributo de competitividad, sino que éstas son cada vez más conscientes de que deben analizar factores distintos que les ayuden a contar con nuevas formas de competencia en su sector productivo, y que da como resultado una mayor inversión en el proceso de diseño, patronaje y modelaje del producto y aplicación

1 Se definen como "redes industriales, sistemas industriales, sistemas tecnológicos, y áreas de recursos, como significados similares al de clúster" (Almquist, Norgren y Strandell, 1998, p. 14).

2 ... un conjunto de actividades similares delimitadas geográficamente, con activos canales de transacciones comerciales, comunicación y diálogo, que comparten infraestructura especializada, mercado de trabajos y de servicios, y que enfrentan oportunidades y amenazas comunes (Rosenfeld, 1996, citado en Otero et al., 2004, p. 7). 
de innovación, que contribuya a mejorar aspectos de valoración por parte de los clientes. En el caso del sector calzado, los consumidores apreciaran distintos aspectos, tales como el confort.

En este contexto, el objetivo de este trabajo es presentar cómo la producción exitosa de calzado ortopédico en la provincia de Tungurahua en los actuales momentos, beneficiará a crear nuevos productos para que estén disponibles en el mercado, con la finalidad de ofrecer a sus clientes y futuros consumidores un producto de calidad, con un diseño que satisfaga sus necesidades, que siga las tendencias y aporte un valor añadido, que en este caso sería la mejora de su postura al caminar.

\section{Marco teórico - Estado de la cuestión}

Tirado (2013, p. 25) comenta que:

La orientación al marketing social ha venido repuntando desde tiempos anteriores; en este enfoque las empresas se interesan no solo por el consumidor individual, sino por la sociedad en su conjunto. Por tanto, se procede al estudio de las necesidades de todos los agentes del mercado (consumidores, clientes, proveedores, competidores, trabajadores y sociedad en general) buscando la creación, intensificación y mantenimiento de relaciones duraderas con ellos.

Es importante recalcar que en la actualidad vemos cómo la concepción y aplicación del marketing en la empresa ha sufrido una reinterpretación sucesiva del concepto que ha abandonado la mentalidad de hace décadas centrada en la producción y la venta llamada también «marketing pasivo», para dar cabida a un enfoque más preocupado por la figura del consumidor, sus necesidades y deseos, con el objetivo último de mejorar las relaciones duraderas con estos y el resto de agentes del entorno, siendo éstas las nuevas estrategias denominadas de «marketing activo».

Según Vargas (2016) la empresa de calzado Lombardía, considera que el impacto de planificar estratégicamente incide en aumentar conocimientos acerca de cómo optimizar los procesos de fabricación de calzado. Conjuntamente con la investigación se lleva a cabo analizar probabilidades de éxito y el cumplimiento de objetivos.

Desde este punto de vista, la planificación incide directamente en la producción, teniendo un factor importante dentro de las líneas que manejan principalmente las empresas manufactureras; por eso se busca 
un análisis de factibilidad previo a la implementación de una línea de producción nueva como es la de calzado ortopédico. Con todos estos antecedentes se propone, gracias a la definición de Munuera (2011), el portafolio de productos, entendiendo "la justificada existencia de diferentes productos en la empresa y la interrelación entre ellos" (p.149).

Dentro de las líneas de producción, el portafolio de productos busca ser una estrategia para balancear los tiempos improductivos y cubrir con la capacidad instalada de la empresa. Es decir, que los productores de calzado no descuiden la línea de negocio tradicional, sino que también aprecien que se puede aumentar el portafolio de productos. Así, identificar oportunidades es la capacidad que tiene un emprendedor o un equipo emprendedor para recopilar y consultar información internacional, nacional, regional y local en torno al comportamiento histórico del mercado donde se pretende intervenir en el proyecto a desarrollar.

Determinar el sector al que pertenece el proyecto, el segmento o los segmentos de mercado de interés para el mismo, el mercado potencial para las líneas de productos o de servicios, y la participación de los competidores principales, es fundamental como requisito de línea base, antes de iniciar el estudio de pre factibilidad o factibilidad (Méndez, 2010). También, como parte de la implementación de una nueva línea de productos, es importante realizar un estudio de factibilidad, un análisis de viabilidad y un estudio de mercado que para Méndez (2010) es el análisis detallado de un proyecto desde las siguientes perspectivas: mercado, técnica, legal, organizativa, inversión, fuentes de financiamiento, ingresos, costos y gastos, bondades financieras e impacto socioeconómico.

Sin embargo, la viabilidad de un proyecto no solo abarca aspectos financieros, ésta entendida como la posibilidad de desarrollar un plan de negocio en el cual se tendrá en cuenta viabilidad técnica, legal, financiera y social (Méndez, 2010). Según Madorrán-Álvarez \& Molins-Martin (2016, pp. 50-70), con el estudio de mercado se trata de averiguar la respuesta del mercado ante un producto o servicio, con el fin de planear la estrategia comercial más adecuada.

Ante esto, surge la pregunta ¿Es necesario definir qué es un nuevo producto y la mejor apreciación la tiene, los nuevos productos son la sangre que da vida a la empresa y mantiene su crecimiento? (Kerin, 2011). $\mathrm{Si}$ un producto difiere de otros ya existentes puede definirse como nuevo. 
Se define «producto» como una mercancía capaz de satisfacer una necesidad o un deseo y que se ofrece a un mercado objetivo para su observación, adquisición uso o consumo. Un producto es una totalidad compleja de atributos tangibles, de representaciones y emociones basadas en la notoriedad del fabricante o de su marca, etc. (Kotler, 2012). Del mismo modo Chaín (2011) también considera al producto como un conjunto de atributos, el cual tiene por lo menos tres estados que son: el producto mismo, sus características y usos; el producto agregado que valora el cliente por su diseño, envase, marca y calidad; y el nivel de fidelización, que engloba la instalación del producto, el tiempo de entrega, las garantías y el servicio postventa.

Por su parte, el estudio técnico, también llamado ingeniería del proyecto, inicia con el aspecto organizacional describiendo la figura legal de la organización, seguido de la misión, visión y valores empresariales, su estructura, forma de gobierno, y a los accionistas. Se considera prudente aclarar las competencias de los colaboradores o definir los puestos de trabajo (Hernández, 2010). Después se analiza la localización del proyecto a nivel micro y macro y es conveniente analizar el impacto ambiental. Para determinar la infraestructura, es preciso describir los procesos productivos que con lleva el proyecto, los activos indispensables y las inversiones por hacer.

El estudio técnico tiene como objetivo verificar la posibilidad técnica de la fabricación del producto, así como también analizar y determinar el tamaño, la localización, los equipos, las instalaciones y la organización óptimos requeridos para la realización de la producción (Urbina, 2013). Este estudio es parte integral del éxito de numerosas compañías y difiere considerablemente de una industria a otra (Jacobs, 2014). Entre tanto, la competencia clave de una empresa es lo que la hace mejor que sus competidores, dicha competencia puede ser cualquier cosa, desde el diseño de productos hasta la dedicación sustentable de los empleados de una empresa. El proceso presenta la secuencia básica de los pasos o actividades con que la empresa concibe, diseña y lleva un producto al mercado, es decir, son las fases del proceso genérico del desarrollo de productos. 


\section{Metodología}

La presente investigación es de alcance descriptivo, diseño cuantitativo-no experimental con muestreo probabilístico, basada en el análisis de datos obtenidos durante un horizonte de tiempo comprendido de 1 año (2016). Las técnicas implementadas para la recopilación de la información fueron: la utilización de fichas de observación directa en los puntos de venta de la empresa "Calzado LIWI», una entrevista a un experto calzadista y una encuesta aplicada a 112 clientes, quienes utilizan productos de calzado de la precitada empresa mayorista y quienes en la actualidad son productores de calzado ortopédico en la provincia de Tungurahua (Ecuador).

La encuesta, aplicada a través de cuestionario conformado por 10 preguntas, fue validada por la opinión de dos profesionales-expertos del sector calzado, quienes tienen nexo de colaboración a la Cámara de Calzado de Tungurahua. El análisis de datos se realizó a través del instrumento estadístico IBM SPSS® y su interpretación fue mediante discusiones participativas de los autores.

\section{Resultados}

Procesando los resultados obtenidos en la encuesta aplicada a los potenciales clientes que serían el público objetivo de la empresa, se pudo obtener información acerca del nivel de aceptación de los productos de calzado ortopédico dirigido a los infantes con edades comprendidas entre 0 y 4 años. Así, se comprobó que el $84 \%$ de la población encuestada estaría interesada en adquirir calzado ortopédico para los pies de sus hijo/as, mientras que el $2 \%$ de los encuestados indica no estar interesado en adquirir este tipo de producto. Llama la atención que el $14 \%$ restante, estaría interesado en adquirir el producto si se le facilitara información sobre aspectos adicionales, tales como: precio, colores, diseño, entre otros.

A este respecto, el gráfico 1 muestra los factores que los clientes valoran al momento de realizar la compra de un producto de calzado, entre el que destaca la «durabilidad» con un $37 \%$ y la «calidad» con un $31 \%$. 


\section{Gráfico 1. Factores que valoran los clientes encuestados al adquirir un producto de calzado}

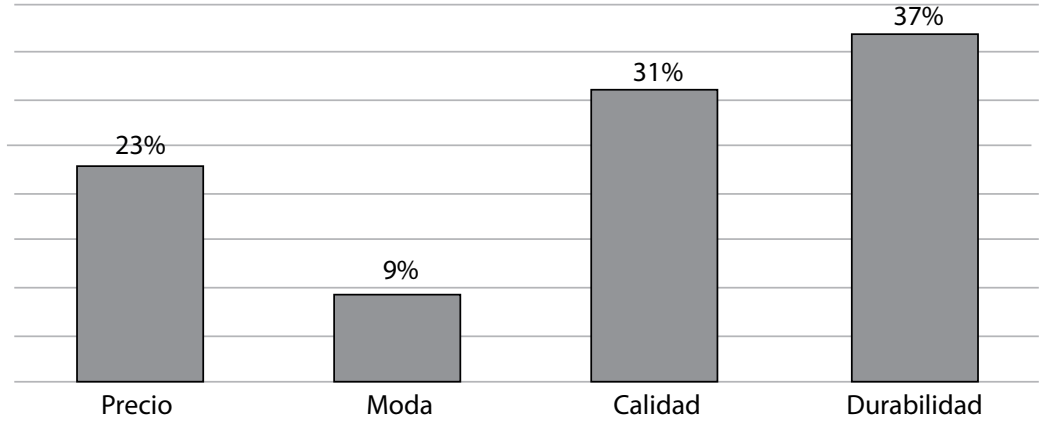

Factores valorados por el cliente

A su vez, y tal como detalla el gráfico 2, los encuestados consideran que la utilización de calzado ortopédico mejorará la calidad de vida de sus hijos, debido a que podrán caminar con un zapato que no perjudicará su modo de andar, sino más bien ayudará a corregir los problemas detectados.

\section{Gráfico 2. Percepción de los encuestados sobre la mejora de calidad de vida de sus hijos con el uso de calzado ortopédico}

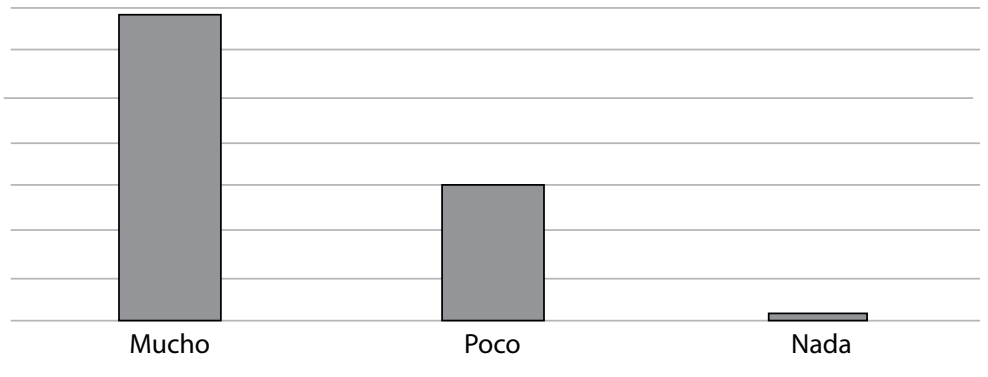

Percepción de uso del calzado ortopédico

La encuesta también facilitó información sobre lo escasamente informada que está la población en tema de patologías, evidenciando que el $67 \%$ de los encuestados no ha escuchado hablar nunca sobre el 
pie pronador ${ }^{3}$ o supinador ${ }^{4}$ (gráfico 3), problemática que afecta a los niños en los primeros años de vida y que si no se trata debidamente puede dejar secuelas para su futuro.

Gráfico 3. Conocimiento de los encuestados acerca de las patologías ortopédicas existentes

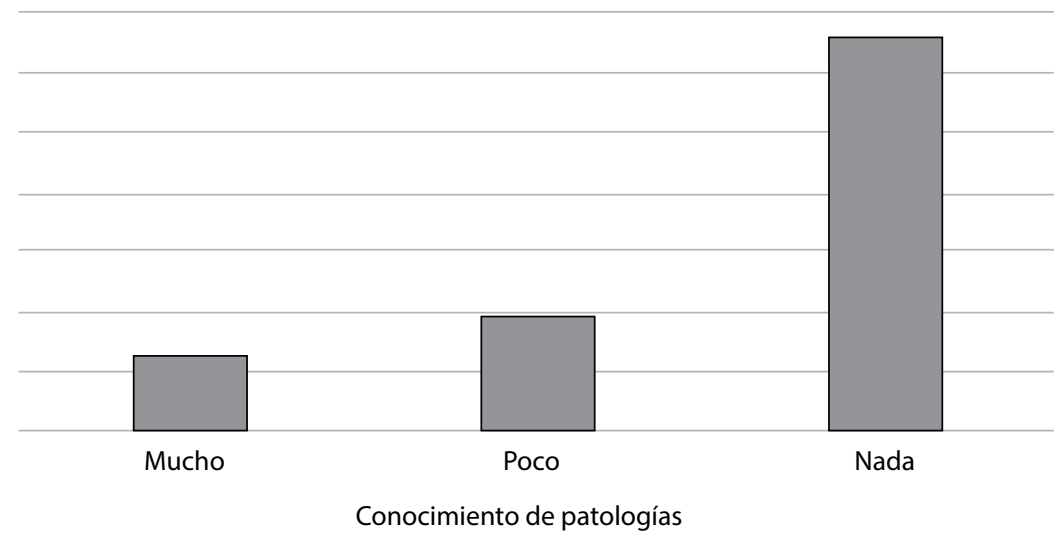

Otra de las patologías que desconocen los encuestados es que el $55 \%$ no conocen qué es el pie plano ${ }^{5}$, por lo que se entiende puede existir un porcentaje de la población que sufra de pie plano y lo desconozca, sin tener tampoco conocimiento que hay productos para su tratamiento.

Respecto a la competencia, la encuesta muestra que los clientes sí conocen empresas que producen productos de ortopedia y que ofrecen soluciones para problemas de los pies, siendo el calzado de la empresa «Calzado LIWI» y «Centro Ortopédico Freire» los más conocidos en la provincia de Tungurahua.

El gráfico 4, por su parte, detalla que el 94\% de los encuestados estrarían dispuestos a adquirir calzado ortopédico para niños si las

3 Se entiende por pronación a la pisada cuya la rotación medial sobre el eje del hueso, el pie se 'hunde' hacia dentro del pie.

4 Se entiende por supinación a la pisada cuya rotación lateral sobre el eje del hueso, 'hundimiento' hacia el exterior del pie

5 Se define como la deformación caracterizada por la desaparición del puente del pie, de manera que para andar se apoya toda la planta en el suelo. 
empresas de productos de calzado incrementaran su oferta. Ello evidencia que hay un público sin atender respecto a este tipo de producto.

\section{Gráfico 4. Intención de compra de los encuestados}

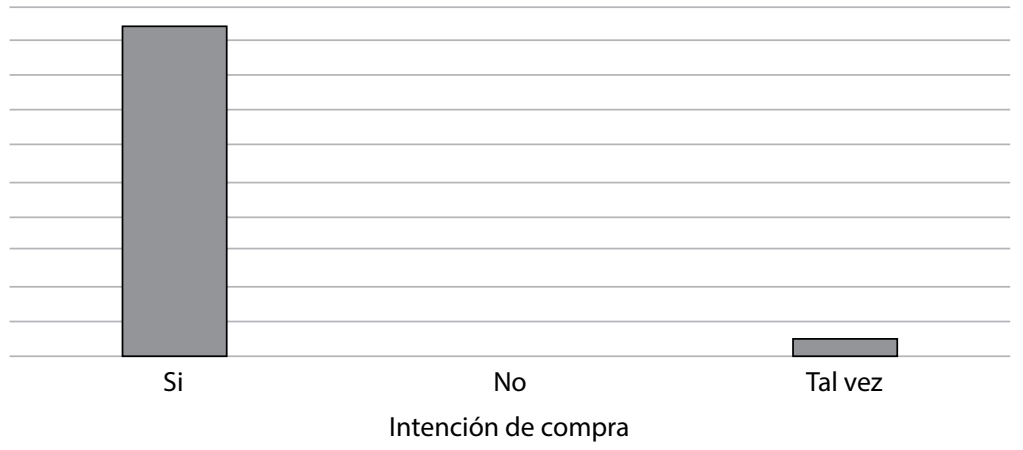

Los precios que los padres de los niños estarían dispuestos a pagar se encuentran en: USD 39,90 por un 79\% de los encuestados, mientras que el 21\% restante estaría dispuesto a pagar un precio de hasta USD 59,90; ello en función a las bondades que el calzado ortopédico brinde (gráfico 5). En este sentido, el $46 \%$ de los encuestados menciona tener poco conocimiento sobre los beneficios que otorga el uso del calzado ortopédico y un $19 \%$ lo desconoces totalmente.

\section{Gráfico 5. Disposición a pagar por calzado ortopédico para los pies de su hijo/a}

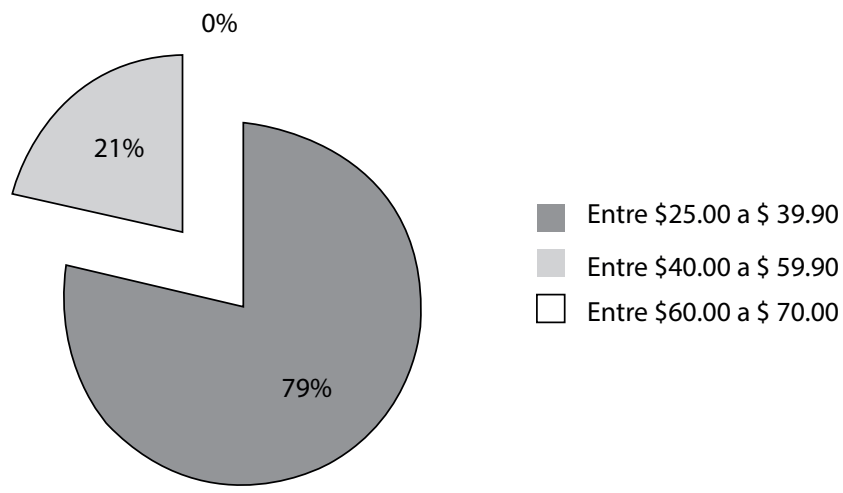




\section{Gráfico 6. Grado de conocimiento sobre las bondades del calzado ortopédico}

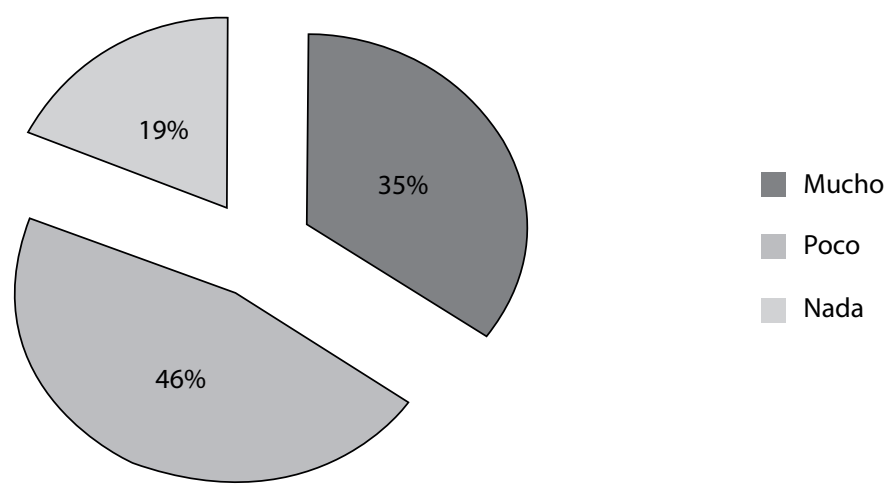

La ficha de observación en este caso ayudó a determinar la viabilidad y la factibilidad a nivel patológico para poder desarrollar el calzado que será producido y comercializado para los infantes de Tungurahua. Para el estudio se realizaron 112 fichas de observación, correspondientes a cada uno de los niños que conformaron la muestra, con edades comprendidas entre 0 y 4 años (tabla 1 ). A estas edades tan tempranas es primordial identificar problemas en el apoyo, balanceo y marcha del infante (Chico, 2008).

Tabla 1. Resultados ficha de observación

\begin{tabular}{|l|l|}
\hline \multicolumn{1}{|c|}{ Criterios de la marcha } & \multicolumn{2}{c|}{ Número de observaciones } \\
\hline Pie plano & 31 \\
\hline Supinación & 15 \\
\hline Pronación & 66 \\
\hline
\end{tabular}

El análisis de la demanda dentro del sector productivo de calzado en la actualidad parte de la situación gubernamental que obliga a que cada uno de los productores ofrezcan al mercado productos diferenciados, no solo en sus materiales sino también en su funcionalidad, situación que obliga al empresario/productor a realizar un profundo análisis del mercado objetivo al que desea proyectarse, así como también la interpretación de las preferencias de los consumidores y la evolución de las tendencias de la nueva era. 
Según el estudio Antropométrico realizado en el año 2013 por la Cámara Nacional de Calzado en conjunto con Plasticaucho Industrial, en el Ecuador más del 50\% de la población presenta pie plano, así como también un alto índice de obesidad, motivos por los cuales se presentan los principales problemas ortopédicos como son pronación y supinación de los pies (explicados ut supra en nota al pie 3 y 4). Dichas patologías pueden ser corregidas en niños de hasta 12 años de edad, por lo que se recomienda utilizar un calzado adecuado desde la infancia.

Al tomar como referencia el último censo de población del año 2010, se determina que en la provincia de Tungurahua la población de infantes (de 0 a 4 años de edad) corresponde al $9 \%$ de la población, mientras que en el fascículo de la proyección de crecimiento del Ecuador publicado por el INEC, se determina que la población de la provincia de Tungurahua alcanzó un total demográfico de 557563 habitantes, de los cuales el $9 \%$ corresponde a infantes de 0 a 4 años de edad. Así, el cálculo arroja un total de 50181 infantes como población de estudio; mientras que según el estudio antropométrico el $50 \%$ de la población -es decir, aproximadamente 25090 infantes- sufrirían de la patología pie plano. Al recurrir a la encuesta realizada -de carácter exploratoria no inferencial- se determina que el $55 \%$ de la población desconoce esta patología, por lo que el infante puede sufrir de la misma sin que sus padres se den cuenta de ello.

Una vez analizada la participación de cada una de las empresas competidoras, incluida la empresa objeto del presente estudio, se puede determinar la demanda insatisfecha en base a la población de infantes de la provincia de Tungurahua (50 181habitantes) (ver tabla 2).

Tabla 2. Consumo estimado per cápita de pares

\begin{tabular}{|l|l|l|l|l|}
\hline HABITANTES & CONSUMO P/C & $\begin{array}{c}\text { TOTAL, CONSUMO } \\
\text { AL AÑO }\end{array}$ & $\begin{array}{c}\text { \% PER. PIE } \\
\text { PLANO }\end{array}$ & TOTAL \\
\hline 50.181 & 3 & 150.543 & $50 \%$ & 75.272 \\
\hline
\end{tabular}

Se puede calcular la demanda insatisfecha desde dos perspectivas diferentes, como son: Dentro de las encuestas aplicadas, uno de los aspectos relevantes es que el $45 \%$ de los consumidores encuestados no conocen sobre la problemática, por lo que si se aplica este porcentaje a la población de infantes se obtiene: 
Tabla 3. Consumo de pares en base al desconocimiento de la condición ortopédica

\begin{tabular}{|c|c|c|}
\hline Total & $\%$ Desconocim & Total, Consumo pares al año \\
\hline 75272 & $45 \%$ & 33872 \\
\hline
\end{tabular}

Mientras que si se toma desde el punto de vista de la problemática, los consumidores encuestados indicaron que el 33\% de la población tiene algún familiar con esta problemática (ver tabla 4).

Tabla 4. Consumo de pares en base al padecimiento de la condición ortopédica

\section{Total \\ $\%$ Padecen la enfermedad \\ Total, consumo pares al año}

$75272 \quad 33 \%$
24840

Dicho esto, para el cálculo de la demanda insatisfecha se toma de referencia la siguiente formula: Demanda Insatisfecha(DI) $=$ OfertaDemanda, así como los datos desde la perspectiva de quienes tienen familiares que sufren de la enfermedad.

Obteniendo como resultado 13085 pares al año de demanda insatisfecha, que mensualmente representan 1090 pares, lo que significa una oportunidad considerable para que se ofrezca una línea de producto adicional que proporcione a los consumidores todos los beneficios de la construcción biomecánica.

Cabe recalcar que la presente demanda insatisfecha se puede cubrir dentro de la empresa, ya que la capacidad instalada de la maquinaria y equipos es apta para la producción de 3000 pares mensuales, dando una producción de calzado de 36000 pares anuales.

\section{Estudio cualitativo}

A partir de la entrevista realizada al especialista calzadista mediante un cuestionario conformado por 15 preguntas, emergió la siguiente información que complementa lo obtenido con la ayuda de las encuestas analizadas ut supra, a razón se puede tener que:

- Las patologías más comunes en los pies de los niños con edades comprendidas entre los 0 y 4 años son: pisada de pie plano, pisada de pie pronador y pisada pie supinador. 
- Se ha investigado y se determina la no existencia de estudio previo que investigue los tipos de patologías que padecen los niños ecuatorianos y en especial los de la provincia de Tungurahua (Ecuador).

- El desconocimiento y la falta de preocupación por parte de los padres a las patologías que pueden sufrir sus hijos en los pies producen que en, algunas ocasiones, se haga uso de un calzado extremadamente rígido e inadecuado para los primeros meses de vida. Los padres desconocen normalmente que no todos los productos de calzado son adecuados para el pie de los niños.

- Los padres deben optar por acudir a un especialista ortopédico que tratará adecuadamente las condiciones ortopédicas de los niños. Los tratamientos para corregir patologías o deformidades en los niños son de hasta un máximo de 12 años de edad, por lo que es importante reconocer el problema en los años anteriores.

- No existe en el mercado de Tungurahua calzados ortopédicos que ayuden a corregir o paliar las problemáticas en los infantes de la provincia analizada en este estudio. Hay que dar mucha importancia a los materiales con los que se está elaborado y diseñado el calzado ortopédico, tales como: capella, forro, plantilla y suela.

- El calzado ortopédico debe contener elementos anatómicos básicos que proporcionen al producto final una estructura biomecánica. Para lograr todo eso se debe trabajar en una investigación de factibilidad y vialidad que permita presentar un producto acorde al mercado de la provincia con proyección nacional.

- El calzado de uso diario por parte del infante proporciona información sobre la pisada del niño y la posición del pie durante la marcha, lo cual ayuda a ver el requerimiento puntual del cliente.

- Durante el tratamiento es importante que las consultas con el especialista se realicen de manera continua con periodos comprendidos no superiores a 3 meses. El tiempo de duración del tratamiento dependerá del tipo de patología. No obstante, se presentan casos de rehabilitación de hasta 3 años.

- Solo en casos especiales, es decir, dependiendo de la patología, los niños necesitarán de dispositivos adicionales para corregir el problema reconocido. Para el correcto tratamiento de las patologías es necesario que los especialistas actualicen sus conocimientos de manera frecuente. 
- En el proceso de fabricación de calzado es importante contar con un especialista en ortopedia para problemas de los pies que asesore durante dicho proceso y un profesional patronista que ayude a diseñar un producto agradable y que llame la atención tanto de los clientes como lo de los consumidores del calzado.

\section{Conclusiones}

El desconocimiento de las patologías que pueden sufrir los niños con edades comprendidas entre los 0 y 4 años puede producir en sus pies problemas cuyo tratamiento puede durar hasta 3 años. En algunos casos, los padres ignoran la existencia de problemas como pie plano, pie pronador y pie supinador; en otros casos, el uso de calzado adecuado, guiados más por la moda y las preferencias del mercado, puede producir también problemas en la correcta marcha del infante.

En Tungurahua, actualmente no se cuenta con profesionales de la salud de los pies que cuenten con productos de calzado adecuados para cada tratamiento identificado en los pies de los niños. A su vez, los padres encuestados manifestaron su interés de adquirir calzado ortopédico para sus hijos si existiera mayor oferta de estos en el mercado, dando importancia a factores como la calidad y la durabilidad, antes que el precio o la moda.

Es de vital importancia que las patologías sean reconocidas por el especialista en los primeros años de vida debido a que, dependiendo del problema identificado, el tratamiento puede durar hasta un periodo de 3 años, siendo la edad máxima para corregir la patología los 12 años de edad. Las fichas de observación evidenciaron que el uso inadecuado de calzado puede producir en el pie del infante una mala colocación del pie al andar y que puede dar inicio a un problema futuro.

Para una correcta fabricación del calzado ortopédico dirigido a niños en temprana edad es necesario contar con el asesoramiento de un especialista que se cerciore de que el producto se está elaborando de la manera adecuada y con los materiales apropiados.

\section{Referencias}

Alcántara, E., Artacho, M.A., González, J.C., \& García, A.C. (2005). Application of product semantics to footwear design. Part I - Identification of footwear 
semantic space applying diferential semantics. International Journal of Industrial Ergonomics, 35(8), 713-725. doi: https://doi.org/10.1016/j.ergon.2005.02.005

Almquist, G., Norgren, L., \& Strandell, A. C. (1998). Clúster and clúster policy in Sweden. Stockholm: The Swedish National Board for Industrial and Technical Development (NUTEK).

Cámara de Calzado de Tungurahua - CALTU (2011). En sitio web: http://www.caltuecuador.com/

Chaín, N. S. (2011). Proyectos de Inversión, Formulación y Evaluación. Santiago de Chile: Pearson Educación.

Chico, F. (2008). Pie y Calzado: Diseño Biomecánico. México DF: CIATEC.

Hernández-Sampieri R., \& Fernández Collade, B. L. (2006). Metodología de la investigación. México DF: McGraw-Hill.

Instituto Nacional de Estadísticas y Censos - INEC (2014). En sitio web: http://www. ecuadorencifras. gob.ec/institucional/home/

Jacob, R. B. (2014). Administración de Operaciones Producción y Cadena de Suministros. México: Mc Graw Hill / Interamericana Editores S. A. de C. V.

Munuera, J. (2007). Estrategias de marketing: un enfoque basado en el proceso de dirección. Madrid: ESIC.

Kerin, H. R. (2011). Marketing. México DF: Mc Graw Hill.

Kotler, P. (2012). Fundamentos de Marketing. Madrid: McGraw-Hill.

Madorrán-Álvarez, M.E., \& Molins-Martin, M. (2016). El Estudio del Mercado. Madrid: McGrawHill.

Méndez, R. (2010). Formulación y evaluación de proyectos; enfoque para emprendedores. Bogotá: Incotec Internacional.

Otero, G., Lódola, A., \& Menéndez, L. (2004). El rol de los gobiernos subnacionales en el fortalecimiento de Clúster productivos. Consultado en agosto de 2005, de http:// www.ec.gba.gov.ar/GIE/Investigacion/Archivos/Abril2004.pdf

Prospecta, C. D. (2013). World Footware Yearbook. Obtenido en enlace web: http:// www.prospecta.mx/pdf/340.pdf

Tirado, D. M. (2013). Fundamentos de Marketing. Castellón de la Plana: L'une.

Tirado, S. (2012). Administración de la Producción. México DF: McGraw Hill.

Urbina, G. B. (2013). Evaluación de Proyectos. México DF: McGraw-Hill/Interamericana.

Vargas, T. (2016). La Planificación Estratégica para mejorar la producción en una empresa artesanal de calzado. Ambato: PUCESA. 

Retos, $n^{\circ} \mid 4$, vol.VIII, 2017

\title{
¿Lo volvería a hacer? Revisitando la implementación del paradigma del emprendimiento en una universidad de México
}

\section{Would I do it again? Revisiting the implementation of the entrepreneurship paradigm in a University in Mexico}

\begin{abstract}
Oscar Montiel es líder del Grupo de Investigación Creatividad, Innovación y Emprendimiento y responsable Cap. 20 de Emprendimiento, Incubación y Creación de Empresas de la Academia de Ciencias Administrativas (ACACIA) (México) (oscar.montiel@uacj.mx) (http://orcid.org/0000-0003-0434-1649)
\end{abstract}

Claudia Ivette Rodríguez Lucio es profesora-investigadora de la Universidad Autónoma de Ciudad Juárez (México) (Ivette.rodriguez@uacj.mx) (http://orcid.org/0000-0002-6135-4799)

\begin{abstract}
Resumen
La autoetnografia es un método de investigación reconocido y utilizado en las Ciencias Sociales, aun cuando su uso dentro del área de emprendimiento ha sido escaso y pocos investigadores de esta área han utilizado la propia narrativa (Engstrom, 2012). El presente artículo aborda desde este método las experiencias de dos maestros (Montiel \& Rodríguez, 2016) al realizar la gestión y ser miembros de una academia transversal enfocada al emprendimiento, y narra sus vivencias al impulsarlo como motor del cambio de paradigma de una Universidad pública en México, revisitándolo ahora desde una generalización analítica según lo sugerido por Chang (2008). Los resultados apuntan a realizar una amplia reflexión sobre aspectos organizacionales, sociales y culturales que están inmersos en los procesos de cambio de toda institución, y cómo estos influyen en la intención de modificación del contexto reciente hacia uno donde la creatividad, innovación y emprendimiento sean los ejes que coadyuven a las instituciones en alcanzar y estar a la par de las nuevas políticas nacionales y globales dirigidas hacia la conformación de un ecosistema emprendedor.
\end{abstract}

\begin{abstract}
Autoethnography is a recognized research method used broadly in the social sciences. Its use within the area of entrepreneurship has been scarce, few researchers in this area have used the narrative itself (Engstrom, 2012). This article deals with the experiences of two teachers members of the university's entrepreneurship transversal academy, and its experience in promoting it as the engine of a paradigm shift on a public university in Mexico, revisiting it now using analytical generalization following Chang (2008). The results suggest a broad reflection on organizational, social and cultural aspects, which are immersed in the processes of change in every institution, and how they influence the intention to modify the recent context to one where creativity, innovation and entrepreneurship are the axes that contribute in reach the new national and global policies directed towards the formation of an entrepreneurial ecosystem in a university.
\end{abstract}

\section{Palabras clave | keywords}

Autoetnografía, emprendimiento, transversalidad, universidad emprendedora, ecosistema emprendedor, cambio organizacional.

Autoethnography, entrepreneurship, transversality, entrepreneurial university, entrepreneurship ecosystem, organizational change. 


\section{Introducción}

Oportunidad que no podía pasar. Recién había sido contratado como profesor investigador e iniciaba una vida profesional académica después de laborar 15 años en la empresa familiar. No conocía nada del emprendimiento como constructo, tampoco su medioambiente. Me ofrecían hacerme cargo de la incubadora de empresas de la Universidad. El contexto era muy bueno, había apoyo del gobierno y de la institución. Iniciamos con gran fuerza y empezamos a crecer, tanto dicha área como profesionalmente. Después todo cambio. Se volvió una encrucijada. Por un lado, el gobierno rediseñaba el sistema de apoyo a emprendedores con la constitución del Instituto Nacional del Emprendedor (INADEM). Por el otro, surgió escasez presupuestaria, y apoyar el emprendimiento en la institución era cada vez -y con razón- más difícil. Los organismos acreditadores de la Asociación de Universidades e Instituciones de Educación Superior (ANUIES) empezaban a exigir indicadores de emprendimiento en los programas académicos. Ya en 2011 se había propuesto operar una Academia Transversal de Emprendimiento (ATE), compuesta de maestros de los 4 institutos, y que en dicho seno tuvieran la posibilidad de intercambiar experiencias. Sin embargo, la falta de continuidad en su liderazgo e interés truncó el esfuerzo.

Siendo así, y con algunas personas mirando con escepticismo este proyecto, en septiembre de 2013 soy nombrado -al mismo tiempo que ya lo era de la incubadora- coordinador de la ATE. Sin exagerar, era empezar de cero y en muchas aristas. Ya Sperrer, Müller y Soos (2016) señalan que aún es relativamente escaso el conocimiento sobre mejores prácticas de cómo desarrollar e implementar nuevos programas en emprendimiento en universidades. La presente narrativa es una modesta aportación a ese estado de la cuestión desde una perspectiva no-tradicional: La autoetnografía.

La Universidad tiene cerca de 28000 alumnos. La ATE tenía como misión impulsar y apoyar el desarrollo de un ecosistema y cultura emprendedora en la comunidad universitaria y en la región, y su visión era fomentar una formación integral en los estudiantes, coadyuvando a mejorar la calidad de vida de la región al promover la creación de empresas, intraemprendimiento en las organizaciones e innovación en general, convirtiendo a la universidad en la líder estatal y nacional en la cultura del emprendimiento. Como objetivo a largo plazo, también se 
deseaba cooperar en la construcción de un ecosistema interno de creatividad, innovación y emprendimiento, tomando como base el modelo Rainforest y al Aspen Institute.

Poseía transversalidad académica y multidisciplinariedad (sugeridas por el Banco Mundial y las Naciones Unidas), compuesta por maestros de emprendimiento de los cuatro institutos (Ciencias Administrativas, Ingeniería y Tecnología, Arquitectura Diseño y Arte, y Ciencias Biomédicas). Aproximadamente el $50 \%$ de sus miembros tenía experiencia emprendedora.

Algunas de las actividades surgidas de la ATE fueron:

- Homologación de contenidos de la materia en los 4 institutos, con las últimas metodologías: i) Lean Startup; ii) Opportunity Canvas; iii) Lean Canvas y; iv) Business Model Canvas.

- Conversatorios y actividades formativas del Instituto Mexicano de la Propiedad Industrial (IMPI) a los estudiantes.

- Establecimiento del «Día del Emprendedor», hoy una gestión distinta cambió el nombre, pero el formato, entonces muy criticado, curiosamente es muy semejante. Se realizaron cinco eventos semestrales, 369 proyectos emprendedores, en el que participaron un total de 1292 estudiantes, 3292 asistentes y varias conferencias impartidas.

- Fundación del grupo de investigación Creatividad, Innovación y Emprendimiento.

- Participación exitosa de estudiantes en concursos, obteniendo premios regionales y nacionales.

- Comunicaciones publicadas en congresos e investigaciones difundidas en revistas arbitradas nacionales e internacionales.

- Inicio de la serie de libros «Emprendimiento: Multidimensionalidad, Cambio e Innovación», participando investigadores nacionales e internacionales.

- No se conoce institución nacional o internacional que gestione un modelo como la ATE.

\section{Método}

Autores como Tahar (2009) y Ellis, Adams y Bochner (2010) señalan a la autoetnografía como una estrategia válida de investigación. Aun cuando han existido voces contrarias, la literatura sugiere que es un con- 
texto superado (Denzin y Lincoln, 2000) teniendo un incremento en su uso y aceptación dentro de la investigación antropológica y sociológica (Haluza-DeLay, 2008; Muncey, 2010) y educativa (Starr, 2010).

La autoetnografía implica investigar sobre uno mismo, escribir experiencias que han tenido un impacto significativo en la vida del investigador (Ellis, Adams y Bochner, 2010). Este método fue seleccionado debido a que su proceso da un acceso profundo a dichas vivencias, abordándose simultáneamente el objeto (tema) y el sujeto (investigador), proporcionando un examen de éstas en relación con aquellas similares experimentadas por otros, como medio de encontrar patrones o teorías. Aborda hechos sociales con gran detalle (Pole y Morrison, 2003), son "altamente personalizadas, textos reveladores en los cuales los autores cuentan relatos sobre su propia experiencia vivida, relacionando lo personal con lo cultural" (Richardson, 2003, p. 512), mientras que su fortaleza radica en que comunica "la inmediatez, la fisicalidad y emocionalidad de la experiencia, pero también sus elementos psicológicos y sociales, el diálogo interno del escritor consigo mismo y también situar la experiencia dentro de un amplio contexto social" (AllenCollinson y Hockey, 2005, p.193).

Engstrom (2012) señala que, en años recientes, investigadores en emprendimiento iniciaron un movimiento donde el objetivo es estudiarlo y describirlo bajo estrategias narrativas (Rae y Carswell, 2000; Hjorth y Steyaert, 2004; Berglund, 2007). Por su parte Fletcher (2011) comenta el trabajo seminal de Johannisson, quien investigó el emprendimiento profundizando en su contextualización (comunidades, regiones y familias), abriendo nuevas posibilidades a métodos de investigación que localizaran al investigador como actor participativo.

La autoetnografía reta a la ortodoxia que coloca al investigador como ente neutral y silencioso, lo cual puede dejarlo vulnerable a ser considerado "irracional, particularista, privado y subjetivo, en lugar de ser razonable, universal, público y objetivo" (Greenhalgh, 2001, p. 55). Esto es aún necesario para una variedad de autores que sugieren que las formas de investigar siguen ancladas en presupuestos positivistas y responden a una "ortodoxia metodológica" (Hesse-Biber, 2010, p. 455). El presente artículo -también realizado por Gottlieb, 2015- lo solventa incluyendo un relato de otro miembro de la ATE, lo que provee un ejercicio de reflexión hacia el investigador y el lector. Asimismo, se hace una 
generalización analítica para correlacionar, como sugiere Chang (2008), las vivencias hacia la parte cultural y social, resultando en autoanálisis y transformación (Chase, 2011) y permitiendo una contrastación.

En la autoetnografía puede usarse la primera persona para elaborar el relato (Ellis, Adams y Bochner, 2010) y generalmente ocurre cuando el autor ha observado, vivido o participado de una forma íntima la historia o hecho social que se pretende analizar. Algunas veces se usa la segunda persona para llevar a los lectores hacia la escena, de ir junto con el autor de forma activa, el presenciar la experiencia contada, de ser parte y no estar distante del hecho social relatado (Glave, 2005; McCauley, 1996; Pelias, 2000), incluso utilizan la tercera persona para establecer el contexto, al reportar los resultados y al presentar lo que otros hacen o dicen (Caulley, 2008). En la presente investigación se han seguido dichas recomendaciones, intentando narrar en primera persona la introducción y el relato, mientras que en tercera persona se redactan los apartados de método y conclusiones.

\section{Análisis y resultados}

\subsection{Relato 1}

El cambio de paradigma

Desde Lewin (1951), hasta Cummings y Worley (2007) y Macrì et al. (2002), se ha abordado la resistencia al cambio organizacional, pero una revisión de la literatura sugiere ha sido escasamente abordado en el caso de las universidades.

Bajo sustento científico y después de un proceso de reflexión, pensé que el emprendimiento podía ser una herramienta de cambio para construir capital social, cambiar paradigmas y reconstituir tejidos sociales e industriales a corto, mediano, y largo plazo, tanto para la ciudad como para la propia institución, tomando como referencia a la ciudad de Barcelona, considerada por la Organización para la Cooperación y Desarrollo Económico (OCDE) el modelo a seguir.

Así, me di a la tarea de localizar a los maestros. Descubrí que, en cada instituto, aun cuando los contenidos estaban orientados hacia esa temática, los nombres de dichas asignaturas eran diferentes. En agosto de 2013 se llevó a cabo el primer intento para reactivar la ATE. La 
invitación se realizó por medio de correos electrónicos, sin embargo, la respuesta fue nula. Por tanto, acudí con mi superior a fin de invitar a los maestros por oficio, enviado desde su jefatura inmediata. La respuesta obviamente mejoró: asistieron ocho personas, a quienes en su mayoría no conocía. La buena noticia es que había asistentes de todos los institutos y ello era estratégico para la conformación de la ATE.

¿Cuál era el objetivo? Simple: Insertar a la Universidad en un cambio de paradigma, inquietudes institucionales que empezaban a permear internacionalmente (como por ejemplo lo expuesto por OCDE, 2012). Durante 40 años había desarrollado un mecanismo muy eficiente hacia cubrir las demandas del mercado laboral, pero hoy se veía, como la mayoría de las universidades del país, insertada en una nueva dinámica: generar emprendedores. El contexto exigía indicadores de ello. Simple ¿no? Pero era monumental.

Ya Kuhn (2005) describió los cambios de paradigmas y su dificultad. Tenía que vender la idea de cómo cambiar el nuestro y ello conllevaba una ardua tarea. Era muy consciente que había muchos riesgos. Sacrificar la terminación de mis estudios de doctorado, con el impacto que tendría en mis ingresos -algo nunca valorado por nadie-, tiempo, desarrollar un plan de trabajo incluyente y flexible, y el diseño de estrategias que se implementarían sin experiencia institucional previa.

El primer gran reto era homologar la carta descriptiva, la cual debía reflejar en su contenido lo más reciente en metodologías sobre emprendimiento, enfocado este en un principio a la apertura de empresas. Fue todo un éxito. Los debates eran sumamente enriquecedores. Había puntos de vista y problemáticas particulares de las cuales nadie se percató antes. A diferencia de lo comentado por Nwekeaku (2013), logramos hacer un cambio en el proceso de enseñanza, homologar los contenidos de las materias resultaba relativamente fácil.

Rotación entre institutos

La idea era que los institutos rotaran entre sí la gestión de la ATE a fin de incentivar una dinámica incluyente y transversal. Las tareas se dividieron bajo estos términos, pero no funcionó. Es sistémico. La mayoría de los maestros por honorarios siempre mostraban la mejor disposición, mientras que otros jamás hicieron lo que les fue requerido o su apoyo se reducía a lo indispensable. Por su parte, aquellos que eran de vinculación laboral a tiempo completo, la mayor parte mostraba conductas 
similares, ya que las tareas que realizaban no se reflejaban del todo como actividades valoradas en el programa institucional de estímulos, por lo que no tenían incentivo económico, algo que debería estar concatenado en la estrategia institucional -como lo recomienda la OCDE (2012) -. Las actividades se concentraron en mí y en 5 maestras. Los restantes miembros casi siempre brillaban por su ausencia más no sus críticas, generalmente no constructivas, dentro y fuera de la ATE.

\section{El día del emprendedor}

Un punto angular, ya comentado por la OCDE (2012), era realizar un evento emprendedor incluyente y representativo de nuestra comunidad universitaria, según lo sugerido por Sperrer, Müller y Soos (2016). Lo nombré «Día del Emprendedor» y organizarlo en ese contexto fue muy complicado. No teníamos reconocimiento como ATE en la Universidad, en cada puerta que se tocaba había que explicar sus objetivos y los del evento.

No teníamos recursos o equipo propio (en línea con lo narrado también por Nwekeaku, 2013), todo fue prestado por diversas instancias de la Universidad, quienes muy amablemente y brindándome su confianza, siempre me recibieron con mucha atención y disponibilidad. Salvado este obstáculo, inicié acercamientos ante el empresariado local para que aceptaran asistir como jueces de la competencia. No teníamos claras muchas cosas, así que hice benchmarking con eventos similares realizados en los Estados Unidos. Así nació el «Business Pitch», que realizaban los finalistas de cada categoría.

Se decidió realizar esta actividad semestralmente, a pesar del enorme trabajo y tiempo que suponía. Consideramos en la ATE que mientras no midiéramos que la cultura emprendedora en la Universidad tuviera ya un nivel significativo, era necesario hacerlo así, condición sine qua non para nuestra misión y visión. Los maestros enviaban un listado con los proyectos de sus clases y debían asistir todos.

El número de participantes promediaba 80 proyectos. Se clasificaban en proyectos tradicionales y tecnológicos. Se realizaba en el gimnasio de la Universidad, con capacidad para 5000 personas. El día del evento, abierto al público en general, asistían alrededor de 1500 personas. En ocasiones (segundo y quinto día) hubo apoyo presupuestario para rentar stands para los proyectos. En los otros eventos, hubo que 
solicitar a dos institutos apoyo para que nos prestaran sus mamparas de madera (no en las mejores condiciones y muy pequeñas) para que los estudiantes las usaran como stands. Estéticamente quedaban a deber, pero no había otra forma. Siempre se los agradecimos, la verdad trabajábamos como podíamos.

Los estudiantes se instalaban de 7 a 9 de la mañana. A las 8 yo tenía reunión con los jueces que calificarían la fase A, esto es, a los proyectos a razón de 8-10 stands por juez durante un máximo de 5 minutos en cada uno. Les explicaba qué esperábamos de ellos, cómo calificar, si tenían dudas sobre el formato a utilizar. Para apoyarlos se les asignaban estudiantes voluntarios para acompañarlos en su recorrido. Aquellos con las 15 calificaciones más altas pasaban a la fase B. En ésta realizaban un «Business Pitch» con duración máxima de 2 minutos frente a otro jurado de empresarios. Había tres ganadores (primer, segundo y tercer lugar) en cada categoría.

¿Dificultades? Sí. Enormes. Calaban. Pero podía más la pasión y el compromiso. El primer día se hizo recién 2 meses de haber iniciado la gestión de la ATE, en noviembre del 2013. Fue un parteaguas. Jamás en 40 años la Universidad había hecho algo similar. Lo hicimos en el vestíbulo de su teatro, muy modestamente. Solo eran 29 proyectos provenientes de todos los institutos. Mentiría si digo teníamos claro cómo hacer su gestión, pero era ahora o nunca: teníamos que correr el riesgo; si nos esperábamos, el evento no se realizaría hasta mayo del 2014. Consideramos era demasiado tiempo, teníamos que irrumpir, dar un golpe de timón, mostrar que realmente la ATE bajo mi liderazgo iba en serio y estaba comprometida ante nuestras autoridades.

Para el segundo día nos fuimos a lo grande. Teníamos que seguir innovando, pues somos una gran Universidad con mucho prestigio. Tuve que ir a solicitar fondos de cada instituto para realizar el evento. Alguna gente seguía escéptica que podíamos organizarlo en el espacio más grande e importante de la Universidad. El actual paradigma no veía la dimensión de lo que estaba en juego. Sin embargo, la acogida de los directores de instituto y de la alta gerencia de la Universidad fue sensacional. Todos apoyaron. Todos me dieron su voto de confianza, algo que yo valoraré siempre. Fue desgastante, demasiada responsabilidad. Más de todo, proyectos, empresarios invitados, reconocimientos que imprimir, equipo que pedir prestado, promoción. Todo era 10 veces más. 


\section{El empresariado}

Fue vital, estratégico. Fortaleció las relaciones externas de la institución y el intercambio de conocimiento (OCDE, 2012), y validó muchas dinámicas. Nos dio presencia en toda la ciudad y sobre todo en el sector empresarial, fortaleciendo así nuestra misión y visión institucionales. Rápidamente hice empatía con ellos. Supongo que mi pasado empresarial ayudó. Invitarlos no solo era por estrategia para la construcción del ecosistema interno, sino porque no queríamos que académicos evaluaran los proyectos de emprendimiento, algo que ocurrió durante el primer día. Se prestaba a sesgo y a malos entendidos. Era un intento constante para transparentar procesos.

El invitarlos también era para volver más integral la experiencia de nuestros estudiantes. Que se sintieran exigidos. En la reunión previa les pedí que siempre fueran exigentes al evaluar. No era ni es la única forma de elevar el nivel de los proyectos, lo entendía, sin embargo, era una manera que teníamos al alcance. Siempre tuvieron disposición y la ATE estuvo muy agradecida por ello.

\section{Impacto nacional y binacional}

Lograr que una Universidad norteamericana se interese por nuestras estrategias, hayan viajado para asistir como jueces y pida a partir de ello apoyo para la gestión de su primer «Día del Emprendedor»...no creo sea poca cosa, además sugerido esta internacionalización por la OCDE (2012). También participaron con un capítulo del segundo y tercer libro de la serie, explicados ut supra. Por otra parte, otra institución también norteamericana nos invitó a explorar dinámicas de investigación binacional por medio de dos proyectos, y colaboró con un capítulo en el primer y segundo libro. Algo estábamos haciendo bien.

Institucionalización del día del emprendedor y de la academia Poco a poco, la universidad como institución inició el proceso. La apertura de la jefatura en innovación y emprendimiento fue un paso trascendente. El Instituto de Ingeniería, en lugar de seguir sumándose a la dinámica institucional, inició en paralelo un evento también de corte emprendedor. Varios me decían "es copia del nuestro". ¡A quién le importaba ello! Para mí lo relevante era que iniciará el cambio. En tiempos muy recientes, la ATE fue postulada por la institución para con- 
cursar en el Premio Nacional del Emprendedor del Instituto Nacional del Emprendedor de México (INADEM). Fue el punto más álgido. Sentí que todo el trabajo de la ATE era reconocido.

Hace un año y medio que dejé la coordinación. Ojalá los mecanismos sean los adecuados para que no se pierda el trabajo realizado. Sería una pena, no por mí, sino para la Universidad.

\section{El camino hacia la investigación}

Siempre se invitó a los miembros a realizar investigaciones en el tema. La respuesta fue poca. La gran mayoría de los miembros de la ATE eran maestros de honorarios, por lo que no les generaba retribución -obviamente un emprendedor no lo vería así-. Y en aquellos que eran de tiempo completo, a quienes sí se les reconocía a través del programa de estímulos, tal vez no veían el potencial que podíamos generar. Era empezar de cero, ya que la vía más fácil era pertenecer a algún cuerpo académico consolidado que permitiese el acceso a fondos y redes ya establecidas. Y algunos efectivamente la escogieron.

A pesar de todo ello no desistí y junto con una colaboradora de la ATE nos arriesgamos. Creyó en mí y no podía fracasar. Fue todo un éxito, y de ahí han seguido muchas colaboraciones.

Cuando sentí que la ATE había alcanzado cierta estabilidad y madurez, consideré presentar ante las autoridades de la Universidad la formación de un grupo de investigación en Creatividad, Innovación y Emprendimiento. Por políticas internas, hacía varios años que no se autorizaban. Sin embargo, nuestra propuesta sí lo fue. Ello terminó por impulsar la visión. Ya no era solo una academia de maestros que impulsaban la cultura emprendedora y tenían cierto impacto institucional, sugerido por la OCDE (2012). Iniciábamos una nueva etapa: Generar conocimiento, colocarnos como referentes nacionales e internacionales, bajo una estructura temporal a corto, mediano y largo plazo.

Este grupo fue diseñado siguiendo los principios de la ATE, multidisciplinario. De la serie ya mencionada ya van dos libros editados por la Universidad, construcción de redes nacionales e internacionales, participaciones en congresos, mucho en solo año y medio. En la invitación de presentación del primer libro hubo detalles, pero mi colega y yo, coordinadores de la serie, hicimos caso omiso. No tiene ya importancia. 


\section{La barrera informal}

¿Cómo puede a veces el debate ser de tan bajo nivel? Recuerdo tiempo atrás leí una investigación sobre el mobbing (acoso laboral) en universidades de España ¿Anécdotas? Demasiadas. Desde por qué yo ganaba con mis estudiantes siempre algún premio en los eventos, que había algo raro en ello, que si manipulaba la mesa de evaluación -la cual siempre estuvo con toda intención frente al público, en donde cualquiera podía verificar que las evaluaciones eran capturadas correctamente- ¡hay tantas! Un maestro afirmó incluso que sus alumnos no habían recibido 2 evaluaciones de los jueces solo una, esto a pesar de que la carpeta que contenía éstas estaban frente a él y nunca quiso revisarlas. Todavía comentó que seguramente la segunda había sido hecha a escondidas y en un baño, como si fuéramos ladronzuelos de quinta. Y aquella persona "bueno, pues el representante de Contraloría pues sí estuvo presente, pero no todo el tiempo" ¿Qué culpa tengo de que mis estudiantes iban bien preparados, con ideas innovadoras, siempre intentando trascender, de que fuera exigente con ellos y que los que vociferaban nunca ganaran nada?

Cuando conseguí para el quinto día premios en efectivo para los ganadores sucedió lo mismo: Acusaciones de que se lo iban a gastar en cerveza, que debíamos de supervisar en que lo erogaban...si no había premios que por qué no conseguíamos fondos, y si los conseguimos... no entiendo. ¡Pero ah! En la foto de familia siempre aparecían.

Pero los resultados se iban dando bajo mi liderazgo que, a los 2 años, cuando llegó el momento de relevar la coordinación, la decisión fue reelección con 5 votos contra 3. Por supuesto la impugnaron, aun cuando la autoridad universitaria estuviera presente dando fe, todo bajo reglamento ¿Por qué me reeligieron? Consideraron que aun y cuando se había acordado rotar por instituto la coordinación para sustentar su enfoque transversal -algo que se respetó en los Días del Emprendedor, ya que cada instituto lo organizó- aun había que solidificar algunos elementos del plan, por lo que era mejor no reestructurar hasta que la ATE estuviera más institucionalizada.

¿Por qué el mexicano no tolera el éxito? Ya Paz (1959) habló de ello. Obstáculo cultural y social general comentado por Fogel, Hawk, Morck y Yeung (2005). Junta tras junta, podía palparse el enorme esfuerzo y resultados de nuestro accionar. Supongo es el precio de cambiar un paradigma. No debería ser así. Somos pares, profesionales, 
con un nivel educativo, maestría, doctorado. Si algo, por más pequeño salía mal, intentaban magnificarlo. No vale la pena escribir más de ello. La mediocridad de la que hablaba Ingenieros (2008) ronda siempre. Sabotaje organizacional que describía Young (2000) y Nwekeaku (2013) como resultado de la falta de un cambio en el sistema de valoración informal que existe en toda organización -ya descritos desde su perspectiva en las universidades nigerianas-.

La mayoría de ellos, aquellos que siempre confiaron en mí y me reeligieron, pero sobre todo a mis autoridades que siempre apoyaron, jamás podré pagarles todo el esfuerzo que hicieron y hacen.

Decisión de separación

Todo tiene un final. Era tiempo de separarme de la coordinación de la ATE. Los liderazgos deben terminar en el momento oportuno. Hacia 2 años había cometido el error de no separarme de la coordinación de la incubadora de empresas justo cuando conseguí la acreditación nacional del INADEM. Meses después vinieron los problemas, ajenos a la Universidad que dieron al traste con años de esfuerzo -había construido una red de incubadoras estatal, de las pocas existentes en el país-. Era momento de iniciar un nuevo camino profesional y personal. La autorización del grupo de investigación exigía tiempo completo. El quinto «Día del Emprendedor» había sido todo un éxito. Empresarios, autoridades, estudiantes, en la Academia se sentía el ambiente. En la ceremonia de inauguración era palpable ello. Pero el grupo de investigación necesitaba despegar y desde otra trinchera apoyar la construcción del ecosistema. Había un plan y no podíamos fallar.

Agradecimiento a mi casa: la universidad

Sin duda. La experiencia que mi institución me dio es invaluable. Fue una oportunidad indescriptible. Me hizo tener aún más pasión hacia el emprendimiento y su relevancia empresarial y social. La «camiseta» la tengo tatuada. Suena demasiado político, no me importa. Así es y será.

¿Consideraciones finales? Si algo salía mal, era yo. Si algo salía bien éramos todos ¿Me explico? Pero de nuevo, no había de otra, estaba mi prestigio en juego. No quiero sonar dramático, ni ser un héroe. No es mi intención. Siempre decidí lo último, había mucha responsabilidad hacia la Universidad, hacia las personas que apoyaban, mi vocación 
como investigador, mi ADN emprendedor ¿Qué puedo hacer? Me costó mucho financieramente hablando, roces laborales, momentos incomodos. Pero valió la pena.

Creo que los miembros de una ATE deben ser emprendedores por naturaleza y práctica, de forma que puedan obtener nuevas habilidades. Así también lo sugiere Nwekeaku (2013), pues el emprendimiento resulta vital para el proceso de enseñanza. Un verdadero emprendedor sabe y decide trabajar en equipo, porque es la vía más fácil e inteligente de alcanzar la mayoría de los resultados. Por ello, creo que se debe de elegir $-\mathrm{y}$ no solo por ser docentes de emprendimiento- cuidadosamente a los integrantes de una ATE. Es muy diferente su naturaleza respecto a la mayoría de academias en el nivel universitario.

Dedique casi 3 años. Pero he recibido, aun a pesar de algunas malas experiencias, otras recompensas. Diseñé un seminario virtual de emprendimiento, único en su tipo a nivel internacional, y vienen otros para 2018 y 2019. He sido nombrado para los próximos tres años responsable del capítulo de emprendimiento de la prestigiosa Academia de Ciencias Administrativas A.C. de México (ACACIA). Ser emprendedor está en mis venas. Trascender. Siempre.

¿Lo volvería a hacer? Sí.

\subsection{Relato 2}

Un emprendimiento personal: la ATE

A principios de 2014, siendo docente por honorarios en el programa de Diseño Gráfico y contando con dicha licenciatura y una maestría en investigación relacionada a procesos creativos, por lo general se me asignaban materias teóricas relacionadas con estos temas. Sin embargo, para mi sorpresa e incluso un poco de insatisfacción, al iniciar el semestre se me asignó la asignatura de formación empresarial atribuido, pienso, por contar con una carrera técnica en Administración. Confieso estuve a minutos de pedir que me la retiraran, pues en un compromiso personal me parecía no era la persona indicada. Lo tomé como una oportunidad de salir de mi área de confort y aprender cosas nuevas sin saber que de frente tendría todo un reto que daría un vuelco a mi vida, personal y profesional.

En marzo de 2014 llegué a la ATE por invitación de una docente con quien compartía la impartición de la asignatura. Lo primero que 
me llamó la atención fue la transversalidad de ésta: había maestros de los cuatro institutos, cosa que jamás había vivido en ninguna academia dentro de la Universidad. Era muy interesante escuchar la diversidad de puntos de vista y, aunque en la maestría discutimos sobre transversalidad, interdisciplinariedad y multidisciplinariedad, no fue hasta este momento que tuve la oportunidad de palpar dicho concepto, pues como menciona Bolívar (1998, p. 60) "el discurso de la transversalidad puede quedarse en una práctica discursiva configurado por una retórica política que crea expectativas pero que luego, en la práctica, no puede generar los cambios esperados". Y esto era lo opuesto al objetivo planteado por esta academia y a las acciones que se llevaban a cabo con la finalidad de alcanzarlo, de tal modo que el compromiso, pasión, entusiasmo y sentido emprendedor de los miembros de esta academia, fueron para mí el incentivo más grande para buscar juntos la generación de un cambio de paradigma.

\section{Cambio de paradigma y día del emprendedor}

La Universidad durante años se visualizó bajo un esquema de generadora de empleados para las diferentes necesidades del contexto. Sin embargo, las demandas del mercado actual exigían se redefinieran y reestructuraran las estrategias (OCDE, 2012) que volvieran más competitivos a nuestros alumnos y los ayudaran a adaptarse a los nuevos tiempos. Además, cambios en instancias gubernamentales y educativas exigían una permuta en el esquema actual, pero permear estas transformaciones ha sido sencillo. Girar la dirección hacia la creación de una cultura emprendedora la cual ayudase a gestionar el propio desarrollo e identificar nuevas áreas de oportunidad y ventajas competitivas de ser aprovechadas constituía cuanto menos un reto, porque la mentalidad tenía que modificarse desde el docente. Lo caótico, complejo y falto de linealidad del emprendimiento sugiere que sus maestros deben desarrollar competencias en el descubrimiento, razonamiento e implementación a fin de que los estudiantes puedan sobresalir en los ambientes actuales de gran incertidumbre (Neck y Greene, 2011).

A través del trabajo que se realizaba en la ATE se unificaron contenidos en las cartas descriptivas lo cual permitía que todos los alumnos, aunque las disciplinas fueran distintas, contaran con las mismas habilidades, conocimientos y herramientas para desarrollarse como 
emprendedores. Sin embargo, lograr esto solo dentro del aula no era suficiente. Se tenía que conseguir que el alumno se visualizara y creyera un emprendedor, por lo cual participaban con su proyecto en el evento gestionado por la ATE.

Los retos y dificultades para lograr esto eran grandes. Primero lograr se construyeran buenos proyectos lidiando con deficiencias académicas, en mi caso el área de finanzas. En otros casos el desarrollo visual del proyecto, entre otras cuestiones, que teníamos que solventar con instrucciones rápidas de los temas o con invitaciones de maestros expertos que nos ayudaran en esas áreas que no se dominaban, obstáculos estos ya advertidos por Seikkula-Leino (2007), hasta lograr que el alumno adquiriera y se apasionara con la posibilidad de volver su proyecto realidad. Sin embargo, el trabajo en el aula, aunque arduo, era mucho menos retador que lo que representaba la gestión del evento y todos los obstáculos presupuestarios, de disposición de tiempo y de pasión en el trabajo que se requería para lograrlo. Aunque la ATE estaba constituida por varios miembros, solo pocos manifestábamos un compromiso real y muchas veces sacrificamos familia, tiempo, y dinero por un proyecto que se había planteado en conjunto y por el anhelo de cumplir con aquello trazado.

Evento tras evento se fueron sorteando las dificultades que desgraciadamente no solo provenían de fuera sino algunas de ellas venían del propio seno de la ATE, hasta que llegó el quinto «Día del Emprendedor», evento que obtuvo apoyo del departamento de vinculación de la Universidad, en donde logramos que la estrategia subiera a otro nivel, fuera conocida a través de la institución y entendida como prioridad (OCDE, 2012). En esta actividad se expusieron más de 80 proyectos y se contó con stands para cada uno, donde se sumaron en participación escuelas de media superior, y donde por primera vez se contó con la participación y asistencia de los directores de instituto y el Rector, lo cual indicaba que el trabajo llevado a cabo por fin se visualizaba y reconocía, instalando el evento de forma institucional. Esto claramente reflejaba un cambio de paradigma, un inicio de establecimiento de la cultura emprendedora, nuevas áreas de oportunidad y una educación más integral y de calidad para nuestros estudiantes. El camino fue difícil, definitivamente solo representa el inicio de un transitar que no termina y que debe ajustarse a cambios y condiciones globales actuales. 


\section{Grupo de investigación}

En definitiva, todo lo anterior descrito y vivido, trajo en lo personal la adquisición de conocimiento, habilidades y aptitudes que lograron situarme en posiciones que dieron a mi vida nuevas oportunidades. El área de emprendimiento me apasiona, afortunadamente formo parte del grupo creado a partir de la ATE, donde he participado en diferentes investigaciones, artículos y ponencias, aun cuando para ello se han sorteado diversos obstáculos aun pertenecientes a los viejos paradigmas los cuales no logran comprender la visión holística del emprendimiento y buscan encasillar a un individuo en temas que consideran únicamente pertenecientes a la profesión adquirida (en mi caso diseño, creatividad y publicidad), cuando es precisamente la riqueza de la conjugación de la diversidad de áreas lo que sustenta el crecimiento teórico-práctico de una cultura emprendedora.

Tener un espacio para generar no solo la gestión de esta cultura sino teorizar acerca de la misma, formar parte de redes nacionales e internacionales, la oportunidad de aprender de las personas que estudian el tema, ha sido una oportunidad invaluable. Al día de hoy he coordinado junto a quien fuera coordinador y fundador de esta ATE dos libros de emprendimiento, y otra obra editorial más en proceso de evaluación, la instauración de un seminario virtual de emprendimiento, proyectos en conjunto con la visión de divulgarse y lograr un cambio, y el camino continúa. He descubierto que para trascender hay que arriesgarse, atreverse a ir más allá, desdibujar límites y superar miedos, lo cual no es fácil pero es sumamente enriquecedor, aun cuando esto requiera de un ímpetu que en ocasiones pudiera parecer no fácil de mantener y el cual ha incomodado a terceras personas.

\section{Conclusiones}

En línea con Engstrom (2012), se sugiere debería colocarse en un primer plano la necesidad de penetrar en las experiencias sociales de los emprendedores. Comentan Hjorth y Steyart (2004, p.4) que "Convencer a otros -dirigiendo deseos, organizando recursos, enfrentando obstáculos- y compartiendo imágenes de lo que podría llegar a ser, es realizado en pequeñas narrativas con las cuales la gente puede identificarse". Los eventos y experiencias compartidas en el presente abonaron a la creación de procesos dialécticos (Hargrave y van de Ven, 
2006), y así catalizaron la posibilidad de que emergieran oportunidades e innovaciones institucionales (Ruttan y Hayami, 1984). Al final, el emprendimiento es un hecho social y abordarlo desde diferentes ópticas debería ser una práctica frecuente, académica y pedagógicamente en su enseñanza. Como resultado de revisitar la presente experiencia, y a través de la elaboración de una generalización analítica sugerida por Chang (2008) respecto a realizar autoetnografías analíticas e interpretativas, es menester puntualizar, a) la importancia de manejar mejor las relaciones de poder que se generan hacia el seno y dinámica de grupos o equipos de trabajo, como la ATE y; b) diseñar una estrategia social y organizacional que abordara el profundo cambio institucional que tuvo la Universidad y la cual hubiera facilitado el proceso.

\section{Referencias}

Allen-Collinson, J. \& Hockey, J. (2005). Autoethnography: Self-indulgence or rigorous methodology? En Mike McNamee (Ed.), Philosophy and the sciences of exercise, health and sport: Critical perspectives on research methods (pp.187-202). London: Routledge.

Berglund, H. (2007). Researching entrepreneurship as lived experience. En H. Neergaard y J. P. Ulhoi (Eds.), Handbook of qualitative research methods in entrepreneurship (pp. 75-96). Northampton, MA: Edward Elgar.

Bolívar, A. (1996). Non scholae sed vitae discimus: Límites y problemas de la transversalidad. Revista de Educación, 309, 23-66.

Caulley, D. N. (2008). Making qualitative research reports less boring: The techniques of writing creative nonfiction. Qualitative Inquiry, 14(3), 424-449.

Chase, S. E. (2011). Narrative inquiry: Still a field in the making. En N. Denzin, y V. S. Lincoln (Eds.), The Sage handbook of qualitative research (pp. 421-434). Los Angeles: Sage.

Chang, H. (2008). Autoethnography as Method (Developing Qualitative Inquiry). London: Routledge.

Cummings, T. y Worley, C. (2007). Desarrollo organizacional y cambio. México: Thomson.

Denzin, N. K., y Lincoln, Y. S. (2000). The discipline and practice of qualitative research. en N. K. Denzin y Y. S. Lincoln (Eds.), Handbook of qualitative research (2nd ed., pp. 1-28). Thousand Oaks: Sage.

Ellis, C., Adams, T., y Bochner, A. (2010). Autoethnography: An Overview. Forum: Qualitative Social Research, 12(1). doi: http://dx.doi.org/10.17169/fqs-12.1.1589

Engstrom, C. (2012). An autoethnography account of prosaic entrepreneurship. Tamara Journal for Critical Organization Inquiry, 10(1).

Fletcher D.E. (2011). A curiosity for contexts: Entrepreneurship, enactive research and autoethnography. Entrepreneurship \& Regional Development, 23(1/2), 65-76. 
Fogel, K., Hawk, A., Morck, R. y Yeung, B. (2006). Institutional Obstacles to Entrepreneurship. En Casson, M., Yeung, B., Basu, A. y Wadeson, N. (Eds.), Oxford Handbook of Entrepreneurship. Oxford: Oxford University Press.

Glave, T. (2005). Words to our now: Imagination and dissent. Minneapolis: University of Minneapolis Press.

Gottlieb, F. (2015). Researching entrepreneurship with autoethnography. En Pursuing Innovation Leadership: Proceeding of the 16th International CINet Conference. Continuous Innovation Network (CINet).

Greenhalgh, S. (2001). Under the medical gaze: Facts and fictions of chronic pain. Berkeley: University of California Press.

Haluza-DeLay, R. (2008). Churches engaging the environment: An autoethnography ofobstacles and opportunities. Human Ecology Review, 15(1), 71-81.

Hargrave, T.J., Van de Ven, A.H., 2006. A collective action model of institutionalinnovation. Academy of Management Review, 31, 864-888.

Hjorth, D., y Steyaert, C. (Eds.). (2004). Narrative and discursive approaches in entrepreneurship. Cheltenham: Edward Elgar.

Hesse-Biber, S. (2010). Qualitative Approaches to Mixed MethodsPractice. En Qualitative Inquiry. Thousand Oaks: Sage.

Ingenieros, J. (2008). El hombre mediocre. Ciudad de México: Editorial Porrúa.

Kuhn, T. S. (2005). La estructura de las revoluciones científicas. Madrid: Fondo de Cultura Económica.

Lewin, K. (1951). Field Theory in social science. New York: Harper\&Row.

Macrì D., Tagliaventi M. y Bertolotti F. (2002) Grounded theory for resistance to change in a small organization. Journal of Organizational Change Management, 15(3), 292-310.

McCauley, S. (1996). Let's say. En Patrick Merla (Ed.), Boys like us: Gay writers tell their coming out stories (pp.186-192). New York: Avon.

Montiel, O. y Rodríguez, C. (2016). ¿Lo volvería a hacer? Liderando un cambio de paradigma. El caso de la Academia Transversal de Emprendimiento. En Ojeda, R. y López, L. (Coords.), Gestión Social. Organizaciones Humanas para una Sociedad Incluyente, Memorias del XX Congreso Anual, disponible en http://acacia. org.mx/wp-content/uploads/2016/11/EBook_XX_Congreso_ACACIA.pdf, pp. 7975-8001.

Muncey, T. (2010). Creating autoethnographies. London: Sage.

Neck, H.M. y Greene, P.G. (2011). Entrepreneurship Education: Known Worlds and New Frontiers. Journal of Small Business Management, 49(1), 55-70.

OCDE (2012). A Guiding Framework for Entrepreneurial Universities. Disponible en http://www.oecd.org/site/cfecpr/EC-OECD\%20Entrepreneurial\%20Universities\%20Framework.pdf

$\mathrm{Paz}$, O. (1959). El laberinto de la soledad. México: FCE.

Pelias, R. J. (2000). The critical life. Communication Education, 49(3), 220-228.

Pole, C. y Morrison, M. (2003). Ethnography for education. Maidenhead: Open University Press. 
Rae, D., y Carswell, M. (2000). Using a life-story approach in researching entrepreneurial learning: The development of a conceptual model and its implications in the design of leaning experiences. Education EF Training, 42, 220-227.

Richardson, L. (2003). Writing. A Method of Inquiry. En Denzin, N. y Lincoln, Y. (Eds.), Collecting and Interpreting Qualitative Materials. Thousand Oaks: Sage.

Ruttan, V.W. y Hayami, Y., 1984. Toward a theory of induced institutional innovation. Journal of Development Studies, 20, 203-223.

Schein, E. (1985). Organizational culture and leadership: A dynamic view. Jossey-Bass. USA.

Seikkula-Leino, J. (2007). Opetussuunnitelmauudistus ja yrittäjyyskasvatuksen toteuttaminen (Curriculum reform and entrepreneurship education). Helsinki: Opetusministeriön julkaisuja.

Sperrer, M., Müller, C. y Soos, J. (2016). The Concept of the Entrepreneurial University Applied to Universities of Technology in Austria: Already Reality or a Vision of the Future? Technology Innovation Management Review, 6(10), 37-44.

Starr, L. (2010). The use of autoethnography in educational research: Locating who we are in what we do. Canadian Journal for New Scholars in Education, 3(1), 1-9.

Trahar, S. (2009). Beyond the story Itself: Narrative inquiry and autoethnography in intercultural research in higher education. Forum: Qualitative Social Research, 10(1), Art.30, http://nbn-resolving.de/urn:nbn:de:0114-fqs0901308 [Accesado: 26 de Enero 2016].

Young, A. (2000) I'm just me: A study of managerial resistance. Journal of Organizational Change Management, 13(4), 375-398. 

Retos, $n^{\circ} \mid 4$, vol.VIII, 2017

\title{
Microempresas panificadoras en el Azuay (Ecuador) y su productividad
}

\author{
Bakery small business in Azuay (Ecuador) \\ and their productivity
}

\begin{abstract}
Carlos Armando Romero Galarza es investigador del Grupo de Investigación Empresarial (GIE) en la Facultad de Ciencias Económicas y Administrativas de la Universidad de Cuenca (Ecuador) (armando.romerog@ ucuenca.edu.ec) (http://orcid.org/0000-0003-1149-4299)
\end{abstract}

Gustavo Geovvani Flores Sánchez es Docente de la Universidad de Cuenca e investigador del Grupo de Investigación Empresarial (GIE) en la Facultad de Ciencias Económicas y Administrativas de la Universidad de Cuenca (Ecuador) (gustavo.flores@ucuenca.edu.ec) (http://orcid.org/0000-0003-4123-2644)

\begin{abstract}
Jorge Arturo Campoverde Campoverde es Docente Titular de la Universidad de Cuenca en la cátedra de Investigación de Operaciones e investigador y coordinador del Grupo de Investigación Empresarial (GIE) en la Facultad de Ciencias Económicas y Administrativas de la Universidad de Cuenca (Ecuador) de la Universidad de Cuenca (jorge.campoverde@ucuenca.edu.ec) (http://orcid.org/0000-0002-1633-5644)
\end{abstract}

Katherine Tatiana Coronel Pangol es egresada de la carrera de Administración de Empresas y Ayudante de Investigación del Grupo de Investigación (GIE) en la Facultad de Ciencias Económicas y Administrativas de la Universidad de Cuenca (Ecuador) (katherine.coronelp95@ucuenca.ec) (http://orcid.org/0000-0003-4370-756X)

\section{Resumen}

El sector empresarial representa uno de los ejes fundamentales en la economía de un país, en la generación de empleo y en el desarrollo del sector productivo, comercial y de servicios. Es notoria la participación que tiene la micro, pequeña y mediana empresa debido a la gran cantidad de organizaciones existentes en esta categoría. Cabe recalcar que es preocupante el corto ciclo de vida que mantienen las mismas y las limitantes que éstas mantienen. El estudio presenta un análisis descriptivo y bivariado de 113 microempresas panificadoras en la provincia del Azuay (Ecuador), afiliadas al Ministerio de Industrias y Productividad (MIPRO) de la Zona 6. Los resultados muestran comportamientos relacionados entre el promedio de productividad por empleado que tienen las microempresas y la gestión empresarial estratégica, la capacidad productiva, el grado de innovación en maquinaria, equipo y sistemas de comercialización y sobre el requerimiento de financiamiento adicional para el crecimiento de los negocios. Se considera que es un sector con limitada mano de obra calificada que no le permite un incremento en la productividad y competitividad, factor clave de desarrollo empresarial.

\begin{abstract}
The business sector represents one of the fundamental axes in the economy of a country. It contributes to generate employment; development of the industrial, commercial and services sector. At the same time, the participation of micro, small and medium-sized enterprises is noteworthy due to the large number of organizations in this category. It is important to emphasize in the short life cycle of these companies and the limitations that are present. Through a descriptive and a bivariate analysis, 113 micro-bakeries had been studied in the province of Azuay, which are affiliated to the Ministry of Industries and Productivity (MIPRO) of Region 6. The results show related behaviors between the average productivity per employee of the microenterprises and strategic business management, their productive capacity, their degree of innovation in machinery, the equipment and marketing systems and also on the requirement of additional financing for the growth of business. However, it is considered that it is a sector with limited skilled labor that does not allow an increase in productivity and competitiveness, which is a key factor in business development.
\end{abstract}

\section{Palabras clave | keywords}

Microempresas, productividad, innovación, gestión empresarial, estrategia, financiamiento. Microenterprise, productivity, innovation, business management, strategic, financing. 


\section{Introducción}

Es indiscutible la importancia de la micro y pequeña empresa hoy en día en la economía nacional e internacional. De acuerdo a cifras arrojadas por el INEC - Directorio de Empresas y Establecimientos (2014), en el Ecuador representan el $97.9 \%$ del total de las organizaciones productivas.

El sector manufacturero es uno de los más importantes debido a los grandes encadenamientos que genera en la cadena de valor, generando empleo e innovación. La estructura de encadenamientos en una economía es irrelevante desde el punto de vista neoclásico más ortodoxo, no obstante, otros economistas que dan mayor preponderancia a los hechos estilizados como Kuznets (1966) y Rodríguez, Bernal, \& Cuervo (2012) han sugerido que el crecimiento económico es impulsado por los encadenamientos productivos entre diferentes tamaños de empresas que se dan en los territorios.

Al contrario, América Latina y en especial la de Ecuador, se caracteriza por la presencia de una realidad empresarial fuertemente polarizada y desarticulada "...en la cual conviven polos altamente competitivos con universos dispersos de micro, pequeñas y medianas empresas (Mipymes) escasamente desarrolladas" (Cohen \& Gabriel, 2012).

Las Pymes bien administradas y saludables son fuentes de empleo y creación de riqueza. Contribuyen a la estabilidad social y generar ingresos fiscales. Según la Corporación Financiera Internacional (2009) existe una relación positiva entre el nivel de ingresos de un país y el número de Pymes por cada 1000 personas. Los informes del Doing Business (World Bank Group, 2014) indican que un sector alto de Pymes corresponden a un nivel reducido de actividades en el sector informal o mercado negro.

Por otro lado, en América Latina el impulso a la actividad emprendedora se ha convertido en una de sus principales políticas, considerando a las microempresas y las pequeñas empresas con una representatividad del $80 \%$ del total de la economía (Hidalgo, Kamiya, \& Reyes, 2014). En el Ecuador, de acuerdo al informe trimestral del mercado laboral del Banco Central del Ecuador (2015), se observó que la mayoría de emprendedores se encuentran en establecimientos con menos de 100 empleados Mypimes; este porcentaje se ubica en el 77,4\%; mientras que el 22,6\% restante se ubican en establecimientos con más 
de 100 empleados; es decir, se evidencia un rol importante de las micro y pequeñas empresas en la economía ecuatoriana.

Sin embargo, de acuerdo a Cohen \& Gabriel (2012) las Mypimes tienen algunas dificultades como es el acceso restringido a las fuentes de financiamiento, bajos niveles de capacitación de sus recursos humanos, limitados niveles de innovación y desarrollo tecnológico, poca penetración en mercados internacionales, bajos niveles de productividad, baja capacidad de asociación y administrativa entre los más importantes; factores que limitan su crecimiento empresarial, restando su productividad y eficiencia en los mercados nacional como internacional.

El objetivo de la presente investigación es evidenciar si los factores referidos ut supra afectan la productividad de los empleados de las microempresas panificadoras con la gestión empresarial desarrollada y en qué forma, mediante la influencia de ciertas variables relacionales que forman parte de la organización de los negocios. Las variables relacionales que se incluyen en el análisis están influenciadas con determinadas estructuras de gestión empresarial como son de tipo estratégico, operativo, además de factores de innovación y requerimiento de financiamiento adicional para las operaciones de las microempresas panificadoras.

\section{Marco teórico}

\subsection{Desempeño organizacional}

Para entender el concepto de desempeño organizacional resulta necesario aclarar acepciones que pueden confundirse con la de efectividad organizacional que hace referencia al cumplimiento de objetivos propuestos y la de desempeño de la firma que se constituye en el valor de mercado.

Según Dyer \& Reeves (1995), el desempeño organizacional hace referencia a la medición y evaluación de la obtención de objetivos de la organización y se miden a través de la evaluación de resultados financieros, resultados organizacionales y resultados relacionados con recursos humanos.

Velarde, Araiza, \& García (2014) realizan un estudio en Coahuila, México, en el que tratan de determinar la relación entre los factores de la empresa y el empresario con el éxito empresarial, y concluyen que tan sólo el factor asociado al grado de escolaridad tiene una relación positiva con el crecimiento en la inversión de maquinaria y equipo, mientras que 
el resto de factores de los empresarios no tienen asociación con el éxito económico. Por su parte, los factores de la empresa -tales como estructura jurídica y sector económico en el que se desarrolla la empresa- tienen relación con el éxito de la empresa en lo concerniente a incremento de ventas, incremento de empleados e inversión en maquinaria y equipo.

\subsection{Innovación}

En la actualidad, de acuerdo a Teece, Pisano, \& Shuen (1997), el crecimiento en las organizaciones y en especial las MIPYMES manufactureras requieren entre otras opciones, fortalecer su actividad innovadora y para ello, requieren tener una mayor competitividad. Lochon (2014) considera en sus trabajos de investigación, que la actividad innovadora debe tener una influencia en las empresas de tal manera que ésta debe verse reflejada en los resultados empresariales y en el incremento gradual de su competitividad.

Un modelo de análisis ampliamente reconocido por la literatura asume que la realización de innovaciones por parte de las empresas está influida por un conjunto de variables, las cuales pueden agruparse básicamente en tres grandes bloques como describen Hoffman, Parejo, Bessant, \& Perren (1998), entre las que se cuentan: i) factores extra-organizativos, en particular asociados a características del sector al que pertenece la empresa, ii) las vinculadas a las características de los miembros de la organización, en especial los directivos, iii) las relativas a la propia organización, por ejemplo la orientación estratégica o la estructura financiera.

Según Etzkowitz \& Leydesdorff (2000) la innovación se ha convertido en uno de los elementos clave dentro de una empresa. Ésta trasciende a todas las áreas como lo son producción, finanzas, planificación, gestión de recursos humanos y marketing. Sin embargo, en la pequeña empresa muchas de estas funciones son llevadas a cabo directamente por el propietario o por responsable que ejecuta varios trabajos.

Las pequeñas empresas tienen enormes ventajas en materia de innovación respecto a las grandes empresas como su dinamismo empresarial, su flexibilidad interna y su capacidad de respuesta a las circunstancias cambiantes, además por su tamaño les aporta dinamismo, flexibilidad interna, cortos plazos de entrega de los productos y capacidad de respuesta al cambio, aunque pueden encontrarse con barreras como: 
- Falta de especialistas y personal calificado dentro de las pequeñas empresas.

- Carencia de tiempo y recursos para identificar y utilizar fuentes externas de información, técnicas y conocimientos científicos.

- Dificultades para atraer capital, especialmente capital riesgo

- Incapacidad de la pequeña empresa para distribuir el riesgo a través de una cartera de proyectos debido a sus recursos limitados.

Sin embargo Vossen (1998) afirma que cierta corriente de la literatura considera que existen diferencias entre grandes y pequeñas empresas. Esto justifica que la actividad innovadora de estas últimas sea más desarrollada internamente y esté mayormente vinculada con la figura del empresario y la toma de ciertas estrategias empresariales. Algunos estudios respaldan que las pequeñas empresas suelen ser más exitosas en industrias donde el peso de las habilidades y capacidades personales son más importantes, mientras que otros afirman que las fortalezas de la pequeña empresa no residen en los recursos sino en características como la flexibilidad, la cultura empresarial y la motivación al personal.

Varios autores dan a conocer la importancia que tiene la inversión en innovación para el incremento del nivel de ventas en las micro y pequeñas empresas, así por ejemplo Benavente (2005) determinó que un mayor gasto en Investigación y Desarrollo (I+D), conformado por investigación de las ciencias y el desarrollo tecnológico, está positivamente relacionado al aumento de la importancia que tienen la ventas de productos innovadores sobre las ventas totales de la empresa.

Analizando una muestra de empresas manufactureras chilenas, Griliches (1979) presenta como resultados de su investigación una relación positiva, entre gastos en I+D y el aumento de la productividad. El vínculo existente entre inversión en innovación es también evidenciado por Crépon et al. (1988) y Kemp et al. (2003), aunque cabe recalcar que también existen estudios que indican una no relación consistente entre las mismas variables (Lööf, Heshmati, Asplund, \& Naas, 2001).

Asimismo Córdova \& Naranjo (2017), manifiestan que las empresas pequeñas con menor nivel tecnológico realizan un mayor esfuerzo en actividades de Ciencia Tecnología e Investigación, lo cual no se ve reflejado en ventas innovadoras, mientras que las empresas con mayor nivel de tecnificación superan en niveles de ventas a las anteriores. 
Por otro lado Fairlie (2007), buscó determinar si existe una relación estadística entre la innovación empresarial y la generación de valor agregado, donde las comparaciones realizadas en general demostraron que un $82 \%$ de las PYMES que han aplicado algún tipo de innovación en su empresa en los últimos dos años han visto incrementadas sus ventas en relación a sus competidores, mientras que aquellas que no lo hicieron han tenido un incremento de ventas del 27\%. Las diferencias en ventas entre empresas del mismo rubro con respecto a aquellas que se innovan constantemente es significativa.

\section{Gráfico 1. Funciones de la administración}

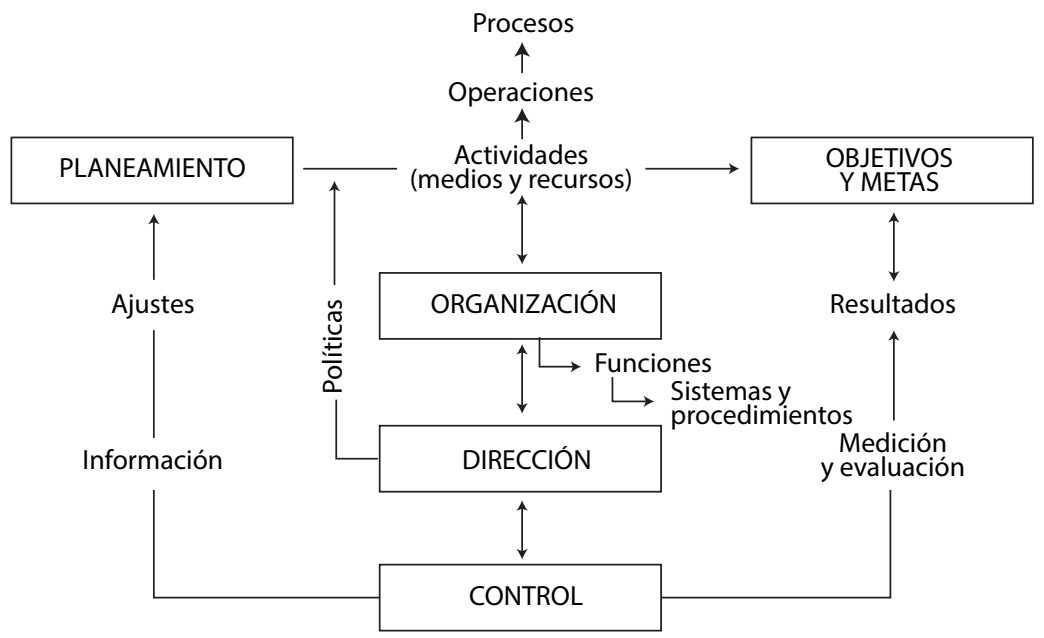

Fuente: Dextre (2010)

\subsection{Rendimiento de las MIPYMES}

Considerando que la administración diseña la estructura sobre la que se soporta la función de control de las empresas, para Solís (2005), el diseño de los sistemas de control debe ofrecer una retroinformación en forma oportuna y barata, que sea aceptable para los miembros de la organización. A partir de ello, se puede afirmar que el sistema de control basado en la estructura de la organización desarrolla las actividades del giro del negocio, bajo políticas claras y definidas orientadas a preservar el fin común. 
La administración tiene como funciones fundamentales el planeamiento, la organización, la dirección y control. La coherencia y cohesión entre ellas produce una administración eficiente, económica y efectiva de los recursos que emplea para el logro de las metas y objetivos planeados. En tal sentido, se definen las funciones de la administración para centrar el análisis en el control y su vinculación con los riesgos de negocios. En el gráfico 1 se puede observar el proceso que sigue el desarrollo de las funciones dentro de la administración.

\section{Materiales y métodos}

\subsection{Tipo de investigación}

La investigación es de tipo experimental, ya que se centra en la puesta en práctica de los conocimientos para la búsqueda del beneficio social, mediante la utilización y estudio de variables que permitirán entender el comportamiento del sector.

\subsection{Método de investigación}

El método de investigación aplicado es el hipotético-deductivo, debido a que permite hacer demostraciones en base a las hipótesis o preguntas de investigación; a su vez también se utilizó el método lógico-deductivo, debido a que admite considerar muestras poblacionales para la estimación de resultados ya que los elementos de la investigación no pudieron ser estudiados en su totalidad.

\subsection{Muestra}

Para la determinar la muestra se consideró como población de estudio a las micro y pequeñas empresas del sector panificador registradas en la base de datos del Ministerio de Industrias y Productividad (MIPRO) en la provincia del Azuay (Ecuador) de enero 2015 a marzo 2016, considerando un total de 137 panaderías; por lo que el levantamiento de información se realizó de manera censal.

De las 137 panaderías, se logró encuestar a 113, lo cual representa un $82,5 \%$ de la población. Del 17,5\% restante, es decir 24 negocios, no se obtuvo respuesta por diversos motivos: el 2,92\% vendió el negocio, el $1,46 \%$ salió de viaje - vacaciones, el 10,20\% no se ubica debido a que 
tanto la dirección como el teléfono están erróneos, un 0,73\% no autoriza, el 1,46\% no colabora, y el 0,73\% cambio de negocio.

En la tabla 1, se da a conocer cómo se determinó el margen de error muestral para poder inferir en toda la población resultante, obteniendo un $+/-3,88$ margen suficiente que permite inferir en toda la población de estudio.

Tabla 1. Parámetros estadísticos muéstrales

\begin{tabular}{|l|l|}
\hline \multicolumn{1}{|c|}{ Descripción } & \multicolumn{1}{c|}{ Valor } \\
\hline Nivel de confianza & $95 \%$ \\
\hline Población & 137 \\
\hline Margen de error muestral & $+/-3,88$ \\
\hline Muestra & 113 \\
\hline
\end{tabular}

\subsection{Fuentes de información}

La información recopilada para la elaboración de la investigación se obtiene mediante información primaria aplicando encuestas a cada una de las microempresas del sector en estudio. También se obtuvo información secundaria que se fundamentó en la revisión de bibliografía de interés. Finalmente se consiguió información de fuentes terciarias que brindaron información a nivel macroeconómico del sector de estudio, tales como el Instituto Nacional de Estadísticas y Censos (INEC).

\subsection{Procedimiento metodológico y herramientas}

El proceso llevado a cabo en el estudio inicia con la obtención de la base de datos de las micro y pequeñas empresas a ser investigadas. Posteriormente se procedió con la recolección de datos en fuentes primarias; luego se elaboraron las herramientas para levantamiento y análisis de información, tales como instrumento-encuesta y plantillas para generación de bases de datos, mismas que fueron puestas a prueba en un análisis exploratorio piloto que sirvió para validar y garantizar la fiabilidad de las mismas.

Las encuestas se aplicaron de manera directa a cada uno de los propietarios y/o administradores de las empresas, por lo que se garantiza la veracidad de los datos. Una vez concluida la aplicación de las encuestas se procedió a verificar el llenado de la información e ingresar los datos en las plantillas del software de análisis. 
Una vez digitalizados los datos de las encuestas fueron procesados en el software estadístico IBM SPSS® v. 20.0, mediante un análisis de información estadística univariado (frecuencias y porcentajes) de las principales variables de estudio. Esto permitió caracterizar al sector panificador en la provincia del Azuay, indagando sus oportunidades y debilidades. Además se realizó un análisis bivariado para contrastar las diferencias entre las medias de más de dos poblaciones. Para el efecto, se utilizó ANOVA para determinar y comparar entre sí las medias de la productividad por empleado de las microempresas con factores relevantes de la gestión empresarial que inciden en su operación manufacturera.

\subsection{Descripción de datos y variables}

Para evaluar a las microempresas panificadoras, se estableció un conjunto de variables consideradas según realidad del sector. Éstas permitieron tener una visión general de la situación. Las variables definidas fueron:

- Variable dependiente: se considera el promedio de productividad del empleado, medido por la facturación mes sobre el número de empleados que disponen las microempresas panificadoras.

- Variables independientes:

$\sqrt{ }$ Gestión Empresarial: definida su misión.

$\sqrt{ }$ Gestión Empresarial: definida su visión.

$\sqrt{ }$ Gestión Empresarial: definido su organigrama.

$\sqrt{ }$ Gestión Empresarial: definidas las políticas internas de la empresa.

$\sqrt{ }$ Capacidad Productiva: número de unidades/día producidas.

$\sqrt{ }$ Cambio o mejora en sus procesos, productos o sistemas gestión en los últimos 2 años.

$\sqrt{ }$ Innovación realizada: Adquisición de tecnología incorporada a maquinaria y equipo.

$\sqrt{ }$ Innovación realizada: Incorporado mejoramiento de los sistemas de comercialización.

$\sqrt{ }$ Financiamiento adicional durante el tiempo que lleva generando actividades.

\subsection{Promedio de Productividad del empleado}

El desempeño laboral es la forma en que los empleados realizan su trabajo. Este se evalúa durante las revisiones de su rendimiento, mediante 
el análisis de factores como la capacidad de liderazgo, la gestión del tiempo, las habilidades organizativas y la productividad para analizar cada empleado de forma individual (Comisión Económica para América Latina y el Caribe - CEPAL, 2001).

Las revisiones del rendimiento laboral, por lo general, se llevan a cabo mensual o anualmente y pueden determinar que se eleve la elegibilidad de un empleado, decidir si es apto para ser promovido o incluso si debiera ser despedido. Por lo tanto, el rendimiento está ligado a la productividad de los empleados, el cual se mide a través del cociente entre la facturación de una empresa y el número de empleados que tiene. El número de empleados, por su parte, es una variable que también indica el tamaño de gran dimensión que tienen las empresas (Bonilla $\&$ Mayorga, 2011).

La productividad de los empleados es consecuencia del rendimiento laboral, que es la relación entre objetivos, metas o tareas alcanzadas y el tiempo que se ha necesitado para lograrlo. Este cálculo ha de realizarse teniendo en cuenta que el tiempo se refiere a las horas trabajadas de calidad y que la variable más importante son las personas encargadas de ejecutar las funciones propias del puesto de trabajo (Rodríguez \& Gómez, 2011).

\subsection{Ventas y productividad general}

De acuerdo a Salazar (2015), el número promedio de ventas que generan los empleados es una buena medida de la productividad, ya que ayuda a determinar en cuánto deben aumentar las ventas para justificar la contratación de un empleado adicional, por lo tanto para obtener un promedio de productividad de los empleados, se deriva la siguiente ecuación:

Promedio de Productividad de los empleados $=\frac{\text { ventas netas }}{\text { Número de empleados }}$

El promedio de productividad de los empleados describe en cuánto debe aumentar las ventas para considerar el costo de contratar a un nuevo miembro del personal en la empresa. Evaluar el desempeño o productividad de los empleados puede proporcionar numerosos beneficios para la organización. Además le permite distribuir de forma equitativa los incentivos de compensación. Las evaluaciones de desempeño de los 
empleados pueden aumentar la eficiencia operativa y la productividad del personal, al mismo tiempo que identifica a los candidatos de alto rendimiento para una promoción futura en las empresas (MaldonadoGuzmán et al., 2011).

Igualmente en la tabla 2 se aprecian los estadísticos descriptivos de la variable de interés, que es el promedio de la productividad de los empleados/mes de las microempresas panificadoras, cuyo valor es de USD 683,28

\section{Tabla 2. Estadístico Descriptivo}

\begin{tabular}{|c|c|l|l|l|l|c|}
\hline Variable & No. & Mínimo & Máximo & Media & Mediana & $\begin{array}{c}\text { Desv. } \\
\text { Típica }\end{array}$ \\
\hline Productividad por empleados & 113 & 20 & 2,400 & 683,28 & 500 & 536,48 \\
\hline
\end{tabular}

Nota: Elaboración propia con el software SPSS $®$ v.20.0

\section{Descripción del sector}

En Ecuador existen 6.879 empresas activas dedicadas a la elaboración de productos de panadería, según el calificador de actividades económicas CIIU4 - C1071. De este total, dentro de la provincia del Azuay se encuentran un total de 621 empresas, de las cuales una representación del $83,89 \%$ se encuentra en el cantón Cuenca. A su vez, las micro y pequeñas empresas representa un $67,99 \%$ del total de empresas ecuatorianas (INEC 2015, Redatam). Su participación en distintos escenarios es muy heterogéneo, siendo el más importante en la generación de empleo, menos importante en la producción y muy pequeña en las exportaciones.

La mayor participación en el empleo, comparada con la producción, indica bajos niveles relativos de productividad. Su escasa participación en las exportaciones muestra su fuerte orientación al mercado interno y su dependencia de la dinámica de la demanda interna. Por ello, su producción está muy determinada por la evolución del empleo y salarios en la economía en su conjunto, contribuyendo de esta manera con el 0,28\% del empleo formal según datos (INEC 2015). La tabla 3, presenta el crecimiento que ha tenido el sector en su nivel de ventas. 
Tabla 3. Variación porcentual de ventas anuales

\begin{tabular}{|l|c|c|}
\hline \multicolumn{1}{|c|}{ Periodo } & $\begin{array}{c}\text { Ventas } \\
\text { (miles de millones de USD) }\end{array}$ & Variación de ventas \\
\hline Año 2011 & $\$ 4430,54$ & $0,00 \%$ \\
\hline Año 2012 & $\$ 4821,58$ & $8,83 \%$ \\
\hline Año 2013 & $\$ 5462,98$ & $13,30 \%$ \\
\hline Año 2014 & $\$ 7340,94$ & $34,38 \%$ \\
\hline Año 2015 & $\$ 7856,61$ & $7,02 \%$ \\
\hline Año 2016 & $\$ 8794,00$ & $11,93 \%$ \\
\hline Año 2017 & $\$ 9731,15$ & $10,66 \%$ \\
\hline Promedio & $\$ 6919,68$ & $14,35 \%$ \\
\hline
\end{tabular}

Fuente: Elaboración propia con datos del INEC (2011 - 2015)

En el periodo 2011-2017 el sector panificador ha mostrado tener un crecimiento constate, mismo que alcanza un promedio de aproximadamente $14,35 \%$. El gráfico 2 muestra la tendencia de crecimiento que ha tenido el nivel de ventas del sector, considerándose un rubro con crecimiento importante en la economía del Ecuador. Las ventas del 2016 y 2017 fueron pronosticadas.

\section{Gráfico 2. Ventas anuales sector panificador}

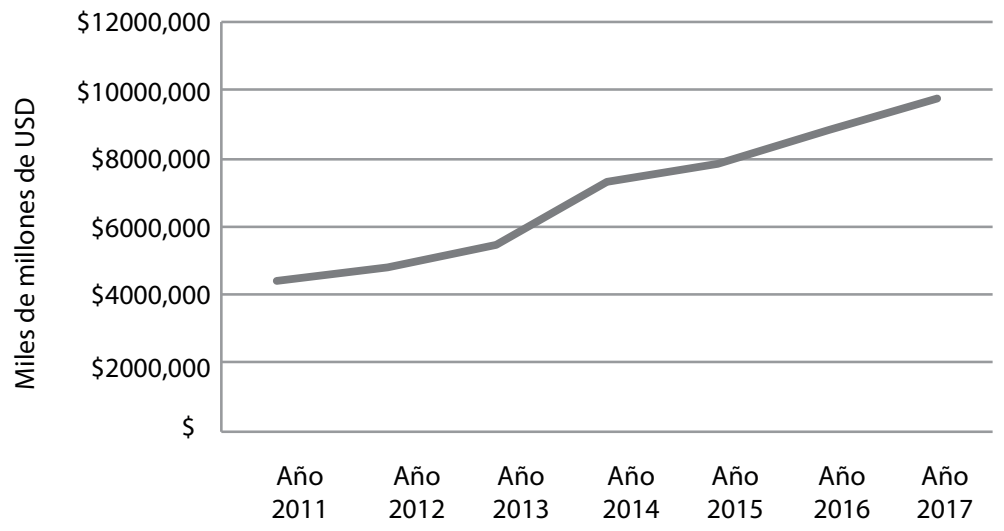

Fuente: Elaboración propia con datos el INEC (201 1-2015) 


\section{Análisis y resultados}

Los resultados obtenidos mediante el análisis descriptivo de las 113 encuestas aplicadas remiten que el 90\% de encuestados están calificados como artesanos afiliados al MIPRO, mientras que el 10\% pertenecen a la Junta del Artesano. De estos, el $89 \%$ no tiene la obligación de llevar contabilidad ya que están calificados bajo la modalidad Régimen Impositivo Simplificado Ecuatoriano (RISE) y tan solo un 11\% tiene la obligación de llevar contabilidad.

Considerando los años de la actividad de las empresas, se tiene que el 44\% mantienen sus actividades entre 1 y 5 años; el 24\% llevan entre 5 y 10 años dedicándose; el 13\% entre 10 y 15 años y el 19\% cumple con sus actividades por más de 15 años.

En la gráfico 3 se observa con meridiana claridad que alrededor del 20\% de los negocios encuestados cuentan con 1 empleado, el 51\% de estos cuentan con 2 empleados, el 17\% disponen de 3 empleados, el $11 \%$ de los negocios disponen de 4 empleados, y solo el 2\% tiene más de 5 empleados; evidenciando que el $99 \%$ de las empresas por su característica son microempresas.

\section{Gráfico 3. Número de empleados que tienen las empresas panificadoras}

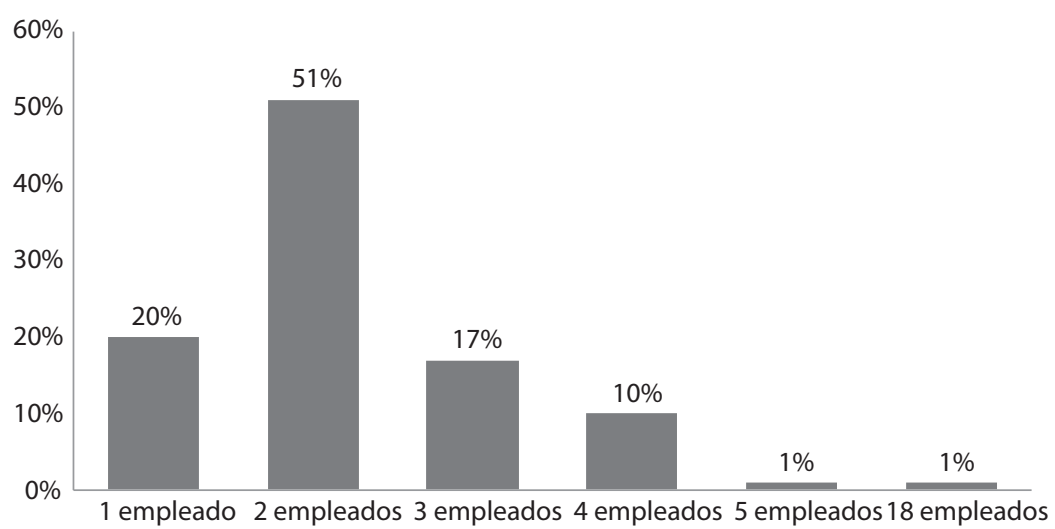

En cuanto al mercado de destino de sus ventas, se observa que el 96\% de su facturación se concentran en la ciudad de Cuenca y el 4\% lo realiza en cantones y provincias cercanas. Por otro lado, en lo que respecta al giro del 
negocio, se tiene que el $93 \%$ de las microempresas producen pan y pastelería, mientras que el 7\% producen solo productos de pastelería.

La facturación mensual promedio de los 113 negocios muestra una media de ingresos mensuales de $\$ 1708,32$. Además se evidencia que existen en promedio 5 locales de la misma actividad económica en un radio de 5 cuadras, considerándolo como un negocio con muchos competidores.

Se observa que los empleados de las microempresas tienen en promedio 8 años de escolaridad; un 43\% de los empleados tienen educación primaria, el 51\% de los empleados tienen educación secundaria, el 5\% tienen una formación universitaria y el restante $1 \%$ tienen un nivel de posgrado.

De igual manera, es relevante mencionar que el $58 \%$ de negocios han recibido capacitación, además que un $59 \%$ de las microempresas que han recibido capacitación lo han realizado en temas como el manejo administrativo y facturación, un $24 \%$ en manejo de proveedores y un $12 \%$ en ventas y atención al cliente, según se indica en el gráfico 4.

\section{Gráfico 4. Áreas de capacitación recibida por los empleados de las empresas panificadoras}

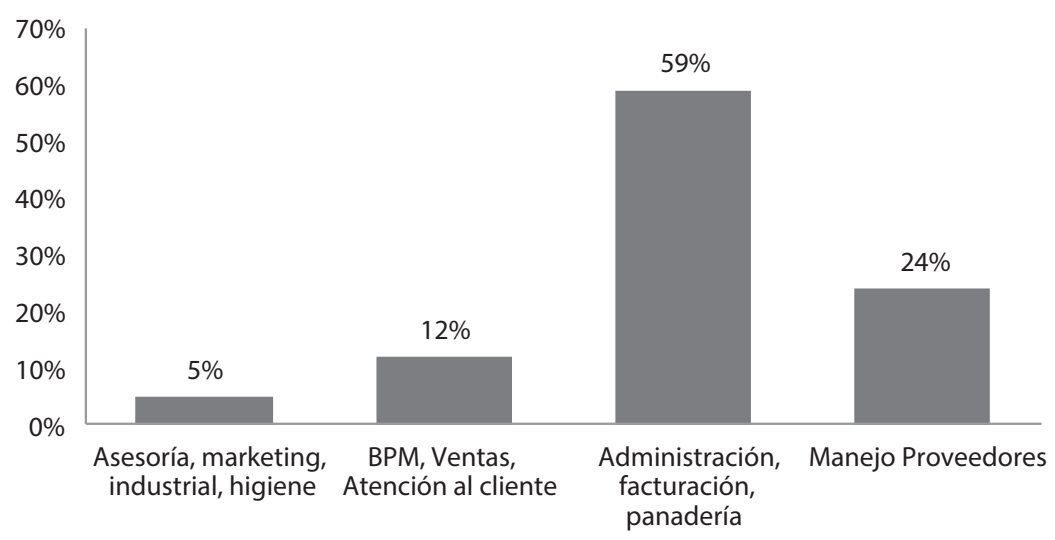

Por otra parte se establece que durante el tiempo que llevan operando los negocios, solo el $43 \%$ de las empresas ha solicitado financiamiento adicional para continuar con sus operaciones, siendo su monto promedio de financiamiento de $\$ 12885,45$. En el gráfico 5 se observa el motivo por el cual requieren financiamiento adicional; un $52 \%$ ha utilizado para la compra de maquinaria, un $30 \%$ para la ampliación física 
del negocio y un 24\% para adquisición de capital de trabajo como es la materia prima, entre los más importantes.

Gráfico 5. Motivo por el cual se requirió financiamiento

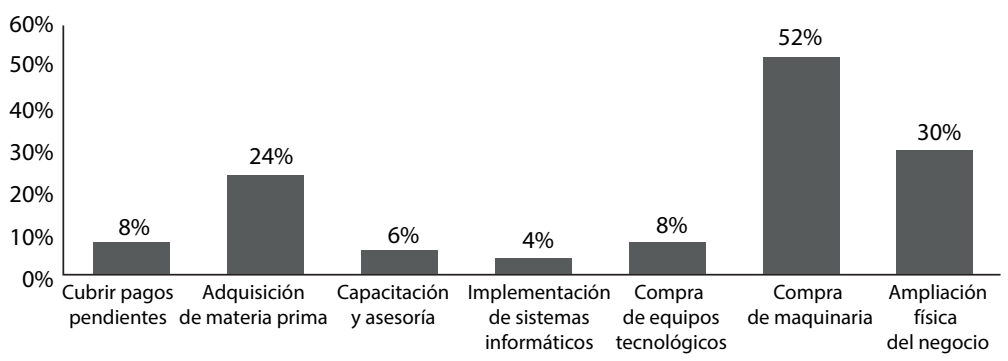

En lo que respecta a tecnología, maquinaria, y al grado de automatización de las microempresas, se aprecia que el 47\% de los negocios tienen una acción manual, es decir que la producción de pan y sus derivados es artesanal, mientras que un 47\% tienen una acción semi-automática y tan solo el $6 \%$ de los negocios tiene un grado automático. El 94\% de las empresas no disponen de programas informáticos para sus procesos o gestión.

Al examinar la relación entre los productos y procesos, definido por el tipo de proceso productivo que disponen las microempresas, se observa que el $71 \%$ lo hacen de una forma continua para la venta, el $19 \%$ produce para stock y solo el 10\% lo hace bajo pedido. Además, el $70 \%$ de las microempresas tienen una capacidad productiva utilizada de más de un $61 \%$, produciendo en promedio al día 658 unidades.

Al mismo tiempo, el 91\% de las empresas panificadoras proyecta su producción diariamente y solo el $9 \%$ lo realiza semanalmente. De igual manera los negocios fabrican un mix de productos, esto quiere decir que un $81 \%$ de las microempresas elaboran en promedio entre 1 y 5 productos, y un $19 \%$ producen más de 6 productos.

En lo que respecta al sistema de calidad que poseen los negocios, se puede apreciar que el $92 \%$ de las microempresas realizan controles de calidad de sus productos terminados, utilizando principalmente el método de inspección visual con un 92\%. Por otro lado, solo un 50\% de las empresas realizan controles de calidad en los procesos productivos; además el 95\% de las empresas no disponen de registros de control de 
calidad. De igual manera, el $70 \%$ de las empresas poseen un plan de mantenimiento de sus maquinarias y equipos, realizando un $46 \%$ mantenimiento correctivo y un $54 \%$ preventivo.

En lo pertinente al conocimiento y gustos del cliente, un 95\% de las empresas afirman conocer el gusto de los consumidores, además el 80\% conocen el hábito de compra de sus clientes. Por otro lado, solo el $43 \%$ identifica los productos y los precios de su competencia; el $26 \%$ presta servicios post venta y el $85 \%$ ofrece garantía en sus productos a sus clientes.

Si se analiza el origen y provisión de las materia prima, se obtiene que un $90 \%$ de las empresas se abastecen principalmente a nivel nacional, adquiriendo a distribuidores mayoristas. Además, el 50\% de las microempresas califican a sus proveedores y un $87 \%$ considera que el aprovisionamiento o la entrega es oportuna. De igual manera el $90 \%$ de las empresas manifiestan que el crédito concedido por sus proveedores es en promedio de 1 a 30 días.

En lo concerniente a la organización y gestión empresarial, se observa que el $92 \%$ de las empresas panificadoras no disponen de una gestión estratégica documentada. Por otro lado, el 78\% de las microempresas no llevan contabilidad general, ni contabilidad de costos; factores importantes para la toma de decisiones de los negocios. De igual manera el $80 \%$ de las empresas no usan planeación financiera como presupuesto de ventas, de compras, de producción y flujos de cajas para las operaciones del negocio.

\section{Gráfico 6. Principales limitantes para el crecimiento de la empresa}

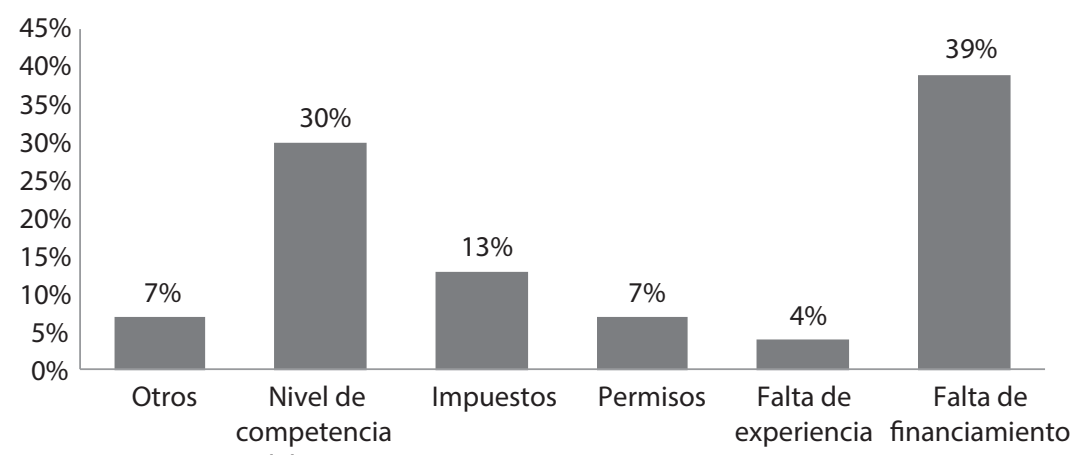


También fueron indagados acerca de las principales limitantes que tienen las microempresas para el crecimiento empresarial y según muestra el gráfico 6, el 39\% manifestó como causa la falta de financiamiento, el 30\%, el nivel de competencia del sector y el 13\% la carga impositiva de los impuestos, entre los más relevantes.

De igual forma, en lo que respecta a la percepción en la gestión en innovación y desarrollo por parte de las empresas, se obtiene que un 94\% consideran que la innovación es importante y muy importante para el desarrollo y crecimiento de las empresas. Inclusive un $62 \%$ de los negocios afirma haber realizado cambios en sus productos, procesos o sistemas de gestión en los últimos 2 años. De igual manera un $86 \%$ de las empresas han realizado innovación en el mejoramiento de los productos; además un $82 \%$ en mejoramiento en los procesos, un $51 \%$ han desarrollado nuevos productos y por último un $46 \%$ de los negocios han implementado normas ambientales y aplicación de tecnologías limpias en sus procesos productivos.

Posteriormente, se analizan las herramientas y equipo que disponen las microempresas, por lo que se observa que un $78 \%$ de las mismas utilizan mesas de trabajo de acero inoxidable, un $43 \%$ usan horno automático, el 53\% emplean horno manual, el $81 \%$ dispone de batidora, y el 59\% utiliza amasadora semi-automática, entre el equipamiento panadero más importante.

En lo relacionado, al análisis bivariado se realiza un análisis de varianza ANOVA de un factor (también llamada ANOVA unifactorial o one-way ANOVA), siendo una técnica estadística que establece si dos variables (una independiente y otra dependiente) están relacionadas en base a que si las medias de la variable dependiente son diferentes en las categorías o grupos de la variable independiente. Es decir, señala si las medias entre dos o más grupos son similares o diferentes.

Para el efecto, en la tabla 4, se presentan los resultados de contraste del análisis de ANOVA de la media de la variable de interés que es la productividad del empleado que tienen las microempresas panificadoras y las medias de las dos muestras independientes o factores concernientes a la gestión empresarial estratégica, operación de las empresas, aplicaciones de innovaciones y requerimiento de financiamiento adicional. Este análisis se generó de manera individual entre cada variable independiente con la variable dependiente. 


\section{Tabla 4. Análisis ANOVA de un factor-Desempeño del empleado / variables independientes}

\begin{tabular}{|c|c|c|c|}
\hline \multirow{2}{*}{\multicolumn{2}{|c|}{ Variables independientes (factor) }} & \multirow[t]{2}{*}{$\mathrm{N}$} & \multirow{2}{*}{$\begin{array}{c}\text { Desempeño } \\
\mathrm{F}\end{array}$} \\
\hline & & & \\
\hline \multirow{2}{*}{ Gestión Empresarial: misión } & $\mathrm{Si}$ & 11 & \multirow{2}{*}{ 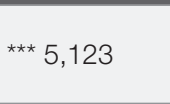 } \\
\hline & No & 102 & \\
\hline \multirow{2}{*}{ Gestión Empresarial: visión } & $\mathrm{Si}$ & 10 & \multirow{2}{*}{$* \star \star 4,661$} \\
\hline & No & 103 & \\
\hline \multirow{2}{*}{ Gestión Empresarial: organigrama } & $\mathrm{Si}$ & 7 & \multirow{2}{*}{ *** 5,247} \\
\hline & No & 106 & \\
\hline \multirow{2}{*}{$\begin{array}{l}\text { Gestión Empresarial: políticas internas de la } \\
\text { empresa }\end{array}$} & $\mathrm{Si}$ & 8 & \multirow{2}{*}{$\star \star \star * 10,536$} \\
\hline & No & 105 & \\
\hline \multirow{2}{*}{$\begin{array}{l}\text { Capacidad Productiva: número de unidades } \\
\text { día producidas }\end{array}$} & $<=658$ & 73 & \multirow{2}{*}{ 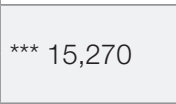 } \\
\hline & $>659$ & 40 & \\
\hline \multirow{2}{*}{$\begin{array}{l}\text { Ha realizado algún cambio o mejora en sus } \\
\text { procesos, productos o sistemas gestión en } \\
\text { los últimos } 2 \text { años }\end{array}$} & $\mathrm{Si}$ & 71 & \multirow[b]{2}{*}{ ** 3,857} \\
\hline & No & 42 & \\
\hline \multirow{2}{*}{$\begin{array}{l}\text { Indique en cuáles ha realizado innovación: } \\
\text { Adquisición de tecnología incorporada a } \\
\text { maquinaria y equipo }\end{array}$} & $\mathrm{Si}$ & 17 & \multirow[b]{2}{*}{ ** 3,839} \\
\hline & No & 96 & \\
\hline \multirow{2}{*}{$\begin{array}{l}\text { Indique en cuáles ha realizado innovación: } \\
\text { Mejoramiento de los sistemas de comer- } \\
\text { cialización }\end{array}$} & $\mathrm{Si}$ & 27 & \multirow{2}{*}{ ** 4,591} \\
\hline & No & 86 & \\
\hline \multirow{2}{*}{$\begin{array}{l}\text { Ha requerido financiamiento adicional duran- } \\
\text { te el tiempo que lleva generando actividades }\end{array}$} & $\mathrm{Si}$ & 49 & \multirow[b]{2}{*}{ ** 4,562} \\
\hline & No & 63 & \\
\hline
\end{tabular}

Nota: significancia *** $1 \% ; * * 5 \% ; * 10 \%$

Como se aprecia en la tabla 4, aquellas microempresas que tienen un desarrollo e implementación de su gestión estratégica empresarial con herramientas como visión, misión, organigrama y políticas internas de manejo de la empresa, tienen una correlación significativa con el promedio de la productividad del empleado; es decir que quienes han logrado desplegar una estrategia empresarial en la organización tienen un promedio de productividad por empleado superior en comparación a aquellas que no lo han desarrollado.

En consecuencia, se evidencia significativamente que aquellas microempresas que han implementado la gestión empresarial tienen un 
incremento promedio de productividad por empleado mes entre USD 583,29 y USD 783,28.

Por otro lado, al analizar la capacidad producida de las microempresas mediante las unidades al día producidas, se evidencia una correlación negativa con respecto al promedio de productividad total de los negocios de panificación; es decir que aquellas microempresas que producen en promedio más de 659 unidades al día tienen un promedio de productividad mes por empleado de USD 934,20 frente a USD 545,79 de aquellas que producen menos de 658 unidades día.

De la misma manera, las microempresas que han realizado cambios o mejoras en sus productos, procesos o sistemas de gestión en los 2 últimos años en adquisición de tecnología incorporada a maquinaria o equipos y en mejoramiento de comercialización, evidencian una media significativa de productividad/mes por empleado que oscila entre USD 587 a USD 895.

De igual forma, las microempresas que han requerido financiamiento adicional durante el tiempo que llevan generando actividades tienen una media significativa de productividad-mes por empleado mayor, que va entre USD 633 a USD 977, en comparación de las que no requirieron financiamiento adicional. Esto tiene una relación directa ya que el recurso que adquiere la empresa se invierte para la compra de maquinaria y ampliación física del negocio, permitiendo un mayor aprovechamiento del desempeño de sus recursos en las microempresas panificadoras.

\section{Conclusiones}

Se aprecia que las microempresas panificadoras tienen una limitada competitividad en factores internos de su propia operación, tales como una gestión administrativa débil, problemas con el mercado, producción y financiamiento, que constituyen elementos que dificultan la gestión e impiden el crecimiento del negocio.

Por otro lado, la capacidad productiva medida por las unidades producidas al día, es un factor que incide en la productividad por empleado, por lo que se ve incrementada considerablemente si las microempresas producen más de 659 unidades. Esto ligado a la capacidad productiva utilizada de las microempresas panificadoras que en promedio tiene un $70 \%$, por lo que se evidencia que las microempresas pueden producir más unidades al día. 
Otro factor que se relaciona con la productividad del empleado en las microempresas panificadoras del Azuay se relaciona con los cambios o mejoras en los procesos, productos o sistemas gestión en los últimos 2 años, especialmente en la adquisición de tecnología incorporada a maquinaria y equipo, y en el mejoramiento de los sistemas de comercialización.

Además, se observa que los empleados de las microempresas panificadoras tienen en promedio 8 años de nivel de educación, por lo que estudios han demostrado que a mayor grado de escolaridad de sus empleados, mayor es la productividad en la empresa; por lo que las microempresas panificadoras tienen un bajo nivel de productividad.

Como se puede apreciar en la caracterización de las microempresas panificadoras en el Azuay, por su estructura organizativa, normativa tributaria y por su restringida gestión empresarial estratégica, hace que tenga una alta limitación para un crecimiento sostenido en el tiempo.

Finalmente, estos factores coadyuvan a que la mayoría de las microempresas se consideren negocios de subsistencia al no disponer de controles operativos para un correcto y oportuno manejo administrativo. Además el hecho de contar con mano de obra no calificada restringe el desarrollo de procesos, productos o sistemas de gestión innovadores. La falta de capacitación del personal en áreas importantes y el bajo nivel de tecnificación de las maquinarias le resta productividad para que los negocios sean rentables y aporten mayores beneficios a la economía del país.

\section{Referencias}

Benavente, J. (2005). Investigación y desarrollo, innovación y productividad: un análisis econométrico a nivel de la firma. Estudios de Economía, 32(1), 39-67.

Bonilla, Y. M., \& Mayorga, J. Z. (2011). Medición de la productividad por el método del valor agregado (MPVA) a las Pymes de familia del sector industria de la ciudad de Bogotá D.C Medición de la productividad por el método del valor agregado (MPVA) a las Pymes de familia del sector industrial. Bogotá, Colombia.

Centro de Comercio Internacional. (2003). Forum de Comercio Internacional. Obtenido de http://www.forumdecomercio.org/La-medici\%C3\%B3n-del-rendimiento/

Centro Europeo de Empresas e Innovación. (2012). Centro Europeo de Empresas e Innovación. Obtenido de http://www.ceeicr.es/innovacion/innovacion-empresarial/

Cohen, M., \& Gabriel, B. (2012). La situación de las PyMEs en América Latina.

Comisión Económica para América Latina y el Caribe (2001). Elementos de Competitividad Sistémica de las PYMEs del Istmo Centroamericano. Naciones Unidas-CEPAL, LC/MEX(L.499), 1-54. 
Córdova, J., \& Naranjo, J. (Abril de 2017). Incidencia de la inversión en innovación en las ventas de productos innovadores. Evidencia empírica en empresas manufactureras de Colombia. Información Tecnológica, 28(2), 153-164.

Crépon, B., Duguet, E., \& Mairessec, J. (1998). Research, innovation and productivity: an econometric analysis at the firm level. Economics of Innovation and New Technology.

Dyer, L., \& Reeves, T. (1995). Human Resource Strategies and Firm Performance: What Do We Know and Where Do We Need to Go? Center for Advanced Human Resource Studies, 1-17.

Etzkowitz, H., \& Leydesdorff, L. (2000). The dynamics of innovation: from National Systems and "Mode 2" to a Triple Helix of university-industry-government relations. Research Policy, 29(2), 109-123. https://doi.org/10.1016/S00487333(99)00055-4

Fairlie, E. (2007). Generación de Valor Agregado en las Pymes a través de la innovación empresarial. Gestión en el tercer milenio. Revista de Investigación de la Facultad de Ciencias Administrativas, Universidad Nacional Mayor San Marcos, 23-27.

Griliches, Z. (1979). Issues in assessing the contribution and development of research to productivity growth. The Bell Journal of Economics, 10(1), 92-116. https:// doi.org/10.2307/3003321

Hidalgo, G., Kamiya, M., \& Reyes, M. (2014). Emprendimientos dinámicos en América Latina (No. $\left.\mathrm{N}^{\circ} 16 / 2014\right)$. Venezuela.

Hoffman, K., Parejo, M., Bessant, J., \& Perren, L. (1998). Small firms, R\&D, technology and innovation in the UK: a literature review. Technovation, 18(1), 39-55. https://doi.org/10.1016/S0166-4972(97)00102-8

Kuznets, S. S. (1966). Modern economic growth : rate, structure, and spread. New Haven: Yale University Press.

Lochon, F. (2014). El salto productivo a la tecnología.

Lööf, H., Heshmati, A., Asplund, R., \& Naas, S. (2001). Innovation and performance in manufacturing industries: a comparison of the Nordic countries. EconStor, SSE/ EFI working paper series in economics and finance(457).

Maldonado Guzmán, G., Martínez Serna, M. del C., Hernández Castorena, O., \& García Pérez de Lema, D. (2011). El impacto de los procesos de producción en el rendimiento de la pyme manufacturera de México: Un estudio empírico. TEC Empresarial, 5(1), 21-30.

Rodríguez, F. X., \& Gómez, L. (2011). Indicadores de calidad y productividad en las empresas. New York.

Rodríguez, L. A., Bernal, M. E., \& Cuervo, L. M. (2012). Teoría y práctica del desarrollo económico local.

Salazar, C. A. (2015). La productividad y competitividad en las PYMES. Quito- Ecuador.

Solís, L. (2005). Procesos de negocios de Pymes insertas en redes colaborativas SMSB negotiating processes inserted into collaborative. Administración de operaciones.

Teece, D. J., Pisano, G., \& Shuen, A. (1997). Dynamic capabilities and strategic management. Strategic Management Journal, 18(7), 509-533. https://doi. org/10.1002/(SICI)1097-0266(199708)18:7<509::AID-SMJ882>3.0.CO;2-Z 
Velarde, E., Araiza, Z., \& García, A. (2014). Factores de la empresa y del empresario y su relación con el éxito económico en la PYMES de la región centro de Coahuila, en México. Revista Internacional de Administración y Finanzas, 7(5), 11-23.

Villegas, C. A. S. (2015). La productividad y competitividad en las PYMES. Quito-Ecuador.

Vossen, R. W. (1998). Relative strengths and weaknesses of small firms in innovation. International Small Business Journal, 16(3), 88-95.

World Bank Group (2014). Doing Business 2014 Measuring Regulatory Quality and Efficiency. https://doi.org/10.1596/978-1-4648-0667-4 


\title{
Mejores prácticas empresariales de responsabilidad social en la inclusión de personas con discapacidad. Estudio de caso en empresas de Ambato, Ecuador
}

\section{Corporate Social Responsibility in the inclusion of people with Disability. Case Study Ambato Companies, Ecuador} Fanny Paulina Pico Barrionuevo es Profesora e Investigadora en la carrera de Trabajo Social de la Universi-
dad Técnica de Ambato (Ecuador) (paulinapico@hotmail.com) (http://orcid.org/0000-0002-2276-8198)

Silvia Susana Torres es Profesora e Investigadora en la carrera de Trabajo Social de la Universidad Técnica de Ambato (Ecuador) (stcvita@yahoo.com) (http://orcid.org/0000-0002-6824-8518)

\begin{abstract}
Resumen
La inclusión de las Personas con Discapacidad (PCD) en el ámbito laboral aún tiene falencias que se debe ir corrigiendo, considerando que este grupo ha sentido la exclusión laboral de alguna u otra forma. El sector empresarial, protagonista principal del mercado laboral y actor fundamental en la realización de una verdadera inclusión, ya sea por cumplimiento de normativas legales establecidas o a su vez por realizar Responsabilidad Social Empresarial, tiene en sus manos la inclusión laboral de personas con esta condición. El objetivo del presente trabajo es identificar la realidad de las empresas en la inclusión laboral de las personas con discapacidad. Para el efecto se aplica un diseño metodológico de tipo cuali-cuantitativo en base a un marco teórico revisado para luego identificar valoraciones que permitan reunir evidencias y emitir un juicio de valor en la investigación. Se aplica el tipo de muestra probabilística aleatoria simple a través de la cual cada elemento de la población tiene la misma oportunidad de ser elegida. La investigación se realiza a través de una encuesta establecida de cuatro dimensiones: i) planificación; ii) inclusión; iii) equidad y; iv) desarrollo. De las 80 empresas encuestadas, el 11,70\% corresponden a aquellas que realizan las mejores prácticas empresariales. También destaca el sector comercial en los ejes de inclusión, equidad y desarrollo. El eje de desarrollo es el que tiene menor porcentaje, por lo que se le debe considerar con mayor interés para mejorar los procesos de inclusión de PcD.
\end{abstract}

\begin{abstract}
The inclusion of persons with disabilities (PcD), in the field of labor still has flaws that should be corrected, considering that this group has been the exclusion of some form, the business sector of the labor market, a key actor in the realization of a true inclusion, either by legal compliance or by making corporate social responsibility, the labor inclusion should be a fundamental part of each company. The aim of this work is to identify the reality of companies in the labor market inclusion of persons with disabilities, to the effect applies a methodology of qualitative-quantitative research on the basis of a revised theoretical framework to then identify ratings to gather evidence and make a judgment of value to the investigation, applies the type of simple random probability sample through which each element of the population has an equal chance of being chosen, the research is performed through a set of four dimensions: Planning, inclusion, equity and development. Of the 80 companies surveyed the $11.70 \%$ correspond to those that perform the best business practices, it also highlights the Commercial Sector in the areas of: inclusion, equity and development. The axis of development is the one that has a lower percentage should be considered to improve the processes that include it.
\end{abstract}

\section{Palabras clave | keywords}

Responsabilidad social, empresa privada, impedido, grupo desfavorecido, trabajo, incapacidad. Social responsibility, private enterprises, disabled persons, vulnerable groups, labour, disabilities. 


\section{Introducción y estado de la cuestión}

En la actualidad se han establecido mecanismos para realizar la inclusión de personas con discapacidad en el sector empresarial. Sin embargo existen varias razones por las cuales este vulnerable grupo no ha logrado tener una inserción total en cada una de las empresas. Por esta razón, la presente investigación pretende identificar la realidad de las empresas con respecto a la inclusión laboral de las personas con discapacidad. En el país se ha puesto en vigencia la Ley Orgánica de Discapacidades, que manifiesta en su artículo 47 sobre la obligatoriedad de contratación a personas con discapacidad:

Artículo 47.- Inclusión laboral.- La o el empleador público o privado que cuente con un número mínimo de veinticinco (25) trabajadores está obligado a contratar, un mínimo de cuatro por ciento (4\%) de personas con discapacidad, en labores permanentes que se consideren apropiadas en relación con sus conocimientos, condiciones físicas y aptitudes individuales, procurando los principios de equidad de género y diversidad de discapacidades. El porcentaje de inclusión laboral deberá ser distribuido equitativamente en las provincias del país, cuando se trate de empleadores nacionales; y a los cantones, cuando se trate de empleadores provinciales (Asamblea Nacional República del Ecuador, 2012).

En este contexto existe una obligatoriedad en la contratación de personas con discapacidad. Por otro lado, la Ley Orgánica de Discapacidad, establece en su artículo 49 la deducción del 150\% adicional para el cálculo de la base imponible del impuesto a la Renta otorgando un incentivo a la empresa privada en la contratación de las Personas con Discapacidad (PcD). Cabe indicar que existe cierto desconocimiento sobre este incentivo en la empresa privada, pues existe una desidia aparente ante la realidad de la inclusión de PcD.

\subsection{La responsabilidad social empresarial (RSE)}

Existen varias discusiones sobre las acciones que realiza la empresa en lo relativo con la responsabilidad social. Sin embargo se debe aclarar que cada individuo que trabaja en una organización tiene una ética y un sentido de responsabilidad, lo cual se proyecta en la organización (Banco Interamericano de Desarrollo, 2011).

En España se analizan a profundidad los temas de responsabilidad social empresarial en el ámbito de la inclusión de personas con discapa- 
cidad. En el caso de las personas con discapacidad intelectual, realizan la inclusión a través de la legislación vigente y conjuntamente con la práctica de Responsabilidad Social Empresarial, que tiene que ver con la integración de personas con discapacidad o la igualdad de las personas (Blanco Prieto, 2015).

El término discapacidad tiene varias definiciones. Una de ellas que se manifestó en la Convención de los Derechos de las Personas con Discapacidad 2006 (como se cita en Ministerio de Relaciones Laborales - CONADIS, 2013) establece que:

(la) discapacidad es un concepto que evoluciona y que resulta de la interacción entre las personas con deficiencias y las barreras debidas a la actitud y al entorno que evitan su participación plena y efectiva en la sociedad, en igualdad de condiciones con las demás.

En la provincia de Tungurahua existen 2158 personas con discapacidad laboralmente activas, de las cuales el 55,46\% tiene discapacidad física (Consejo Nacional de Discapacidades CONADIS - Instituto Ecuatoriano de Seguridad Social IESS, 2016).

\subsection{Discapacidad y la inclusión laboral}

Las personas con discapacidad tienen una menor participación en el mercado laboral, inclusive con menos opciones aquellas con una discapacidad significativa. En este sentido existen organismos e instituciones que de alguna manera forman un canal entre las personas con discapacidad y la empresa privada para lograr su inserción laboral. En España, por ejemplo, existen los Centros Especiales de Empleo (CEE), los cuales son la principal vía de integración de las personas con discapacidad. El objetivo principal de estos centros es reducir el desempleo y la inactividad de los trabajadores con discapacidad (Rodríguez \& Cueto, 2013).

En otras latitudes, en Paraguay las instituciones privadas tienen en su historial alguna forma de relación laboral con las personas con discapacidad, siendo como factores de contratación la responsabilidad social y la iniciativa de diferentes entes gubernamentales y no gubernamentales los que dan hincapié al trabajo como derecho (Reyes Giménez, 2015).

En el Ecuador sobre este tema de discapacidad en el ámbito laboral, se analizan dos aspectos que tienen que ver con la limitada inserción en el mercado laboral. Primero con el grupo vulnerable $(\mathrm{PcD})$ quienes 
tienen un bajo nivel educativo, debido a que existen barreras de comunicación, al medio físico y a la información, lo que impiden la formación y capacitación de este grupo vulnerable (Consejo Nacional de la Igualdad de Discapacidades CONADIS, 2013). Por otro lado se encuentra el sector empresarial, que tiene resistencia hacia la contratación de personas con discapacidad por el prolongado proceso de integración laboral considerando la adaptación del empleado, empleador y equipo de trabajo, que además influye en la falta de aplicación de medidas de acción afirmativa para procesos de selección de personal (adaptación de test y material de selección, evaluación de conocimientos, competencias, habilidades y destrezas). De acuerdo con los requerimientos de cada discapacidad y de alguna forma se presentan irregularidades ante el cumplimiento de la Ley Reformatoria al Código de Trabajo (Ley de cuotas que establece $4 \%$ ).

Continuando en el mismo contexto, en el Ecuador se ha establecido un marco legal para el empleador público o privado que favorece la inserción de las PcD. Así, en el artículo 42, numeral 33 del Código de Trabajo se determina que:

(...) el empleador público o privado, que cuente con un número mínimo de veinticinco trabajadores, está obligado a contratar, al menos, a una persona con discapacidad, en labores permanentes que se consideren apropiadas en relación con sus conocimientos, condición física y aptitudes individuales, observándose los principios de equidad de género y diversidad de discapacidad. A partir del año 2009, el porcentaje obligatorio de contratación de personas con discapacidad, es del 4\% del total de trabajadores de cada empresa o patrono persona natural.

\section{Fundamentos y propósito del estudio}

Sea que la empresa quiera realizar una aplicación de Responsabilidad Social Empresarial a través de buenas prácticas empresariales en la inclusión de personas con discapacidad, es importante identificar cómo el grupo de $\mathrm{PcD}$ ha ingresado en el ámbito laboral empresarial y cómo actúa el empleador. Considerando que en el Ecuador ya se han establecido normativas legales y mejores prácticas para la inclusión de las personas con discapacidad, de tal manera que se establezca una relación socio-laboral entre estos dos actores, en consecuencia se ve la necesidad de realizar una primera investigación diagnóstica-exploratoria verifi- 
cando las variables de estudio, a través de dimensiones que incluyen criterios como la equidad e inclusión que son elementos primordiales para la atención a la población con discapacidad. En este sentido, la investigación se basa en los siguientes paradigmas:

Tabla 1. Paradigmas sobre equidad e inclusión social en el mercado laboral

\begin{tabular}{|l|l|l|l|}
\hline Equidad & \multicolumn{1}{|c|}{ Liberal } & \multicolumn{1}{c|}{ Marxista } & \multicolumn{1}{c|}{ Posestructuralista } \\
\hline $\begin{array}{l}\text { Generación de equi- } \\
\text { paración o igualdad } \\
\text { de oportunidades }\end{array}$ & $\begin{array}{l}\text { Supera las con- } \\
\text { diciones sociales, } \\
\text { políticas y económi- } \\
\text { cas que producen la } \\
\text { dominación }\end{array}$ & $\begin{array}{l}\text { Reconocimiento y potencia- } \\
\text { ción de la multiculturalidad } \\
\text { (esta se fundamenta más en la } \\
\text { diferencia que en la oportu- } \\
\text { nidad) }\end{array}$ \\
\hline $\begin{array}{l}\text { Minorías como } \\
\text { objetos de una } \\
\text { política que provee } \\
\text { un tratamiento dife- } \\
\text { rencial, generalmente } \\
\text { focalizado }\end{array}$ & $\begin{array}{l}\text { Se reconocen las } \\
\text { diferencias culturales } \\
\text { de las minorías; éstas } \\
\text { se explican desde el } \\
\text { modelo de la des- } \\
\text { ventaja social. }\end{array}$ & $\begin{array}{l}\text { Minorías como sujetos partí- } \\
\text { cipes en la construcción de la } \\
\text { política }\end{array}$ \\
\hline $\begin{array}{l}\text { Diversidad orientada } \\
\text { a la asimilación y al } \\
\text { individualismo }\end{array}$ & $\begin{array}{l}\text { Diversidad orientada } \\
\text { a generar contra los } \\
\text { grupos hegemónicos } \\
\text { en lo social cultural y } \\
\text { político }\end{array}$ & $\begin{array}{l}\text { Diversidad orientada al diálogo } \\
\text { e integración intercultural, la } \\
\text { identificación y los consensos } \\
\text { disensos }\end{array}$ \\
\hline $\begin{array}{l}\text { Inclusión } \\
\text { Compensar las } \\
\text { desigualdades con } \\
\text { las que los alum- } \\
\text { nos acceden a la } \\
\text { escuela. Medidas in- } \\
\text { dividuales centradas } \\
\text { en propuestas de } \\
\text { adaptaciones curri- } \\
\text { culares específicas o } \\
\text { programas compen- } \\
\text { satorios }\end{array}$ & $\begin{array}{l}\text { Desarrollar proce- } \\
\text { sos educativos en } \\
\text { programas sociales y } \\
\text { económicos, donde } \\
\text { toda la comunidad } \\
\text { educativa luche por } \\
\text { reducir los orígenes } \\
\text { de desigualdad y la } \\
\text { exclusión, que ge- } \\
\text { neralmente se sitúa } \\
\text { fuera de la escuela }\end{array}$ & $\begin{array}{l}\text { Es una actitud un sistema de } \\
\text { valores y creencias, no una ac- } \\
\text { conjunto de acciones. Implica } \\
\text { reconocer unos ejercicios de } \\
\text { poder, unos lenguajes, unas } \\
\text { relaciones por descontruir y } \\
\text { reorientar. Exige ofrecer una } \\
\text { propuesta de actuación que } \\
\text { impida la transformación de } \\
\text { las diferencias en símbolo de } \\
\text { marginación. }\end{array}$ \\
\hline
\end{tabular}

Fuente: Tomado de Díaz, O.C (1) Equidad, inclusión y discapacidad. CD Memorias II Foro Distrital de Discapacidad, Bogotá, 2005. Citado en (García Ruiz \& Fernández Moreno, 2005)

Las respuestas de inclusión social, requieren de unas propuestas políticas en las cuales se les reconozcan a todos los sujetos como protagonistas y dependerá del interés del sujeto en cada uno de los escenarios, como puede ser educativo o laboral (García-Ruiz \& Fernández-Moreno, 2005). 
En el momento de realizar la inducción, ésta debe ser 100\% inclusiva y adecuada a las necesidades específicas de las personas con discapacidad. En el caso de que se vea en la necesidad de tener un intérprete de lengua de señas -por ejemplo- será imprescindible realizarlo de esta forma (Ministerio de Relaciones Laborales - Dirección de Atención a Grupos Prioritarios - Conadis, 2013).

En el Ecuador, el Ministerio de Inclusión Económica y Social, según el Acuerdo Ministerial No 000154, en su artículo 3 establece la gestión de los principios de igualdad, inclusión, equidad, universalidad e integralidad (Ministerio de Inclusión Económica y Social, 2013), mismos que se consideran en la aplicación de diferentes instrumentos de valoración para la aplicación de procesos en el ámbito laboral y que tienen que ver con las $\mathrm{PcD}$.

\section{Material y métodos}

El objetivo general del presente trabajo es identificar la realidad de las empresas en la inclusión laboral de las personas con discapacidad. Para la realización de la investigación se aplicó el método cuantitativo, el cual se fundamenta en la medición de las características de fenómenos sociales que derivaron de un marco conceptual adecuado a la problemática estudiada (Bernal, 2010). Considerando los criterios establecidos en el cuestionario se determinarán valores que permitirán emitir juicios de valor de acuerdo a los resultados presentados.

También se aplicará el método cualitativo o método no tradicional, en donde se pretende entender los diferentes tipos de situaciones sociales como un todo, considerando sus propiedades y su dinámica (Bernal, 2010).

El grupo analizado será el sector empresarial y las personas con discapacidad en la ciudad de Ambato (Tungurahua, Ecuador). Se aplicó una muestra probabilística aleatoria simple a través de la cual cada elemento de la población tiene la misma oportunidad de ser elegida, y donde la probabilidad de seleccionar a cualquier miembro en particular de la población la primera vez es $1 / \mathrm{N}$ (Berenson, Levine, \& Krehbiel, 2001), de tal forma que $\mathrm{N}=160$ y $\mathrm{n}=80$. El listado de empresas fue proporcionado por la Fundación Cuesta Holguín.

Las empresas participantes se desarrollan en el sector privado y están involucradas en diferentes actividades sectoriales. Se aplicó una encuesta a 80 de ellas, tal como se extrae en la tabla 2: 
Tabla 2. Empresas participantes por Sector

\begin{tabular}{|l|c|}
\hline \multicolumn{1}{|c|}{ Actividad Sectorial } & $\%$ \\
\hline Sector Industrial & 28,57 \\
\hline Sector Comercial & 25,97 \\
\hline Sector Servicios & 45,45 \\
\hline
\end{tabular}

Para la realización del trabajo se aplicó una encuesta establecida a través de cuatro dimensiones: i) planificación; ii) inclusión; iii) equidad y; iv) desarrollo. Cada eje consta de ítems detallados de la siguiente manera:

- Planificación: Incluye 4 ítems y valora si la empresa cuenta con una planificación inicial en el proceso de selección. Establece si se cumple con el porcentaje establecido en la normativa que incluye el tipo de discapacidad, la realización del proceso de selección y la inducción de las PcD.

- Inclusión: Incluye 4 ítems y revisa la inclusión social en la actividad laboral, la accesibilidad física dependiendo del tipo de discapacidad, así como la señalización e información y comunicación adecuada a las PcD.

- Equidad: Incluye 4 ítems y analiza la equidad de derechos y beneficios, sensibilización, la reubicación laboral y el reconocimiento al buen desempeño laboral.

- Desarrollo: Incluye 4 ítems y establece la realización de capacitación, evaluación, desarrollo y promoción así como también la adaptación del puesto de trabajo.

Cada ítem fue valorado a través de tres criterios: i) mejor práctica; ii) buena práctica y; iii) en proceso, entendiéndose cada una de ellas de la siguiente manera:

- Mejor Práctica: Va más allá del cumplimiento de la normativa (Ley Orgánica de Discapacidades, revisada ut supra), es decir que no solamente cumple con la norma sino que además desarrolla mejoras en cada proceso (excelencia), y se lo valora con una puntuación de 10.

- Buena Práctica: Cumple con la normativa establecida y se valora con una puntuación de 5

- En Proceso: Tiene planificado realizarlo y se le valora con una puntuación de 0 


\section{Análisis y resultados}

Se han identificado los resultados luego de haber aplicado las encuestas. Se determinan porcentajes y aplicando la media aritmética se evidencian resultados agrupados por dimensiones, como se detalla en la tabla 3:

\section{Tabla 3. Aplicación de cada dimensión en las empresas por actividad sectorial}

\begin{tabular}{|l|c|c|c|c|}
\hline \multicolumn{1}{|c|}{$\begin{array}{c}\text { Actividad Sectorial } \\
\text { Empresarial }\end{array}$} & Planificación & Inclusión & Equidad & Desarrollo \\
\hline Sector Industrial & $9,09 \%$ & $11,08 \%$ & $8,81 \%$ & $6,96 \%$ \\
\hline Sector Comercial & $9,38 \%$ & $12,03 \%$ & $10,78 \%$ & $8,75 \%$ \\
\hline Sector Servicios & $9,87 \%$ & $10,08 \%$ & $7,41 \%$ & $6,79 \%$ \\
\hline
\end{tabular}

El sector comercial tiene porcentajes que destacan del resto en cuanto a las variables inclusión, equidad y desarrollo, mientras que en el sector servicios destaca en la planificación. La tabla 4 muestra los resultados sobre las mejores prácticas empresariales por actividad sectorial:

Tabla 4. Mejores prácticas empresariales

\begin{tabular}{|l|c|c|c|}
\hline \multicolumn{1}{|c|}{ Actividad Sectorial } & Mejor Práctica & Buena Práctica & En Proceso \\
\hline Sector Industrial & $16,27 \%$ & $51 \%$ & $34,09 \%$ \\
\hline Sector Comercial & $13,95 \%$ & $56,85 \%$ & $29,2 \%$ \\
\hline Sector Servicios & $8,57 \%$ & $60,89 \%$ & $30,31 \%$ \\
\hline
\end{tabular}

Se identifican como mejores prácticas empresariales al sector industrial, con un resultado de $16,27 \%$, en segundo lugar el sector comercial con un $13,95 \%$ y en tercer lugar el sector servicios con un $8,57 \%$. De esta manera se establece un cuadro consolidado (gráfico 1) con la información sobre las mejores prácticas empresariales en la Inclusión de personas con discapacidad.

De las 80 empresas encuestadas, el 11,70\% corresponden a aquellas que realizan las mejores prácticas empresariales, un 57,5\% realizan buenas prácticas empresariales, mientras que un $30,9 \%$ se encuentran en proceso. 


\section{Gráfico 1. Cuadro consolidado de interrelación entre mejores y buenas prácticas y empresas "en proceso"}

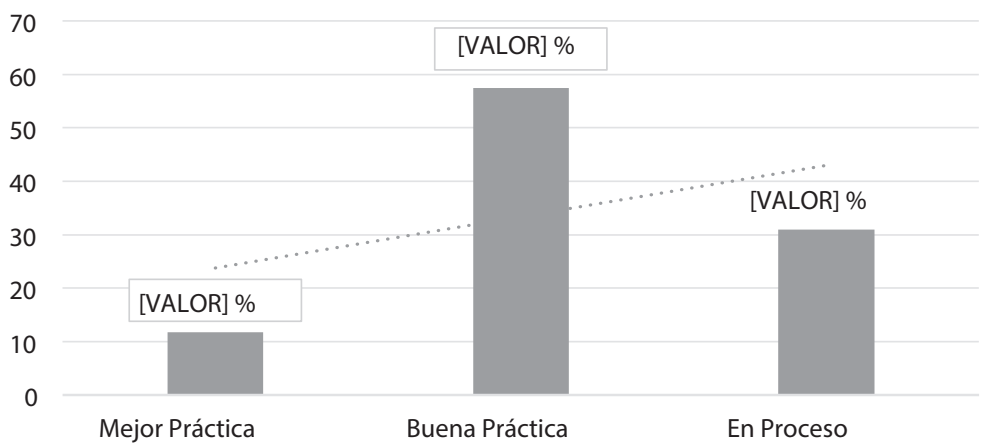

\section{Discusión y conclusiones}

De los cuatro ejes establecidos para la identificación de las mejores prácticas se analiza primeramente la «planificación», la cual se observa un alto porcentaje en el sector de servicios con un 9,87\%, lo cual motiva a las empresas a tener un acercamiento de las empresas hacia organismos como el Consejo Nacional de Discapacidades (CONADIS) y a su vez con los Servicios de Integración Laboral (SILL), organismos que están encargados de brindar asesoramiento empresarial, así como también charlas de sensibilización en materia de inclusión.

También se analiza que los procesos de selección y de inducción deben ser adaptados a las personas con discapacidad, considerando que la empresa debe construir herramientas inclusivas (técnicas de comunicación) que les permitan socializar el código de ética interno, el manual administrativo, el comité de seguridad y salud ocupacional o cualquier otra información relevante con relación a horarios y sueldos (Ministerio de Relaciones Laborales - Dirección de Atención a Grupos PrioritariosConadis, 2013).

El eje de la «inclusión» analiza las actividades sociales y culturales que realiza la empresa y cómo es la participación de las Personas con Discapacidad (PcD). También incluye accesibilidad física, señalización y comunicación en el sector comercial, apreciándose un valor alto con respecto a los otros sectores con un $12,03 \%$. En este sentido, se debe 
indicar que las personas con discapacidad deben tener el mejor trato el cual debe ser prioritario y no diferente, caracterizado por el respeto (Ministerio de Relaciones Laborales - Dirección de Atención a Grupos Prioritarios - Conadis, 2013).

El eje de la «equidad» analiza los beneficios y derechos que tienen las $\mathrm{PcD}$ y si los colaboradores han sido sensibilizados frente a la discapacidad. También si la empresa cuenta con procesos de reubicación socio-laboral y si la organización tiene políticas de reconocimiento por el buen desempeño laboral. En este ámbito el sector comercial cuenta con un 10,78\% sobre los sectores industrial y de servicios.

Finalmente el eje de «desarrollo», que es uno de los ejes que se deben mejorar pues es el más bajo con respecto a los demás, analiza cómo la empresa incluye a las $\mathrm{PcD}$ en procesos de capacitación y formación, así como también analiza si el sistema de evaluación es acorde a los requerimientos de las $\mathrm{PcD}$, ya que según sean las habilidades o destrezas de las personas con discapacidad, se deberán adaptar los instrumentos o realizar ajustes a los mismos (Ministerio de Relaciones Laborales Dirección de Atención a Grupos Prioritarios - Conadis, 2013).

Lo anterior incluye además una revisión sobre las promociones y desarrollo en el ámbito laboral. Algo importante que recalcar es la necesidad de realizar adaptaciones del puesto de trabajo en caso de que sea necesario, de acuerdo al tipo de discapacidad que tenga el colaborador, al igual que en las anteriores dimensiones, los ejes de «inclusión» y «equidad» en el sector comercial destacan un 8,75\% más que los demás sectores.

Finalmente, de las 80 empresas encuestadas el 11,70\% corresponden a aquellas que realizan las mejores prácticas empresariales; quiere decir que sí existe un grupo empresarial preocupado por alcanzar el bienestar y la inclusión de su PcD. Por su parte, un grupo correspondiente al $57,5 \%$-es decir, más de la mitad de empresas encuestadas- obtienen una evaluación positiva de realizar buenas prácticas empresariales, mientras que un 30,9\% se encuentran en proceso de aplicación.

Con respecto al objetivo señalado se puede indicar que las empresas tienen un papel importante en el ámbito laboral y en tal virtud se evidencia que más de la mitad de empresas encuestadas realizan buenas prácticas empresariales, estableciendo procesos de inclusión de acuerdo a los requerimientos de las Personas con Discapacidad (PcD). Por otro lado, se deja abierta la posibilidad de investigaciones futuras para ana- 
lizar cada una de las dimensiones establecidas, así como también investigar sobre las necesidades de los sectores empresariales en la adecuada ubicación de las Personas con Discapacidad.

Las limitaciones del estudio fueron básicamente de tiempo, debido a que se ha determinado como un diagnóstico inicial de cómo se encuentra el sector empresarial frente a la inclusión de personas con discapacidad. En este sentido es importante establecer que se debe estudiar el comportamiento de las variables analizadas en el lapso de un año para identificar nuevos resultados.

\section{Referencias}

Asamblea Nacional República del Ecuador. (25 de septiembre de 2012). Registro Oficial. Ley Orgánica de Discapacidades. Quito, Pichincha, Ecuador: Tribunal Constitucional de la República del Ecuador.

Banco Interamericano de Desarrollo (Mayo de 2011). Responsabilidad de la empresa ante la sociedad - Antonio Vives. La Responsabilidad Social de la empresa en América Latina. New York, Estados Unidos: BID.

Berenson, M. L., Levine, D. M., \& Krehbiel, T. C. (2001). Estadística para administración. México: Pearson Educación.

Bernal, C. A. (2010). Metodología de la Investigación. Bogotá: Pearson Educación.

Blanco Prieto, A. (2015). Responsabilidad social empresarial e integración laboral de personas con discapacidad intelectual. Estudio de Caso. Revista Española de Discapacidad, 211-217.

Consejo Nacional de Discapacidades CONADIS - Instituto Ecuatoriano de Seguridad Social IESS. (1 de julio de 2016). Estadísticas Conadis. Obtenido de Estadísticas Conadis: http://www.consejodiscapacidades.gob.ec/estadistica/index.html

Consejo Nacional de la Igualdad de Discapacidades CONADIS. (2 de diciembre de 2013). Agenda Nacional para la Igualdad en Discapacidades 2013 - 2017. Cambiando Vidas. Quito, Pichincha, Ecuador: Equipo Técnico Consejo Nacional de Discapacidades. Obtenido de http://www.planificacion.gob.ec/wp-content/uploads/downloads/2014/09/Agenda-Nacional-para-Discapacidades.pdf

Consejo Nacional para la Igualdad de Discapacidades. (1 de julio de 2016). Consejo Nacional para la Igualdad de Discapacidades. Obtenido de www.consejodiscapacidades.gob.ec/estadistica/index.html

Fundación General Ecuatoriana (2010). I Reconocimiento empresarial a las mejores prácticas en inclusión sociolaboral de personas con discapacidad. Quito: Fundación General Ecuatoriana.

García Ruiz, A. S., \& Fernández Moreno, A. (2005). La inclusión para las personas con discapacidad: entre la iguladad y la diferencia. Revista Ciencias de la Salud, 235246. Obtenido de http://www.redalyc.org/pdf/562/56230213.pdf

Ministerio de Inclusión Económica y Social. (9 de enero de 2013). Ministerio de Inclusión Económica y Social. Obtenido de http://www.inclusion.gob.ec/ 
wp-content/uploads/downloads/2013/02/ESTATUTO-ORGA\%CC\%81NICO-POR-PROCESOS-MIES-al-09-enero-2013-5.pdf

Ministerio de Relaciones Laborales - CONADIS. (4 de Diciembre de 2013). Ministerio de Trabajo. Manual de buenas prácticas para la Inclusión laboral de personas con discapacidad. Quito, Pichincha, Ecuador. Obtenido de Manual de Buenas Prácticas para la inclusión laboral de personas con discapacidad: http://www. trabajo.gob.ec/wp-content/uploads/2013/12/MANUALFIN.pdf

Ministerio de Relaciones Laborales - Dirección de Atención a Grupos Prioritarios Conadis. (2013). Consejo de Discapacidades. Obtenido de Manual de Buenas prácticas para la Inclusión laboral de Personas con Discapacidad: http://www. consejodiscapacidades.gob.ec/wp-content/uploads/downloads/2014/06/manual_buenas_practicas_inclusion_laboral.pdf

Reyes Giménez, A. (2015). Empleabilidad de personas con discapacidad desde el marco rector de SENADIS, Paraguay. Revista Internacional de Integración en Ciencias Sociales, 209-222. Obtenido de http://revistacientifica.uaa.edu.py/index. $\mathrm{php} / \mathrm{riics} /$ article/view/268

Rodríguez, V., \& Cueto, B. (2013). El trabajo de las personas con discapacidad ante la crisis. Revista Internacional de Organizaciones, 61-86. Obtenido de https:// dialnet.unirioja.es/servlet/articulo?codigo $=4994810$ 


\section{Normas editoriales básicas}

Universidad Politécnica Salesiana del Ecuador

\section{Información general}

«Retos» es una publicación científica bilingüe de la Universidad Politécnica Salesiana de Ecuador, editada desde enero de 2011 de forma ininterrumpida, con periodicidad fija semestral, especializada en Desarrollo y sus líneas transdisciplinares como Administración Pública, Economía Social, Marketing, Turismo, Emprendimiento, Gerencia, Ciencias Administrativas y Económicas, entre otras.

Es una Revista Científica arbitrada, que utiliza el sistema de evaluación externa por expertos (peer-review), bajo metodología de pares ciegos (doble-blind review), conforme a las normas de publicación de la American Psychological Association (APA). El cumplimiento de este sistema permite garantizar a los autores un proceso de revisión objetivo, imparcial y transparente, lo que facilita a la publicación su inclusión en bases de datos, repositorios e indexaciones internacionales de referencia.

«Retos» se encuentra indexada en el directorio y catálogo selectivo del Sistema Regional de Información en Línea para Revistas Científicas de América Latina, el Caribe, España y Portugal (Latindex), en el Sistema de Información Científica REDALYC, en el Directorio de Revistas de Acceso Abierto DOAJ y en repositorios, bibliotecas y catálogos especializados de Iberoamérica.

La Revista se edita en doble versión: impresa (ISSN: 1390-62911) y electrónica (e-ISSN: 1390-8618), en español e inglés, siendo identificado además cada trabajo con un DOI (Digital Object Identifier System).

\section{Alcance y política}

\subsection{Temática}

Contribuciones originales en materia de Desarrollo, así como áreas afines: Administración Pública, Economía Social, Marketing, Turismo, Emprendimiento, Gerencia... y todas aquellas disciplinas conexas interdisciplinarmente con la línea temática central. 


\subsection{Aportaciones}

«Retos» edita preferentemente resultados de investigación empírica sobre Desarrollo, redactados en español y/o inglés, siendo también admisibles informes, estudios y propuestas, así como selectas revisiones de la literatura (state-of-the-art).

Todos los trabajos deben ser originales, no haber sido publicados en ningún medio ni estar en proceso de arbitraje o publicación. De esta manera, las aportaciones en la revista pueden ser:

- Investigaciones: 5.000 a 6.500 palabras de texto, incluyendo título, resúmenes, descriptores, tablas y referencias.

- Informes, estudios y propuestas: 5.000 a 6.500 palabras de texto, incluyendo título, resúmenes, tablas y referencias.

- Revisiones: 6.000 a 7.000 palabras de texto, incluidas tablas y referencias. Se valorará especialmente las referencias justificadas, actuales y selectivas de alrededor de unas 70 obras.

«Retos» tiene periodicidad semestral (20 artículos por año), publicada en los meses de abril y octubre y cuenta por número con dos secciones de cinco artículos cada una, la primera referida a un tema Monográfico preparado con antelación y con editores temáticos y la segunda, una sección de Misceláneas, compuesta por aportaciones variadas dentro de la temática de la publicación.

\section{Presentación, estructura y envío de los manuscritos}

Los trabajos se presentarán en tipo de letra Arial 10, interlineado simple, justificado completo y sin tabuladores ni espacios en blanco entre párrafos. Solo se separarán con un espacio en blanco los grandes bloques (título, autores, resúmenes, descriptores, créditos y epígrafes). La página debe tener 2 centímetros en todos sus márgenes.

Los trabajos deben presentarse en documento de Microsoft Word (.doc o .docx), siendo necesario que el archivo esté anonimizado en Propiedades de Archivo, de forma que no aparezca la identificación de autor/es.

Los manuscritos deben ser enviados única y exclusivamente a través del OJS (Open Journal System), en el cual todos los autores deben darse de alta previamente. No se aceptan originales enviados a través de correo electrónico u otra interfaz.

\subsection{Estructura del manuscrito}

Para aquellos trabajos que se traten de investigaciones de carácter empírico, los manuscritos seguirán la estructura IMRDC, siendo opcionales los epígrafes de Notas y Apoyos. Aquellos trabajos que por el contrario 
se traten de informes, estudios, propuestas y revisiones podrán ser más flexibles en sus epígrafes, especialmente en Material y métodos, Análisis y resultados y Discusión y conclusiones. En todas las tipologías de trabajos son obligatorias las Referencias.

1) Título (español) / Title (inglés): Conciso pero informativo, en castellano en primera línea y en inglés en segunda. Se aceptan como máximo 80 caracteres con espacio. El título no solo es responsabilidad de los autores, pudiéndose proponer cambios por parte del Consejo Editorial.

2) Nombre y apellidos completos: De cada uno de los autores, organizados por orden de prelación. Se aceptarán como máximo 3 autores por original, aunque pudieren existir excepciones justificadas por el tema, su complejidad y extensión. Junto a los nombres ha de seguir la categoría profesional, centro de trabajo, correo electrónico de cada autor y número de ORCID. Es obligatorio indicar si se posee el grado académico de doctor (incluir Dr./Dra. antes del nombre).

3) Resumen (español) / Abstract (inglés): Tendrá como extensión máxima 230 palabras, primero en español y después en inglés. En el resumen se describirá de forma concisa y en este orden: 1) Justificación del tema; 2) Objetivos; 3 ) Metodología y muestra; 4) Principales resultados; 5) Principales conclusiones. Ha de estar escrito de manera impersonal "El presente trabajo analiza...". En el caso del abstract no se admitirá el empleo de traductores automáticos por su pésima calidad.

4) Descriptores (español) / Keywords (inglés): Se deben exponer 6 descriptores por cada versión idiomática relacionados directamente con el tema del trabajo. Será valorado positivamente el uso de las palabras claves expuestas en el Thesaurus de la UNESCO.

5) Introducción y estado de la cuestión: Debe incluir el planteamiento del problema, el contexto de la problemática, la justificación, fundamentos y propósito del estudio, utilizando citas bibliográficas, así como la literatura más significativa y actual del tema a escala nacional e internacional.

6) Material y métodos: Debe ser redactado de forma que el lector pueda comprender con facilidad el desarrollo de la investigación. En su caso, describirá la metodología, la muestra y la forma de muestreo, así como se hará referencia al tipo de análisis estadístico empleado. Si se trata de una metodología original, es necesario exponer las razones que han conducido a su empleo y describir sus posibles limitaciones.

7) Análisis y resultados: Se procurará resaltar las observaciones más importantes, describiéndose, sin hacer juicios de valor, el material y métodos empleados. Aparecerán en una secuencia lógica en el texto y las tablas y figuras imprescindibles evitando la duplicidad de datos. 
8) Discusión y conclusiones: Resumirá los hallazgos más importantes, relacionando las propias observaciones con estudios de interés, señalando aportaciones y limitaciones, sin redundar datos ya comentados en otros apartados. Asimismo, el apartado de discusión y conclusiones debe incluir las deducciones y líneas para futuras investigaciones.

9) Apoyos y agradecimientos (opcionales): El Council Science Editors recomienda a los autor/es especificar la fuente de financiación de la investigación. Se considerarán prioritarios los trabajos con aval de proyectos competitivos nacionales e internacionales. En todo caso, para la valoración científica del manuscrito, este debe ir anonimizado con XXXX solo para su evaluación inicial, a fin de no identificar autores y equipos de investigación, que deben ser explicitados en la Carta de Presentación y posteriormente en el manuscrito final.

10) Las notas (opcionales) irán, solo en caso necesario, al final del artículo (antes de las referencias). Deben anotarse manualmente, ya que el sistema de notas al pie o al final de Word no es reconocido por los sistemas de maquetación. Los números de notas se colocan en superíndice, tanto en el texto como en la nota final. No se permiten notas que recojan citas bibliográficas simples (sin comentarios), pues éstas deben ir en las referencias.

11) Referencias: Las citas bibliográficas deben reseñarse en forma de referencias al texto. Bajo ningún caso deben incluirse referencias no citadas en el texto. Su número debe ser suficiente para contextualizar el marco teórico con criterios de actualidad e importancia. Se presentarán alfabéticamente por el primer apellido del autor.

\subsection{Normas para las referencias}

\section{Publicaciones periódicas}

Artículo de revista (un autor): Valdés-Pérez, D. (2016). Incidencia de las técnicas de gestión en la mejora de decisiones administrativas [Impact of Management Techniques on the Improvement of Administrative Decisions]. Retos, 12(6), 199-2013. https://doi. org/10.17163/ret.n12.2016.05

Artículo de revista (hasta seis autores): Ospina, M.C., Alvarado, S.V., Fefferman, M., \& Llanos, D. (2016). Introducción del dossier temático "Infancias y juventudes: violencias, conflictos, memorias y procesos de construcción de paz" [Introduction of the thematic dossier "Infancy and Youth: Violence, Conflicts, Memories and Peace Construction Processes"]. Universitas, 25(14), 91-95. https://doi.org/10.17163/uni.n25.\%25x

Artículo de revista (más de seis autores): Smith, S.W., Smith, S.L. Pieper, K.M., Yoo, J.H., Ferrys, A.L., Downs, E.,... Bowden, B. (2006). 
Altruism on American Television: Examining the Amount of, and Context Surronding. Acts of Helping and Sharing. Journal of Communication, 56(4), 707-727. https://doi.org/10.1111/j.1460-2466.2006.00316.x

Artículo de revista (sin DOI): Rodríguez, A. (2007). Desde la promoción de salud mental hacia la promoción de salud: La concepción de lo comunitario en la implementación de proyectos sociales. Alteridad, 2(1), 28-40. (https://goo.gl/zDb3Me) (2017-01-29).

\section{Libros y capítulos de libro}

Libros completos: Cuéllar, J.C., \& Moncada-Paredes, M.C. (2014). El peso de la deuda externa ecuatoriana. Quito: Abya-Yala.

Capítulos de libro: Zambrano-Quiñones, D. (2015). El ecoturismo comunitario en Manglaralto y Colonche. En V.H. Torres (Ed.), Alternativas de Vida: Trece experiencias de desarrollo endógeno en Ecuador (pp. 175198). Quito: Abya-Yala.

\section{Medios electrónicos}

Pérez-Rodríguez, M.A., Ramírez, A., \& García-Ruíz, R. (2015). La competencia mediática en educación infantil. Análisis del nivel de desarrollo en España. Universitas Psychologica, 14(2), 619-630. https://doi. org.10.11144/Javeriana.upsy14-2.cmei

Es prescriptivo que todas las citas que cuenten con DOI (Digital Object Identifier System) estén reflejadas en las Referencias (pueden obtenerse en http://goo.gl/gfruh1). Todas las revistas y libros que no tengan DOI deben aparecer con su link (en su versión on-line, en caso de que la tengan, acortada, mediante Google Shortener: http://goo.gl) y fecha de consulta en el formato indicado.

Los artículos de revistas deben ser expuestos en idioma inglés, a excepción de aquellos que se encuentren en español e inglés, caso en el que se expondrá en ambos idiomas utilizando corchetes. Todas las direcciones web que se presenten tienen que ser acortadas en el manuscrito, a excepción de los DOI que deben ir en el formato indicado (https://doi. $\operatorname{org} / \mathrm{XXX)}$.

\subsection{Epígrafes, tablas y gráficos}

Los epígrafes del cuerpo del artículo se numerarán en arábigo. Irán sin caja completa de mayús-culas, ni subrayados, ni negritas. La numeración ha de ser como máximo de tres niveles: 1./1.1./1.1.1. Al final de cada epígrafe numerado se establecerá un retorno de carro.

Las tablas deben presentarse incluidas en el texto en formato Word según orden de aparición, numeradas en arábigo y subtituladas con la descripción del contenido. 
Los gráficos o figuras se ajustarán al número mínimo necesario y se presentarán incorporadas al texto, según su orden de aparición, numeradas en arábigo y subtituladas con la descripción abreviada. Su calidad no debe ser inferior a $300 \mathrm{ppp}$, pudiendo ser necesario contar con el gráfico en formato TIFF, PNG o JPEG.

\section{Proceso de envío}

Deben remitirse a través del sistema OJS de la revista dos archivos:

1) Presentación y portada, en la que aparecerá el título en español e inglés, nombres y apellidos de los autores de forma estandarizada con número de ORCID, resumen, abstract, descriptores y keywords y una declaración de que el manuscrito se trata de una aportación original, no enviada ni en proceso de evaluación en otra revista, confirmación de las autorías firmantes, aceptación (si procede) de cambios formales en el manuscrito conforme a las normas y cesión parcial de derechos a la editorial (usar modelo oficial de portada).

2) Manuscrito totalmente anonimizado, conforme a las normas referidas en precedencia.

Todos los autores han de darse de alta, con sus créditos, en la plataforma OJS, si bien uno solo de ellos será el responsable de correspondencia. Ningún autor podrá enviar o tener en revisión dos manuscritos de forma simultánea, estimándose una carencia de cuatro números consecutivos (2 años). 


\section{Basic writing rules}

Universidad Politécnica Salesiana del Ecuador

\section{General information}

"Retos" is a bilingual scientific publication by the Universidad Politécnica Salesiana de Ecuador, which has been edited on a bi-annual basis since January 2011. The journal focuses on Development and transdisciplinary issues including Public Administration, Social Economics, Marketing, Tourism, Entrepreneurship, Management, Administrative and Economic Science, etc.

It is an arbitrated Scientific Journal that uses an external evaluation system known as peer-review, employing double-blind review, in accordance with the American Psychological Association (APA) style rules. By using this system, the authors have access to an objective, impartial and transparent review process, which facilitates their publication being included in databases, repositories, and international indexed references.

"Retos" is indexed in the selective directory and catalog of the Online Regional Information System for Scientific Journals in Latin America, the Caribbean, Spain, and Portugal (Latindex), in the REDALYC Scientific Information System, the Directory of Open Access Journals in repositories, libraries, and specialized catalogs in Ibero-America.

The Journal is published with two different editions: printed (ISSN: 1390-62911) and electronic (e-ISSN: 1390-8618), in Spanish and English, and each article is identified with a DOI (Digital Object Identifier System).

\section{Scope and policies}

\subsection{Themes}

Original contributions in Development issues, as well as related fields: Public Administration, Social Economics, Marketing, Tourism, Entrepreneurship, Management...and all other disciplines related to the central thematic issue. 


\subsection{Contributions}

"Retos" preferably publishes the results of empirical research about Development, written in Spanish and/or English, while reports, studies, and proposals are also accepted, as well as reviews of state-of-the-art literature.

All of the publications must be original, never have been published in any other journal, and not be undergoing any arbitration or publication processes. Contributions to the journal can include any of the following:

- Research: 5,000 to 6,500 words of text, including the title, abstracts, keywords, tables, and references.

- Reports, Studies, and Proposals: 5,000 to 6,500 words of text, including the title, abstracts, tables, and references.

- Reviews: 6,000 to 7,000 words of text, including tables and references. Justified, current, and selective references shall be evaluated, and should include around 70 publications.

"Retos" is published bi-annually (20 articles per year), in April and October, and each edition has two sections with five articles each, the first containing a Monograph theme edited by subject matter experts, and a second Miscellaneous section, made up of diverse contributions related to the publication's theme.

\section{Presentation, structure, and submission of manuscripts}

Papers are to be presented with Arial 10 typeface, single line spacing, all justified, without indentation or blank spaces between paragraphs. A space is only to be included between the major sections (title, authors, abstracts, keywords, credits, and epigraphs). All margins on each page must be $2 \mathrm{~cm}$.

The papers are to be presented in Microsoft Word format (.doc or .docx), and the file is to be anonymous in the File Properties such that the author(s) is(are) not identified.

Manuscripts are to be submitted only through the OJS (Open Journal System), in which all authors must first register. Original papers sent via email or another interface are not accepted.

\subsection{Manuscript Structure}

For papers that are empirical research, the manuscripts are to follow IMRDC structure, while Notes and Contributions epigraphs are optional. Papers that constitute reports, studies, proposals, and reviews are afforded 
greater flexibility in terms of epigraphs, especially in relation to Materials and Methods, Analysis and Results, and Discussion and Conclusions. All types of papers are required to include References.

1) Title (Spanish) / Title (English): Concise but informative, the first line in Spanish and the second, in English. Maximum 80 characters are accepted, including spaces. The Editorial Board is allowed to propose changes to the author's title.

2) First and last names: of each of the authors, organized in order of priority. Maximum three authors are accepted per original paper, although justified exceptions may be allowed, based on the theme, complexity, and length. The names are to be followed by the professional category, workplace, each author's email address and ORCID number. It is mandatory to include whether the author has a doctorate degree (Dr. before the name).

3) Abstract (Resumen, Spanish) / Abstract (English): This section can contain a maximum of 230 words, first in Spanish and then in English. The abstract shall concisely contain the following, and in this order: 1) Justification of the theme; 2) Objectives; 3) Methods and sample; 4) Main results; 5) Main conclusions. It should be written impersonally "This paper analyzes..." In the abstract, automatic translation is not accepted due to its poor quality.

4) Keywords (descriptores, Spanish) / Keywords (English): Six keywords are to be included for each language, and must be directly related to the paper's theme. This requirement shall be scored based on whether the keywords can be found in the UNESCO Thesaurus.

5) Introduction and State of the Question: The section proposes the question, the context of the issue surrounding it, justification, basis, and proposal for the study, using bibliographic references, including the most important up-to-date literature on the theme, both nationally and internationally.

6) Material and Methods: This is to be composed in such a way that the reader can easily understand how the research was performed. As appropriate, describe the method, sample, sampling, and refer to the type of statistical analysis used. If it is an original method, present the reasons for applying it, and describe any possible limitations.

7) Analysis and Results: This section should seek to highlight the most important observations, and without including any value 
judgments, describe the methods used. Throughout the text, essential tables and figures shall be included in a logical sequence, without repeating any data.

8) Discussion and Conclusions: This section summarizes the most important findings related to any observations from relevant studies, pointing out contributions and limitations, without repeating data from other sections. The discussion and conclusions paragraph is to include inferences and new lines of research for the future.

9) Contributions and acknowledgment (optional): The Science Editors Board recommends that the author(s) specify the financing source for their research. Priority shall be given to work endorsed by competitive national or international projects. Regardless, for the manuscript to be scientifically evaluated, it is to be anonymized with an XXXX only for the initial evaluation, in order to avoid identification of any of the authors or research teams, which are to be named in the Cover Letter and later, in the final manuscript.

10) Notes (optional) are included, only if necessary, at the end of the article (before the references). They are to be included manually, since the Word footnotes are not recognized by the layout systems. Note numbers are to be included using superscript, both in the text and in the final note. Notes including simple bibliographic references (without comments) are not allowed, since these are supposed to be included in the references.

11) References: Bibliographic references are to follow the text references. Under no circumstances should references be included that have not been cited in the text. There should be enough references in order to contextualize the theoretical framework, and be based on criteria of contemporary relevance and importance. They are presented alphabetically, according to the author's last name (if the last name has more than one word, based on the first word of the last name).

\subsection{Rules for references}

\section{Periodical publications}

Journal article (one author) Valdés-Pérez, D. (2016). Incidencia de las técnicas de gestión en la mejora de decisiones administrativas [Impact 
of Management Techniques on the Improvement of Administrative Decisions]. Retos, 12(6), 199-2013. https://doi.org/10.17163/ret.n12.2016.05

Journal article (up to six authors): Ospina, M.C., Alvarado, S.V., Fefferman, M., \& Llanos, D. (2016). Introducción del dossier temático "Infancias y juventudes: violencias, conflictos, memorias y procesos de construcción de paz" [Introduction of the thematic dossier "Infancy and Youth: Violence, Conflicts, Memories and Peace Construction Processes"]. Universitas, 25(14), 91-95. https://doi.org/10.17163/uni.n25.\%25x

Journal article (more than six authors): Smith, S.W., Smith, S.L. Pieper, K.M., Yoo, J.H., Ferrys, A.L., Downs, E.,... Bowden, B. (2006). Altruism on American Television: Examining the Amount of, and Context Surronding. Acts of Helping and Sharing. Journal of Communication, 56(4), 707-727. https://doi.org/10.1111/j.1460-2466.2006.00316.x

Journal article (with no DOI). Rodríguez, A. (2007). Desde la promoción de salud mental hacia la promoción de salud: La concepción de lo comunitario en la implementación de proyectos sociales. Alteridad, 2(1), 28-40. (https://goo.gl/zDb3Me) (2017-01-29).

Books and chapters of books

Complete books: Cuéllar, J.C., \& Moncada-Paredes, M.C. (2014). El peso de la deuda externa ecuatoriana. Quito: Abya-Yala.

Chapters of a book: Zambrano-Quiñones, D. (2015). El ecoturismo comunitario en Manglaralto y Colonche. En V.H. Torres (Ed.), Alternativas de Vida: Trece experiencias de desarrollo endógeno en Ecuador (pp. 175198). Quito: Abya-Yala.

\section{Electronic media}

Pérez-Rodríguez, M.A., Ramírez, A., \& García-Ruíz, R. (2015). La competencia mediática en educación infantil. Análisis del nivel de desarrollo en España. Universitas Psychologica, 14(2), 619-630. https://doi. org.10.11144/Javeriana.upsy14-2.cmei

All reference that have a DOI (Digital Object Identifier System) must be included in the References (which can be obtained at http://goo. $\mathrm{gl} / \mathrm{gfruh} 1$ ). All of the journals and books that do not have a DOI are to appear with a link (to the online version, if available, shortened using Google Shortener: http://goo.gl) and the date of query in said format.

Journal articles are to be listed in English, except for those that are available in Spanish and English, in which case, both languages are to be included in brackets. All internet addresses presented are to be shortened in the manuscript, except for the DOI, which are to be included in the established format (https://doi.org/XXX). 


\subsection{Epigraphs, Tables, and Graphs}

The epigraphs in the article's body are in Arabic numbers. These are to avoid all capital letters, underlining, or bold text. Numbering should use maximum three levels: 1. / 1.1. / 1.1.1. A carriage return is to be used at the end of each epigraph.

Tables are to be included in the text in Word format, according to their order of appearance, with Arabic numbering and captioned with a description of their content.

Graphics or figures should be kept to a minimum and incorporated into the text, in accordance with their order of appearance, with Arabic numbers and captions with a short description. Quality should be no less than 300 ppp, if necessary, using TIFF, PNG, or JPEG formats.

\section{Submission process} OJS system:

The papers are to be submitted in two files through the journal's

1) Cover letter and title page, which includes the title in Spanish and English, first and last names of the authors (standardized format) with ORCID number, abstract in Spanish and English, keywords in Spanish and English, and a declaration that the manuscript constitutes an original contribution that has not been sent for evaluation in another journal, confirmation of the authorship, acceptance (as the case may be) of formal changes to the manuscript according to the rules, and partial transfer of copyright to the publishing house (use the official format).

2) Completely anonymized manuscript in accordance with the preceding rules.

All authors are to register on the OJS platform, even if only one of them will be in charge of correspondence. No author can submit two manuscripts simultaneously, with a penalty of not being able to participate in four consecutive editions ( 2 years). 